
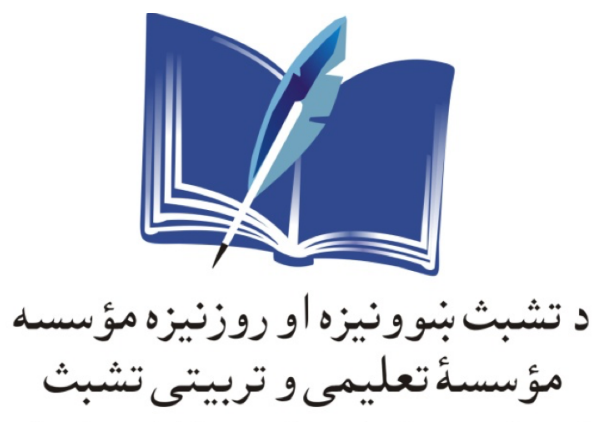

Tashabos Educational Organization

\title{
Impact Assessment of the Tashabos Program
}
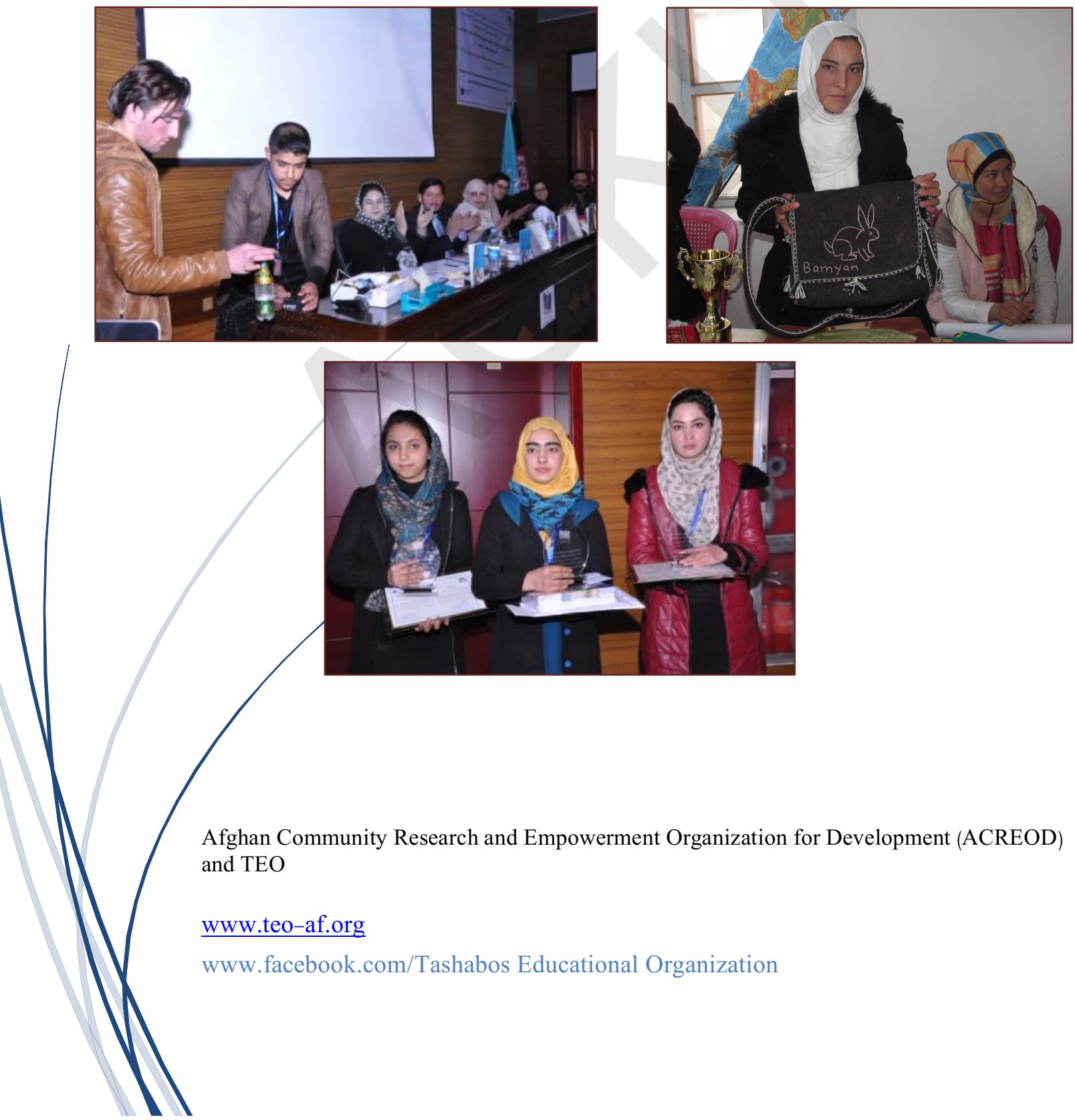

Afghan Community Research and Empowerment Organization for Development (ACREOD) and TEO

www.teo-af.org

www.facebook.com/Tashabos Educational Organization 


\title{
Assessment Design and Direction
}

Afghan Community Research and Empowerment Organization for Development (ACREOD) and Tashabos Eucational Organization (TEO)

\author{
Author \\ Dr. Akmal Nasrat \\ Reviewer \\ Fazel Rabi Haqbeen \\ Fieldwork \\ Hafizullah Dildar \\ Arzoo Haidari \\ Sayed Jalal Rahmani \\ Farahnaz Afzali \\ Design \\ Dr. Akmal Nasrat \\ Fazel Rabi Haqbeen
}

All print rights are reserved with the Tashabos Education Organization

\section{About Tashabos Education Organization}

Established in December 2010, the Tashabos Education Organization (TEO) is a youth focused organization that promotes responsible citizenship and leadership, democratic governance and lessons in market economy, and facilitates networking to high school students in Grades 10, 11 and 12 in Kabul, Nangarhar, Parwan and Bamyan Provinces. The 34,000 students in the program, includes girls (52\%) and boys (48\%) graduating around 10,000 students annually. TEO grew out of a Center for International Private Enterprises (CIPE) projects to promote entrepreneurship. TEO has a collaborative Memorandums of Understanding with the Ministry of Education (MoE). TEO is an indigenous, nonprofit and non-governmental organization.

With funding from National Endowment (NED), TEO teaches youth the skills to become entrepreneurs through educational activities, including training on market based economies, fighting poverty and corruption, and the promotion of good governance and ethical business practices. 


\section{Table of Contents:}

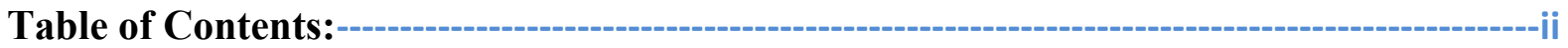

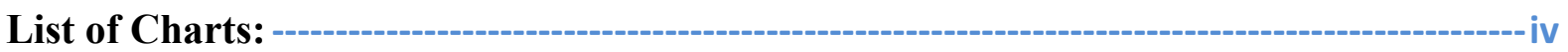

List of Tables: ------------------------------------------------------------------------------------------- viii

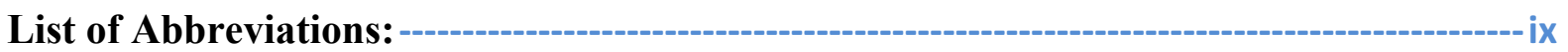

Executive Summary: --------------------------------------------------------------------------------------- 1

Chapter 1: Introduction to the Assessment Study ------------------------------------------------- 3

The Study and Its Context:-------- 3

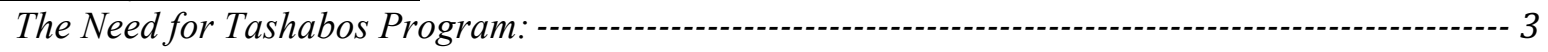

The Tashabos Program -- 5

Purpose of the Assessment: -------

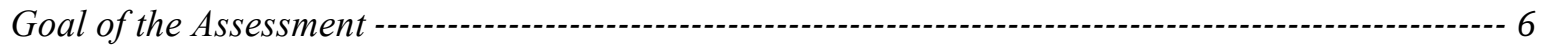

Objectives of the Assessment --- 6

Approach and Methodology: -------

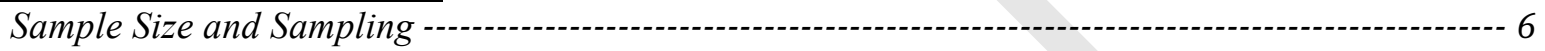

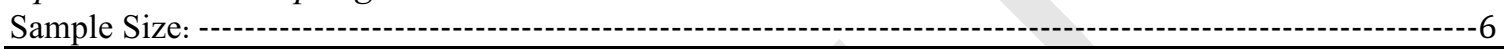

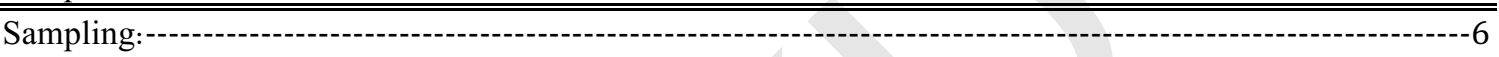

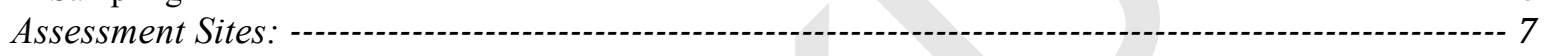

Data Collection Methodologies: -

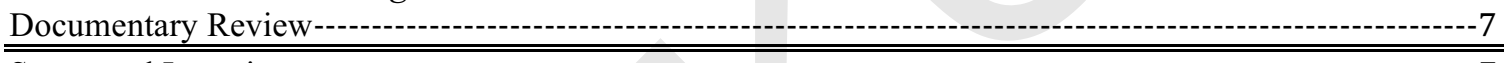

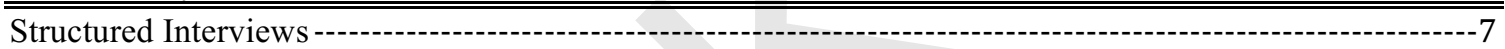

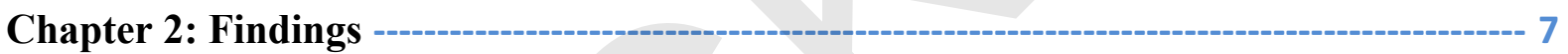

General Information----------

Afghanistan Education System: -

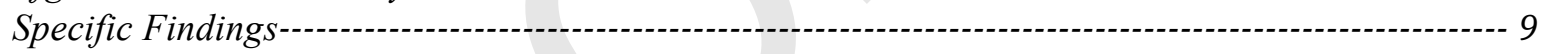

Findings of the Tashabos Students' Assessment: - 9

General Characteristics of Tashabos Students:--

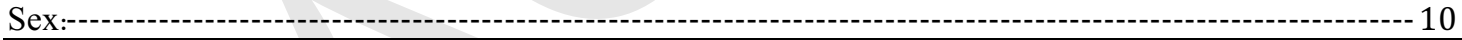

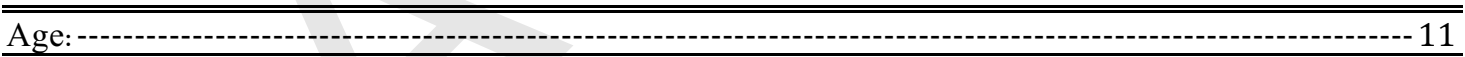

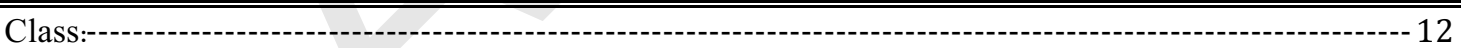

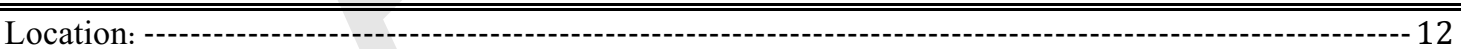

Tashabos and Students' Businesses/Employments ---

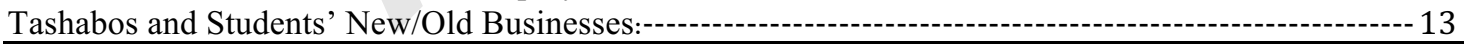

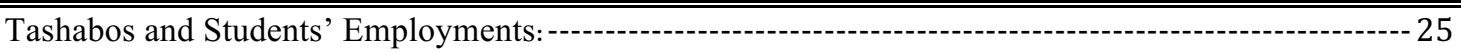

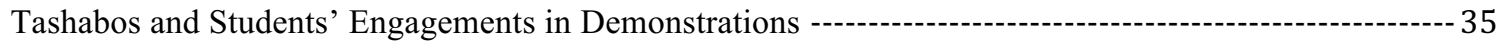

Students' Product Demonstrations -

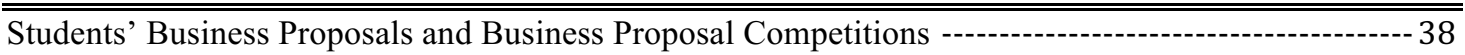

Findings of the Tashabos Teachers' Assessment: ---

General Characteristics of the Respondents: -

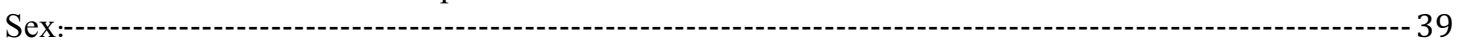

Teachers' Background with Tashabos --.-- 40

Teachers' Orientation of the Subject---

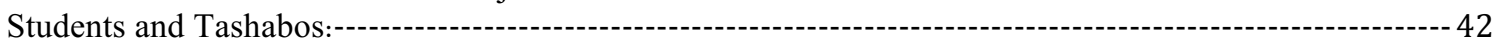

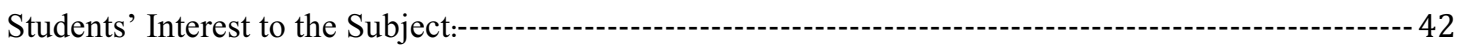

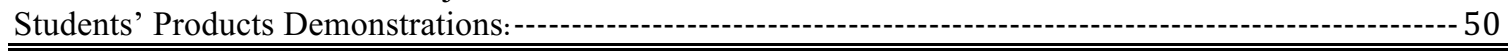

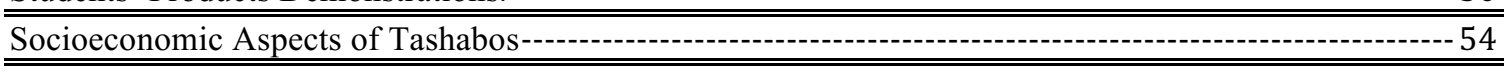

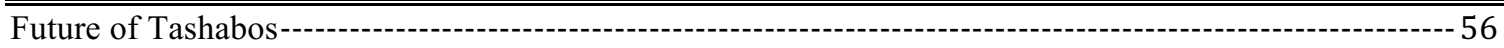

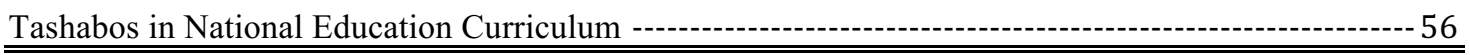

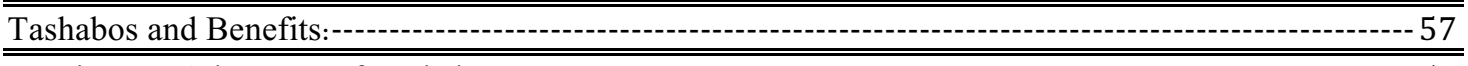

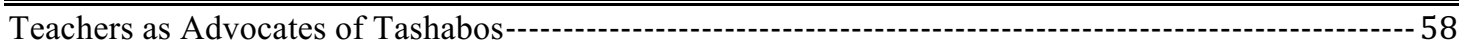


Findings for School Administrations' Assessment: -

General Characteristics of the Respondents: -

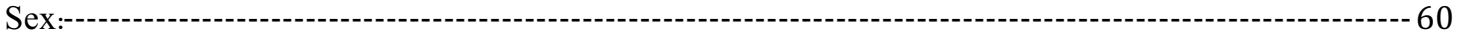

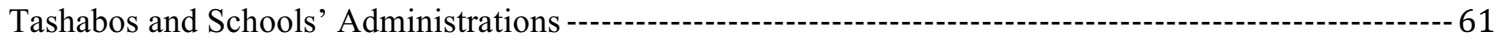

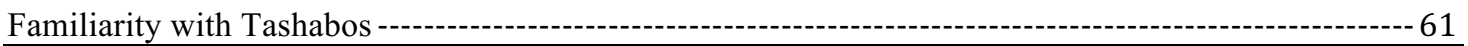

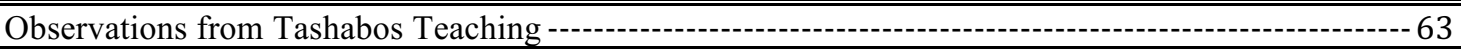

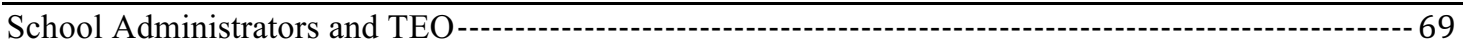

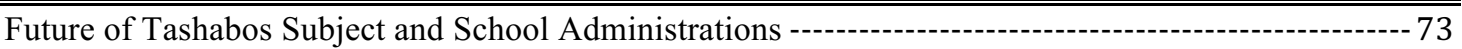

Findings for Parents' Assessment: ------

General Characteristics of the Parent Respondents:--

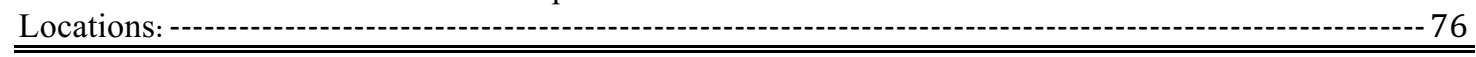

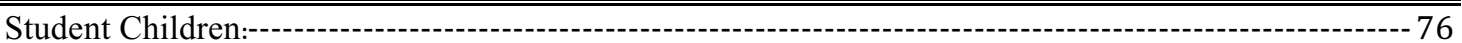

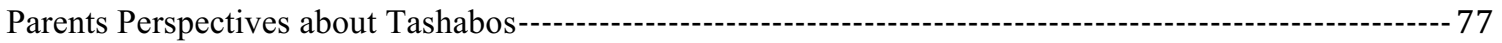

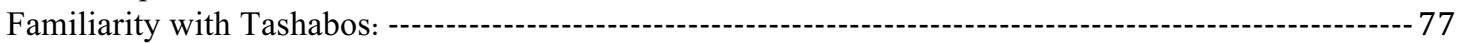

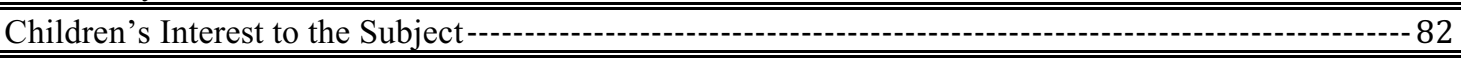

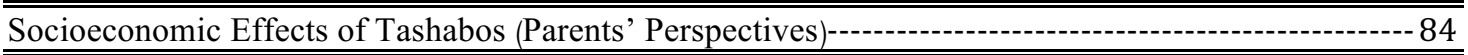

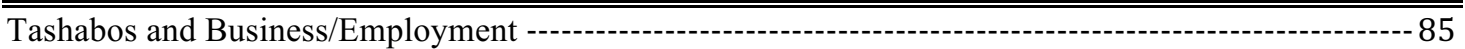

Chapter 3: Conclusions and Recommendations --------------------------------------------- 93

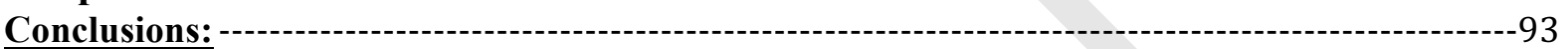

Recommendations: 


\section{List of Charts:}

Chart 1: 2013-14 University Entrance Exam Results for Grade 12 Graduates 4

Chart 2: 2014-15 University Entrance Exam Results for Grade 12 Graduates

Chart 3: 2015-16 University Entrance Exam Results for Grade 12 Graduates __ _ 4

Chart 4: 2015-16 University Entrance Exam Results for Grade 12 Graduates ___ 4

Chart 5: Gender disaggregation of the Interviewed Students___ 10

Chart 6: Gender disaggregation of the Interviewed Students in Urban and Rural Areas__ 10

Chart 7: Gender disaggregation of the Interviewed Students in Target Areas ___ 10

Chart 8: Age disaggregation of the Interviewed Student____ 11

Chart 9: Age disaggregation of the Interviewed Student in Urban and Rural Areas___ 11

Chart 10: Age disaggregation of the Interviewed Student according to Gender___ 11

Chart 11: Grade Disaggregation of the Interviewed Students ___ 12

Chart 12: Grade Disaggregation of the Interviewed Students in Urban and Rural Areas ___ 12

Chart 13: Grade Disaggregation of the Interviewed Students according to Gender ___ 12

Chart 14: Tashabos Assisted Students in Establishing a New Business___ 13

Chart 15: Tashabos Assisted Students in Establishing a New Business in Urban and Rural Areas___ 13

Chart 16: Tashabos Assisted Students in Establishing a New Business according to Gender___ 14

Chart 17: Topics of the Subject Helped the Students during Establishing a New Business___ 14

Chart 18: Topics of the Subject Helped the Students during Establishing a New Business in Target Areas _ 14

Chart 20: The Subject Assists the Students in the Future in Running the Business___ 15

Chart 21: How Would the Subject Help the Students in the Future? 15

Chart 22: Tashabos Importance in Expanding a Business (Students' Perspectives)___ 16

Chart 23: Tashabos Importance in Expanding a Business (Students' Perspectives) in Urban and Rural Areas

Chart 24: Tashabos Importance in Expanding a Business (Students' Perspectives according to Gender)__ 16

Chart 25: Tashabos Topics Important for Expansion of the Businesses __ 17

Chart 26: Tashabos Topics Important for Expansion of the Businesses in Urban and Rural Areas ___ 17

Chart 27: Tashabos Topics Important for Expansion of the Businesses according to Gender___ 17

Chart 28: Classmates Have Initiated or Expanded a Business___ 18

Chart 29: Classmates Have Initiated or Expanded a Business in Urban and Rural Areas __ 18

Chart 30: Classmates Have Initiated or Expanded a Business according to Gender______ 18

Chart 31: Importance of Tashabos for Gender Types of the Students___ 19

Chart 32: Importance of Tashabos for Gender Types of the Students in Urban and Rural Areas ___ 19

Chart 33: Importance of Tashabos Subject on Gender Types of the Students___ 20

Chart 34: Tashabos Provided Opportunities during the Business_____ 20

Chart 35: Tashabos Provided Opportunities during the Business in Urban and Rural Areas___ 20

Chart 36: Tashabos Provided Opportunities during the Business according to Gender______ 21

Chart 37: Provided Opportunities by Tashabos during Business/Employment of the Students____ 21

Chart 38: Provided Opportunities by Tashabos during Business/Employment of the Students in Urban and

Rural Areas

Chart 39: Provided Opportunities by Tashabos during Business/Employment of the Students according to

Gender

Chart 40: Observed a Challenge within Business ___ 22

Chart 41: Observed a Challenge within Business in Urban and Rural Areas ___ 22

Chart 42: Observed a Challenge within Business according to Gender _____ 23

Chart 43: Types of Challenges Observed by the Students and Managed through Tashabos___ 23

Chart 44: Types of Challenges Observed by the Students and Managed through Tashabos in Urban and Rural

Areas__ 24

Chart 45: Types of Challenges Observed by the Students and Managed through Tashabos according to

Gender

Chart 46: Faced any Risks within Business___ 25

Chart 47: Faced any Risks within Business in Urban and Rural Areas___ 25

Chart 48: Faced any Risks within Business according to Gender _ 25

Chart 49: Types of Risks Faced by Students and Tackled with the Help of Tashabos___ 25

Chart 50: Able to Find Employment___ 26

Chart 51: Able to Find Employment in Urban and Rural Areas___ 26

Chart 52: Able to Find Employment according to Gender___ 26

Chart 53: Types of Employments Found by Students____ 26 
Chart 54: Effectiveness of Tashabos in Assisting the Students Find Themselves jobs 27

Chart 55: Performed the Employer Role

Chart 56: Performed the Employer Role in Urban and Rural Areas __ 28

Chart 57: Performed the Employer Role according to Gender ___ 28

Chart 58: Types of Employments Offered by Employer Students___ 28

Chart 59: Importance of Tashabos in Performing the Employer Role__ 28

Chart 60: Business as Employment for Students___ 29

Chart 61: Business as Employment for Students in Urban and Rural Areas___ 29

Chart 62: Business as Employment for Students according to Gender______ 29

Chart 63: Role of Tashabos in Various Stages of the Business____ 30

Chart 64: Importance of the Tashabos in Various Stages of the Business___ 30

Chart 65: Tashabos Offered Employments__ 31

Chart 66: Tashabos Offered Employments in Urban and Rural Areas____ 31

Chart 67: Tashabos Offered Employments according to Gender___ 31

Chart 68: Types of Employments Offered by Tashabos ___ 31

Chart 69: Importance of Tashabos in Creating Employment Opportunities__ 32

Chart 70: Tashabos Important for Girls or Boys in Creating Employments____ 32

Chart 71: Importance of Tashabos in Creating Job Opportunities for Specific Gender Type ___ 32

Chart 72: Tashabos Changed Viewpoints on Employment___ 33

Chart 73: Tashabos Changed Viewpoints on Employment in Urban and Rural Areas___ 33

Chart 74: Tashabos Changed Viewpoints on Employment according to Gender___ 33

Chart 75: Changes in Viewpoints on Employment____ 34

Chart 76: Tashabos Supported Matching Skills during Employments___ 34

Chart 77: Tashabos Supported Matching Skills during Employments in Urban and Rural Areas___ 35

Chart 78: Tashabos Supported Matching Skills during Employments according to Gender___ 35

Chart 79: Students Skills Polished by Tashabos___ 35

Chart 80: Participated in the Products' Demonstrations____ 36

Chart 81: Participated in the Products' Demonstrations in Urban and Rural Areas___ 36

Chart 82: Participated in the Products' Demonstrations according to Gender___ 36

Chart 83: Products Demonstrated___ 36

Chart 84: Process of Selling Products during the Demonstrations___ 37

Chart 85: Number of Business Proposals Developed by Students___ 38

Chart 86: Number of Business Proposals Competitions Attended by Students___ 38

Chart 87: Positions Held by Students during Business Proposal Competitions___ 38

Chart 88: Gender Disaggregation of the Tashabos Teachers___ 40

Chart 89: Gender Disaggregation of the Tashabos Teachers in Urban and Rural Areas ___ 40

Chart 90: Tashabos Teachers Oriented to the Subject______ 41

Chart 91: Disaggregation of Oriented Tashabos Teachers according to Location___ 41

Chart 92: Disaggregation of Oriented Tashabos Teachers according to Gender___ 42

Chart 93: Disaggregation of Oriented Tashabos Teachers according to Gender and Location ___ 42

Chart 94: Tashabos Teachers' Perspectives on Students' Interest with Tashabos _______ 42

Chart 95: Tashabos Teachers' Perspectives on Students' Interest with Tashabos in Urban \& Rural Areas_ 43

Chart 96: Tashabos Teachers' Perspectives on Students' Interest with Tashabos according to Gender___ 43

Chart 97: Reasons for Students' Interest with Tashabos (Teachers' Perspectives)___ 43

Chart 98: Reasons for Students' Interests in Urban and Rural Areas (Teachers' Perspectives) ___ 44

Chart 99: Reasons for Students' Interests with Tashabos (Teachers' Perspectives according to Gender) __ 44

Chart 100: Interesting Topics from Tashabos to Students (Teachers' Perspectives)___ 45

Chart 101: Interesting Topics for Students in Tashabos (Teachers' Perspectives in Urban and Rural Areas) 45

Chart 102: Interesting Topics for Students in Tashabos (Teachers' Perspectives according to Gender)__ 46

Chart 103: Reasons for Difference in Students' Interest Level to Tashabos Subject (Teachers' ____ 47

Perspectives)_______ _ 47

Chart 104: Reasons for Difference in Students' Interest Level to Tashabos Subject (Teachers' Perspectives in

Urban and Rural Areas)____ 47

Chart 105: Reasons for Difference in Students' Interest Level to Tashabos Subject (Teachers' Perspectives according to Gender)____ 47

Chart 106: Students of Lower Grades Talk about Tashabos (Teachers' Perspectives)____ 48

Chart 107: Students of Lower Grades Talk about Tashabos (Teachers' Perspectives in Urban and Rural Areas)

Chart 108: Students of Lower Grades Talk about Tashabos (Teachers' Perspectives according to Gender) _ 48 
Tashabos Impact Assessment May 18 2017.docx

Chart 109: Discussion Points between Teachers and Lower Grade Students on Tashabos 49

Chart 110: Students Know about the Importance of the Subject (Teachers' Perspectives)___ 49

Chart 111: Students Know about the Importance of the Subject (Teachers' Perspectives in Urban and Rural Areas)

Chart 112: Students Know about the Importance of the Subject (Teachers' Perspectives according to Gender)

Chart 113: Points Asserted by Students about Importance of Tashabos (Teachers' Perspectives)___ 50

Chart 114: Students' Products Demonstrated (Teachers' Perspectives)____ 51

Chart 115: Students' Products Demonstrated (Teachers' Perspectives in Urban and Rural Areas)__ 51

Chart 116: Students' Products Demonstrated (Teachers' Perspectives according to Gender) ___ _ 51

Chart 117: Frequency of Demonstrations (Teachers' Perspectives) ___ 52

Chart 118: Frequency of Demonstrations (Teachers' Perspectives in Urban and Rural Areas) ___ 52

Chart 119: Role of the Teachers in Business Proposals Development___ 52

Chart 120: Role of the Teachers in Business Proposals Development in Urban and Rural Areas ___ 53

Chart 121: Role of the Teachers in Business Proposals Development according to Gender of the Teachers__ 53

Chart 122: Innovative Business Ideas Leading to Students'Self-Reliability (Teachers' Perspectives) ___ 53

Chart 123: Innovative Business Ideas Leading to Students' Self-Reliability (Teachers' Perspectives in Urban

and Rural Areas)

Chart 124: Socioeconomic Effects of Tashabos (Teachers' Perspectives)___ 54

Chart 125: Socioeconomic Effects of Tashabos (Teachers' Perspectives in Urban and Rural Areas) ___ 55

Chart 126: Socioeconomic Effects of Tashabos (Teachers' Perspectives according to Gender) ___ 55

Chart 127: Role of Tashabos in Initiating/Expanding a Business (Teachers' Perspective)___ 55

Chart 128: Tashabos Be Incorporated into the National Curriculum (Teachers' Perspectives)___ 56

Chart 129: Tashabos Be Incorporated into the National Curriculum (Teachers' Perspectives in Urban and

Rural Areas) ___ 56

Chart 130: Tashabos Be Incorporated into the National Curriculum (Teachers' Perspectives according to

Gender) __ 56

Chart 131: Reasons for inclusion of the Subject into the National Curriculum (Teachers' Perspectives)__ 57

Chart 132: Benefited from Tashabos Teaching ___ 57

Chart 133: Benefited from Tashabos Teaching in Urban and Rural Areas__ 58

Chart 134: Benefited from Tashabos Teaching according to Gender___ 58

Chart 135: Shared information about Tashabos____ 58

Chart 136: Shared information about Tashabos in Urban and Rural Areas __ 59

Chart 137: Type of Information Shared about Tashabos__ 59

Chart 138: Gender Disaggregation of the Administration Respondents___ 60

Chart 139: Gender Disaggregation of the Administration Respondents in Urban and Rural Areas___ 60

Chart 140: Occupation Distribution of Administrator Respondents in Urban and Rural Areas___ 61

Chart 141: Occupation Distribution of Administrator Respondents in Urban and Rural Areas___ 61

Chart 142: Familiarity Level of the School Administrations from Tashabos___ 62

Chart 143: Shared Information about the Subject______ 63

Chart 144: Shared Information about Tashabos from Administrations in Urban and Rural Areas___ 63

Chart 145: Percentage of School Administrations Observed Tashabos Teaching____ 64

Chart 146: School Administrations Observed Tashabos Teaching in Urban and Rural Areas___ 64

Chart 147: School Administration Observed Tashabos Teaching According to Gender____ 64

Chart 148: School Administrations Observed Tashabos Teaching According to Gender and Location __ 65

Chart 149: Quality of Teaching Tashabos in Schools___ 65

Chart 150: Quality of Teaching Tashabos in Urban and Rural Areas___ 66

Chart 151: Quality of Teaching Tashabos according to Gender___ 66

Chart 152: Quality of Teaching Tashabos according to Gender and Location ___ 67

Chart 153: Quality of Teaching Tashabos in Target Areas_____ 67

Chart 154: Quality of Teaching Tashabos in Target Areas according to Gender________ 67

Chart 155: School Administrators' Thoughts about Effectiveness of Teaching Tashabos____ 68

Chart 156: School Administrators Thoughts about Effectiveness of Teaching Tashabos in Urban and Rural

Areas

Chart 157: School Administrators familiarity with TEO__ 69

Chart 158: Percentage of Teachers Trained on Tashabos (School Administrators Perspective)___ 69

Chart 159: Other Teachers Keen to Teach Tashabos (School Administrators Perspective) ___ _ 70

Chart 160: School Administrators Observed a Change in the Teaching of Tashabos__ 70 
Chart 162: Schools Administrators Observed a Change in the Teaching of Tashabos according to Gender_ 71 Chart 163: Schools Administrators Observed a Change in the Teaching of Tashabos according to Gender and Location

Chart 164: Schools Administrators Observed a Change in the Teaching of Tashabos in Target Areas

Chart 165: Changes in Teaching Skills in Urban and Rural Areas (School Administrators Perspective) __ 73

Chart 166: Changes in Teaching Skills of Tashabos according to Gender____ 73

Chart 167: Tashabos Be Incorporated into the National Curriculum (School Administrators' Perspectives) 74 Chart 168: Other Administrations Eager to Incorporate the Subject into the Routine Curriculum (School Administrators Perspectives)

Chart 169: Other Administrations Eager to Incorporate the Subject into the Routine Curriculum in Urban and Rural Areas (School Administrators Perspectives) ___ 75 Chart 170: Address Disaggregation of Parent Respondents___ 76 Chart 171: Number of Children Enrolled at Schools for Parent Respondents___ 77 Chart 172: Parent Respondents Aware about their Children's Grades__ 78 Chart 173: Parent Respondents Have Information about Tashabos__ 78 Chart 174: Parent Respondents Have Information about Tashabos___ 78 Chart 175: \% Parent Respondents in Urban and Rural Areas and \% Male and Female Parent Respondents 79 Chart 176: Parent Respondents' Information about Tashabos Subject___ 80 Chart 177: Sources of Acquiring Information on Tashabos ___ 81 Chart 178: Parent Respondents' Children Study Tashabos at Home___ 82 Chart 179: Parent Respondents' Children Study Tashabos at Home according to Gender and Location__ 82 Chart 180: Reasons for Children's Interest to the Subject Chart 181: Reasons for Children's Interest to Subject (Parents' Perspectives)___ 84 Chart 182: Tashabos Effective on Children's Socioeconomic Lives (Parents' Perspectives) ___ 84 Chart 183: Parents' Agreement to Socioeconomic Effects of Tashabos in Urban and Rural Areas__ 85 Chart 184: Parents Ever Run a Business 85 Chart 185: \% Male and Female Parents Involved in Business (Left) and \% Parents Involved in Business in Urban and Rural Areas (Right)

Chart 186: Parents' Involvement in Business 86

Chart 187: Used the Concepts of Tashabos in Business 86

Chart 188: Utilization of Tashabos Concepts in Business___ 86

Chart 189: Role of Tashabos in Running Business____ 87

Chart 190: Importance of Utilizing Tashabos Knowledge in Business___ 87

Chart 191: Children Able to Initiate/Expand a Business (Parents' Perspectives)___ 88

Chart 192: Parents' Perceptions on Children Able to Initiate/Expand a Business___ 88

Chart 193: Success Level of the Businesses Initiated/Expanded with the Help of Knowledge from Tashabos (Parents' Perspectives)

Chart 194: Reasons for Success in the business Initiated/Expanded with Tashabos Concepts___ 91 Chart 195: Securing Employments for the Parent Respondents' Children with the Help of Knowledge from Tashabos.

Chart 196: Securing Employments with the Knowledge from Tashabos (Parents' Perspectives)___ 92

Chart 197: Reasons for Importance of Tashabos in Securing Employments 
Tashabos Impact Assessment May 18 2017.docx

\section{List of Tables:}

Table 1: Schools Administrators Observed a Change in the Teaching of Tashabos in Target Areas according to Gender

Table 2: Shared Information on Tashabos by Parent Respondents according to Gender and Location 80 Table 3: Sources of Acquiring Information on Tashabos According to Gender and Location 81

Table 4: Success Level of Business if Initiated or Expanded with the Concepts of Tashabos (Parents' Perspectives) 89

Table 5: Success Level of Business if Initiated or Expanded with the Concepts of Tashabos (Parents' Perspectives)

Table 6: Success Level of Business if Initiated or Expanded with the Concepts of Tashabos (Parents' Perspectives) 90

Table 7: Reasons for Success in Businesses Initiated/Expanded with Knowledge from Tashabos (Parents'

Perspectives) 90 91 


\section{List of Abbreviations:}

1 ACBAR

2 AISA

3 ANA

4 ANDS

5 CIPE

6 GPI

7 MoCI

8 MoE

9 MoHE

10 MoLSAMD

11 NER

12 NRVA

13 SMEDD

14 SRS

15 TEO

16 TTCs

17 TVET
Agency Coordination Body for Afghan Relief and Development Afghanistan Investment Support Agency

Afghanistan National Army

Afghanistan National Development Strategy

Center for International Private Enterprise

Gender Parity Index

Ministry of Commerce and Industries

Ministry of Education

Ministry of Higher Education

Ministry of Labor, Social Affairs, Martyrs and Disables

National Enrollment Rate

National Risk and Vulnerability Assessment

Small and Medium Enterprise Development Directorate

Stratified Random Sampling

Tashabos Educational Organization

Teacher Training Colleges

Technical and Vocational Education Training 


\section{Executive Summary:}

Tashabos Educational Organization has been supporting Tashabos teaching in 43 schools across 4 provinces in close coordination with the Ministry of Education. However, a comprehensive study denoting the effectiveness of the program was yet to be carried out. Therefore, impact assessment was planned to be conducted during late 2015/16. The primary goals were to:

Evaluate the effectiveness of Tashabos on youth socio-economic empowerment and selfreliance.

Determine the percent of Tashabos students who initiated a new business, expanded their old businesses, were able to secure employment and/or offered employments to other youth.

\section{Questionnaires}

Questionnaires were developed to collect data from 400 students, 61 Tashabos teachers, and 43 school administrations where Tashabos has been taught, and 80 parents of students. Since nearly 34,000 students have studied the subject and assessing the entire student body seemed daunting, the student sample size was selected as per the standard international sampling procedures. However, all the Tashabos teachers and school administrators were interviewed. From the parents of over 200 students who initiated/expanded/secured employment or offered employment, 80 were included in the assessment.

The preliminary interviews findings from the four populations show impressive support for the effectiveness of Tashabos in both the personal and employment aspects of the students. The initial findings for each of the assessed groups are highlighted in subsequent paragraphs.

\section{Students}

Students identified for the assessment were from Grades 10,11 and 12 who have studied the Tashabos subject. The data collected from 400 students showed that Tashabos helped $69 \%$ of them initiate a new business. When asked how Tashabos helped, the students mentioned the business linked topics, motivation for developing business proposals and generating innovative business ideas for scale-up. Among the remaining $31 \%, 85 \%$ of them mentioned utilizing Tashabos knowledge in initiating a business in the future. The subject assisted more than half of the student respondents expand their family businesses due solely to the students' acquaintance with business principles. However, $77 \%$ of the students gave more weight to the subject's importance during business initiations than business expansions. Tashabos enables students to initiate a business following standard business principles. It also plays critical role creating possibilities for professional expansion and scaling-up of businesses. Sixty percent of the student respondents, both girls and boys, thought the subject important for initiating a business. This suggests that Tashabos has an equal effectiveness on improving economy and supporting economic self-reliability for both genders.

Interestingly, studying Tashabos has brought behavior changes in business management among $58 \%$ of the student respondents. One of the most important impacts our teaching has had is that $81 \%$ of the student respondents found employment opportunities because they studied Tashabos. After studying Tashabos 58\% of the students were able to attract investment for their businesses. In addition, $70 \%$ of the student respondents believed that they could manage their business capital better than before. Tashabos enabled $29 \%$ of the student respondents to offer jobs and employment to other youths. These students talked about behavior changes as employers that they could not have achieved without Tashabos knowledge. Importantly, 79\% of the students thought if Tashabos principles were applied in daily business activities, more youth job opportunities would be created. After studying Tashabos, $79 \%$ of the students witnessed a change in their communications, relationships, networking, leadership, decision- 
making, planning and executing planning, and support skills. In applying the principles of Tashabos in business, $69 \%$ of the students were able to develop at least one business proposal, while $31 \%$ of them developed more than one business proposal.

Forty-eight percent of the student respondents demonstrated their products in exhibitions, reflecting student motivation to expose their products to a wider audience. $87 \%$ of the students eagerly attended Tashabos sessions, showing their interest in economic self-reliance. One-fourth of the student respondents mentioned knowing students in other schools who initiated businesses due to Tashabos.

\section{Teachers}

Among the Tashabos teachers, $98 \%$ stated that students have deep interests in the subjects, especially learning about business. Interestingly, lower grade students, below Grade10, have talked about the Tashabos subject with $64 \%$ of the Tashabos teachers. This suggests the Tashabos students are communicating the importance of Tashabos subjects to lower grade students. 97\% of the teacher respondents replied that their students understand the importance of the subject, creating a higher willingness among students to learn Tashabos. Besides economic empowerment, all the teacher respondents believed that Tashabos had an effect on students' social lives as well. Students of $89 \%$ of the teachers were able to either initiate or expand a business, while students of $93 \%$ of Tashabos teacher secured employment. Forty-seven percent of the Tashabos teachers mentioned students in nonTashabos schools wanting to study the subject.

\section{Schools' Administration}

It is important to note that school administrations in all 43 schools were familiar with the subject and the support provided by TEO for the teaching the subject. As per the interest of the school administrations, 92\% of the school administrations have observed Tashabos teaching within their schools and $69 \%$ of the school administrations called Tashabos teaching effective. In addition, $89 \%$ of the administrators have observed a positive change in the teaching skills of the Tashabos teachers. Seventy-six percent of the school administrators added that due to the importance of the subject other teachers are also willing to teach the subject. Finally, $32 \%$ of the administrations mentioned that other school administrations have expressed an interest in initiating Tashabos teaching at their schools.

\section{Parents}

Parents of the students were also interviewed; $82 \%$ of them knew about Tashabos. This reflects the importance of the subject to families of the students. Ninety-two percent of the parents mentioned that their children are so eager to learn about the subject that they study Tashabos at home too. In addition, $82 \%$ of the parents mentioned that they have regular communication about the subject with their children. 96\% of the parents believe that the subject is important for improving their children's socioeconomic lives. Sixty-four percent mentioned that they have used Tashabos knowledge and principles in their businesses and their children have been the source of that knowledge. Fifty-two percent believe that if their children initiate a business following the Tashabos principles, the business be successful.

\section{Overall Findings}

The assessment findings suggest that TEO has implemented an effective program due to the high number of students able to either use the subject knowledge in initiating a new business or securing employment. A majority of the students mentioned using the knowledge in the future for their financial empowerment and sustainability. Tashabos teachers and school administrations were so impressed by the subject's importance that $98 \%$ of the teachers and $92 \%$ of the administration proposed incorporation of the subject into the national curriculum. 


\section{Chapter 1: Introduction to the Assessment Study}

\section{The Study and Its Context:}

Established in December 2010, the Tashabos Education Organization (TEO) is a youth focused organization that promotes responsible citizenship and leadership, democratic governance and lessons in market economy, and facilitates networking to high school students in Grades 10, 11 and 12 in Kabul, Nangarhar, Parwan and Bamyan Provinces. TEO grew out of a Center for International Private Enterprises (CIPE) projects to promote entrepreneurship.

TEO is a Kabul-based indigenous, nonprofit, nongovernmental organization registered with the Ministry of Economy, signed a Memorandum of Understanding (MoU) with Ministry of Education (MoE) and is member of the Agency Coordinating Body for Afghan Relied and Development (ACBAR). TEO has an active board of highly qualified members.

TEO teaches youth the skills to become entrepreneurs through educational activities, including training on market based economies, fighting poverty and corruption, and the promotion of good governance and ethical business practices. The TEO's mission is to advance the spread of democratic principles and sustainable development through the education of our Afghan youth.

\section{The Need for Tashabos Program:}

Three to four decades ago, the size of the Afghan national and provincial governments increased. At that time there were few higher education institutions that graduated only a couple of hundred students annually, and the government needed to hire many new staff. The graduates, especially proficient ones, were introduced to the ministries in need. All university graduates found jobs, and even some Grade 12 certificated students were hired as teachers in the newly established schools nationwide.

Now Afghanistan has around one hundred universities and higher education institutes, state and private, graduating around 20,000 to 30,000 bachelor's degrees annually, a number expected to grow based on their capacity and number. The government structure has around 365,000 positions that are already filled and vacancies are very rare. Each year graduates are added to the ranks of jobless young people who hope to be appointed to government positions as was usual from the 1940s through the 1970s, but there is no such need.

Figures 1, 2, 3 and 4 show Afghanistan's 2013-14, 2014-15 and 2015-16 Grade 12 graduates who participated in the national university entrance exam. In 2013-14 the Ministry of Higher Education could only enroll the $60 \%$ of the students who passed. The remaining $40 \%$ did not meet the enrolment requirements. The number of students who cannot find their way into higher education institutes increases each year as in 2014-2015 the number rose to 48\% unfortunately. Fortunately, the national university entrance exam improved drastically and below charts for 2015-16 shows the changes. 
Chart 1: 2013-14 University Entrance Exam Results for Grade 12 Graduates

Total 12 Grade Students 230,050

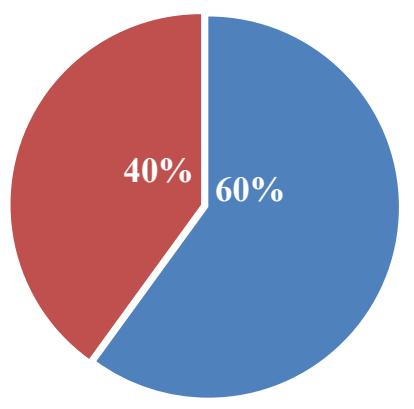

- Passed the Exam 138,606

- Did Not Pass 91,444

Chart 2: 2014-15 University Entrance Exam Results for Grade 12 Graduates

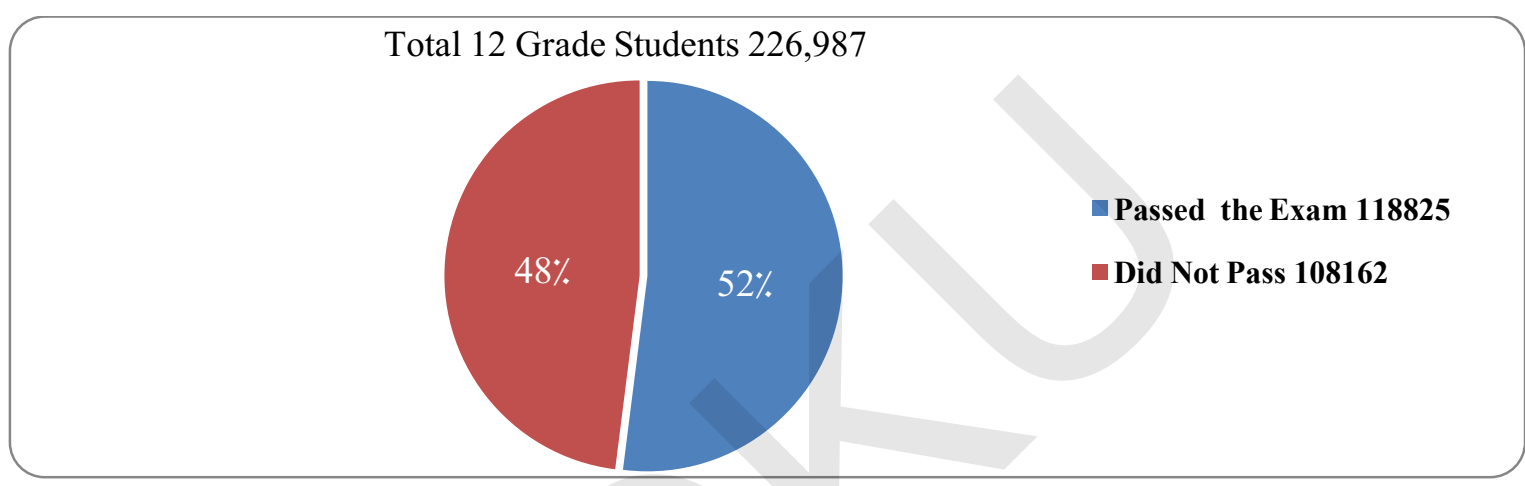

Chart 3: 2015-16 University Entrance Exam Results for Grade 12 Graduates

Total 12 Grade Students 181,836

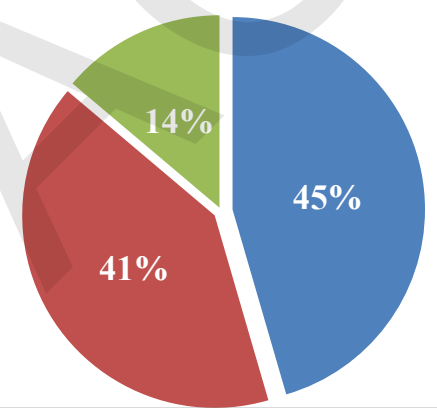

Passed the Exam (Public Universities) 82,729

- Passed the Exam (Private Universities or Semi higher Education Institutes) 73,952

Did Not Pass 25,155

Chart 4: 2015-16 University Entrance Exam Results for Grade 12 Graduates

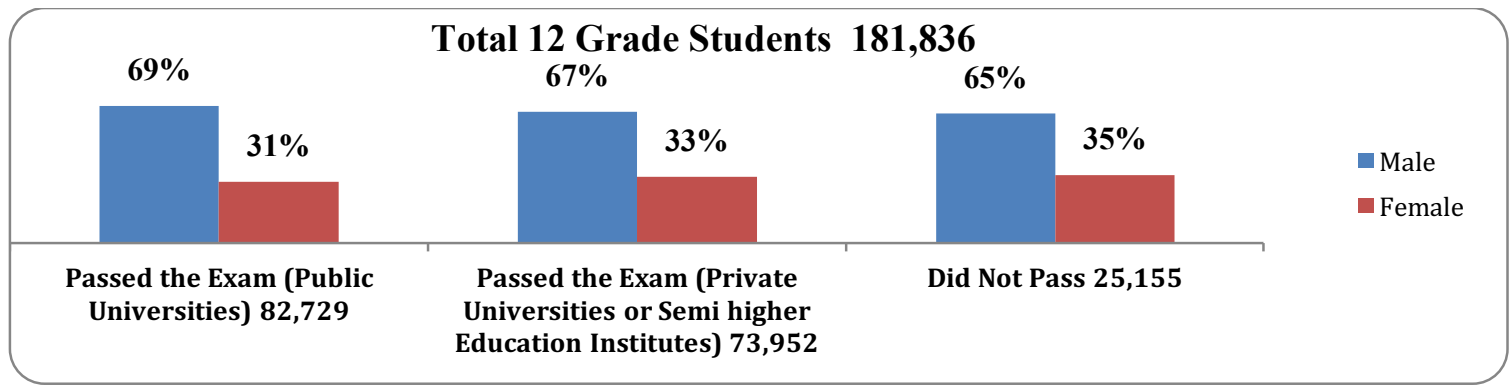


This vast population of high school and university graduates with no foreseeable employment has a high potential for joining insurgents or gangs, or developing extreme ideas and opinions. The Tashabos program appropriately meets the needs of these graduates by providing the skills necessary to find or create jobs in a free market economy.

This is especially important for girls; they have very good business sense and are very interested, but for many years have lacked opportunities. Thus it would be good to continue and expand the Tashabos program to other schools and other provinces nationwide. It is the goal of the TEO leadership and board of directors to have TEO partnered with relevant stakeholders and institutions or programs.

\section{The Tashabos Program}

The Tashabos Educational Organization implements the Tashabos high school entrepreneurship curriculum in four provinces. CIPE developed this curriculum to educate Grades 10-12 students about entrepreneurship before graduation and implemented the program in 2004. TEO took over implementation in May 2014.

The Tashabos program has 43 participating high schools; 29 schools are in Kabul, five in Bamyan, four in Nangarhar, and five in Parwan. Over 34,000 students are learning the curriculum. The program works with 61 teachers who teach the Tashabos curriculum in their schools during the educational year. The teachers conduct pre- and post-teaching assessments of the Tashabos students. All student scores are recorded and sent to TEO. Every participating school has an exhibition room to bring together and exhibit sample products produced by these business students. The participating schools include those for both girls and boys; there are 17 schools for boys and 26 for girls. At the beginning of the school year, students are encouraged to develop their own business by writing a business proposal; proposal writing is optional. Proposals can be for a new business or improvement of an existing family business. At the school level proposals are checked and reviewed by the Tashabos teachers who choose the top ten. These ten students then present their proposals to a panel of the TEO delegation, Tashabos teachers and the schools' principals. This panel picks the top three for further review by TEO; after review TEO picks the top 50. TEO then selects the top ten from among the top 50 for the final competition. The final business proposals competition is evaluated by an independent jury of university teachers and representatives from the Ministry of Education (MoE) and the private sector. The jury picks three finalists from among the top ten.

TEO provides awards to all ten final competitors, and appreciation certificates to the top 50 students. TEO provides additional training to the top 50 and the top ten, and introduces them to relevant organizations such as the Small and Medium Enterprises Development Directorate (SMEDD) of the Ministry of Commerce and Industries (MoCI), Afghanistan Investment Support Agency (AISA) or donors for potential support.

The subject has been taught to thousands of students, but the study was yet to be evaluated in terms of effectiveness. Therefore, it was considered necessary to have a comprehensive study from the program to gauge the changes the subject has brought in terms of thoughts of the students, teachers, school administrations and students' parents. The National Endowment for Democracy (NED) funded, TEO to accomplish the above. 


\section{Purpose of the Assessment:}

\section{Goal of the Assessment}

The overall goal of the study was to explore the effectiveness of Tashabos in terms of changing the socioeconomic lives of students.

\section{Objectives of the Assessment}

The specific objectives of the study were:

To explore the knowledge levels of the students about the subject and its important

To assess the contribution of teachers in transforming the students towards a change in their socioeconomic lives.

To review the acquaintance of the school administration of the subject and the effects the subject have on students

To know about parents' viewpoints about the subject.

\section{Approach and Methodology:}

\section{Sample Size and Sampling}

\section{Sample Size:}

It should be mentioned that around 32,375 students were studying the subject. In addition, covering all the students seemed implausible. Therefore, a sampling method was applied considering the universally accepted sample size calculators. Therefore, considering the 5\% confidence interval, $95 \%$ confidence level and 32,375 students, the sample size was selected for the study which was 400 . In addition, the target sample for other target groups were also selected. Among the teachers, all the teachers were selected for the study and one of the school administrations were interviewed in each of the schools. Finally, the

parents of the students were also calculated base on the mentioned criteria and 80 parents were selected for the interview.

\section{Sampling:}

Since covering the entire students seems implausible with the study considering the time limitation, sampling methodologies was applied to achieve a sufficient number of the program beneficiaries for the study so that the study results are credible. In order to have a clear picture of entire students, the sampling followed a standardized pathway and included: (1) definition of research population, (2) specifying the sampling frame, (3) specifying a sampling method, (4) determining the sample size, (5) implementation of the sampling plan, and (6) sampling at the field level and data collection. It is already mentioned that it was impossible to interview the entire students for the purpose of the effectiveness of the Tashabos in improving the socioeconomic indicators of the students. Therefore, the population for the study is defined. The definition allowed identifying the inclusion and exclusion criteria of the research sample. Therefore, the sampling included: Students studied Tashabos in 4 provinces (Kabul, Nangarhar, Parwan and Bamyan) in 43 schools and were beneficiaries of the Tashabos program through TEO. To add more on the population definition, gender disaggregation of the sample size was also taken into consideration. As per the definition, Students out of the 43 schools, students haven't studied the subject and students of lower classes were not regarded as target sample for the study. As a second stage, the sampling frame for the study population was specified. Sampling frame enabled the study to figure out the sample size from a very large number of students within the schools. The study used the probability sampling method because chance of participation in the study was provided to every students fitting the inclusion criteria. Explicitly, the study will use a multi-staged Stratified Random Sampling (SRS) to determine the sample size. The total number of the students who were beneficiaries 
for the program were divided into 43 strata and each one of them as considered as a sample unit. This allowed the study to collect a wide range of information about the effectiveness and efficiency of the subject from various provinces with various settings. At the second stage, students of various schools within one province were distributed into the clusters. Finally, within the school clusters, Simple Random Sampling (SRS) was applied to identify the total number of students for the interview. To have identified the starting point, the study listed all the students within a school cluster and interviewed every specific numbered student on the list considering the size of the target students in each school. However, the number of the interviewees within one cluster was solely dependent to the number of students within the school cluster. The sample size was calculated using the online sample size calculators so that representative sample complies with the international sampling best practices. However, more common variables for sample size calculation was taken into consideration with confidence level of $95 \%$, confidence interval of $5 \%$ and a total number of students in the 4 provinces of 32,375 . The variables would allow us to interview 380 students in the interview and about an additional $8 \%$ would be sampled to cover biases, confounders, non-respondents, and to minimize the risk of information unreliability and inconsistency. The $[\mathrm{b}$ refore, the total sample was 408 students. As the sample size constituted a very small portion of the total students, the sampling scheme will favor nonreplacement of selected units. It means that once an interviewee is interviewed, he/she will not a get a chance for a second interview to reach the total number of interviews under the study. In order to have a valid data collection, the defined sampling methodologies and sample size would be followed to reduce sampling biases, over coverage and under coverage.

\section{Assessment Sites:}

The assessment was conducted in 4 provinces across 43 schools. Of the 43 schools, 27 schools were female schools while the remaining 16 were male schools. 29 schools were in Kabul province, 4 in Nangarhar province, 5 in Bamyan and 5 in Parwan province. It should be mentioned that TEO has been providing the support of teaching the subject in these 43 schools.

\section{Data Collection Methodologies:}

In order to have collected sufficient information from the students, structured questionnaires were developed for the purpose.

\section{Documentary Review}

The data collection on the study was initiated with disk research. During documentary review, policy documents reflecting education system were reviewed. However, other relevant documents on the topic were also reviewed to collect information about the education system of the Afghanistan and current challenges.

\section{Structured Interviews}

The bulk of the information from the target populations in the study was collected after administering structured interviews. The structured questionnaires were used to collect both quantitative and qualitative data. It should be mentioned that questions selected for the purpose of the study were shared with TEO and were finalized by them. The structured questionnaires were used to collect information about the effectiveness of the program from the students, teachers, school administrations and students' parents. It should be mentioned that separate questionnaires were developed for each of the mentioned target samples.

\section{Chapter 2: Findings}

In the findings sections, first an overall information about the education system in Afghanistan is provided which is subsequently followed by the findings collected during the study. 


\section{General Information}

Afghanistan bore a very fragile conditions during the previous three decades due to the civil war. Every infrastructure including education turned into ashes. However, hopes were regenerated among Afghans after collapse of Taliban and taking over of the new administration. Several efforts have been taken to reconcile and reconstruct the country's infrastructures. There has been considerable progress over the past ten years in terms of access to education in Afghanistan. Enrolment has increased from just about 1 million children, almost all boys, in 2001 to over 9 million in 2013 of which 39\% are girls. All education-related indicators- including gender equality indicators - show improvement since NRVA 2007-08, even though at the same time it is observed that the pace of improvement has slowed down. Despite major achievements in the last decade, education performance in Afghanistan is still among the poorest in the world, and the current rate of improvement will fail to achieve the ANDS targets by 2020 . The share of the Afghan population, 25 years and older, that has completed any level of formal education is very small- less than $7 \%$, and for women as few as $3 \%$ However, major improvements in primary and secondary school completion are observed for the younger age group 15-24 years, especially for girls. This is the result of increasing school attendance in the past decade. The Net Enrolment Rates (NER) in primary education for girls and boys were 64 and $86 \%$ in 2013, while NER in General Education (Grades 1-12) were 50 and 71 for girls and boys respectively. The downside of these figures is that 3.3 million children are still out of school according to MOE Planning Department estimations. Opportunities to attend education are inadequate, especially for girls and women, and rural and Kuchi (nomadic tribe) populations in general, even though the gender gap in education and literacy show continuous improvement, in both absolute and relative terms. Thus, the Gender Parity Index (GPI) in primary, secondary and tertiary education was $0.74,0.53$ and 0.42 respectively in 2012, compared to $0.69,0.49$ and 0.28 in 2007-08. Barriers to access to education include: insecurity, poverty, and child work, lack of schools in remote areas, long walking distance to schools, and harassment of children on their way to school.

\section{Afghanistan Education System:}

The structure of the Afghan education system consists of three levels of general education from grades $1-12$, a parallel system of Islamic education, technical and vocational education as well as teacher training from higher secondary level and Higher education above grade 13.

\section{Primary Education: 6 years Grade 1-6 age 7-13}

The government provides free academic education at state schools. From age 7 to age 13 pupils attend primary schools where they learn the basics of reading, writing, arithmetic and their national culture. Religious education is the responsibility of clerics at mosques, but it is being regulated by the Department of Islamic education under MoE.

\section{Lower Secondary Education: 3 years Grade 7-9 age 13-16}

Three years of middle school follow where academic-style education continues. Students must pass an examination at the end of this phase if they wish to study further.

\section{Higher Secondary Education: 3 years, grade 10-12 age 16-19}

At secondary school students have a choice between continuing with an academic path for 3 years that could perhaps lead on to university, or study subjects such as applied agriculture, aeronautics, arts, commerce and teacher training instead. Both programs culminate in a Baccalaureate examination.

Vocational Education: from short-term courses to formal training grades 10-12 and 13-14 Technical and Vocational Education (TVET) programs are delivered in formal education led by MOE and nonformal courses and programs led by MOLSAMD and NGOS. 


\section{Tertiary Education: grade 13 and onwards}

Teacher Education (grade 13-14) is offered at Teacher Training Colleges (TTCs) under the Teacher Education Department of MOE. Higher education is led by MoHE and is provided by a large number of public and private universities. The general structure consists of Bachelor Degrees (4 years), Masters' Degrees $(3$ years) and doctorate/PhD degrees $(3$ years). The Islamic Dar-ul-Ulom system offers education at the level of grade 13-14.

Non-formal Education: In addition to the above-mentioned formal education structure non-formal TVET (short courses) are run by Ministry of Labor, Social Affairs, Martyrs and the Disabled (MoLSAMD) and NGOs. Furthermore, non-formal literacy courses, non-formal adult education courses, etc. are run by MOE Department for Literacy and other ministries, e.g. Ministry of the Interior offer literacy courses for the police and Ministry of Defense offer courses for the Afghan National Army (ANA).

Tashabos has been taught under the formal education system within 43 schools across 4 provinces to high school students

\section{Specific Findings}

\section{Findings of the Tashabos Students' Assessment:}

High school students of 43 schools are the main recipients of Tashabos Educational Organization's (TEO) support because these students have been taught the subject and the students utilize the gained knowledge in their daily social and incoming lives. The students have shown the direct impact of the program with initiating/expanding a business or securing employments for themselves. Therefore, majority of the needed information would be collected from the students because they have been applying the subject and they should know about the implication of the subject in daily lives. Consequently, students studying the subject in 10 to 12 grades were targeted for the study. In addition, almost 32,375 students study the subject and interviewing all of them require much resources and time, which was lacked by the study. Therefore, sampling methods were applied. As as result nearly 400 students were selected based on the standardized sampling methodologies with $95 \%$ confidence level and $5 \%$ confidence interval. Moreover, the students were distributed into schools and within schools into classes considering the volume of students within schools and within classes. Therefore, it can be inferred that the collected data serves for the entire student population studying Tashabos as a complementary subject within their schools.

Keeping the importance of the collected information, the students were administered a comprehensive questionnaire covering all the important data the students have studied in the subject. The students' questionnaire was organized in 6 sections collecting information about students' general characteristics; students and business; students and employment; socioeconomic effects of Tashabos; exhibitions; and future of the subject. The collected information from the students would give a clear picture of the progress made by TEO in terms of upgrading students' lives. In order to have collected substantially useful data, the students were allowed to provide their own thoughts and viewpoints regarding the subject and its importance.

The nature of this report is also arranged in the mentioned 6 categories to explicitly elucidate the impact and effectiveness of the subject.

\section{General Characteristics of Tashabos Students:}

Before talking about the viewpoints of the students, it was necessary to talk about the general characteristics of Tashabos students. Therefore, information was collected on gender, age, class and location of each interviewed student. 
Sex:

Sex:

Each of the students were inquired about their genders and it was found that $48 \%$ of Tashabos students were males while the remaining 52\% interviewed students were females. It should be mentioned that generally, female students constitute larger portion of the Tashabos entire student populations $(32,375)$. Hence, higher number of female students were also interviewed. When the data was further analyzed for the location of the respondents, it was found that female students dominated (54\%) the interviewed population in urban areas and male students with $76 \%$ were the most prevalent interviewed students in rural areas. When the data was analyzed for each of the target areas, it was found that male students were interviewed more in Nangarhar (73\%), Bamyan (59\%), Paghman district (63\%), Charasyab district (67\%), Shakardara district (100\%) and Guldara district (100\%). However, in Kabul city, Estalif District and Parwan and higher number of female students were interviewed with $59 \%, 100 \%, 53 \%$ respectively. In order to have a complete information about the gender disaggregation of the interviewed students, please refer to charts 5, 6 and 7 .

\section{Chart 5: Gender disaggregation of the Interviewed Students}

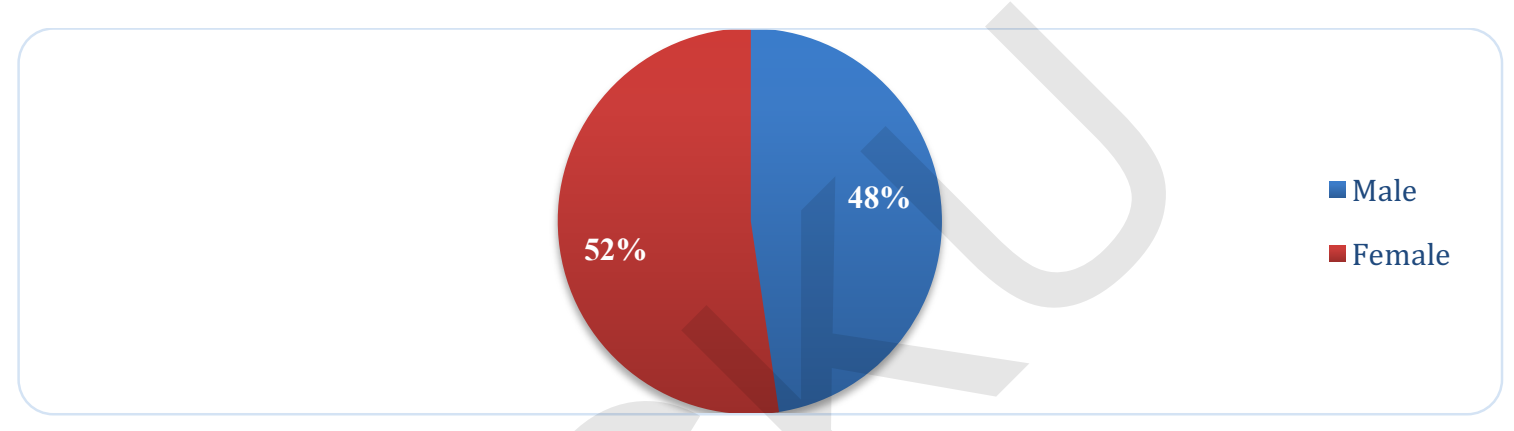

Chart 6: Gender disaggregation of the Interviewed Students in Urban and Rural Areas

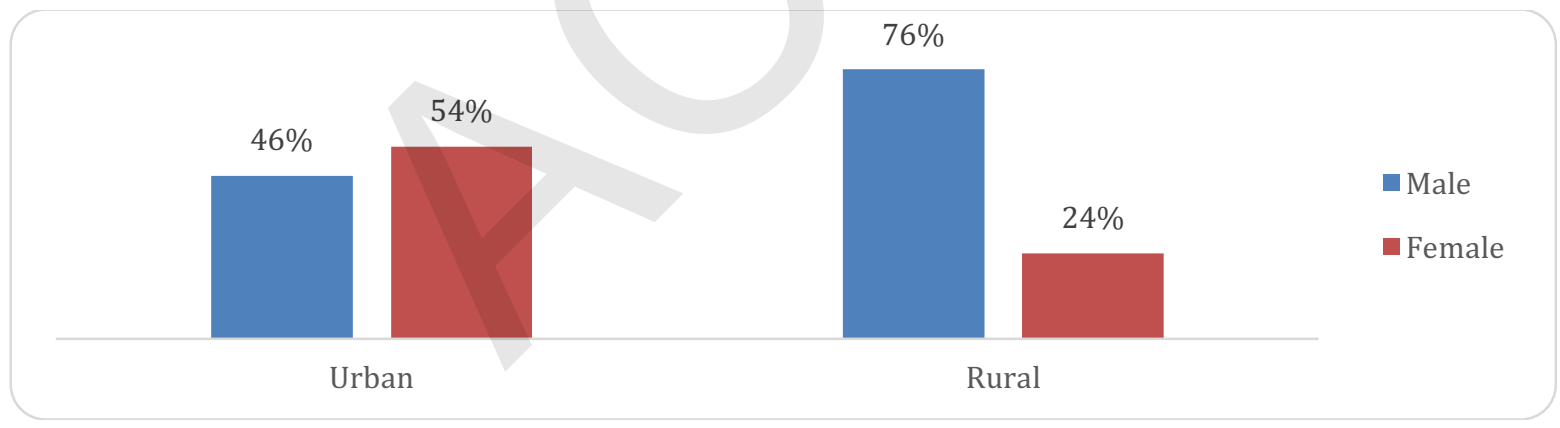

Chart 7: Gender disaggregation of the Interviewed Students in Target Areas

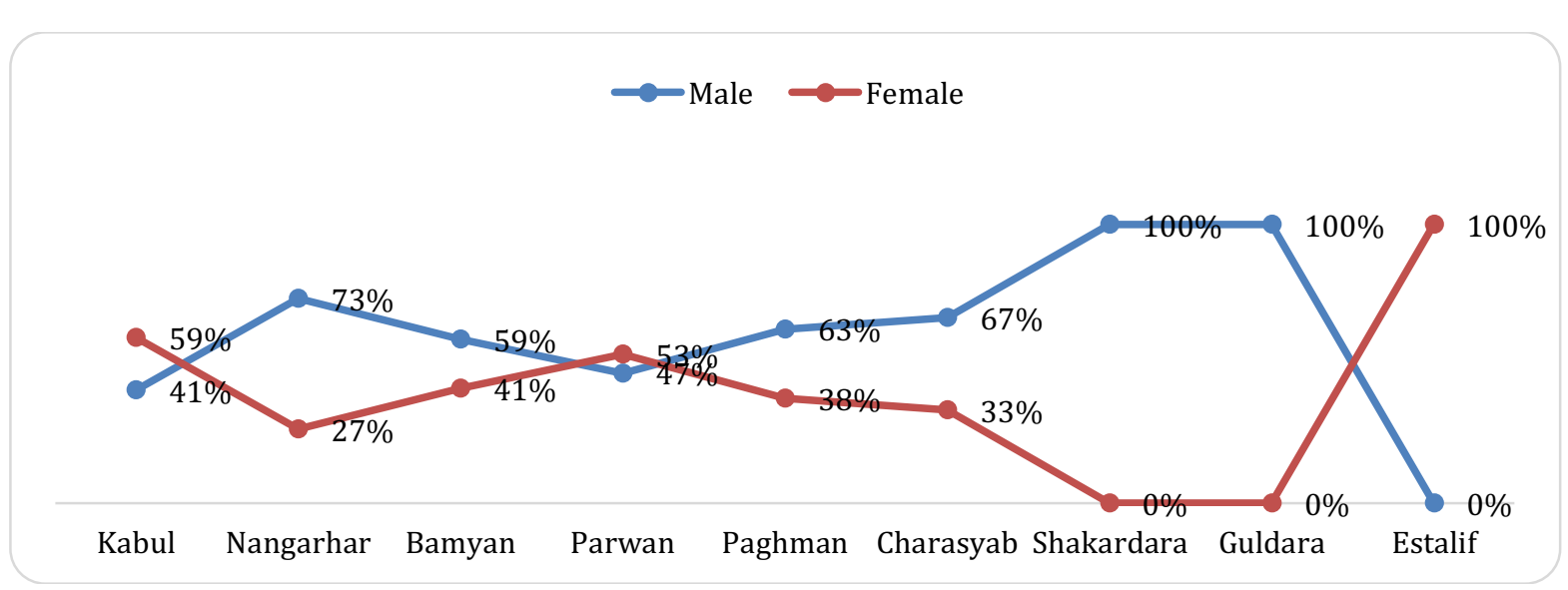


Age:

The second parameter in the general characteristics of the students was their ages. As the students were of high school grades, it was expected to have teenagers and adolescents constitute the majority of the respondents. It should be mentioned that the interviewed students were as young as 14 -year and as old as 22 -years. However, when the data was analyzed, it was found that majority of the students (26\%) were 17 -year old. Similarly, one fourth $(25 \%)$ of the students were 18 -year old and the third majority $(22 \%)$ were 16-year old. Therefore, it can be inferred that nearly three fourth $(73 \%)$ of the students were aged between 16 to 18 years. When talking about the location of the respondents, it was found that in urban areas majority of the students (27\%) were aged 17 years comparing to $40 \%$ in rural areas aged 18 years. At the same time, ages for most of the students according to their genders were different as $33 \%$ of male students were 18 -year old while $30 \%$ of the female students were aged 16 -year. Charts 8,9 and 10 give the complete picture of the age disaggregation of the interviewed students.

\section{Chart 8: Age disaggregation of the Interviewed Student}

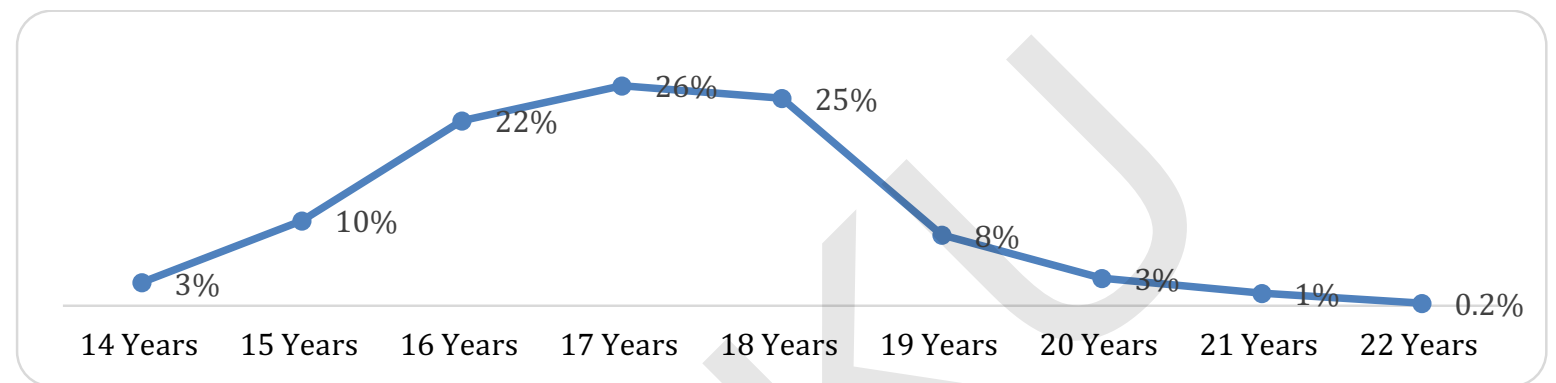

Chart 9: Age disaggregation of the Interviewed Student in Urban and Rural Areas

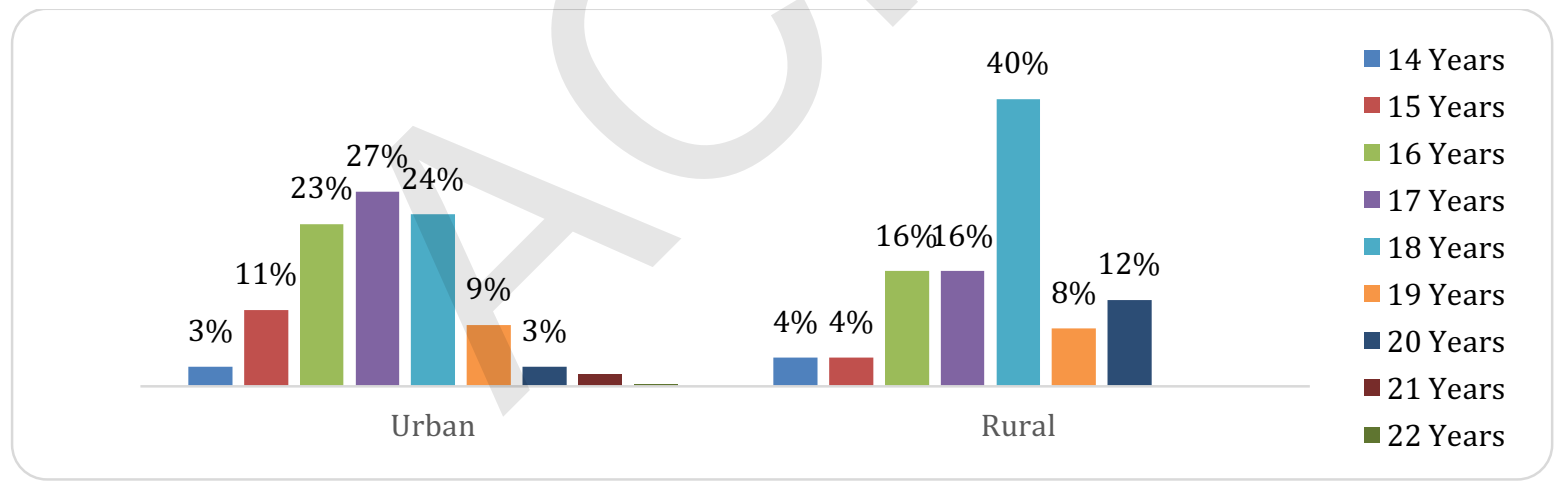

Chart 10: Age disaggregation of the Interviewed Student according to Gender

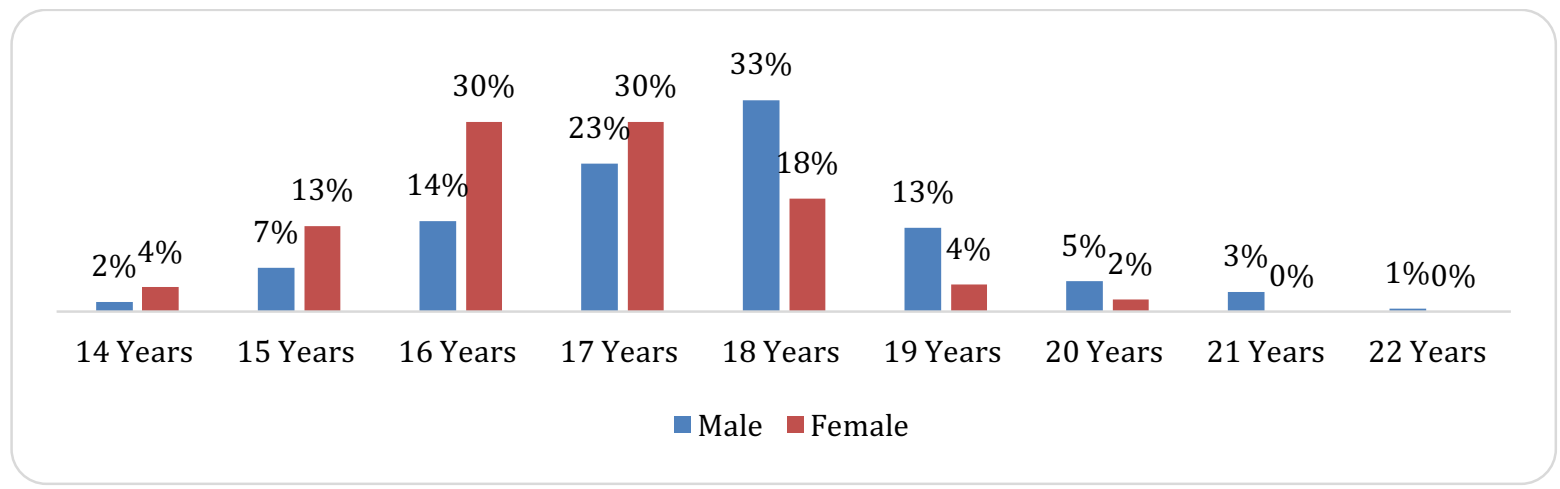


Class:

After collecting the data about the ages of the respondents, the data was collected about the grade of the interviewed students. It should be mentioned that students were selected from 10 to 12 grades and the number of the students selected from each class were based on the number of students in each of the class. Therefore, it was found that majority of the interviewed students were from $11^{\text {th }}$ grade $(36 \%)$, while an equal number of students were interviewed from $10^{\text {th }}$ and $12^{\text {th }}$ grades with $32 \%$ each. When the data was analyzed for urban and rural students, it was found that the disaggregation of the students was similar in both

areas as $36 \% 11^{\text {th }}$ grade, $32 \% 10^{\text {th }}$ grade and $32 \% 12^{\text {th }}$ grade students were interviewed in both urban and rural areas. Finally, the data was analyzed for the gender type of the student and it was discovered that most of the interviewed male respondents were from $10^{\text {th }}$ grade with $35 \%$ and subsequently $34 \%$ from $11^{\text {th }}$ grade and $32 \%$ from $12^{\text {th }}$ grade. However, the female students were higher in number from $12^{\text {th }}$ grade $(36 \%)$ comparing to $10^{\text {th }}$ grade $(33 \%)$ and $11^{\text {th }}$ grade $(31 \%)$. Charts 11,12 and 13 provide the detailed information grade disaggregation of the interviewed students.

\section{Chart 11: Grade Disaggregation of the Interviewed Students}

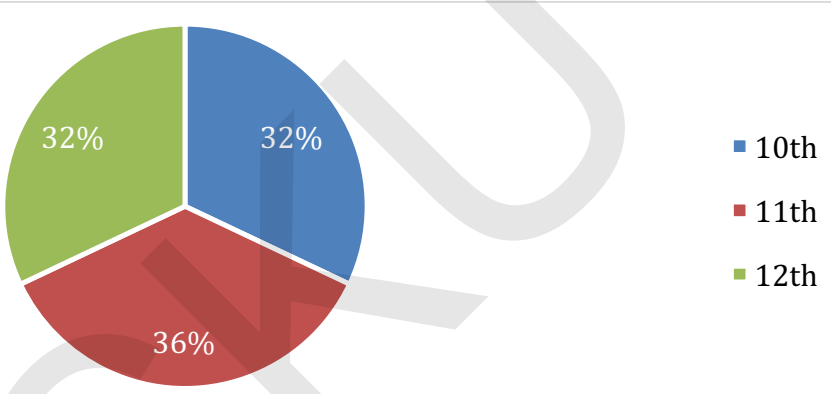

\section{Chart 12: Grade Disaggregation of the Interviewed Students in Urban and Rural Areas}

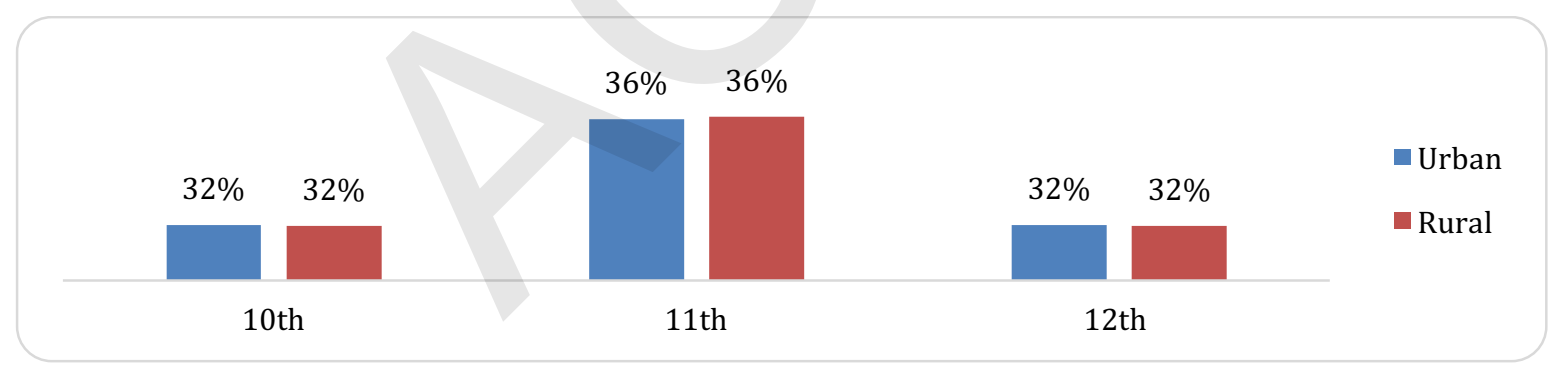

Chart 13: Grade Disaggregation of the Interviewed Students according to Gender

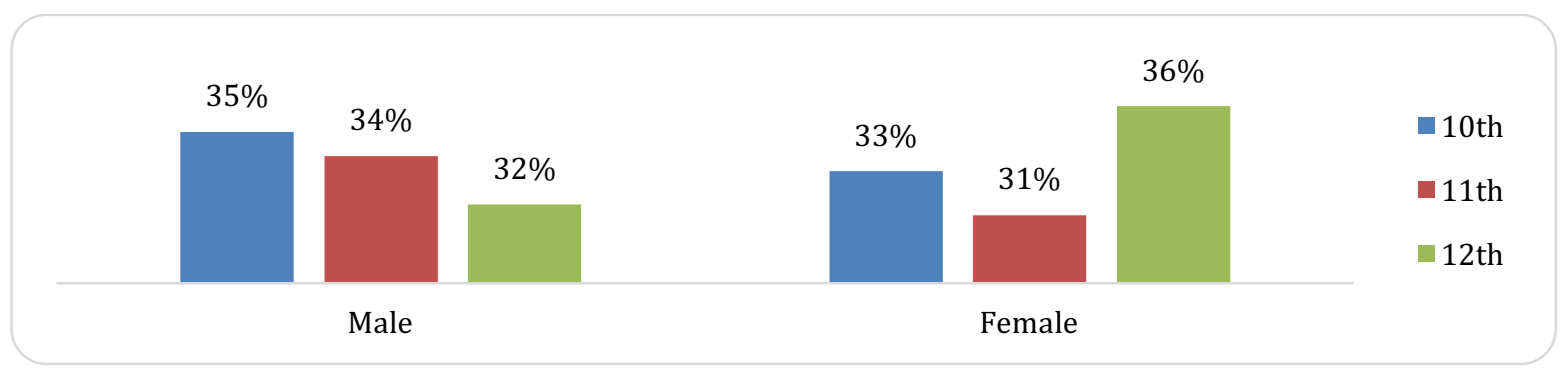

\section{Location:}

The students were, then, asked about the location of the respondents and it was found that the majority of the respondents (89\%) were from the urban areas. However, only $10 \%$ of the respondents were from 
the semi-urban areas (10\%) despite that almost $13 \%$ schools were in districts and only 1 of the total 400 respondents were from the rural area.

\section{Tashabos and Students' Businesses/Employments}

It is evident that Tashabos deals with improving the conditions for students' business. Therefore, the most important portion of the report is collecting information about the opportunities Tashabos has created for students' businesses. This portion of the report will cover information about: assistance of Tashabos in initiating a business; assistance of Tashabos in expanding a business; assistance of Tashabos in various components of running a business.

\section{Tashabos and Students' New/Old Businesses:}

Since Tashabos has covered a lot of topics necessary for initiating a business. Therefore, all the respondent students were asked if Tashabos has assisted them in initiating a new business. As expected a higher majority of the students $(69 \%)$ mentioned that Tashabos had assisted them in initiating a new business. However, it was quite unsatisfactory that nearly three tenth $(31 \%)$ of the students didn't get the assistance of the subject during establishing their business. It was further explored that those who had business talked about the assistance, while the $31 \%$ lacked their own businesses. Therefore, $31 \%$ of the students mentioned that the subject was of less importance during establishing a business. The data was further analyzed for location of the respondents and it was found that the subject assisted rural students $(100 \%)$ more in establishing a business comparing to their rural counterparts $(67 \%)$. In addition, higher number of females $(71 \%)$ responded about the assistance of the subject during establishing a business comparing to male students (65\%). Charts 14,15 and 16 give the complete detail about the students'

\section{Chart 14: Tashabos Assisted Students in Establishing a New Business}

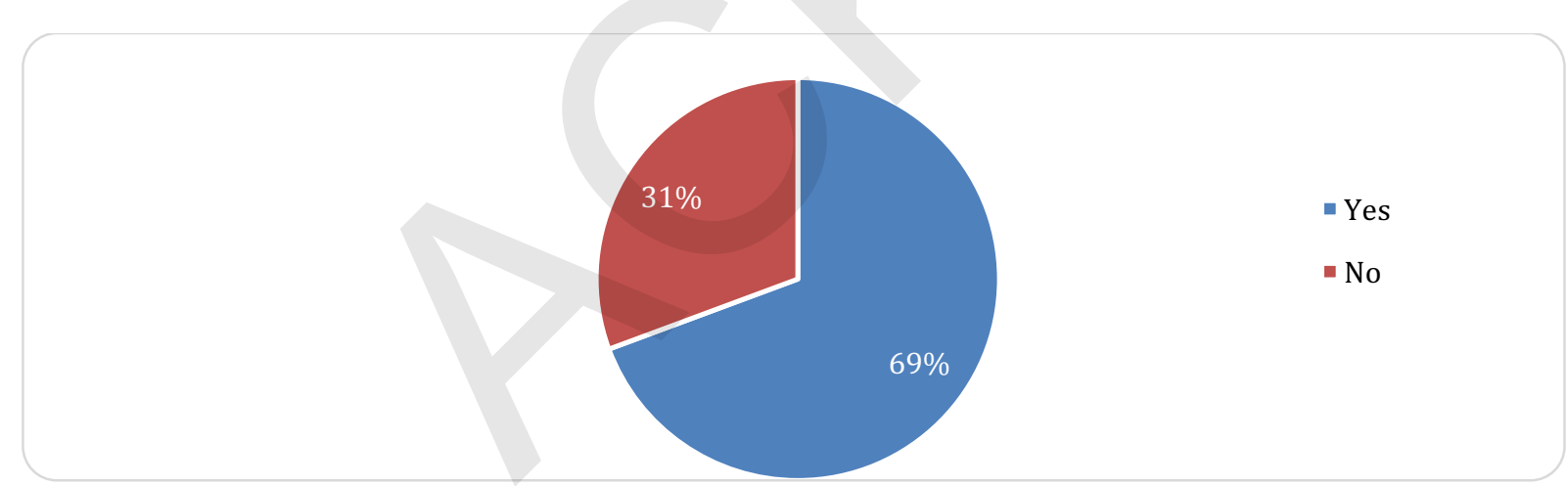

Chart 15: Tashabos Assisted Students in Establishing a New Business in Urban and Rural Areas

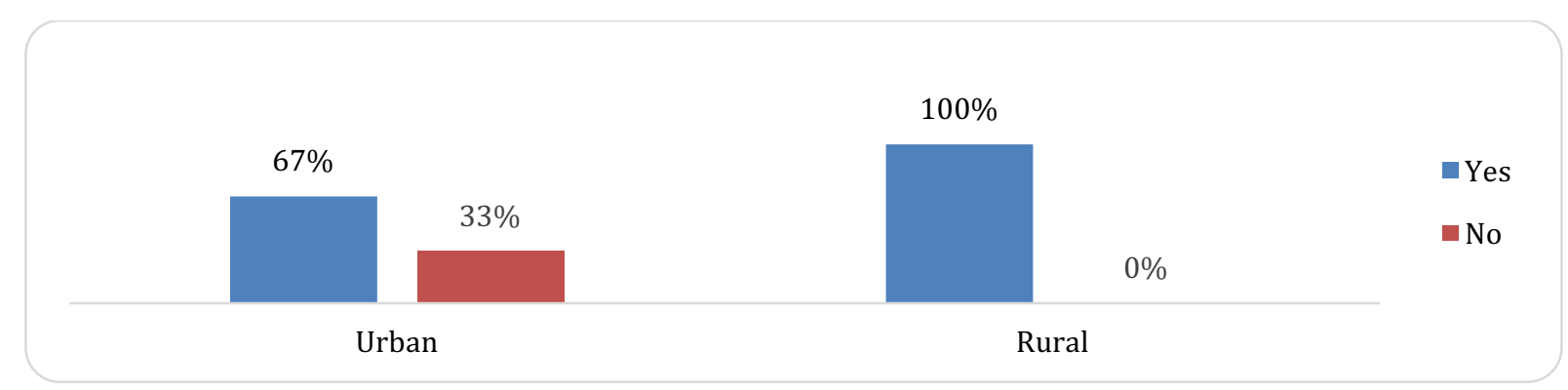


Tashabos Impact Assessment May 18 2017.docx Tashabos and Students' New/Old Businesses:

Chart 16: Tashabos Assisted Students in Establishing a New Business according to Gender

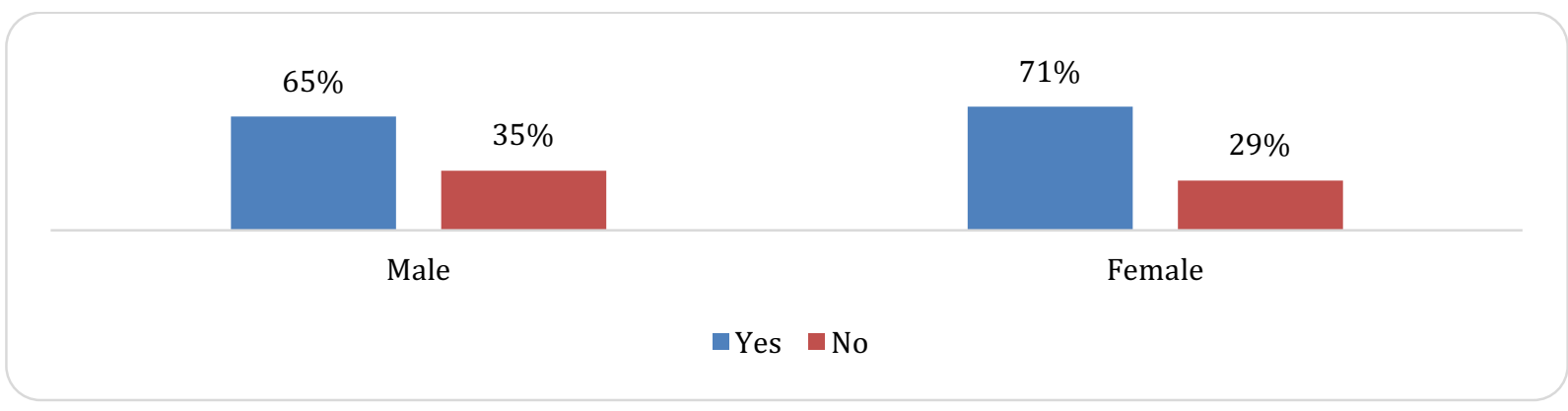

When such a huge number of the students confessed that Tashabos has helped them during initiating a new business, it was considered to know about the topics, which helped the students establish a new business with great outcomes. Most of the students (29\%) replied that Tashabos helped them initiate a business with smaller investments and subsequently expand the business. However, $21 \%$ of the students believed that Tashabos helped them in form of planning and management of the business and only $15 \%$ of the students talked about investments which they learned from the subject. The data was subsequently analyzed for location of the respondents and it was found that for students of the urban areas initiating a business with smaller investments were the highlight topics for $30 \%$ of the students, while $40 \%$ of the rural students were inspired from Omid and Lema story contained in the Tashabos curriculum. However, when talking gender types of the students, it was discovered that both male $(31 \%)$ and female students $(30 \%)$ mentioned about initiating a business with smaller investments that helped the students during initiating a new business. Charts 17,18 and 19 provide the detailed information about the topics helped the students during establishment of a new business.

\section{Chart 17: Topics of the Subject Helped the Students during Establishing a New Business}

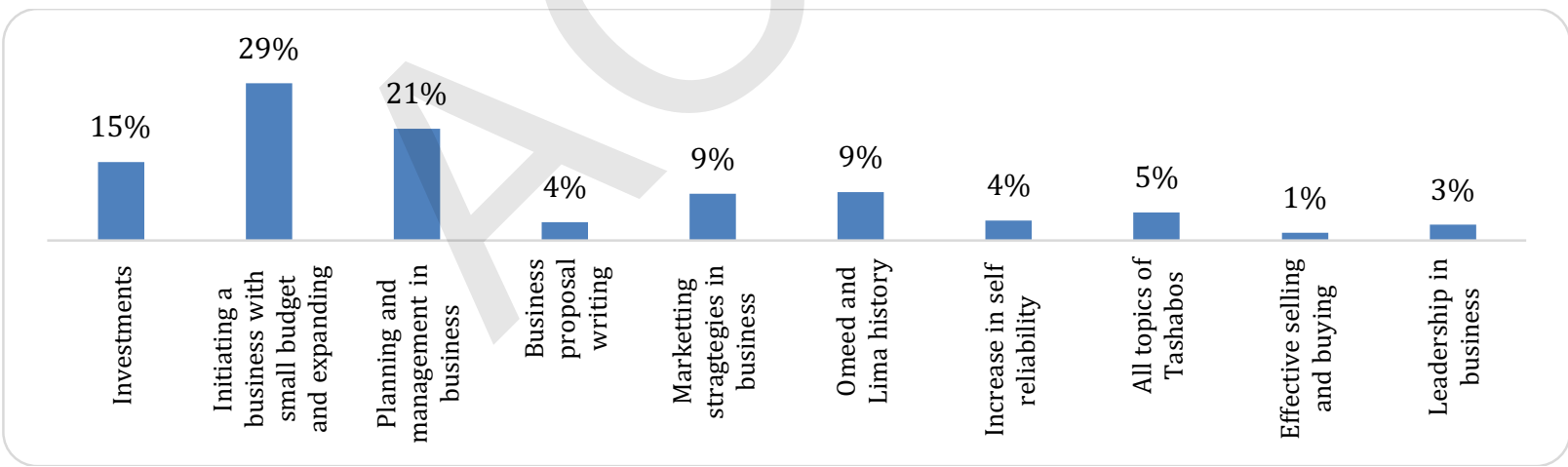

Chart 18: Topics of the Subject Helped the Students during Establishing a New Business in Target Areas

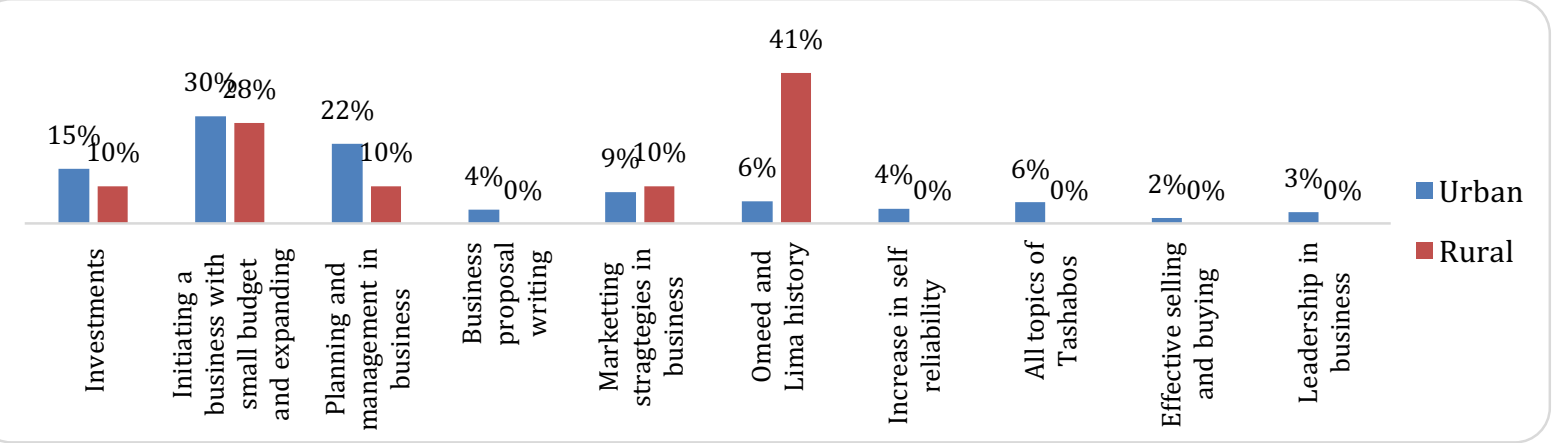


Tashabos Impact Assessment May 18 2017.docx Tashabos and Students' New/Old Businesses:

Chart 19: Topics of the Subject Helped the Students during Establishing a New Business According to Gender

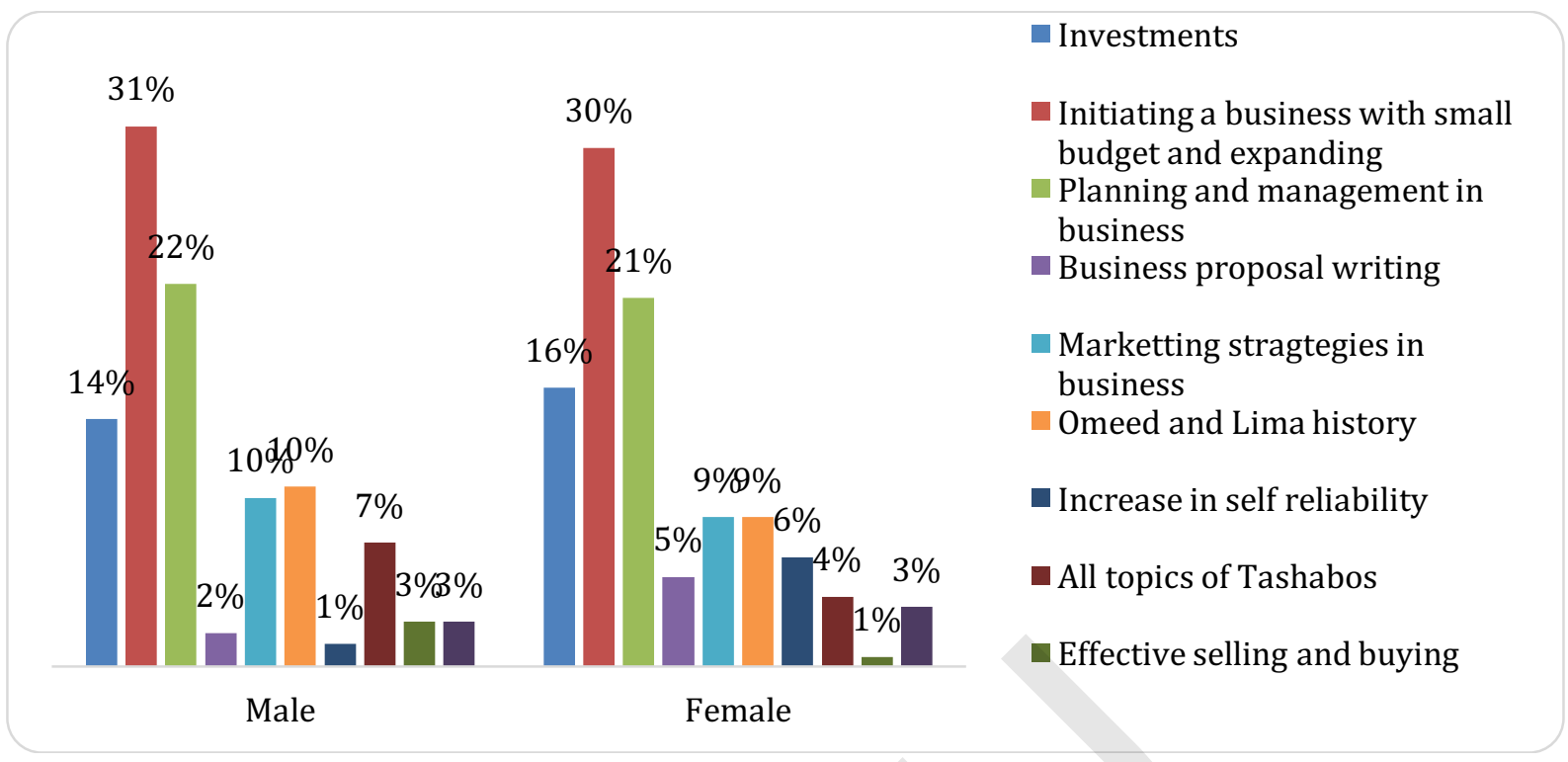

The students who were not assisted by the subject during establishment of their businesses were asked if the subject would help them in the future. Fortunately, a higher number of students $(85 \%)$ replied positively that the subject would help them in the future in case they have businesses. When the students were how they would be assisted by the subject, $46 \%$ of them replied that they would utilize the gained knowledge in running their businesses. Charts 20 and 21 explain assistance of the subject in the future.

\section{Chart 20: The Subject Assists the Students in the Future in Running the Business}

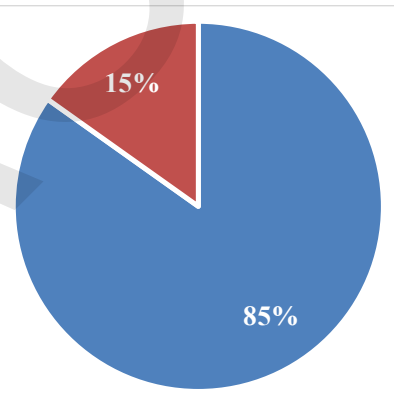

Chart 21: How Would the Subject Help the Students in the Future?

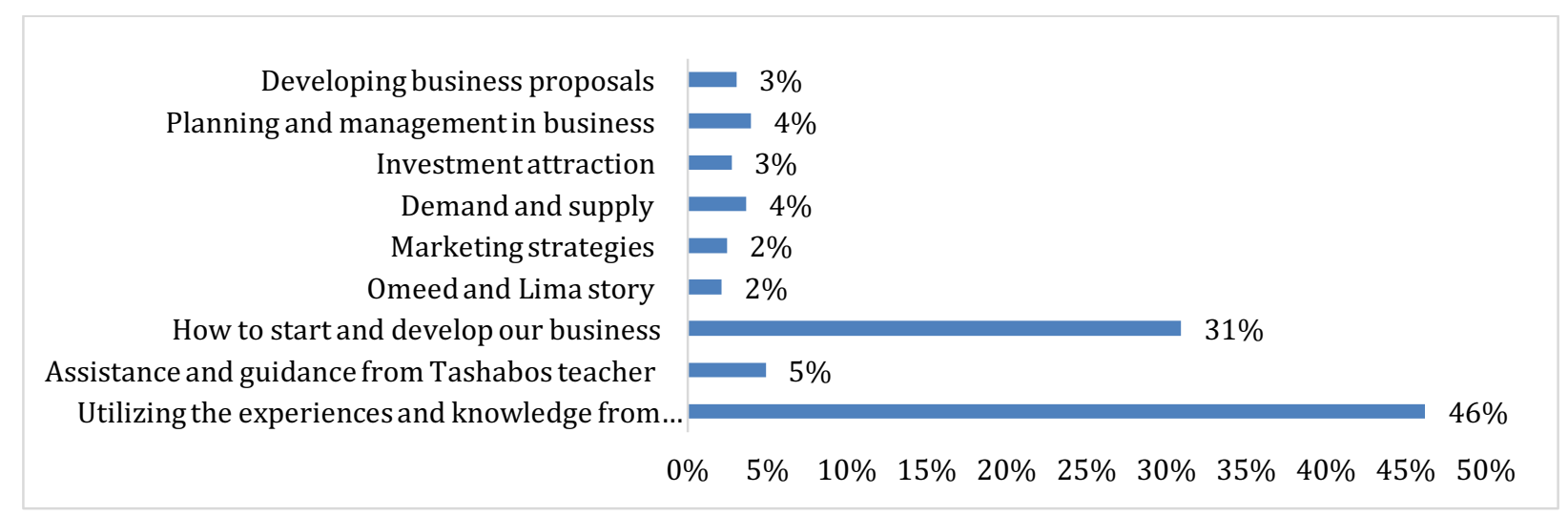


After acquiring the detailed information about students' new businesses, the students were asked if the subject have been effective in expanding students' existing businesses. Over half of the students $(51 \%)$ replied that Tashabos has assisted them during expanding their existing businesses. It should be mentioned that Tashabos assistance during expanding a business was far more important in rural areas $(90 \%)$ comparing to urban areas $(48 \%)$. However, when we are talking about the gender of the students, we discover that male students (57\%) utilized the knowledge from Tashabos more than their female counterparts $(46 \%)$. Charts 22,23 and 24 explain the importance of the subject in expansion of the business from students' perspectives.

\section{Chart 22: Tashabos Importance in Expanding a Business (Students' Perspectives)}

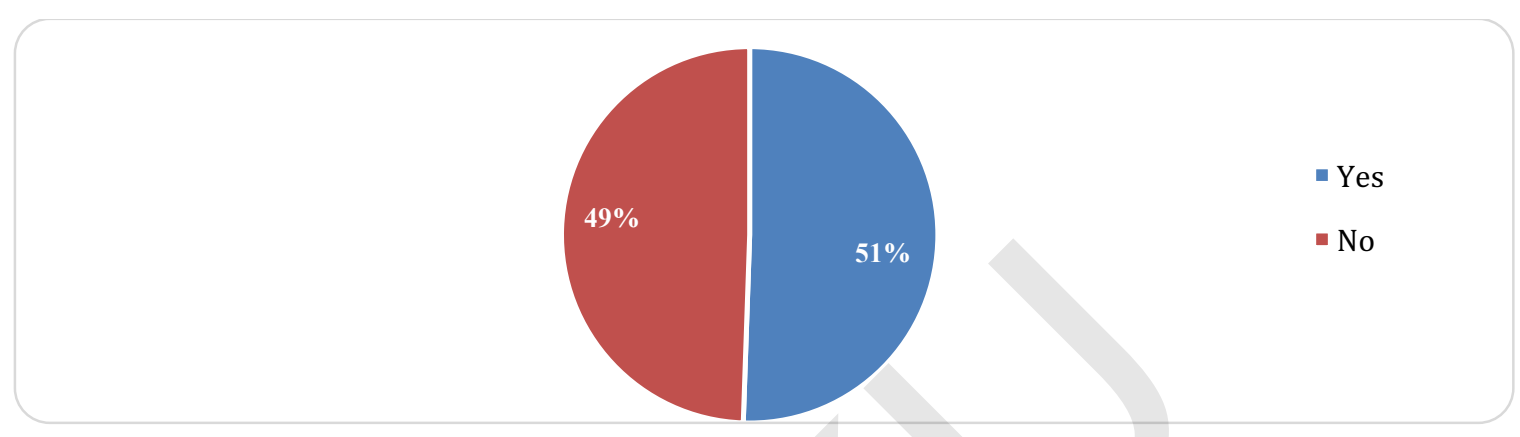

Chart 23: Tashabos Importance in Expanding a Business (Students' Perspectives) in Urban and Rural Areas

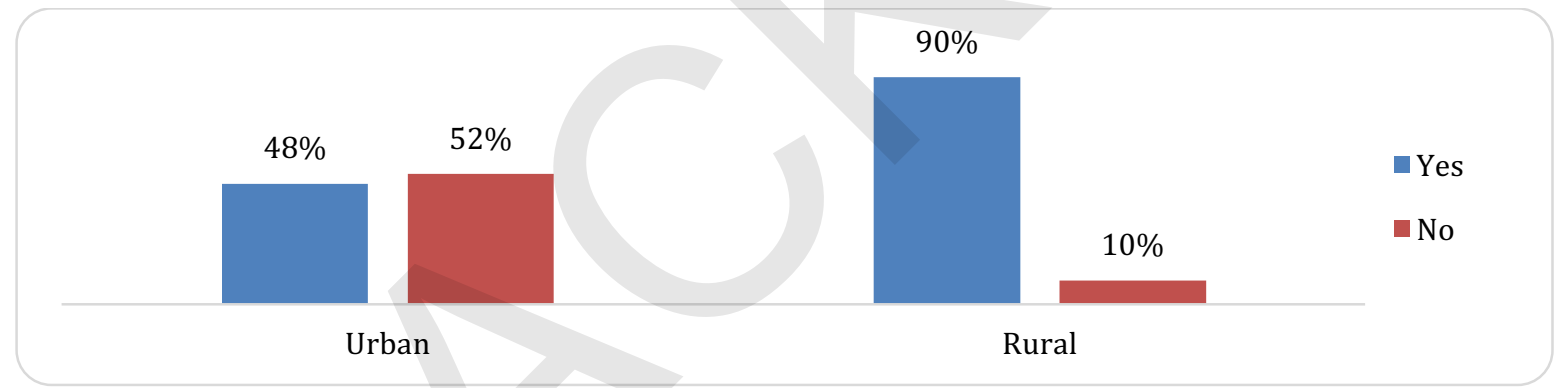

Chart 24: Tashabos Importance in Expanding a Business (Students' Perspectives according to Gender)

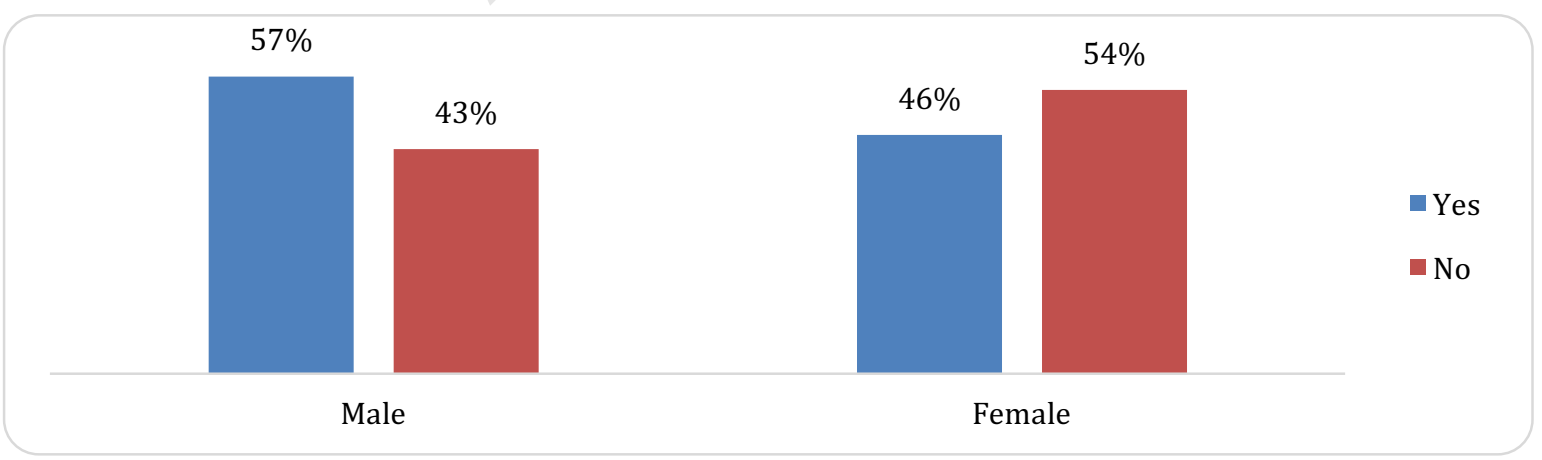

Afterwards the students were asked about the topics influenced students during expanding their business. One fourth $(25 \%)$ of the students mentioned that business development steps has helped them during expanding their business, while 19\% of the students believed that all the topics of the subject were important during the process. When talking about the location of the students, it was found that business development skills helped majority of the students in both urban $(24 \%)$ and rural areas $(27 \%)$. In 
Tashabos Impact Assessment May 18 2017.docx Tashabos and Students' New/Old Businesses:

addition, the gender types (male students with $27 \%$ and female students with $22 \%$ ) of the students had similar notions about the importance of the subject during expansion of the students. Charts 25,26 and 27 explain the important topics of the subject during expansion of the students' businesses.

\section{Chart 25: Tashabos Topics Important for Expansion of the Businesses}

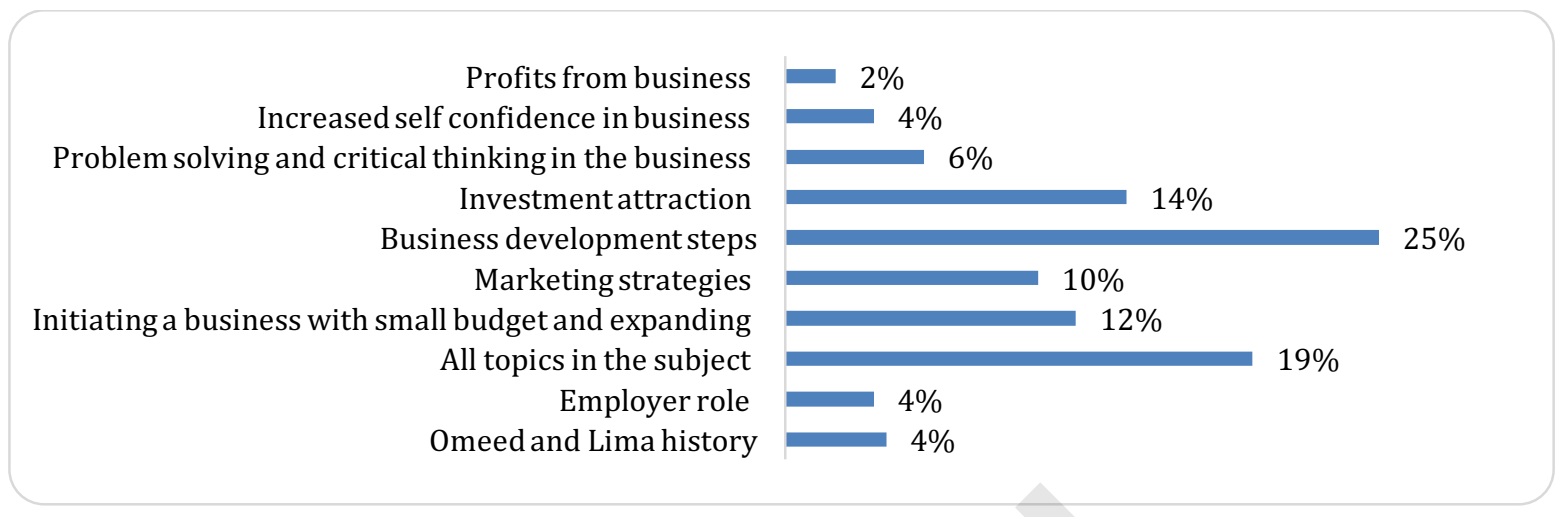

Chart 26: Tashabos Topics Important for Expansion of the Businesses in Urban and Rural Areas

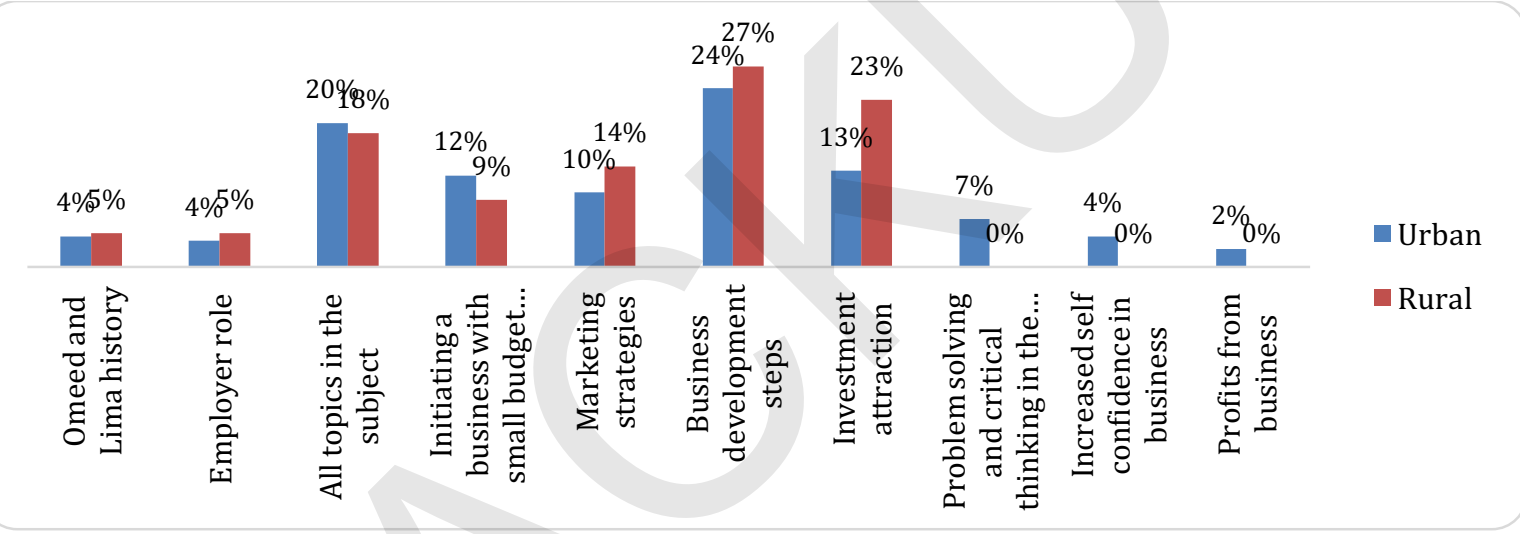

Chart 27: Tashabos Topics Important for Expansion of the Businesses according to Gender

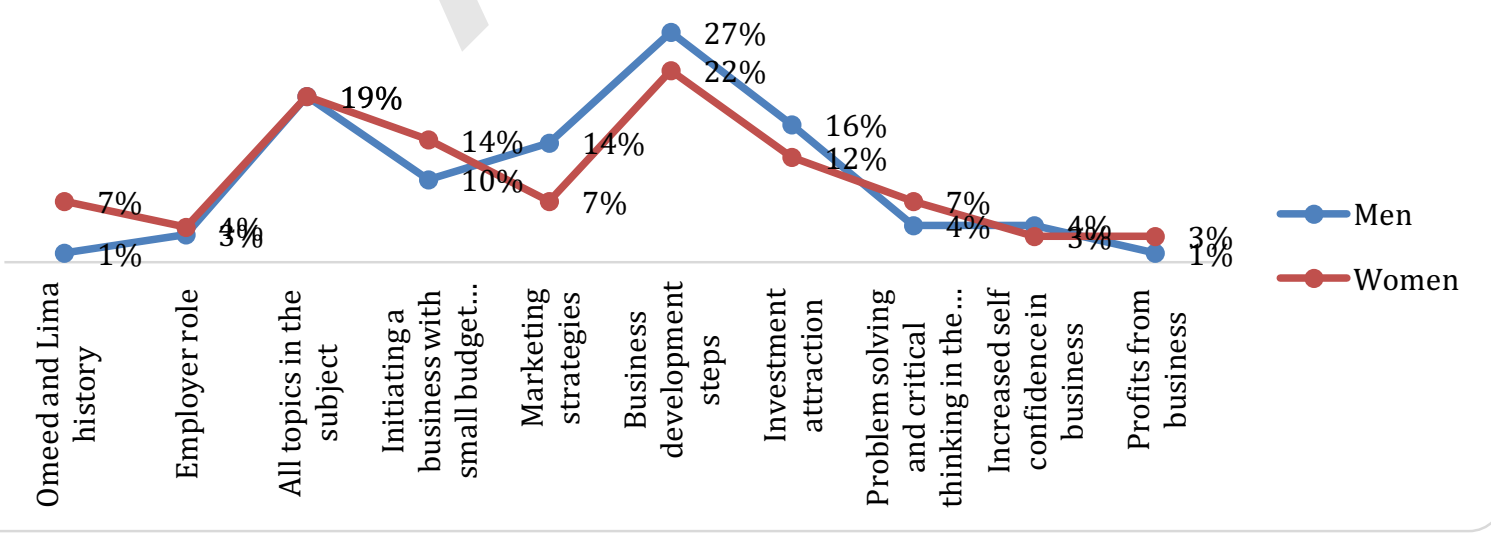

The students were, then, asked if the subject has been effective during either initiation or expansion of the business. As explained earlier, majority of the students had utilized the gained knowledge during initiation of the business. Therefore, $77 \%$ of the students mentioned that Tashabos is effective during initiation a business rather than expanding $(23 \%)$. 
After collecting sufficient information about the students' own businesses, the students were asked if they knew any of their classmates initiated or expanded a business. It was quite informative that $63 \%$ of the students mentioned that at least one of their fellow had initiated or expanded a business. Considering the location of the students, it was found that more fellows of rural students $(87 \%)$ had either initiated or expanded a business than urban students $(61 \%)$. Afterwards, the data was analyzed for gender types of the students and it was discovered that male students (64\%) edged female students $(61 \%)$ in number of fellows initiated or expanded a business. Charts 28, 29 and 30 depict the complete information about students' classmates initiated or expanded a business.

\section{Chart 28: Classmates Have Initiated or Expanded a Business}

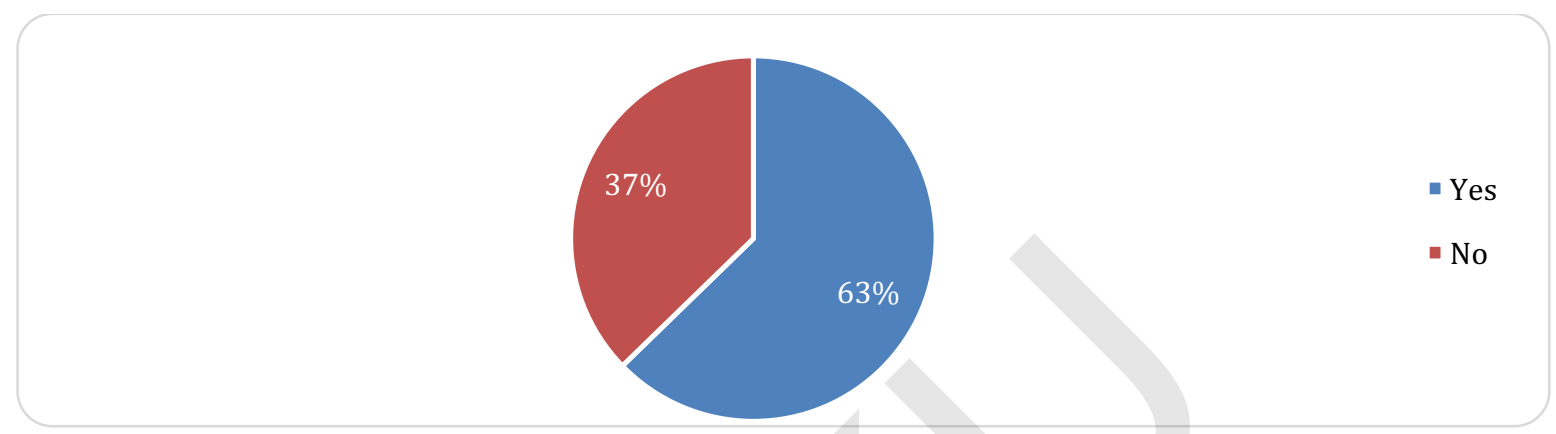

Chart 29: Classmates Have Initiated or Expanded a Business in Urban and Rural Areas

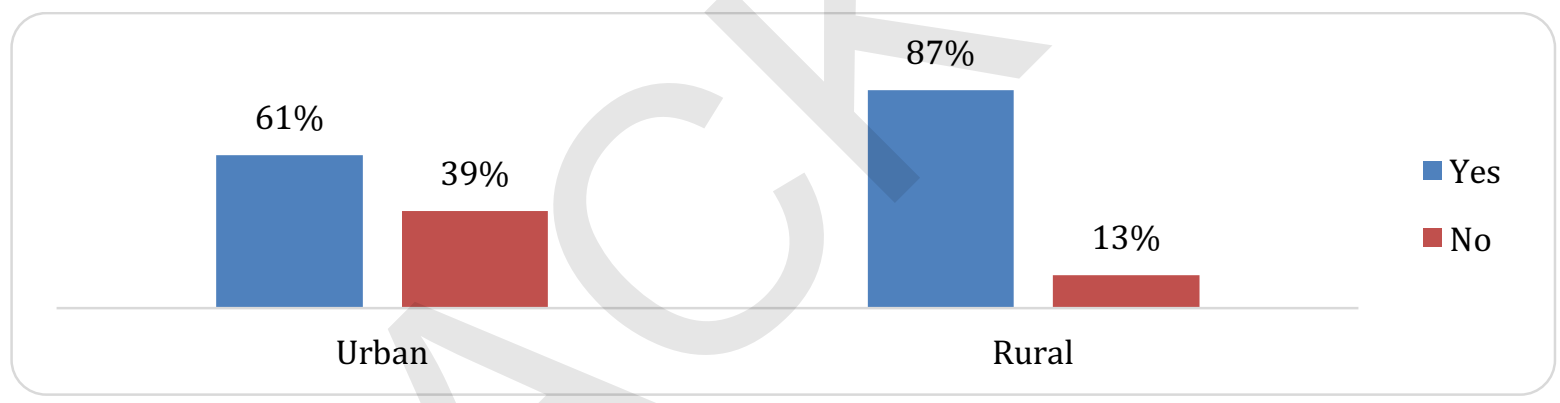

\section{Chart 30: Classmates Have Initiated or Expanded a Business according to Gender}

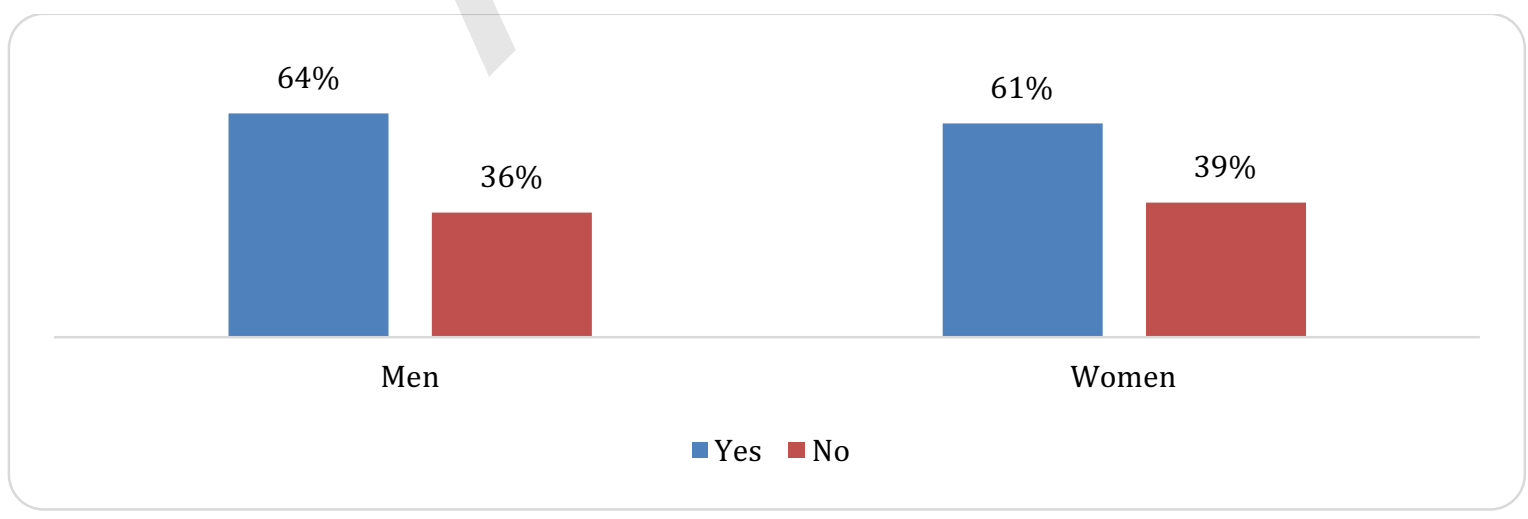

Now that the Tashabos has helped a majority of the students in either initiating or expanding a business, it was considered vital to know which of the gender types have been benefited the most by the subject during initiating a business. Therefore, all the students were asked about the importance of the subject on gender types of the students. $60 \%$ of the students replied that the subject is effective for both girls and boys, while $29 \%$ of them thought that Tashabos might be useful for only boys and $12 \%$ pointed girls 
as the most fertile recipients for the subject. The data was analyzed for the location and it was found that in both areas majority of the students $60 \%$ in urban areas and $56 \%$ in rural areas) explained that Tashabos has been an important subject for both genders in initiating or expanding a business. Chart 31 and 32 explain students' viewpoints on importance of the subject on gender types of the students.

\section{Chart 31: Importance of Tashabos for Gender Types of the Students}

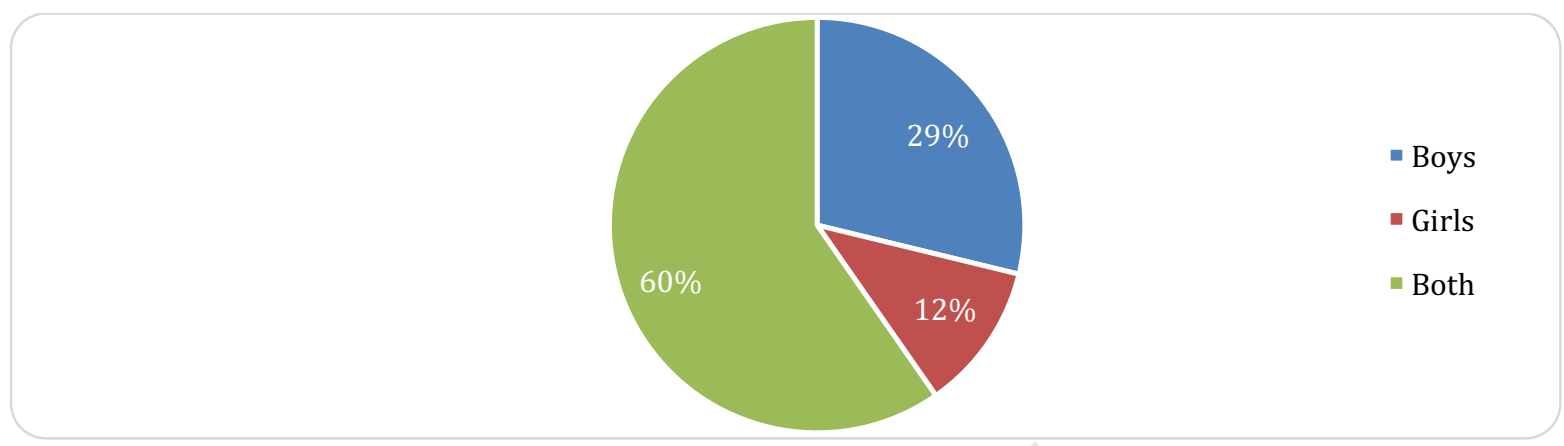

Chart 32: Importance of Tashabos for Gender Types of the Students in Urban and Rural Areas

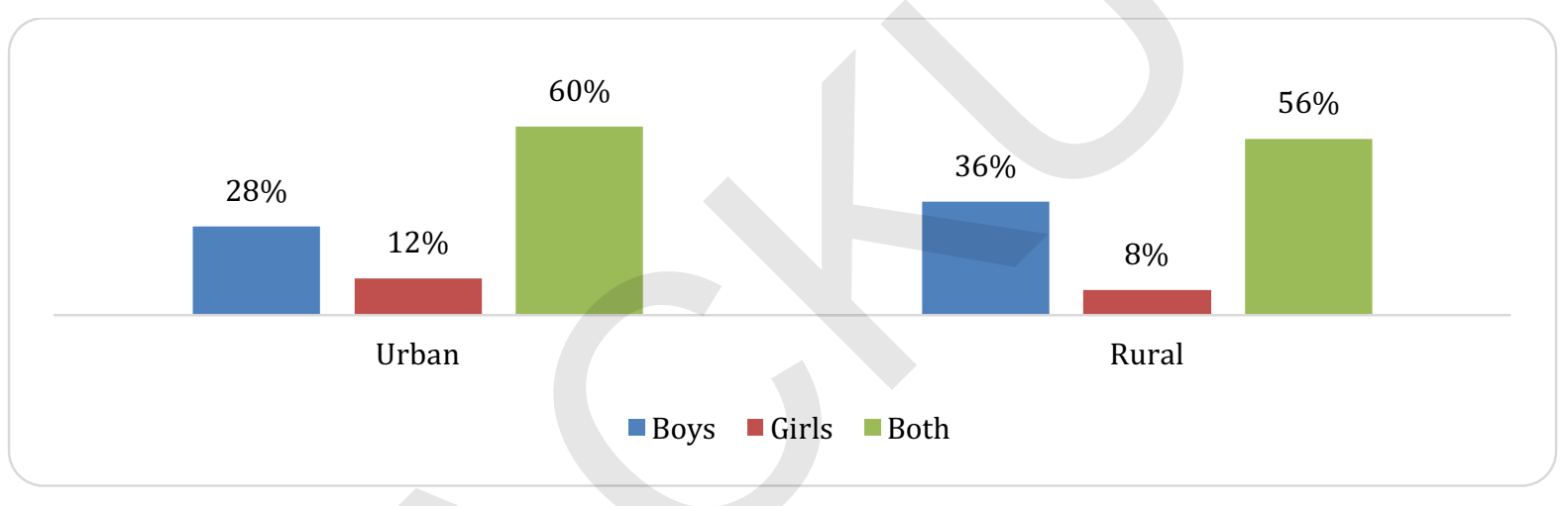

Afterwards, the students were asked how the subject has been effective on each of the gender types. The majority of the students provided their comments on the equivalent effect of the subject on both genders as $28 \%$ of the students highlighted that Tashabos is important for both genders because both have gotten equal talents, while $22 \%$ of them were in the favor that Tashabos should be taught for both the genders because both genders are required to have employments. However, it should be mentioned that $16 \%$ of the students were saying that Tashabos should have been taught to only boys because boys have more freedom than girls. The complete list of the students' viewpoints on importance of the subject on gender types is presented in chart 33 . 


\section{Chart 33: Importance of Tashabos Subject on Gender Types of the Students}

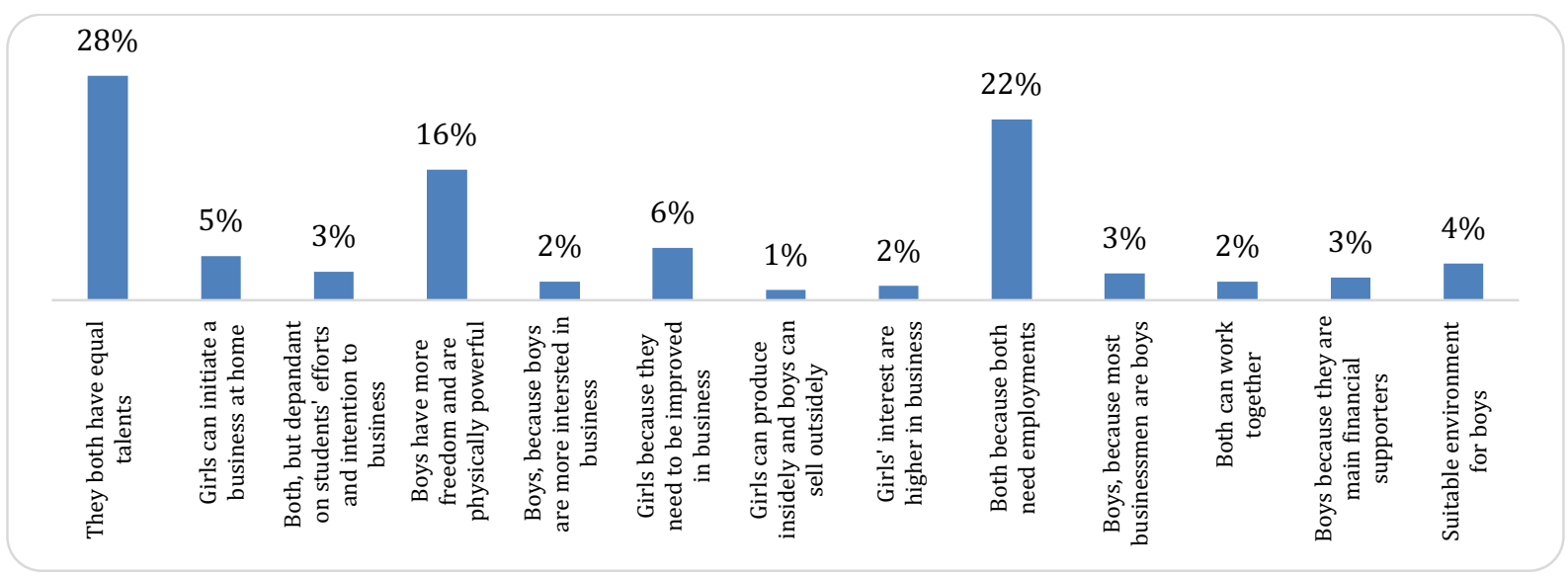

Now that the subject has provided a platform for successful running of the business, it was considered vital to know about any opportunities provided by the subject during business and employment. $81 \%$ of the students reported that the subject had provided them the opportunities during their businesses. It should be mentioned that the subject has provided more opportunities for rural students (96\%) comparing to urban students $(80 \%)$. When speaking about the gender types of respondents, it was found that male students $(82 \%)$ were slightly ahead of their female counterparts $(80 \%)$ in having more opportunities from the subject. Charts 34,35 and 36 explain the opportunities provided for students by Tashabos

\section{Chart 34: Tashabos Provided Opportunities during the Business}

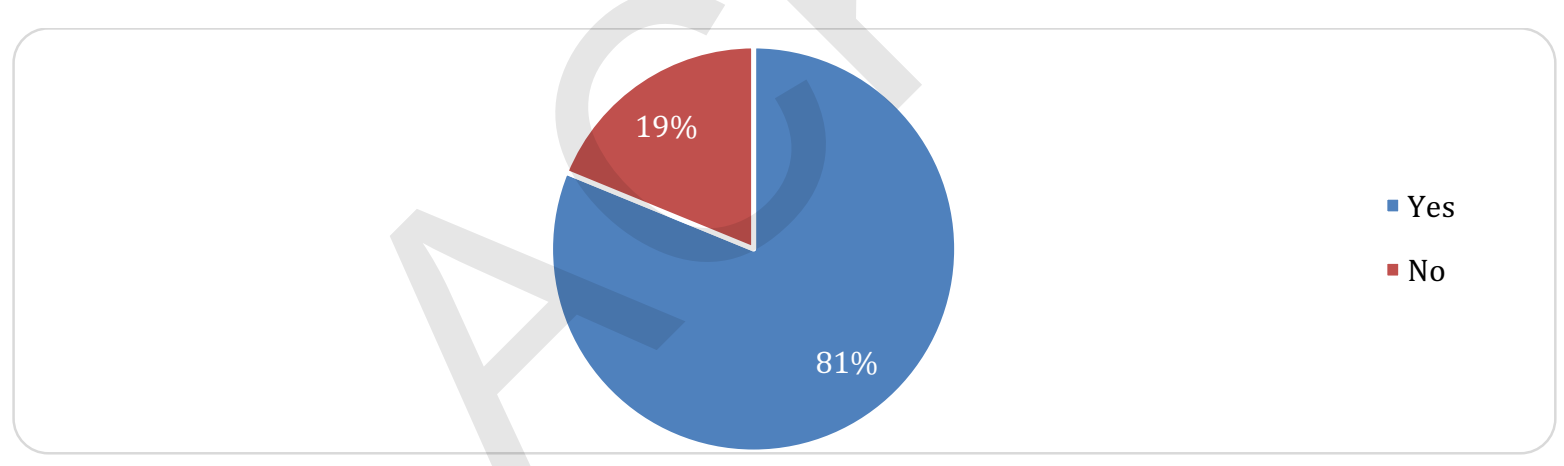

Chart 35: Tashabos Provided Opportunities during the Business in Urban and Rural Areas

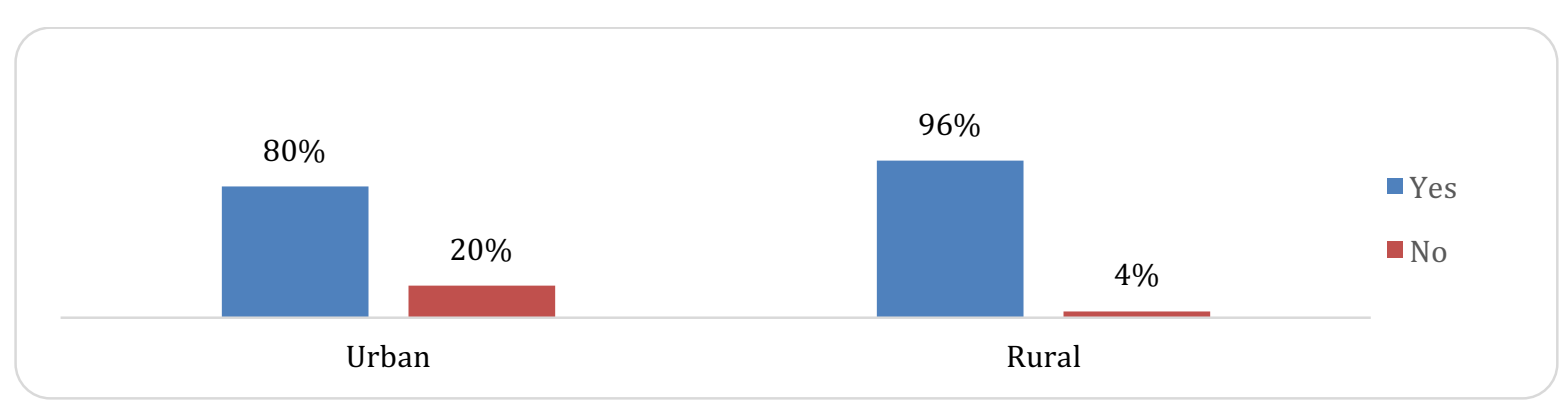


Tashabos Impact Assessment May 18 2017.docx Tashabos and Students' New/Old Businesses:

Chart 36: Tashabos Provided Opportunities during the Business according to Gender

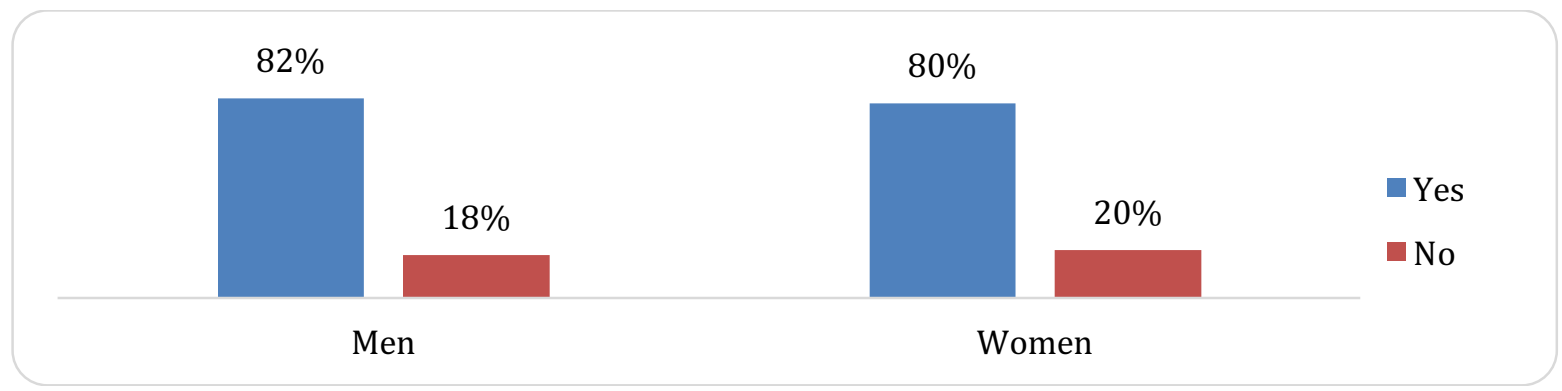

Furthermore, the students were, then, inquired about the type of opportunities provided by the subject during the business/employment of the students. $41 \%$ of the students mentioned that Tashabos helped them to initiate a business with smaller amount of business, while $39 \%$ of them mentioned that Tashabos provided the opportunities of employment for graduate youths. Coming to the location of the respondents, it was found that students of both urban (40\%) and rural (53\%) areas have shared the common notion about assistance of the subject in initiating a business with smaller amount of budget. However, it should be mentioned that gender types of the students had various comments on the provided opportunities. $42 \%$ of the male students mentioned that Tashabos had opened the gates of employment to the youths, while $44 \%$ of the female students talked about their abilities to initiate a business with smaller amounts of budgets. Charts 37, 38 and 39 depict the complete picture provided opportunities by the subject.

\section{Chart 37: Provided Opportunities by Tashabos during Business/Employment of the Students}

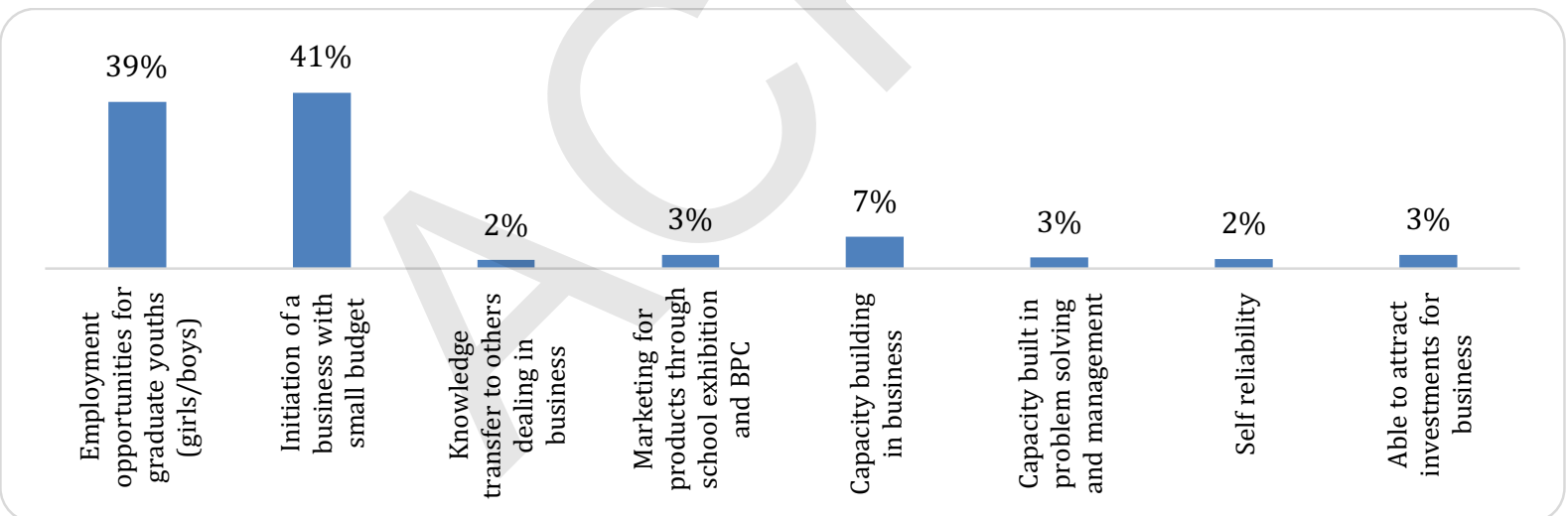

Chart 38: Provided Opportunities by Tashabos during Business/Employment of the Students in Urban and Rural Areas

\begin{tabular}{|c|c|c|c|c|c|c|c|}
\hline $39 \% 35 \%$ & $\begin{array}{l}53 \% \\
40 \%\end{array}$ & 2\% 0\% & $3 \% 0 \%$ & $7 \% 12 \%$ & $3 \% 0 \%$ & $2 \% 0 \%$ & $3 \% 0 \%$ \\
\hline 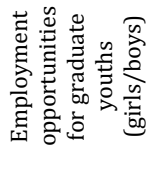 & 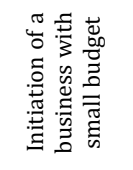 & 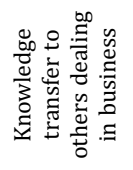 & 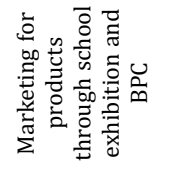 & 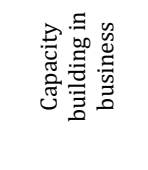 & 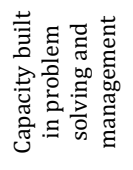 & 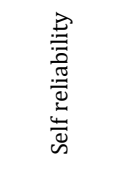 & 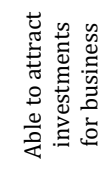 \\
\hline & & & Urban & - Rural & & & \\
\hline
\end{tabular}


Tashabos Impact Assessment May 18 2017.docx Tashabos and Students' New/Old Businesses:

Chart 39: Provided Opportunities by Tashabos during Business/Employment of the Students according to Gender

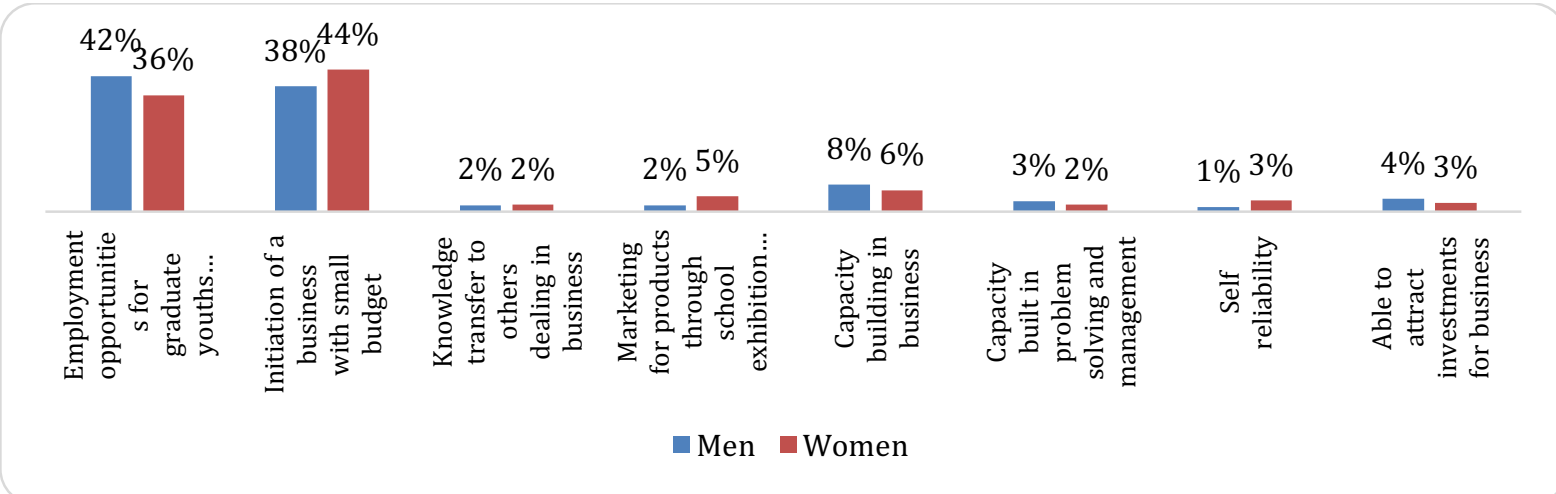

It is evident that challenges are part of any adventure. Therefore, all the students were asked if they have had faced any challenges during their businesses. As expected over six tenth $(61 \%)$ of the students has observed the challenges. It should be mentioned that almost a similar number of students from urban $(61 \%)$ and rural $(60 \%)$ have observed the challenges within their businesses. However, when we are talking about the gender types of the students, it was found that more male students (63\%) comparing to female students (59\%) have observed a challenge within their businesses. Charts 40, 41 and 42 explain the observance of the challenges by students in details.

\section{Chart 40: Observed a Challenge within Business}

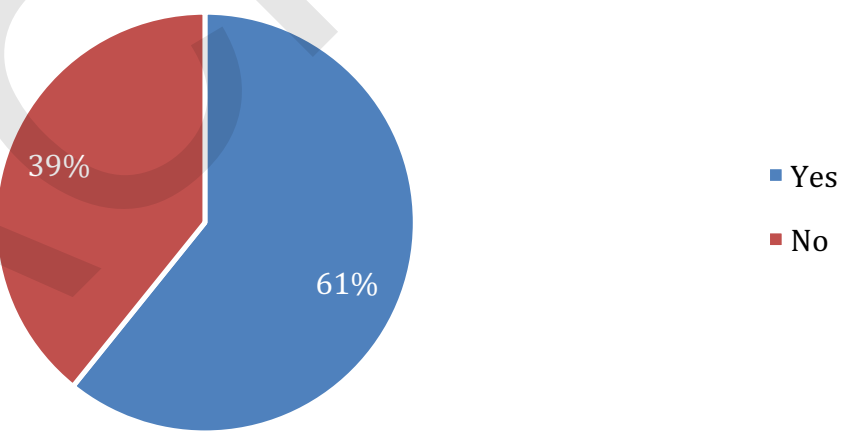

Chart 41: Observed a Challenge within Business in Urban and Rural Areas

$61 \%$

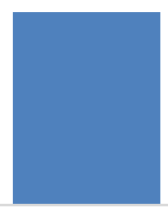

Urban
$60 \%$

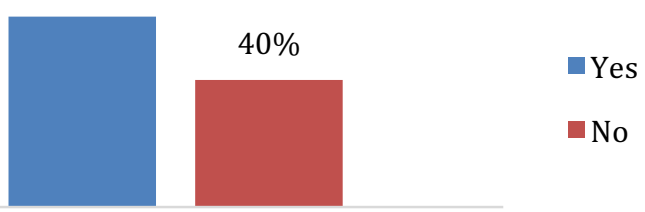

Rural 


\section{Chart 42: Observed a Challenge within Business according to Gender}

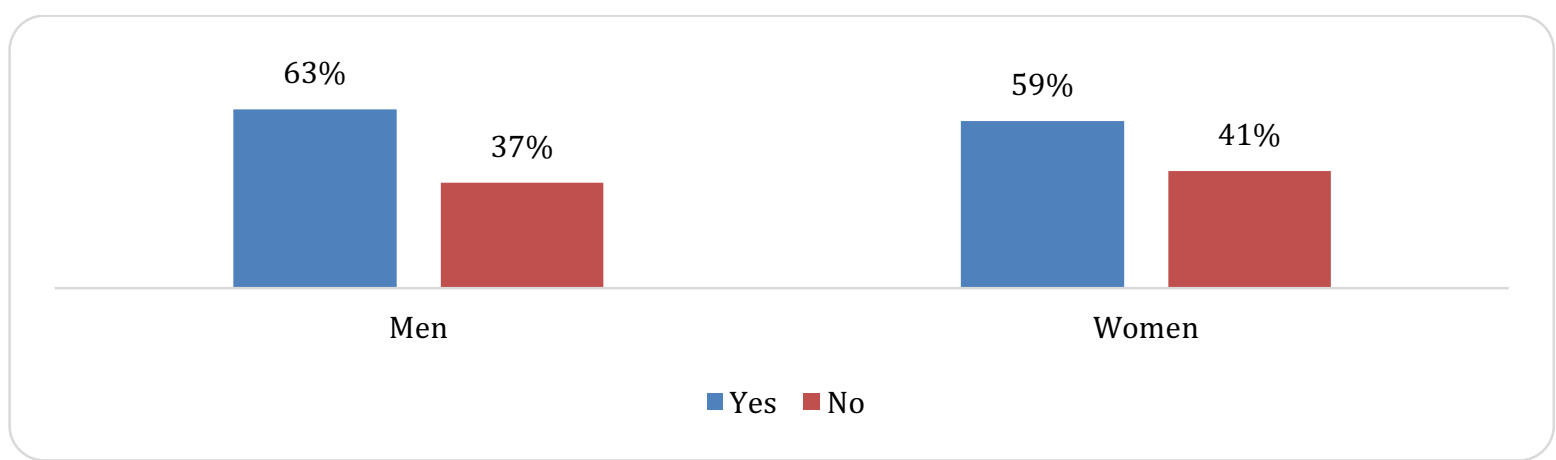

Since more than half of the students have observed challenges within their businesses, it was considered vital to know about the types of the challenges and the importance of Tashabos in managing the challenges. Majority of the students $(16 \%)$ mentioned that they had challenges for investments within their business, but with the help of the knowledge they had gained from Tashabos, they were able to solve the challenge. At the same time, $14 \%$ of the students mentioned that they couldn't maintain their daily economics for their business. However, Tashabos helped them overcome the challenge. Finally, $11 \%$ of the students were talking about the challenges they had faced for marketing strategies of their business, but the challenge was successfully handled with the help of the subject. Different challenges were observed by students of urban and rural areas as $17 \%$ of the urban students mentioned the investment challenges, while $33 \%$ of the rural students talked about marketing challenges within their businesses. However, it should be stated that majority of both male (15\%) and female students (17\%) faced the challenge of investment within their businesses. Charts 43,44 and 45 give the complete information about the types of challenges observed by the students within their businesses.

\section{Chart 43: Types of Challenges Observed by the Students and Managed through Tashabos}

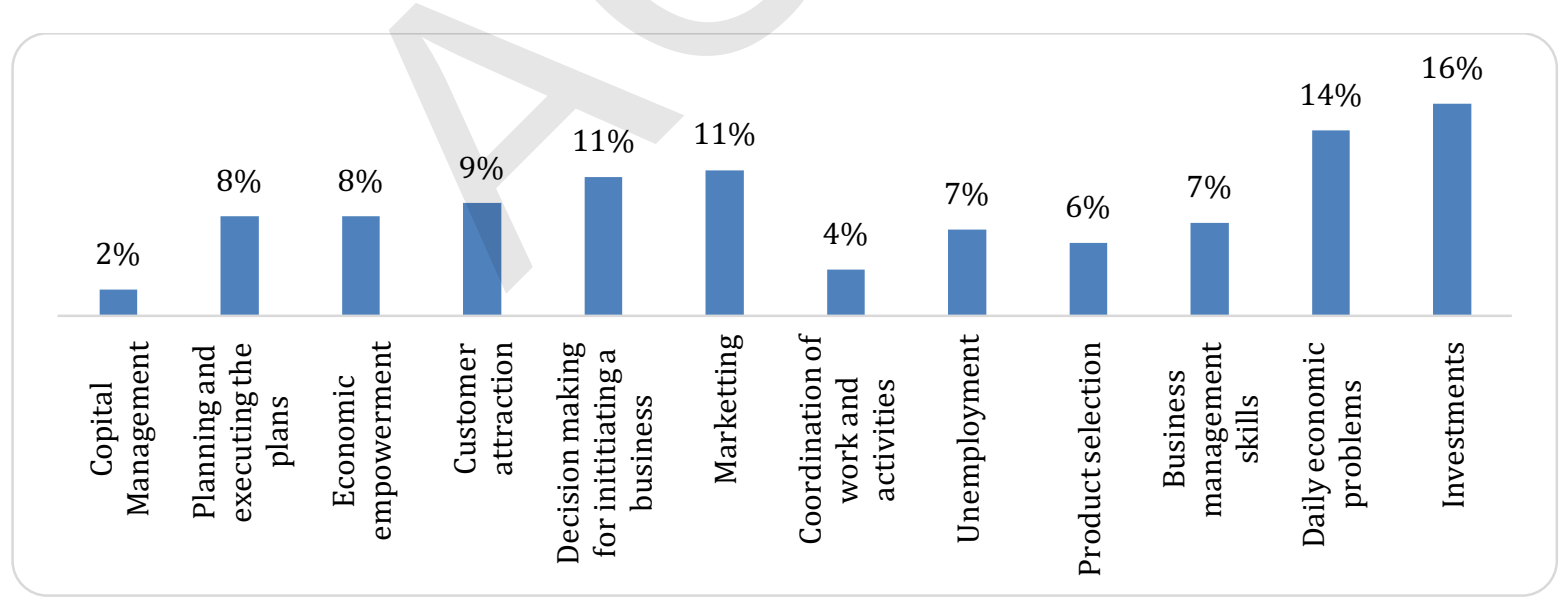


Tashabos Impact Assessment May 18 2017.docx Tashabos and Students' New/Old Businesses:

Chart 44: Types of Challenges Observed by the Students and Managed through Tashabos in Urban and Rural Areas

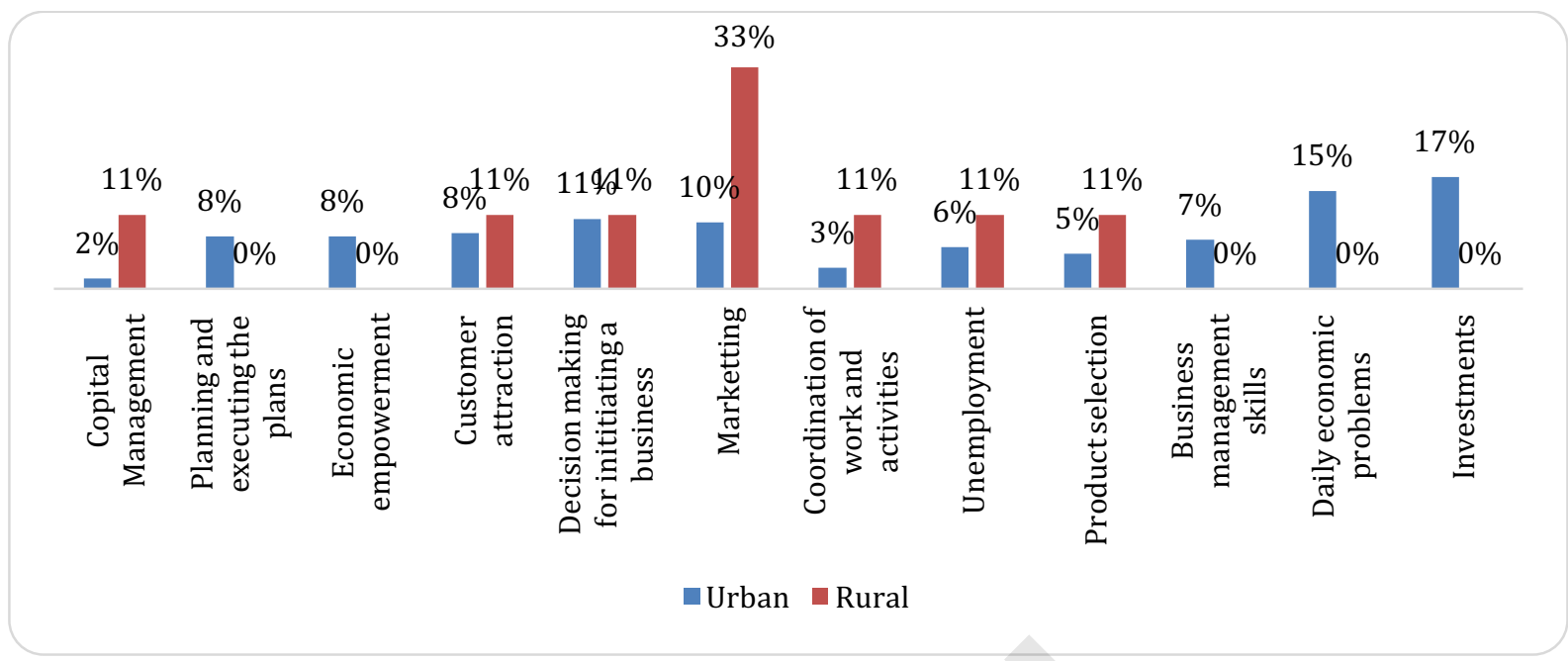

Chart 45: Types of Challenges Observed by the Students and Managed through Tashabos according to Gender

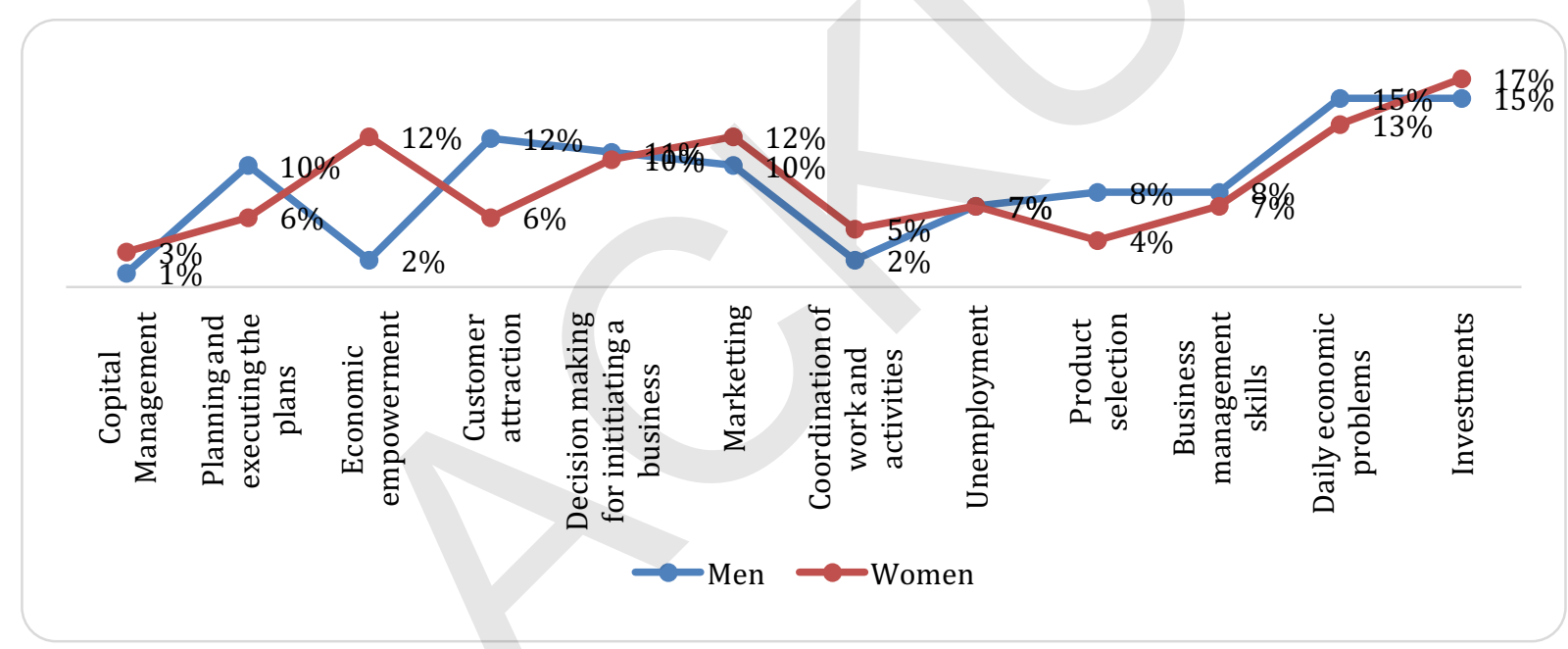

Besides challenges, there are risks associated with the businesses. Therefore, all the students were inquired about any risks they have faced within their businesses. Fortunately, that a lower number of students $(30 \%)$ had faced the risks within their businesses. It should be mentioned that rural students $(46 \%)$ had faced risks more often comparing to students from urban areas (29\%). Among the gender types, more male students $(38 \%)$ had faced risks comparing to female students $(23 \%)$. Furthermore, the students were inquired about the types of the risks they had faced and was solved with the help of Tashabos. $22 \%$ of the students mentioned that they didn't have the ability to rightly make a decision on their businesses. However, with the help of the subject the students were able to lower the effect of the risk and improve their decision making abilities. However, 14\% of the students lacked sufficient knowledge about business development, which they attained after studying Tashabos. Charts 46, 47, 48 and 49 explain more about the risks the students had faced. 


\section{Chart 46: Faced any Risks within Business}

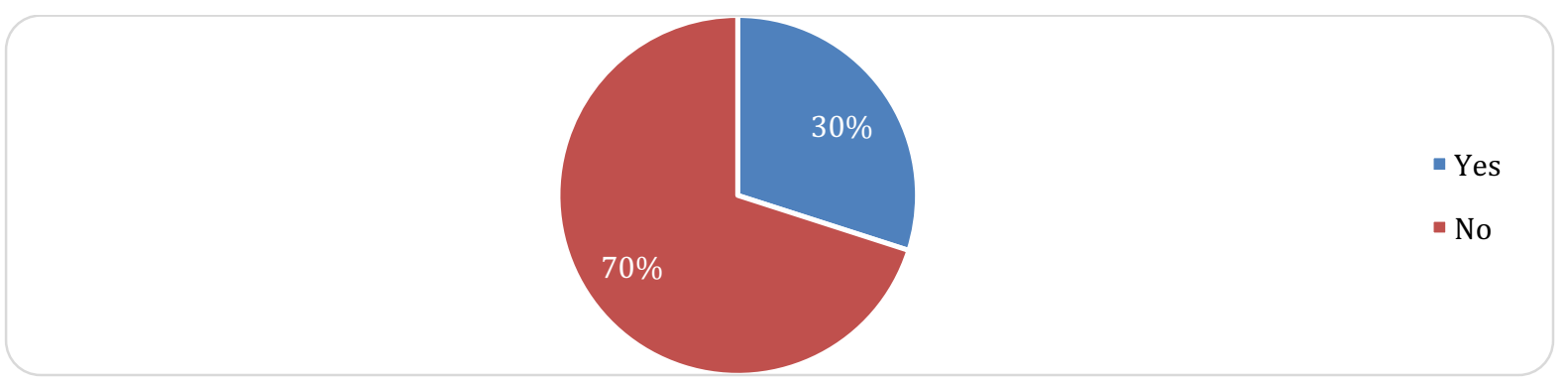

Chart 47: Faced any Risks within Business in Urban and Rural Areas

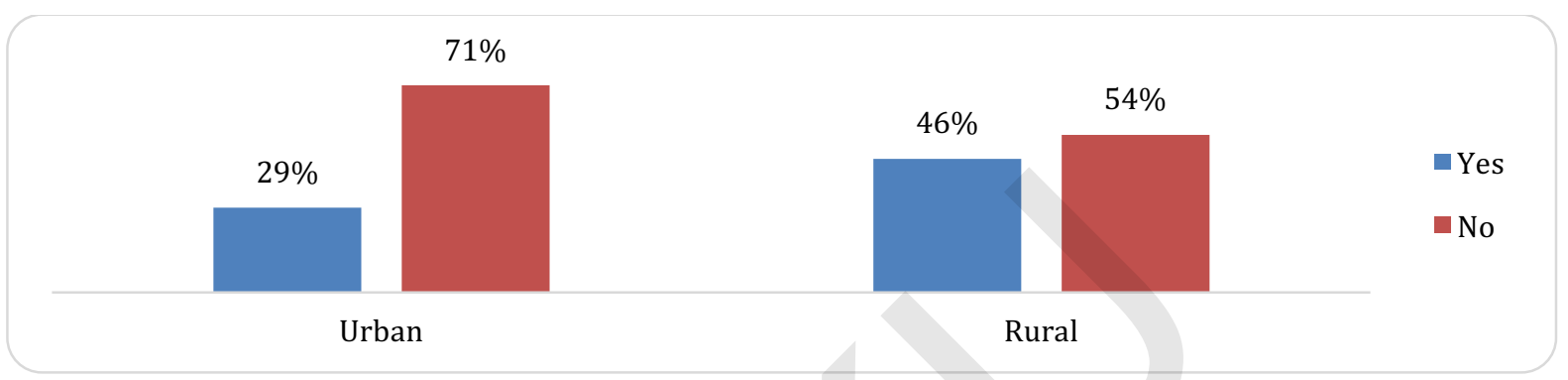

Chart 48: Faced any Risks within Business according to Gender

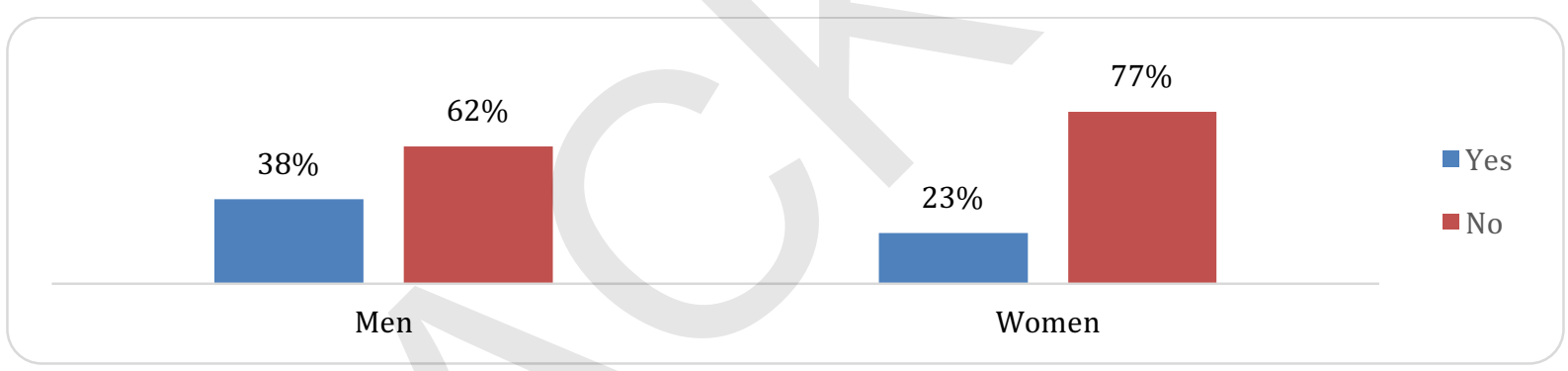

Chart 49: Types of Risks Faced by Students and Tackled with the Help of Tashabos

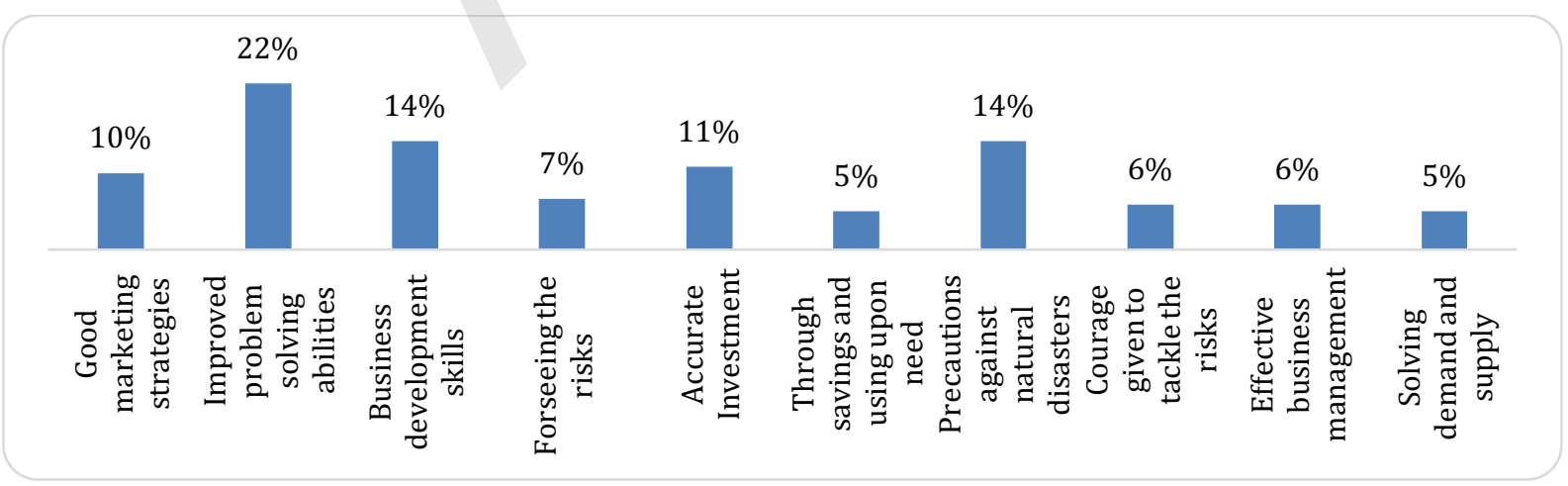

Tashabos and Students' Employments:

When sufficient information was collected about the businesses of the students, it was the time to collect information about the students' employments as well because Tashabos is effective on youths' employments as well. The first question asked from the students was if the students were able to find employments for themselves. $42 \%$ of the students were able to find themselves an employment. It should be mentioned that students from rural areas $(72 \%)$ were more proactive in finding jobs than urban 
Tashabos Impact Assessment May 18 2017.docx Tashabos and Students' Employments:

students $(40 \%)$. Similarly, more male students $(45 \%)$ were able to find themselves an employment comparing to female students $(39 \%)$. When the students were asked about the type of the employment they have found for them, $35 \%$ of the students replied that they are doing their employments in the form of handicraft business while $32 \%$ relied on shop keeping as an employment for themselves. Charts 50 , 51,52 and 53 give the complete information about students' employments.

\section{Chart 50: Able to Find Employment}

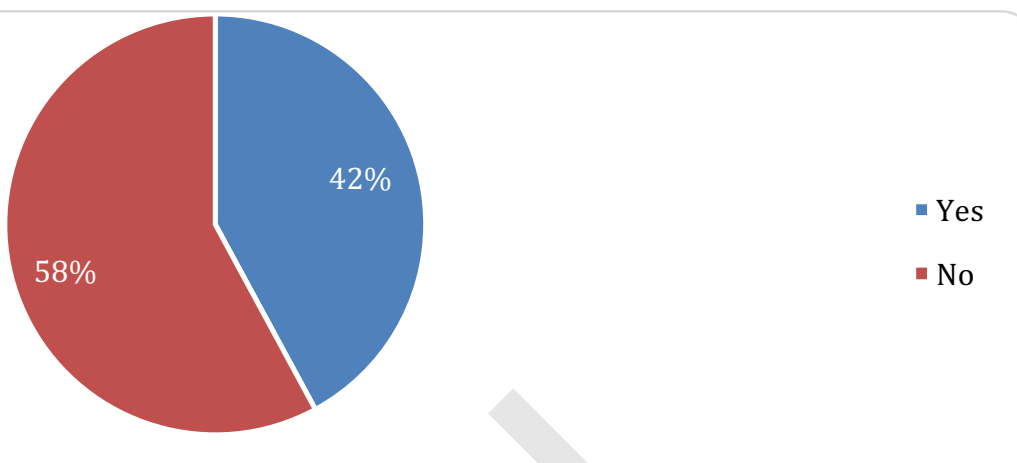

Chart 51: Able to Find Employment in Urban and Rural Areas

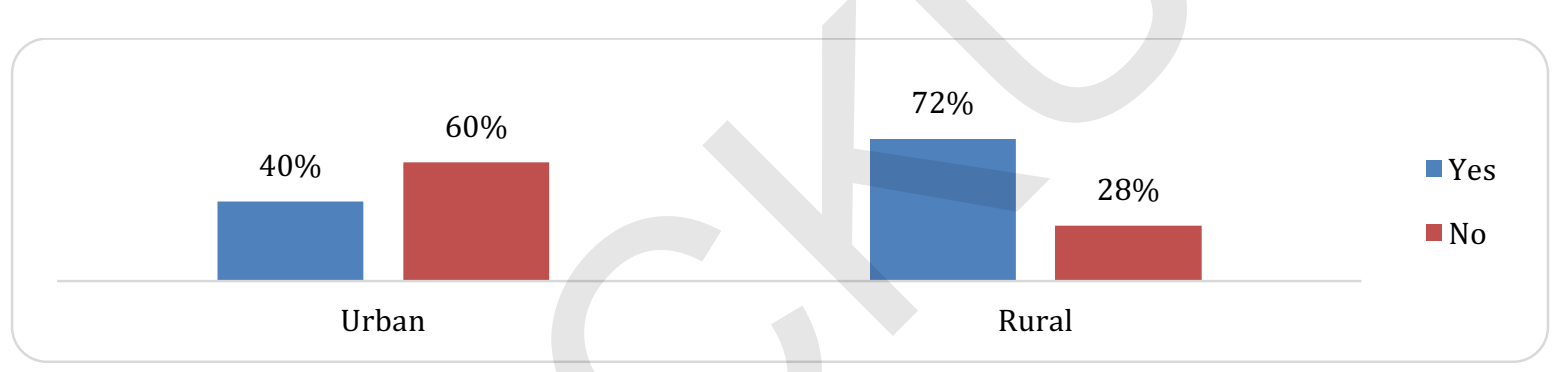

Chart 52: Able to Find Employment according to Gender

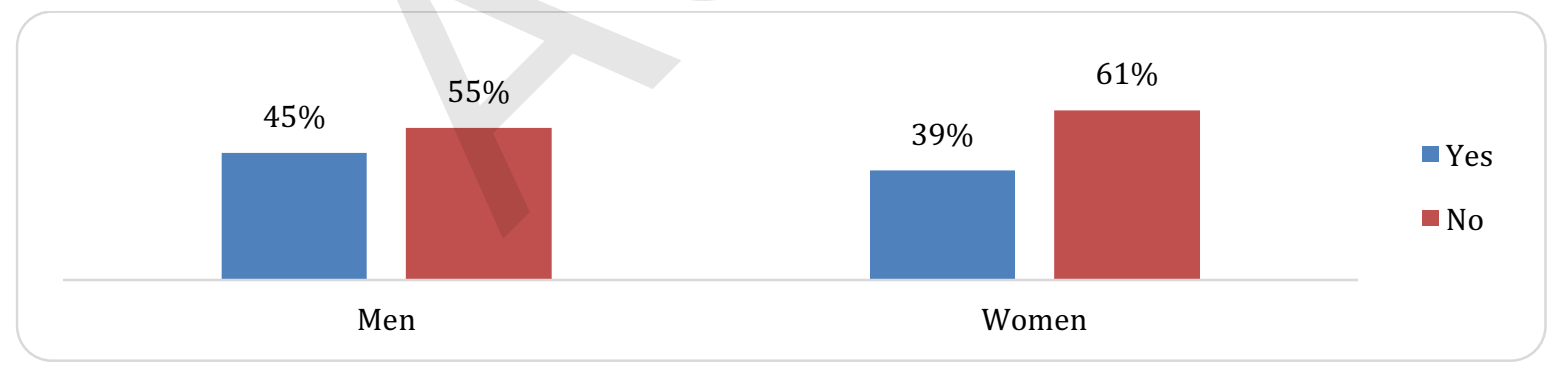

Chart 53: Types of Employments Found by Students

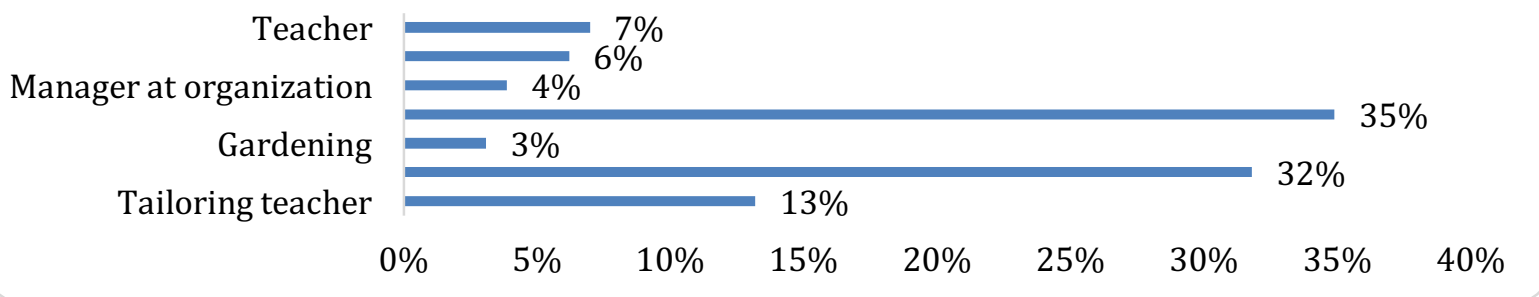


Furthermore, the students were asked to add on the effectiveness of the subject in helping the students find themselves the employments. $27 \%$ of the students mentioned that Tashabos has increased self reliability of the students, while $25 \%$ of the students mentioned that Tashabos has helped them learn about business management. At the same time, 14\% of the students mentioned that Tashabos has been very effective in assisting the students in finding jobs for themselves. Chart 54 adds more about the effectiveness of the subject in assisting them to find employments.

\section{Chart 54: Effectiveness of Tashabos in Assisting the Students Find Themselves jobs}

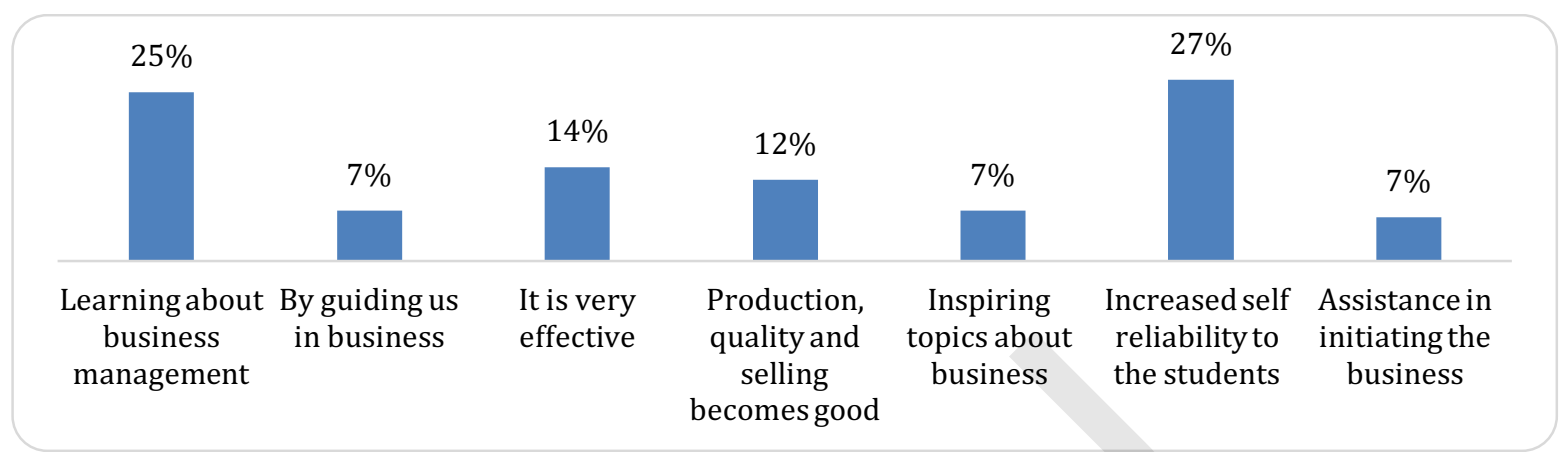

Among the students, not only job seekers were available, there were some employers as well. Therefore, all the students were asked if they had the employer role in their lives. As expected a very small population $(29 \%)$ of the students had the employer role. It should be mentioned that more rural students $(40 \%)$ comparing to urban students $(28 \%)$ had had the role of the employer. Similarly, higher number of male students $(31 \%)$ comparing to female students $(27 \%)$ had the employer role in their employments. When the students were asked what type of employments the students had offered during their employer period, $22 \%$ of them mentioned that they offered the worker employment to others, while $19 \%$ of them talked about offered roles in the management levels of their employments and $15 \%$ mentioned that they had offered the employments considering the capacities of the employees. Furthermore, the employer students were asked to describe the role of the subject in performing the employer job, $57 \%$ of the students mentioned that Tashabos assisted them to accurately plan, control and manage their business and their employees. Charts 55, 56, 57, 58 and 59 give the complete information about the students' employer role.

\section{Chart 55: Performed the Employer Role}

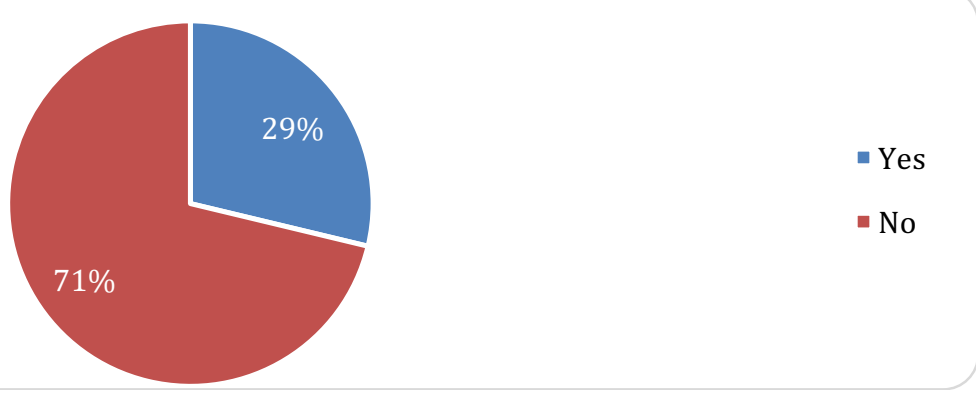


Tashabos Impact Assessment May 18 2017.docx Tashabos and Students' Employments:

Chart 56: Performed the Employer Role in Urban and Rural Areas

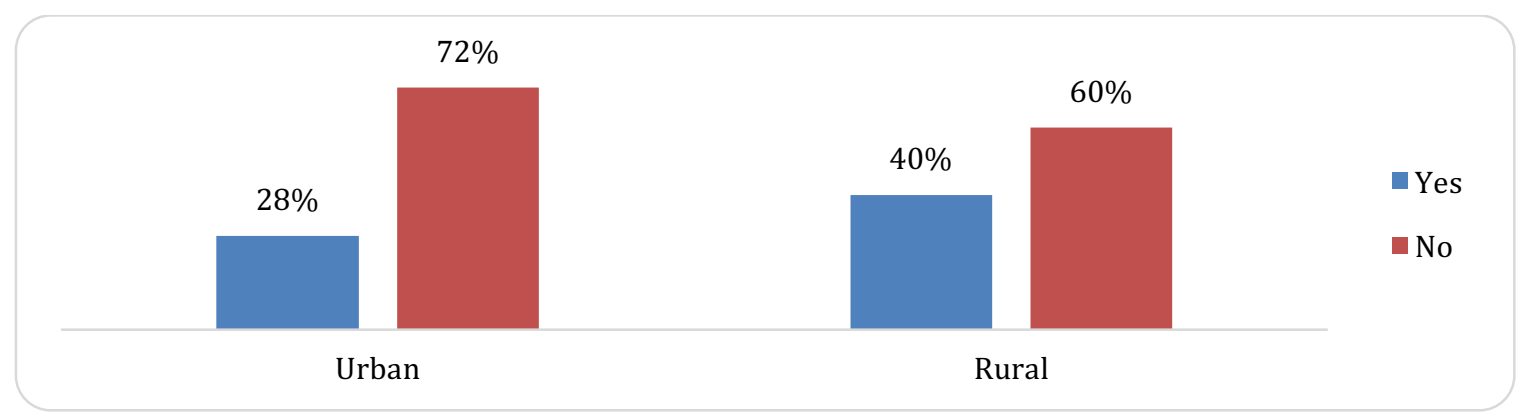

Chart 57: Performed the Employer Role according to Gender

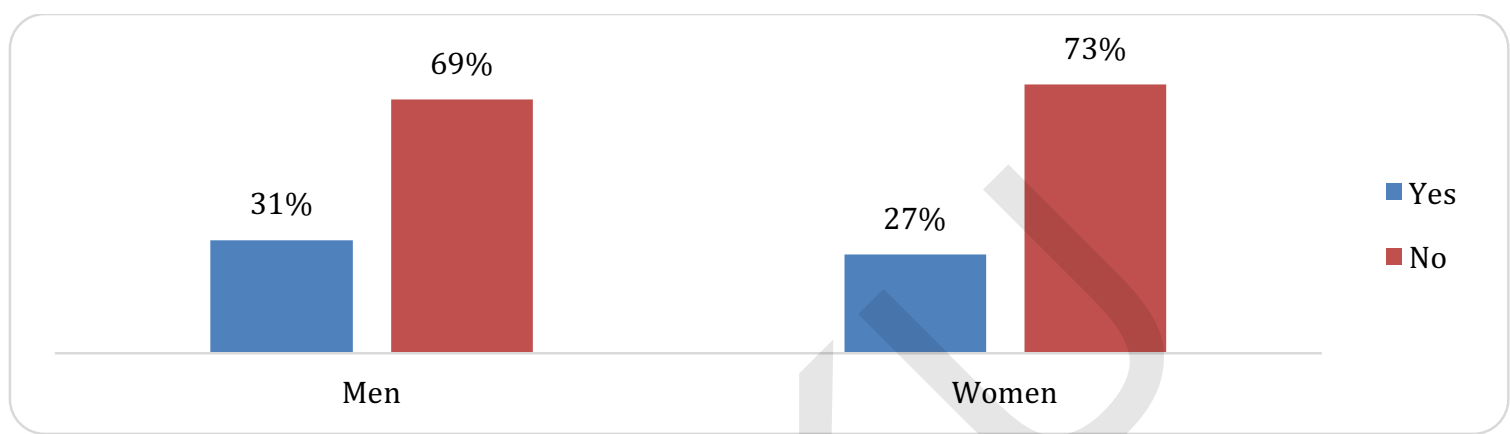

Chart 58: Types of Employments Offered by Employer Students

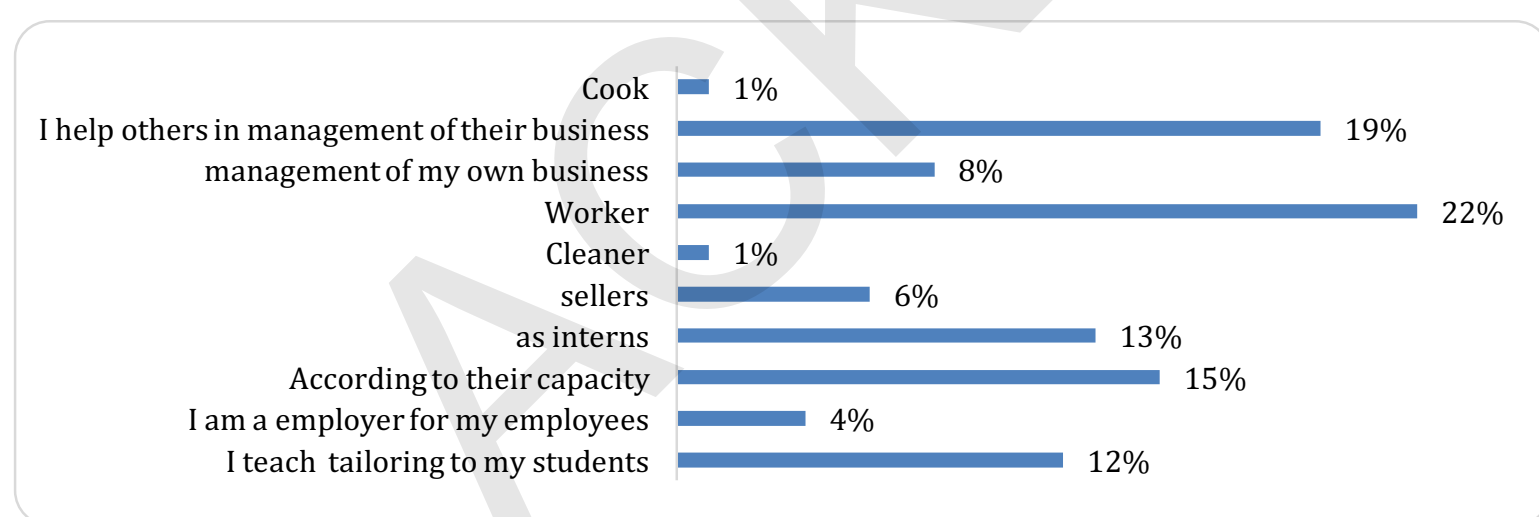

Chart 59: Importance of Tashabos in Performing the Employer Role

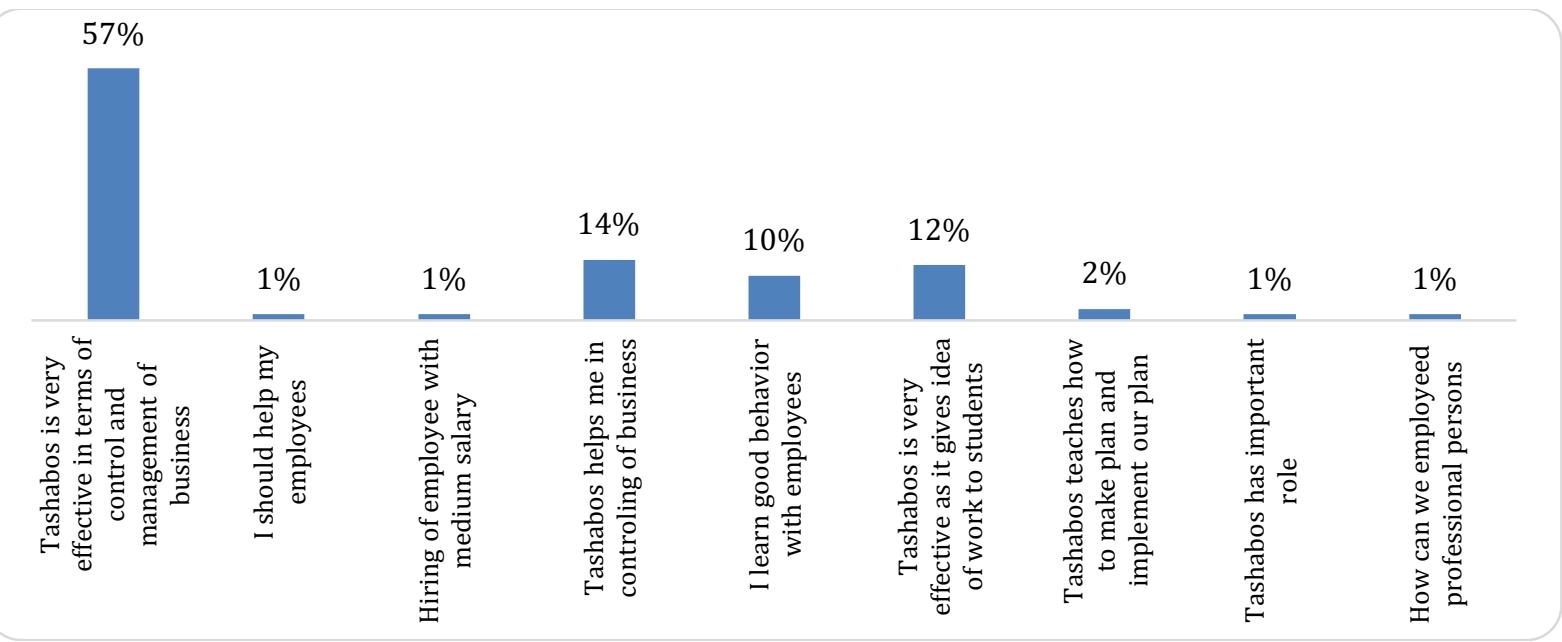


Tashabos Impact Assessment May 18 2017.docx Tashabos and Students' Employments:

Furthermore, the students were asked if business is their employment. It was found that $45 \%$ of the students' employments were business. Similar to other parameters of the employment for students, business was far more prevalent among rural students (84\%) comparing to urban students $(43 \%)$. However, the number of students having business was nearly equal between male students (46\%) and female students $(45 \%)$. The students were further asked that at what stages of their business the subject was very effective. $71 \%$ of the students replied that Tashabos is important during initiating the business, while $22 \%$ of them mentioned that Tashabos is very fruitful during expansion of the businesses. Furthermore, the students were asked about the role of Tashabos in various stages of the business development. 29\% of the students replied that Tashabos is necessary during initiating the business and then expanding the business. At the same time, $18 \%$ of the students mentioned that Tashabos has been a guide for a successful business. Charts $60,61,62,63$ and 64 depict the entire picture of the business of students as their employments.

\section{Chart 60: Business as Employment for Students}

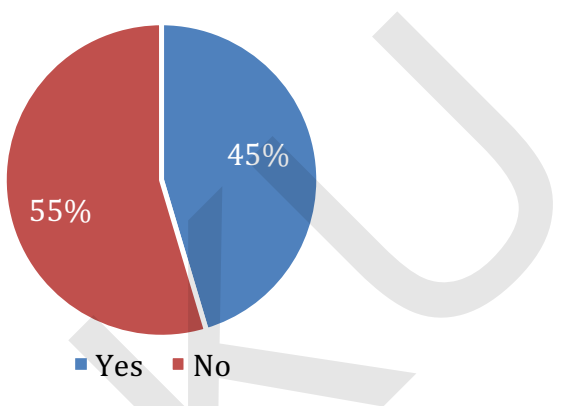

Chart 61: Business as Employment for Students in Urban and Rural Areas

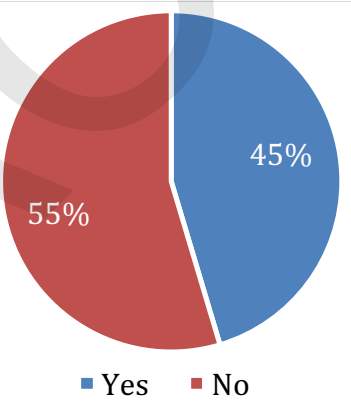

Chart 62: Business as Employment for Students according to Gender

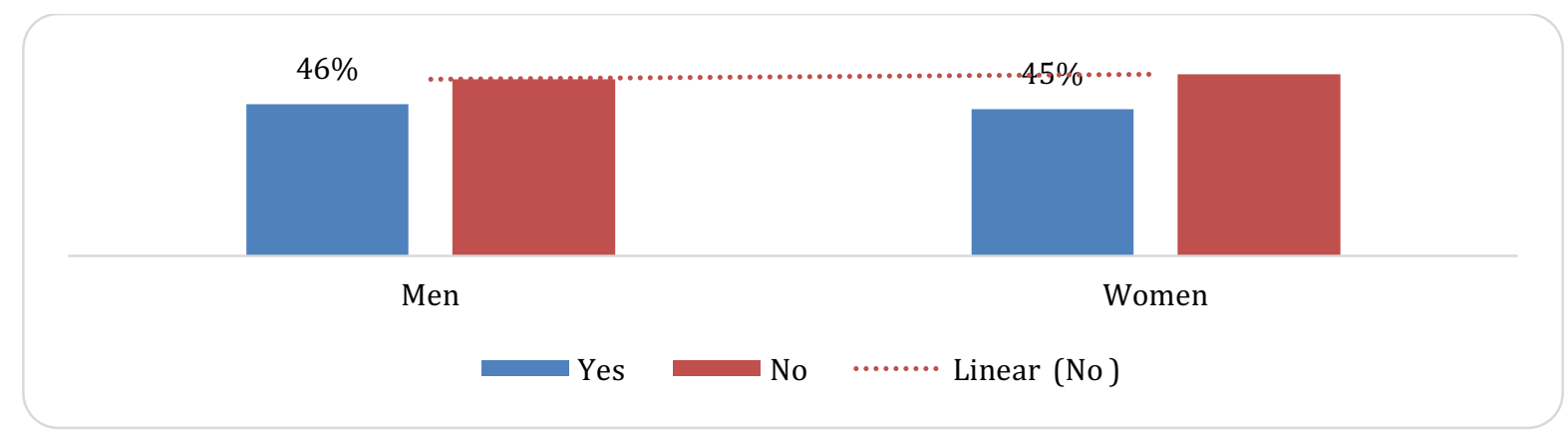




\section{Chart 63: Role of Tashabos in Various Stages of the Business}

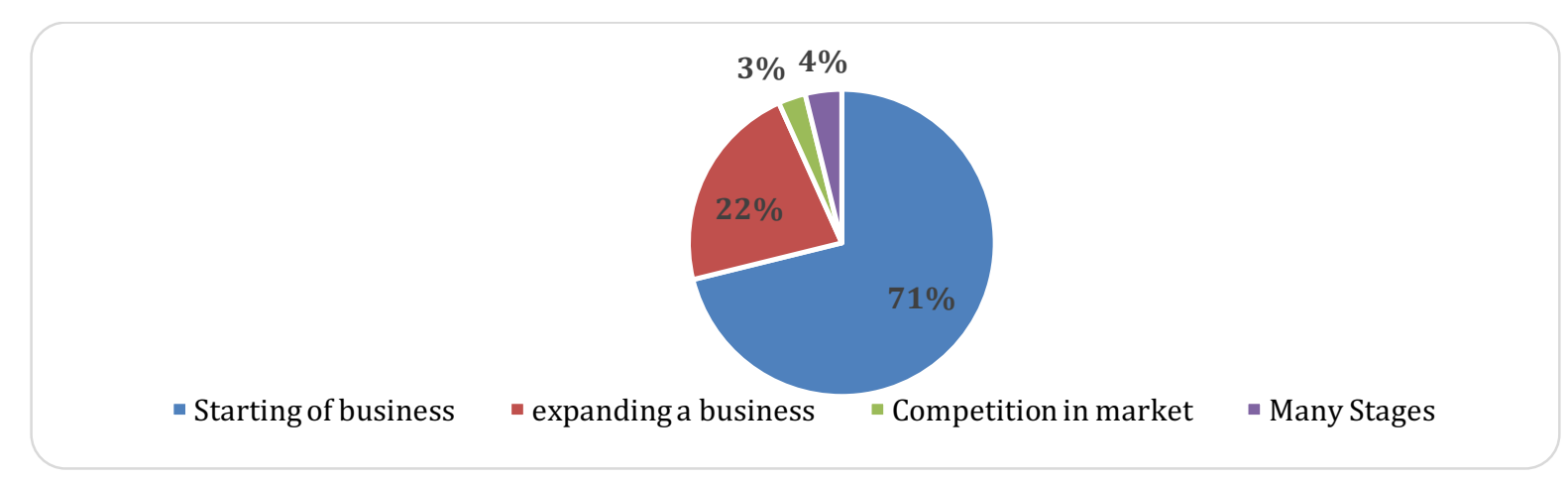

\section{Chart 64: Importance of the Tashabos in Various Stages of the Business}

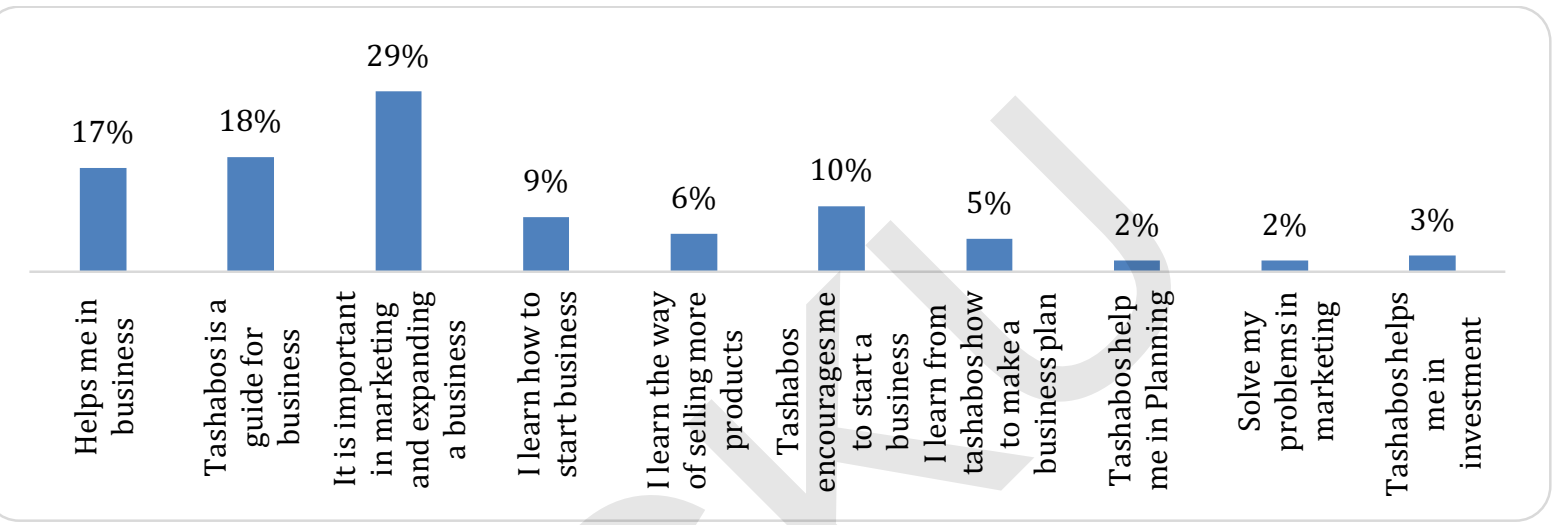

At the next level, the students were asked if Tashabos was effective in creating job opportunities for students. Nearly eight tenth $(79 \%)$ of the students believed that Tashabos has been effective in creating job opportunities for the students. This belief was higher among rural students (83\%) comparing to urban students $(79 \%)$ and higher among male students $(84 \%)$ comparing to female students $(74 \%)$. When the students were asked about the types of the employments created by Tashabos, $28 \%$ of the students mentioned that Tashabos has created the platform for multiple employments, while $17 \%$ thought that tailoring was the most prevalent occupation offered by the subject and $12 \%$ believed that all the small business could be created and initiated with the help of the subject. The students were also inquired about how does the subject create employment opportunities. $49 \%$ of them replied that Tashabos helps the students learn about the employments and businesses, while $26 \%$ relied only on Tashabos as a reference subject for business in creating the job opportunities. Charts 65, 66, 67, 68 and 69 give the complete information about employments offered by Tashabos. 
Tashabos Impact Assessment May 18 2017.docx Tashabos and Students' Employments:

\section{Chart 65: Tashabos Offered Employments}

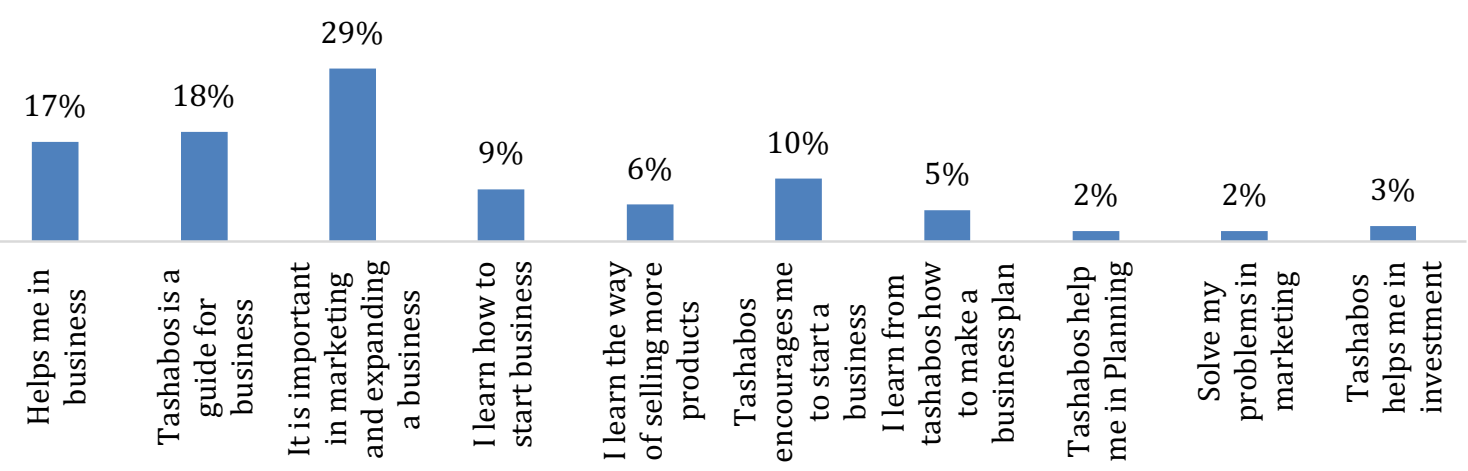

Chart 66: Tashabos Offered Employments in Urban and Rural Areas

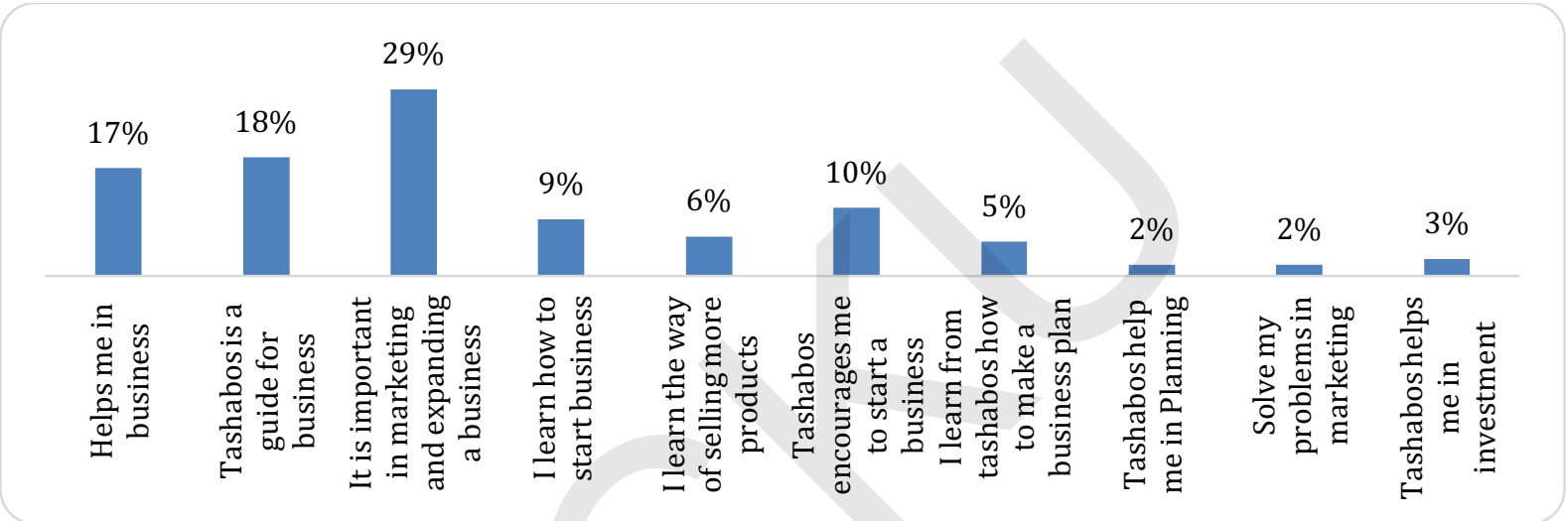

Chart 67: Tashabos Offered Employments according to Gender

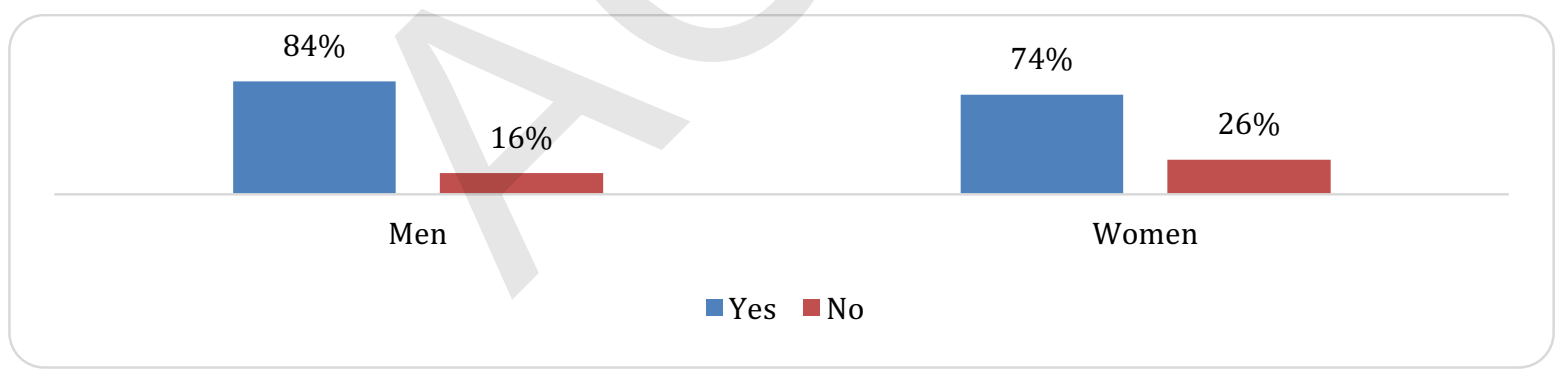

Chart 68: Types of Employments Offered by Tashabos
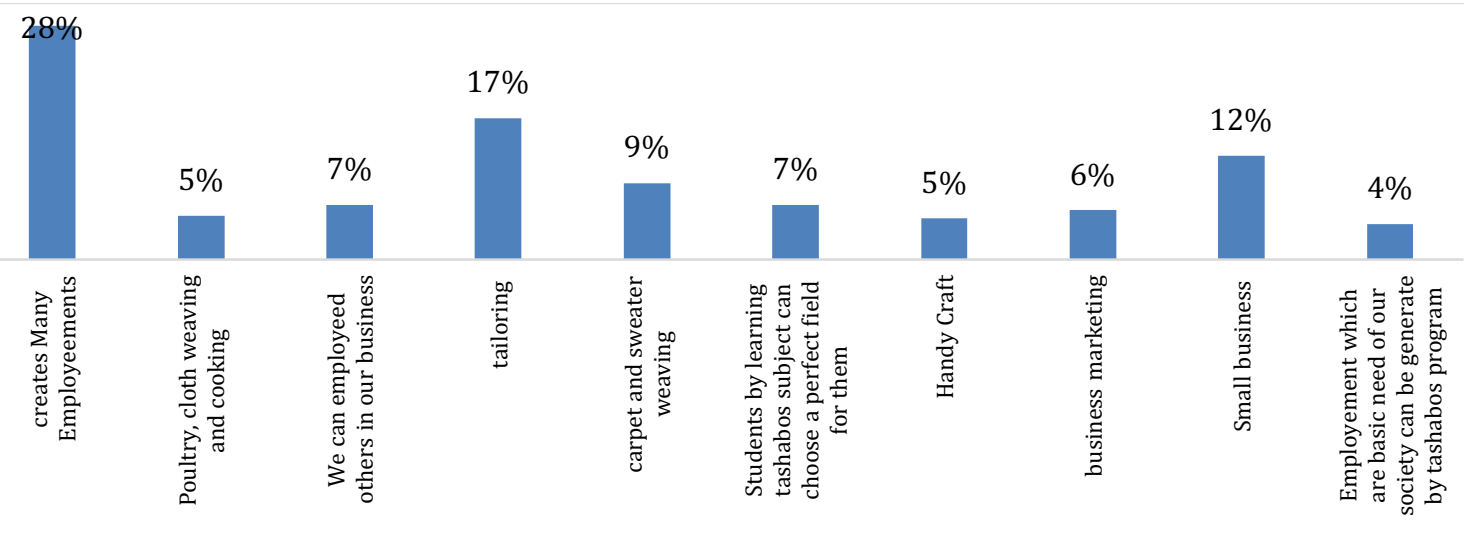
Tashabos Impact Assessment May 18 2017.docx Tashabos and Students' Employments:

\section{Chart 69: Importance of Tashabos in Creating Employment Opportunities}

$\begin{aligned} \text { Tashabos has major role in expanding private business } & 1 \% \\ \text { Tashabos teaches management } & 2 \%\end{aligned}$

Furthermore, the students were asked if Tashabos is effective in creating employment opportunities for male or female students. $58 \%$ of the students mentioned that Tashabos has been effective for boys while the remaining $42 \%$ of them mentioned that the subject is effective for girls. When the students were asked about the effectiveness of the subject on a specific gender, $23 \%$ of them replied that boys can work outside of the house and $17 \%$ of them mentioned that businesses are usually run by boys than girls. Charts 70 and 71 adds more on the effectiveness of Tashabos on specific gender type in terms of employment.

\section{Chart 70: Tashabos Important for Girls or Boys in Creating Employments}

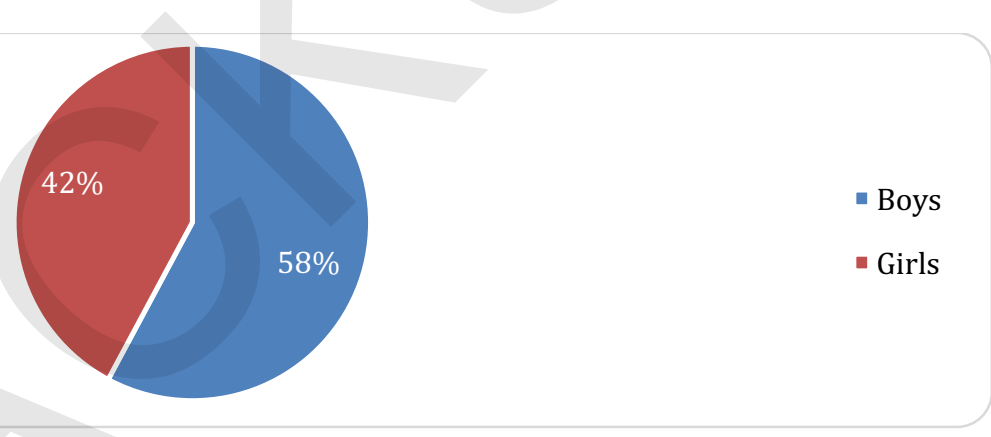

Chart 71: Importance of Tashabos in Creating Job Opportunities for Specific Gender Type

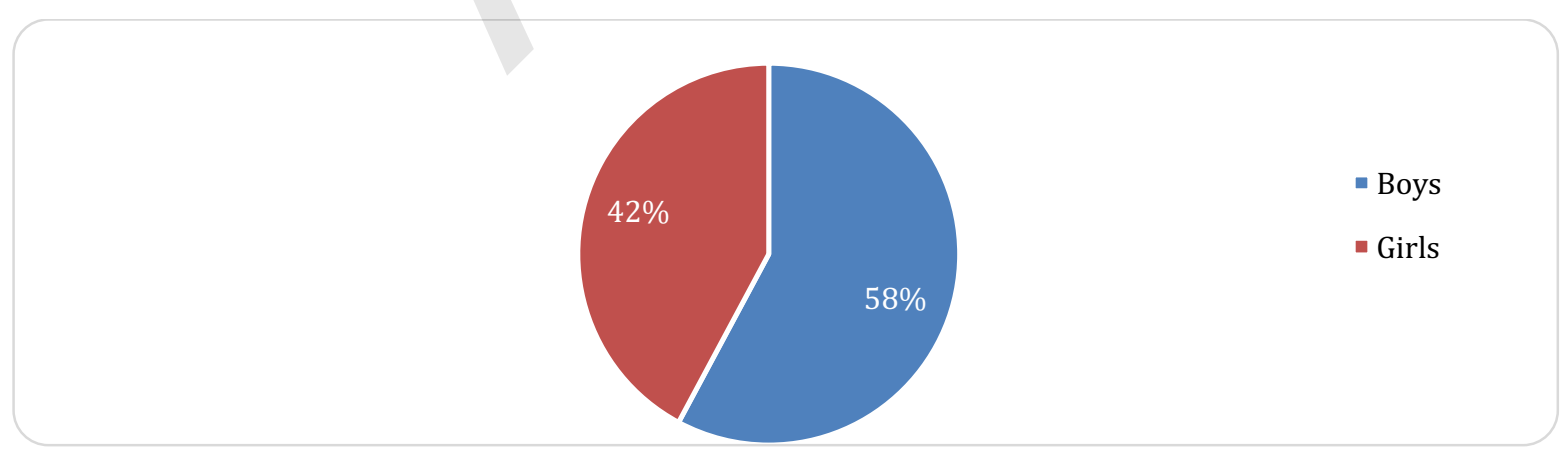

The students were asked if the subject has had effects on students' viewpoints on employments. Therefore, all the students were asked if Tashabos has changed their viewpoints regarding employment. Fortunately, the subject has changed the thoughts of $78 \%$ of students. It should be mentioned that the subject had changed thoughts of $100 \%$ of the students in rural areas comparing to $77 \%$ of the students in urban areas. Similarly, the subject had changed the viewpoints of more male students $(80 \%)$ comparing to female students $(77 \%)$. Afterwards, the students were asked what types of changes have been observed within the students. $21 \%$ of them mentioned that Tashabos has helped them expand their knowledge 
Tashabos Impact Assessment May 18 2017.docx Tashabos and Students’ Employments:

about management and 16\% mentioned that they could now take steps towards expanding their businesses. Charts 72, 73, 74 and 75 add more information about effectiveness of Tashabos on changing students' viewpoints regarding employments.

\section{Chart 72: Tashabos Changed Viewpoints on Employment}

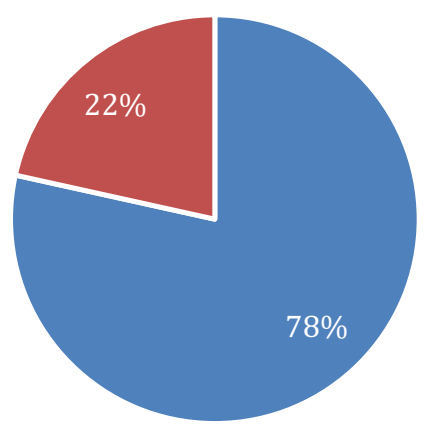

Chart 73: Tashabos Changed Viewpoints on Employment in Urban and Rural Areas

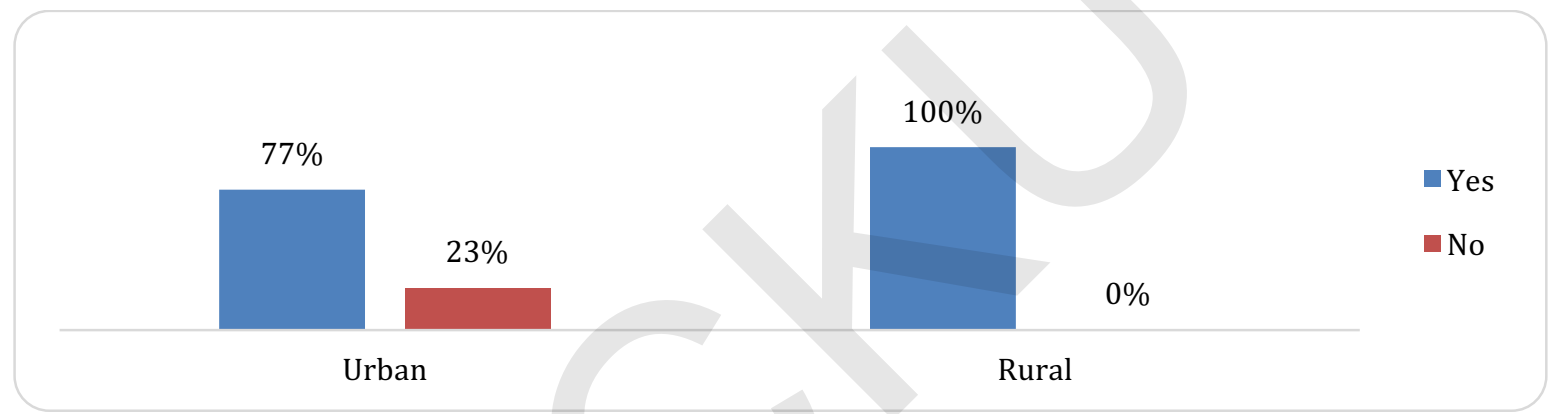

Chart 74: Tashabos Changed Viewpoints on Employment according to Gender

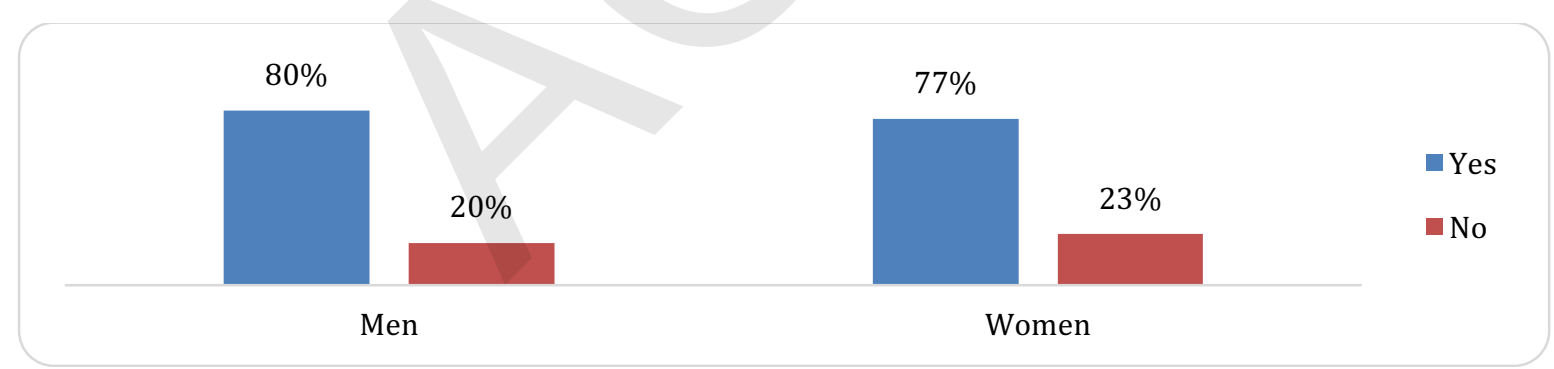




\section{Chart 75: Changes in Viewpoints on Employment}

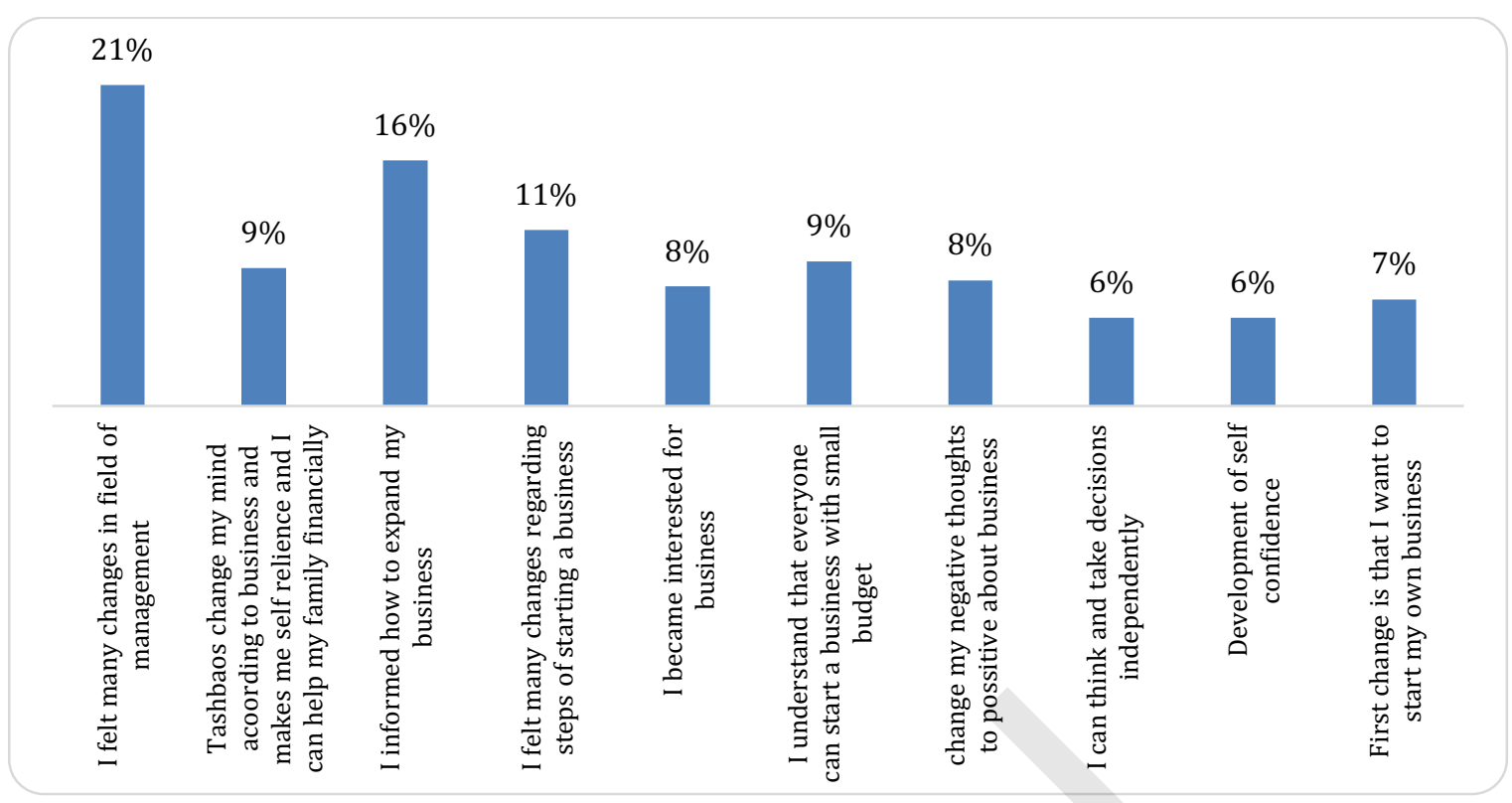

Finally, within employments, the students were asked if Tashabos supports matching skills opportunities during the employments. $62 \%$ of the students mentioned that Tashabos does support matching skills opportunities. $91 \%$ rural and $60 \%$ urban students responded positively to the above question and they mentioned that yes Tashabos support matching skills opportunities. According to gender, more male students (69\%) than female students (56\%) believed that Tashabos support matching skills opportunities during employments. Finally, the students were asked to point out any matching skills they had to find an employment. $30 \%$ of the students mentioned that they have more information about business, which they could utilize in successful employments. Similarly, 25\% of the students mentioned that Tashabos has encouraged the students to use their potentials. Charts 76, 77, 78 and 79 gives the complete information about the linkage of matching skills with Tashabos.

\section{Chart 76: Tashabos Supported Matching Skills during Employments}

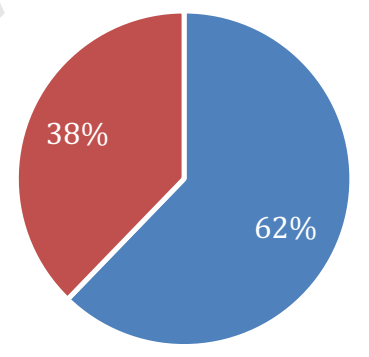


Chart 77: Tashabos Supported Matching Skills during Employments in Urban and Rural Areas

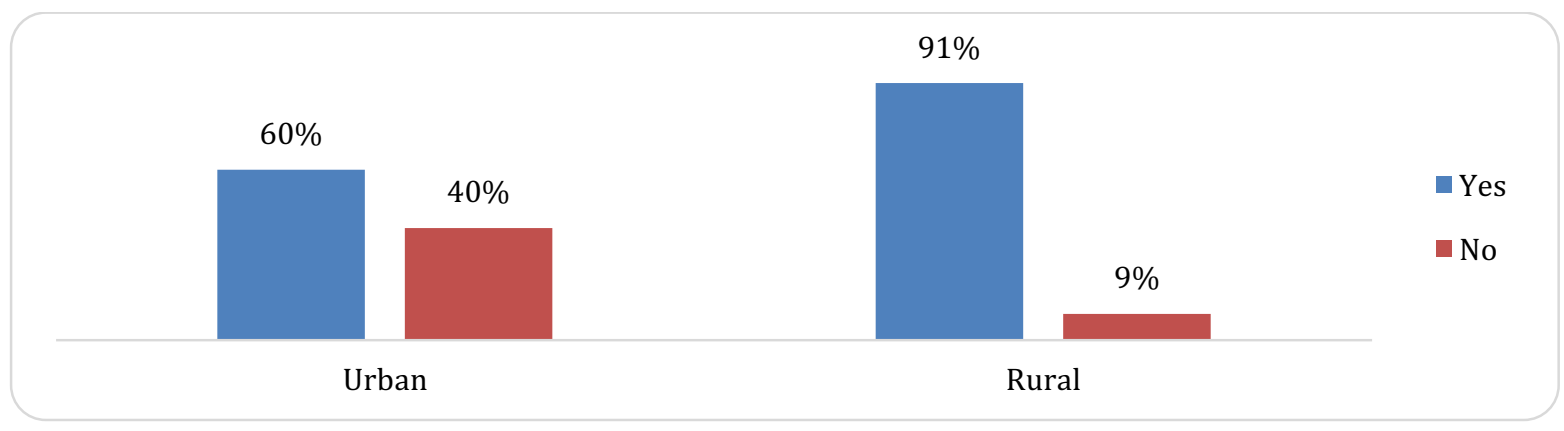

Chart 78: Tashabos Supported Matching Skills during Employments according to Gender

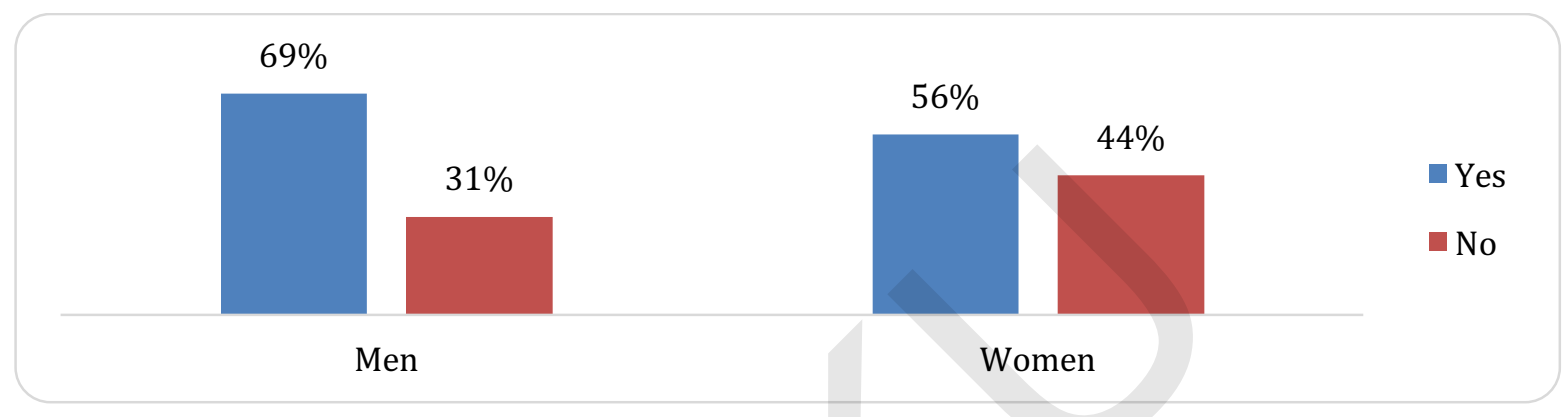

Chart 79: Students Skills Polished by Tashabos

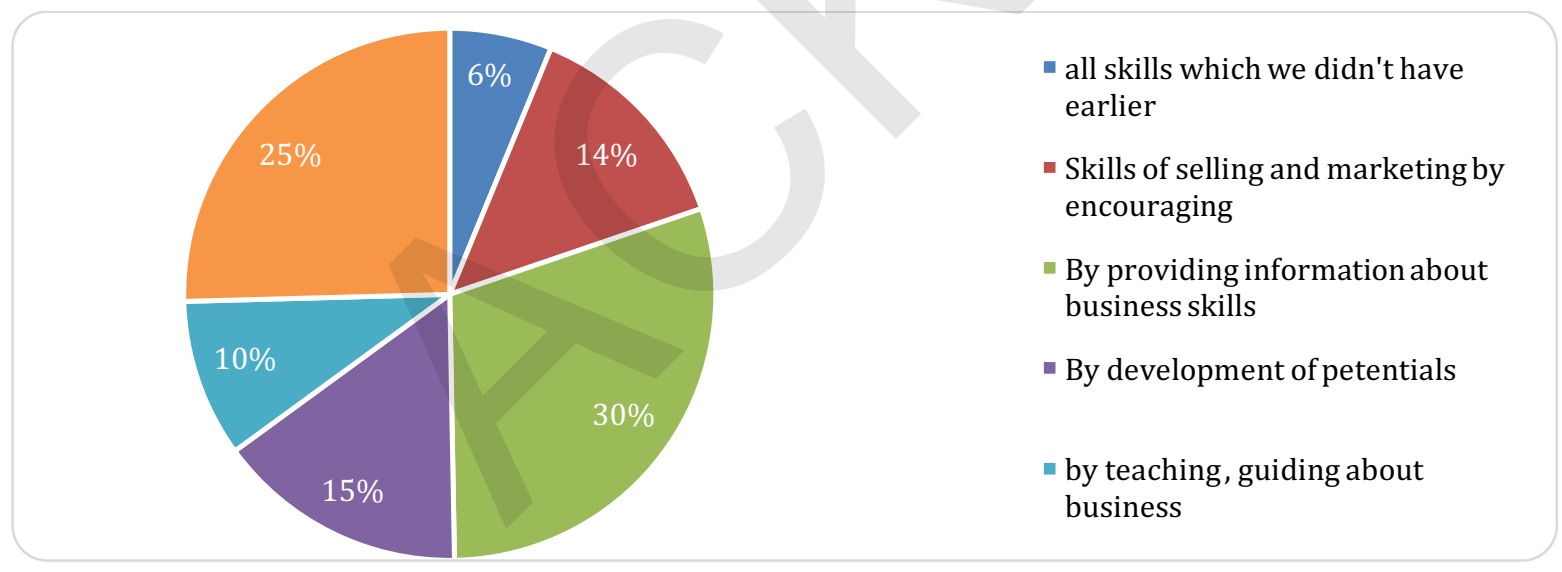

Tashabos and Students' Engagements in Demonstrations

One of the core activities of Tashabos has been demonstrations of the students' products. Therefore, a separate section in the questionnaire was allocated for the purpose. Therefore, the information has been collected around demonstration of the students' products; business proposals; and business proposal competitions.

\section{Students' Product Demonstrations}

The students were inquired about their participations in the demonstrations. $48 \%$ of the students had participated in the demonstrations. It should be mentioned that more students of rural areas (68\%) had taken part in the demonstrations than $(47 \%)$ students of the urban areas. As expected more female students $(44 \%)$ had participated in the demonstrations than their male counterparts $(41 \%)$. When the students were asked the products they had taken to the demonstrations, embroidery items have been the most prevalent product taken to the demonstrations by $30 \%$ of the students. Furthermore, the students were asked about the process of selling their goods during the demonstrations. $32 \%$ of the students 
pointed out that the process of selling their products was very good. Charts $80,81,82,83$ and 84 provides the complete information about the demonstrations of students' products.

\section{Chart 80: Participated in the Products' Demonstrations}

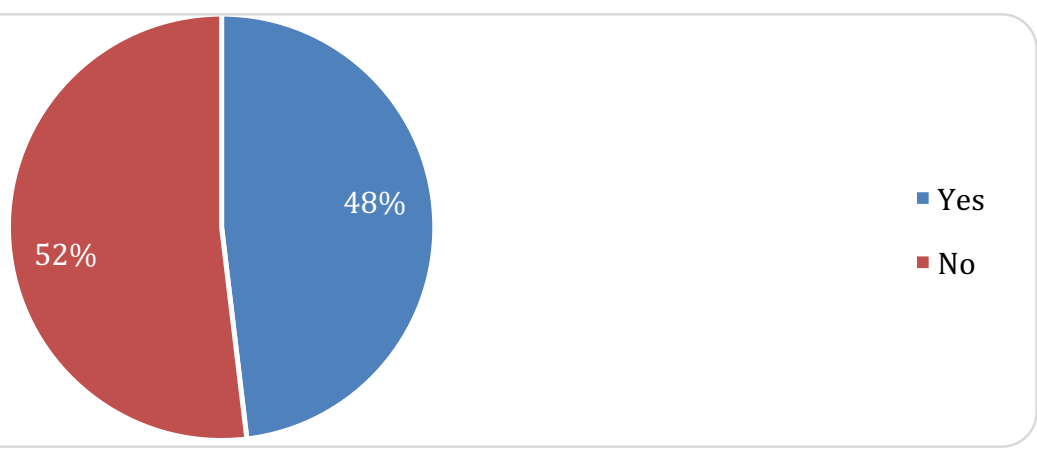

Chart 81: Participated in the Products' Demonstrations in Urban and Rural Areas

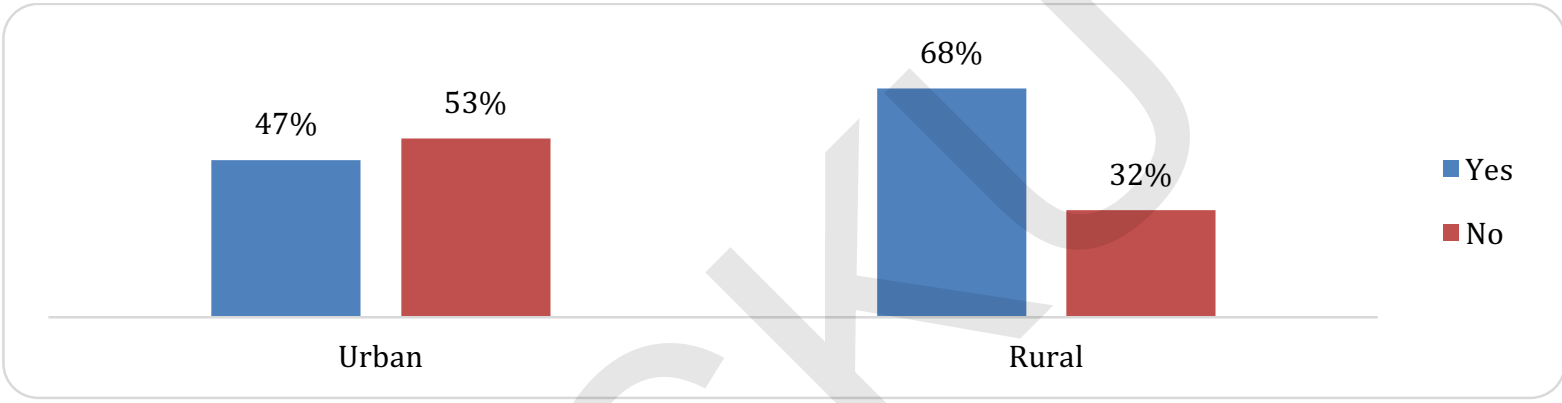

Chart 82: Participated in the Products' Demonstrations according to Gender

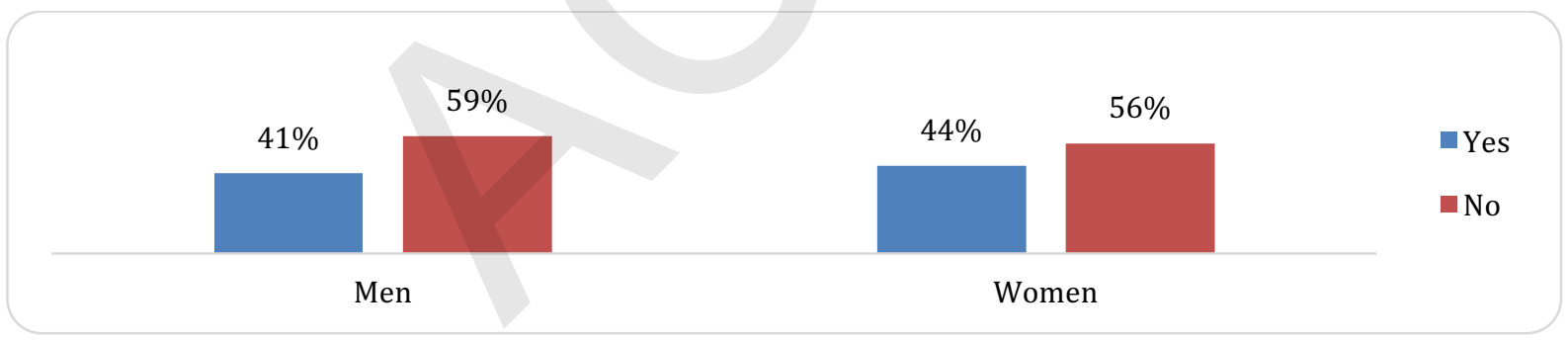

\section{Chart 83: Products Demonstrated}

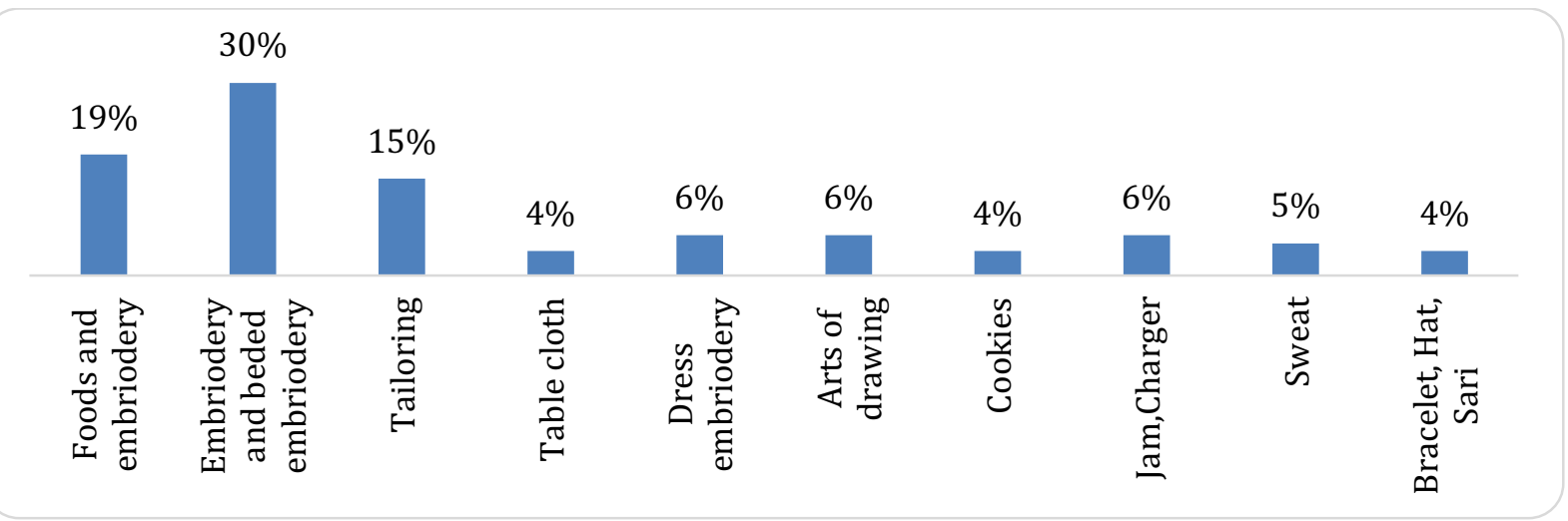


Tashabos Impact Assessment May 18 2017.docx Students' Product Demonstrations

Chart 84: Process of Selling Products during the Demonstrations

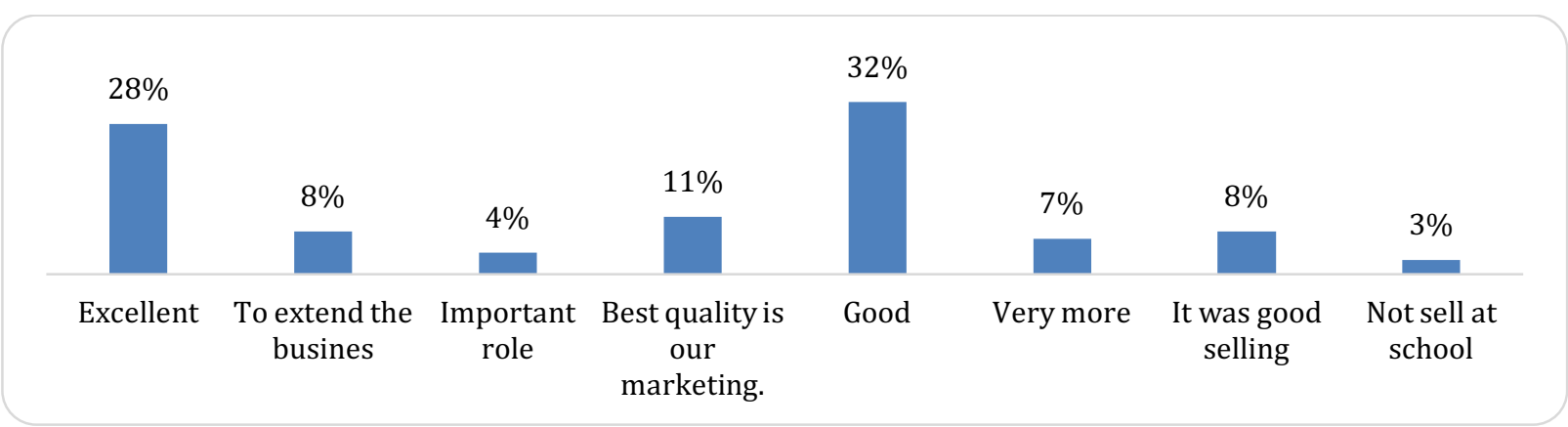


Tashabos Impact Assessment May 18 2017.docx Students' Business Proposals and Business Proposal Competitions

\section{Students' Business Proposals and Business Proposal Competitions}

The students were, then, asked about the business proposals they had developed. $69 \%$ of the students had developed only one business proposal while $20 \%$ of the students had developed two. Chart 85 gives the complete information about number of business proposals each student had developed.

\section{Chart 85: Number of Business Proposals Developed by Students}

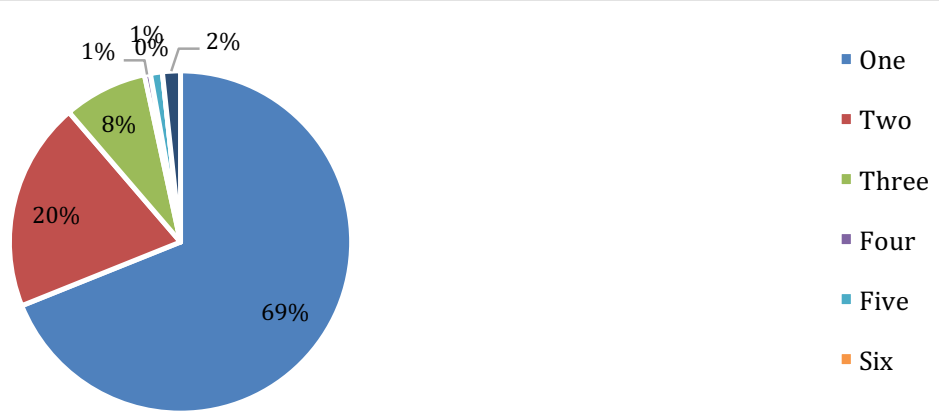

In addition, the students were asked how many of the business proposal competitions the students have participated. $77 \%$ of the students participated in at least one business proposal competitions, while $13 \%$ of the students have participated in two competitions. When the students were asked about the positions the students have held in the competitions, $17 \%$ of the students got the first, $18 \%$ the second, $18 \%$ the third and $46 \%$ of the students had made it to the top 10 . Charts 86 and 87 give the complete information about business proposal competitions.

\section{Chart 86: Number of Business Proposals Competitions Attended by Students}

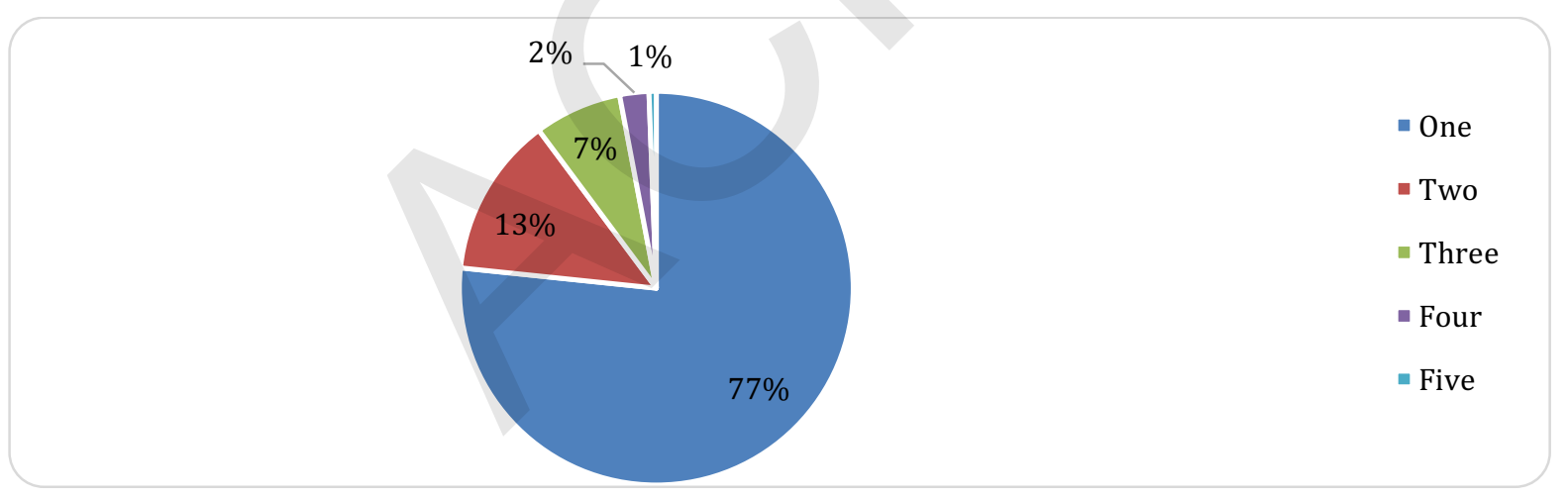

\section{Chart 87: Positions Held by Students during Business Proposal Competitions}

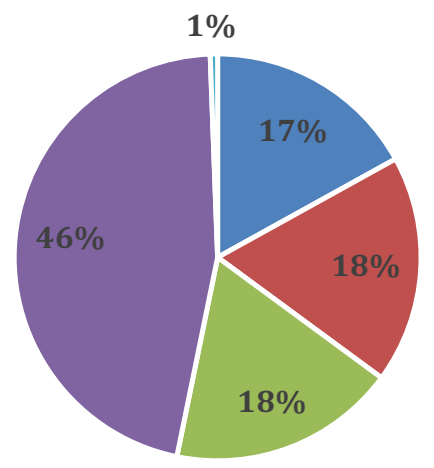

- First

- Second

" Third

- 10 Best

- 50 Best 


\section{Findings of the Tashabos Teachers' Assessment:}

Tashabos teachers have been the key component of the program and they have been teaching the subject over the years. A total of 61 teachers have been engaged with program in 43 schools across 4 provinces. Therefore, Tashabos teachers have gotten a clear insight of the program, its importance and the need for continuing the subject. Consequently, Tashabos teachers were among the key informants in the Tashabos program assessment. Hence all the available teachers within 43 schools were interviewed.

It should be mentioned that specific questionnaires aimed at collecting both qualitative and quantitative data about the program were developed for the assessment of the Tashabos teachers Tashabos teachers' inputs in the assessment have help TEO administration attain deeper knowledge about: a) current capacities of the teachers respective to Tashabos teaching, b) students' interest towards studying Tashabos, c) awareness of the students from the importance of the subject, d) importance of the BPC and exhibitions in schools, e) effects (socioeconomic) of the subject on students' daily lives, f) experiences of students initiated/expanded a business or secured employments for them, and g) the need for expanding the Tashabos program and incorporating the subject into the national curriculum. The collected data was then analyzed considering various parameters (general analysis, location based analysis, gender based analysis, gender and location based analysis, target areas' based analysis and gender based analysis in target areas). The analyzed data was, then, organized into a comprehensive report featuring: a) general characteristics of the respondents, b) Tashabos experiences, c) Tashabos and Students, d) Tashabos and Exhibitions, e) Socioeconomic Effects of Tashabos, and f) Future of the Subject.

\section{General Characteristics of the Respondents:}

Before the main questions of the assessment were asked from the Tashabos teachers, the assessment collected some information about the general characteristics (gender, age and location) of the respective respondents.

Sex:

It is already mentioned that TEO has been supporting Tashabos teaching in 43 schools (27 GHS and 16 BHS). In addition, the distribution of urban and rural schools was $84 \%$ (36 schools) and $16 \%$ (7 schools) respectively. Moreover, it is customary that female teachers outnumber male teachers in girl schools considering the gender sensitivities. Therefore, it was expected to have higher number of female Tashabos teachers as more girl schools were targeted by TEO comparing to boy schools and so was true because $61 \%$ of the total Tashabos teachers were female comparing to $39 \%$ male Tashabos teachers. Of the total $61 \%$ female Tashabos teachers $58 \%$ were in urban areas, but only $3 \%$ of the total female Tashabos teachers have been busy teaching the subject in rural schools. On the other hand, from the total male Tashabos teachers (39\%) $32 \%$ of them were in urban areas comparing to $7 \%$ in rural areas. At the other level, urban and rural distribution of the Tashabos teachers was analyzed and it was found that female teachers $(64 \%)$ in urban areas dominated female teachers $(33 \%)$ in rural areas as far as numbers was concerned. However, the reverse was true for male Tashabos teachers as male teachers were higher in rural areas $(67 \%)$ comparing to urban areas $(36 \%)$. This should be mentioned that the distribution of the Tashabos teachers in urban and rural areas followed the unique trend as boys and girls' schools distributed in urban and rural areas. The data shows that of the total urban schools (36) 12 were boys while the remaining 24 were girls' schools. Therefore, it is inferred that boys' schools constituted half $(50 \%)$ of the girls' schools. On the other hand, of the total 7 rural schools 3 were girls and 4 were boys' schools. Therefore, it is known that boy schools constitute $67 \%$, while the girl schools $33 \%$ Keeping the mentioned analysis in mind, distribution of the male and female Tashabos teachers in urban and rural areas is true with higher female teachers in urban areas and higher number of male teachers in rural 
areas. Taking the data at the target areas levels it was found that female Tashabos teachers were greater in numbers in Kabul City (73\%) and Parwan City (60\%). Conversely, in Nangarhar Province, Charasyab and Paghman Districts equal number of male $(50 \%)$ and female $(50 \%)$ teachers have taught the subject to their students. Finally, in the remaining target areas as Bamyan City $(80 \%)$, Shakardara District (100\%), Guldara District (100\%) and Estalif District (100\%) male teachers outstripped female Tashabos teachers. Charts 88 and 89 explain the gender disaggregation of the Tashabos teachers in details.

\section{Chart 88: Gender Disaggregation of the Tashabos Teachers}

\section{Sex Disaggregation of the Respondents}

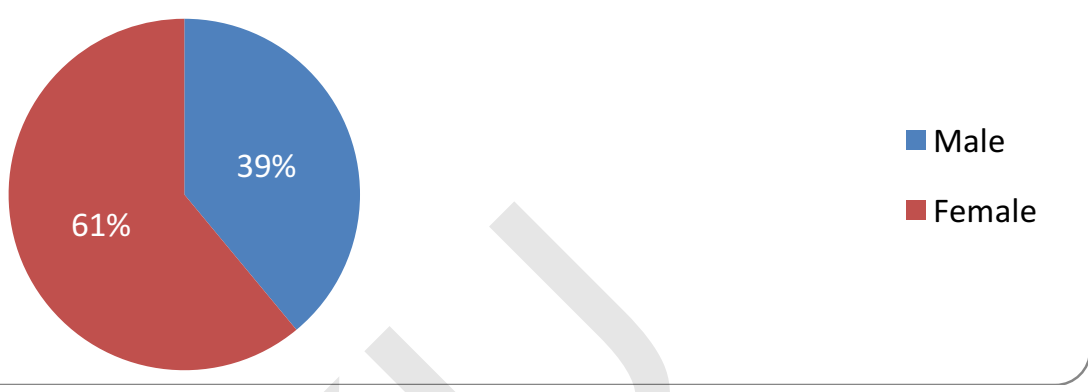

Chart 89: Gender Disaggregation of the Tashabos Teachers in Urban and Rural Areas

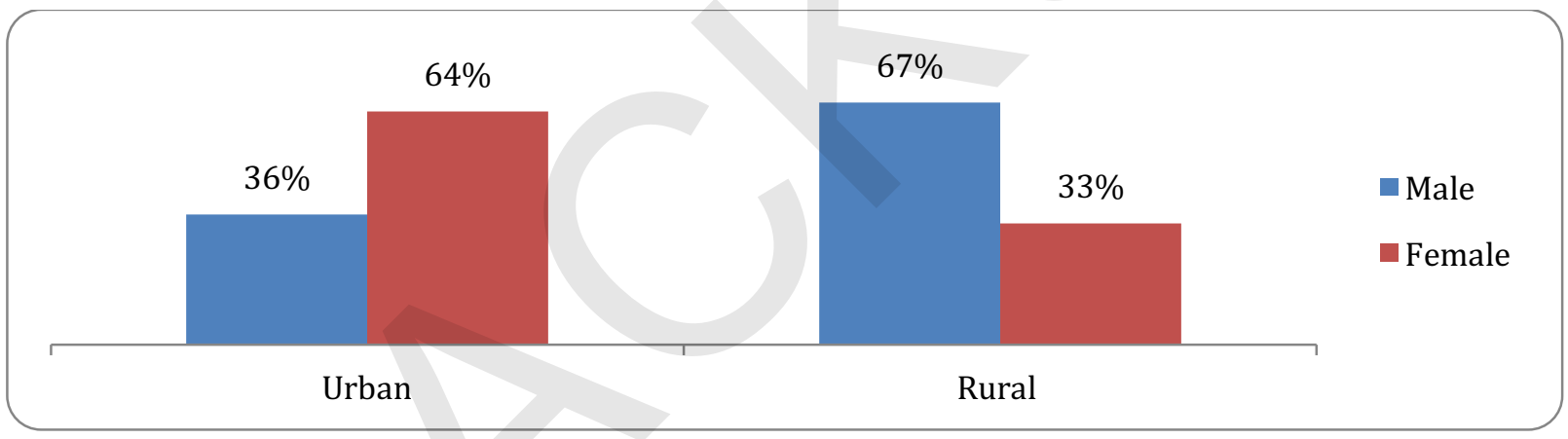

Teachers' Background with Tashabos

After talking about the general characteristics of Tashabos teachers, the foremost point alarming the brains of the program is to collect information about the experiences Tashabos teachers have had with the subject. Therefore, areas around Tashabos teachers' association with the subject was covered by the study, which will be discussed more in details in the subsequent paragraphs.

\section{Teachers' Orientation of the Subject}

Before standing in front of a class to teach a subject is important to know about the familiarity of the teacher with the subject. Familiarity to a subject can be pertained to prior academic education in the subject, teaching experiences of the subject or at least orientation to the subject by relevant stakeholders. Since Tashabos has been among the newly introduced subject linked to business and economic concepts, teachers might not have been academically familiar with the subject. However, long years of teaching experiences and orientation to the subject have added to the importance of issue as far as teachers' ability to teach the subject. Therefore, the study took the last two parameters under consideration to gauge the capacities of Tashabos teachers in teaching the subject. Of the two factors, orientation to the subject by any of the stakeholders was studied first. Therefore, all the interviewed teachers were asked if they were oriented to the subject by any of the stakeholders. Fortunately, over 
nine tenth $(93 \%)$ of the Tashabos teachers were oriented to the subject. This is considered a huge achievement to the program despite higher staff turnover in Afghanistan. In addition, implementing the program with over $90 \%$ oriented teachers could always impact positive. Therefore, it is recommended for the program to cover the remaining $7 \%$ of the teachers during the coming years so students are maximally benefited from the program. Chart 90 depicts the proportion of Tashabos teachers oriented.

\section{Chart 90: Tashabos Teachers Oriented to the Subject}

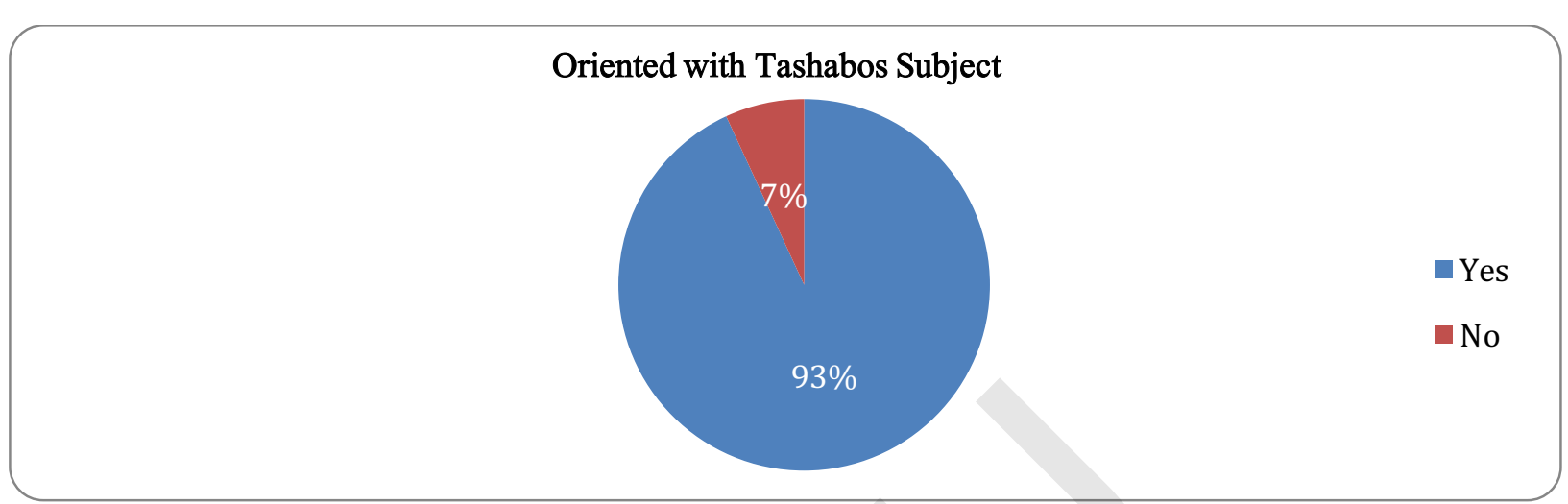

Since only $7 \%$ of the Tashabos teachers were yet to be oriented to the subject, it was necessary to know about the location of the non-oriented teachers. Thence, the data was further analyzed for the location of the respondents and it was discovered that only $8 \%$ of the urban Tashabos teachers were not oriented with the program, while the remaining $92 \%$ in urban areas and $100 \%$ in rural areas were fully familiarized with the program. Charts 91, 92 and 93 explain the orientation detail. Therefore, the program will easily cover the remaining $7 \%$ of the total non-oriented teachers due to their urbanity. Then, the data was considered for gender types of the oriented teachers and it was understood that higher number of male Tashabos teachers $(97 \%)$ were oriented to the program comparing to female teachers $(95 \%)$. At the next level, the data for orientation of the teachers was analyzed for both gender and location. Since it is already mentioned that the entire teachers in rural areas were oriented by the program, gender disaggregation of only urban teachers were evaluated and it was found that non-oriented urban female teachers with $9 \%$ outnumbered their male counterparts with $5 \%$

\section{Chart 91: Disaggregation of Oriented Tashabos Teachers according to Location}

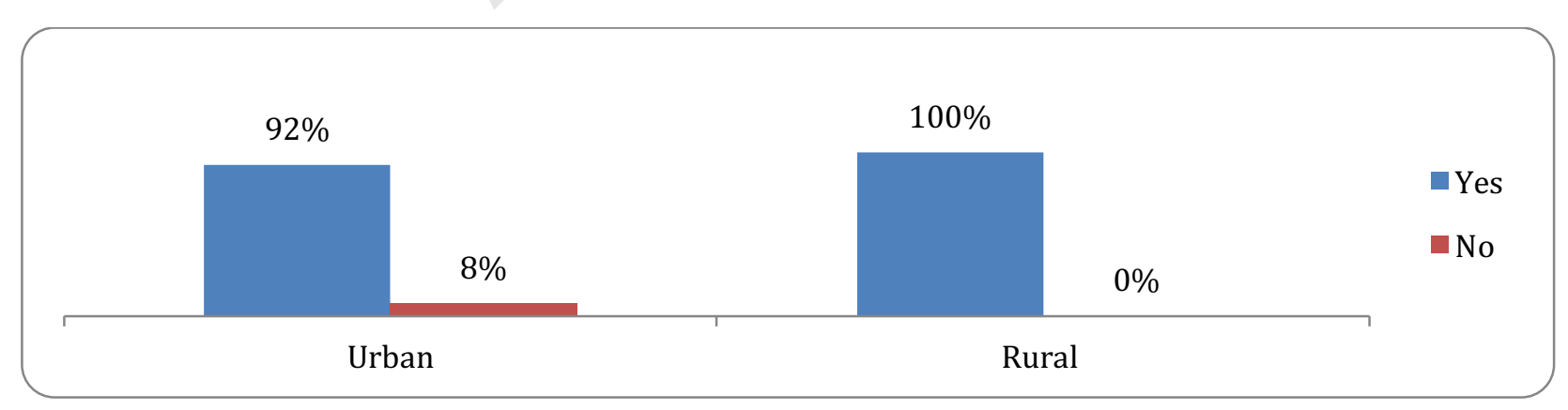




\section{Chart 92: Disaggregation of Oriented Tashabos Teachers according to Gender}

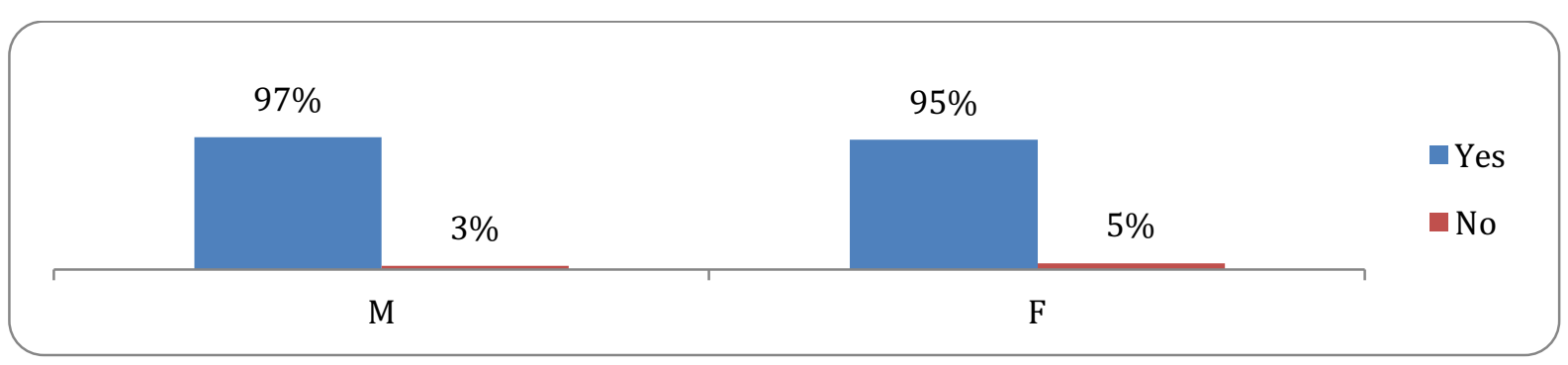

Chart 93: Disaggregation of Oriented Tashabos Teachers according to Gender and Location

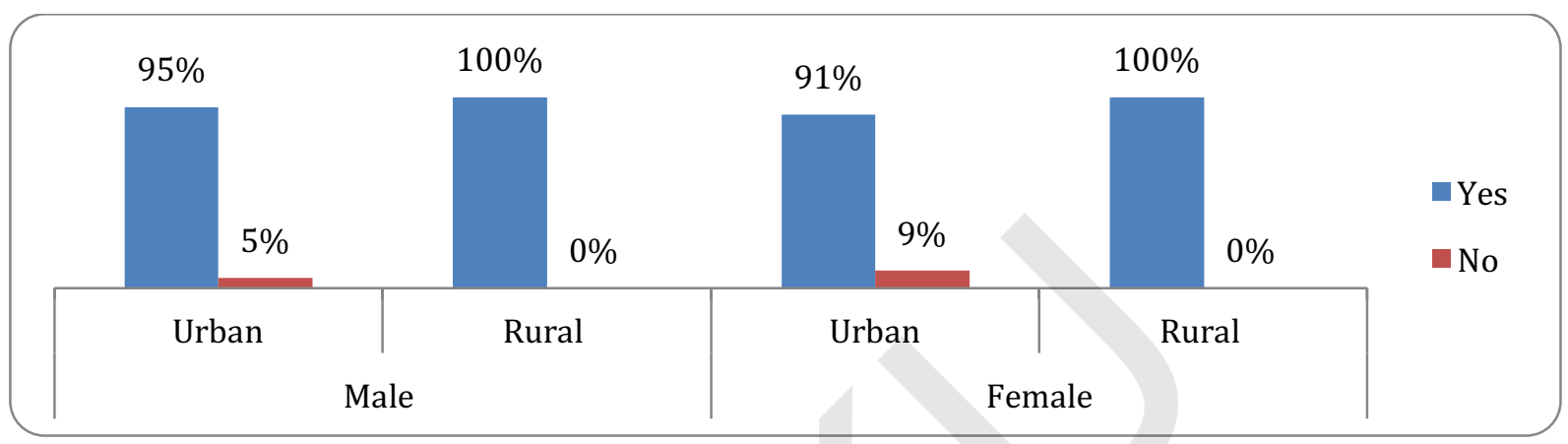

\section{Students and Tashabos:}

The next paragraphs of the report will deal with information about the students and Tashabos. This information includes students' interest to the subject; comparison of interest levels between students and schools; and students' awareness about Tashabos. Each of these issues is taken into separate consideration under subtitles.

\section{Students' Interest to the Subject:}

Since Tashabos is not among the essential subjects of the students, having information about students' interest was very important. Therefore, all the interviewee teachers were inquired if their students have been interested with the subject. Nearly, all the teachers replied $(98 \%)$ that students have had interest with the subject. However, analyzing the data, it was found that $2 \%$ of the urban teachers replied that students don't show their interest with the subject while all the teachers $(100 \%)$ in rural areas replied that students have been fascinated with the subject. Charts 94 and 95 tell us more about the students' interest from teachers' perspectives.

\section{Chart 94: Tashabos Teachers' Perspectives on Students' Interest with Tashabos}

\section{Students Interested in Studying Tashabos}

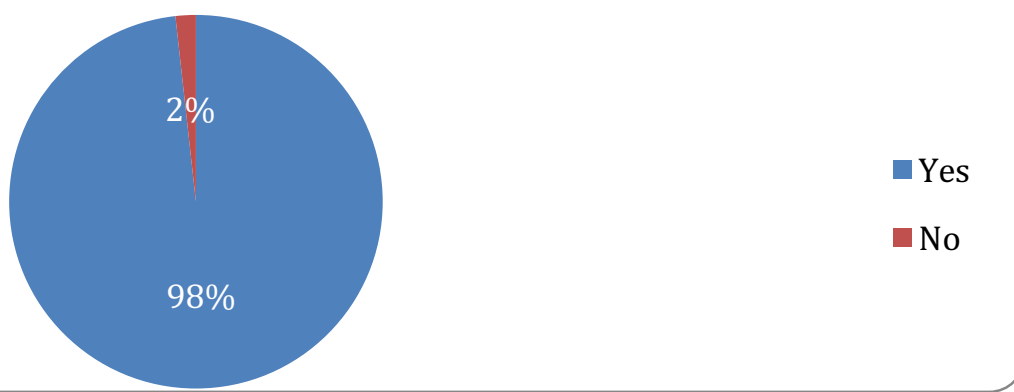


Chart 95: Tashabos Teachers' Perspectives on Students' Interest with Tashabos in Urban \& Rural Areas

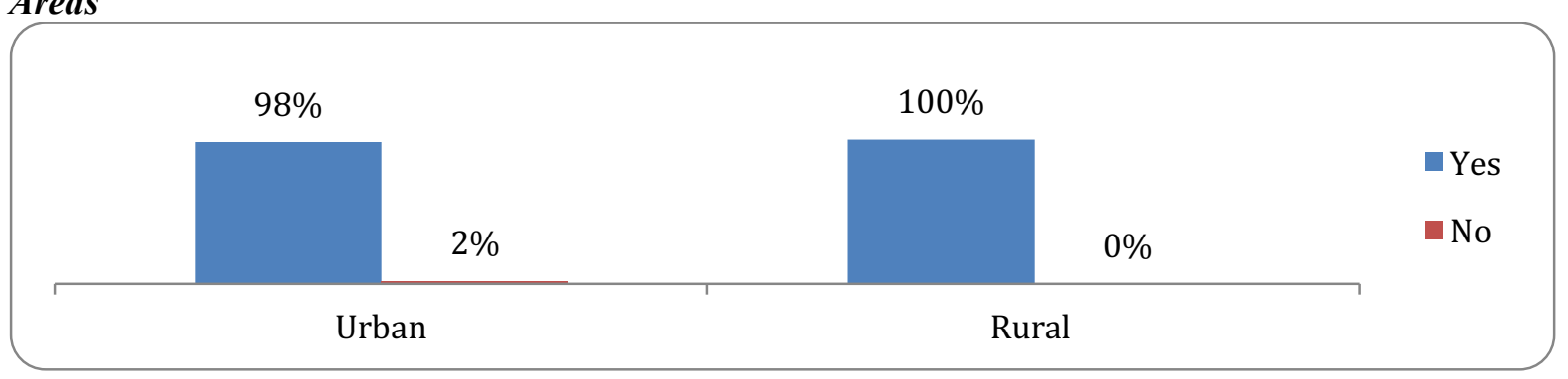

When the data was further analyzed for the gender type of the Tashabos teachers, it was found that students of female teachers (100\%) have shown their interest with the subject comparing to $97 \%$ of male Teachers'. However, when gender and location of the teachers were taken into consideration, it was discovered that only $5 \%$ of male teachers in urban areas replied that their students haven't shown their interests with the subject, whereas male teachers $(100 \%)$ in urban areas and female teachers in both urban $(100 \%)$ and rural areas $(100 \%)$ have expressed that their students have been keen to learn the subject. Chart 96 depicts the complete picture of the teachers' perspectives on students' interest with the subject according to gender and according to gender and location.

Chart 96: Tashabos Teachers' Perspectives on Students' Interest with Tashabos according to Gender

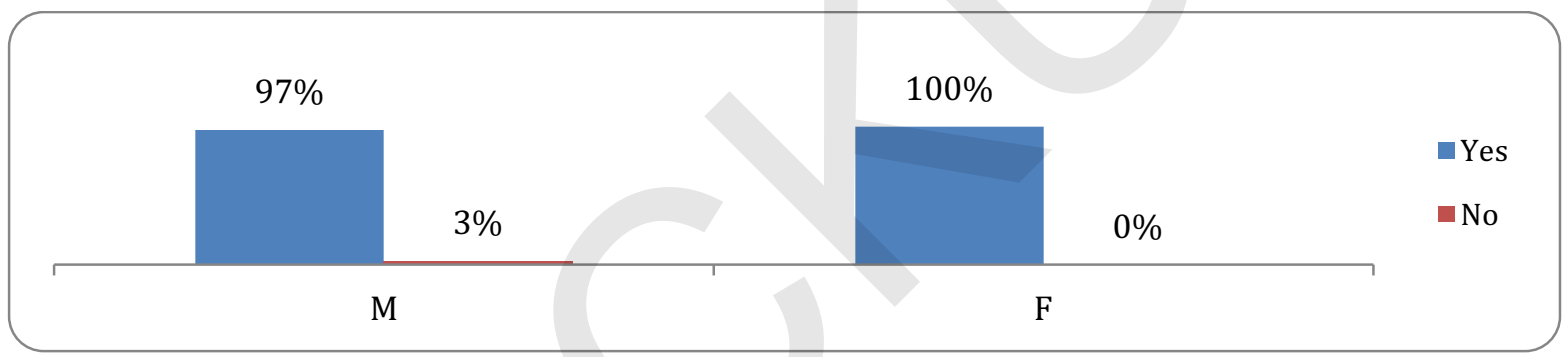

After learning that students of higher number of teachers were keen with the subject, it was necessary to know the reasons behind students' interest. It was found that students of $23 \%$ of teachers were interested with the subject because Tashabos taught the students about business skills. At the same time, $21 \%$ of teachers replied that Tashabos increases self-reliability of the students and hence the students are interested with the subject. On the other hand, for students of $19 \%$ of the teachers "business proposals and exhibitions" were the sole cause of students' interests with the subject. There were other responses by the remaining 37\% of the teachers, which are highlighted in Chart 97.

\section{Chart 97: Reasons for Students' Interest with Tashabos (Teachers' Perspectives)}

\begin{tabular}{|c|c|c|c|c|c|c|c|c|c|c|}
\hline \multicolumn{11}{|c|}{ Reasons for Students Interest to the Subject } \\
\hline $4 \%$ & & & & $9 \%$ & $12 \%$ & $2 \%$ & $4 \%$ & $4 \%$ & $4 \%$ & \\
\hline 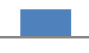 & & & & & & = & 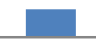 & ב & 1 & \\
\hline 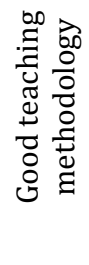 & 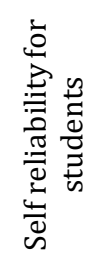 & 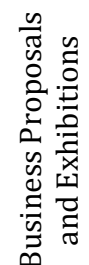 & 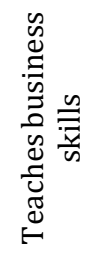 & 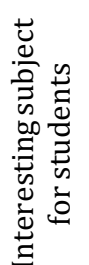 & 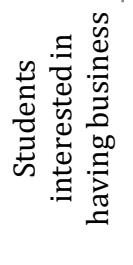 & 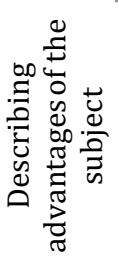 & 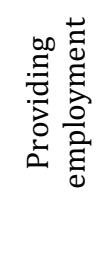 & 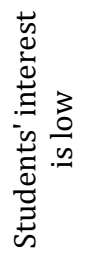 & 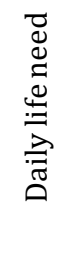 & Reasons \\
\hline
\end{tabular}


The reasons were, then, analyzed for the urban and rural teachers. It was found that students of Tashabos teachers in urban areas were interested because of: the subject increases self-reliability (24\%); the subject teaches business skills (22\%); and business proposals and exhibitions $(20 \%)$. Conversely, half of the teachers in rural areas (50\%) answered that students are keen to have businesses of their own and it attracts the students' towards the subject. 33\% of the teachers in rural areas thought that Tashabos teaches business skills to the students while the remaining $17 \%$ informed us about the students' interest with the subject through business proposals and exhibitions. Chart 98 depicts the complete picture of comparison in rural and urban areas for the reasons of the students' interests with the subject.

\section{Chart 98: Reasons for Students' Interests in Urban and Rural Areas (Teachers' Perspectives)}

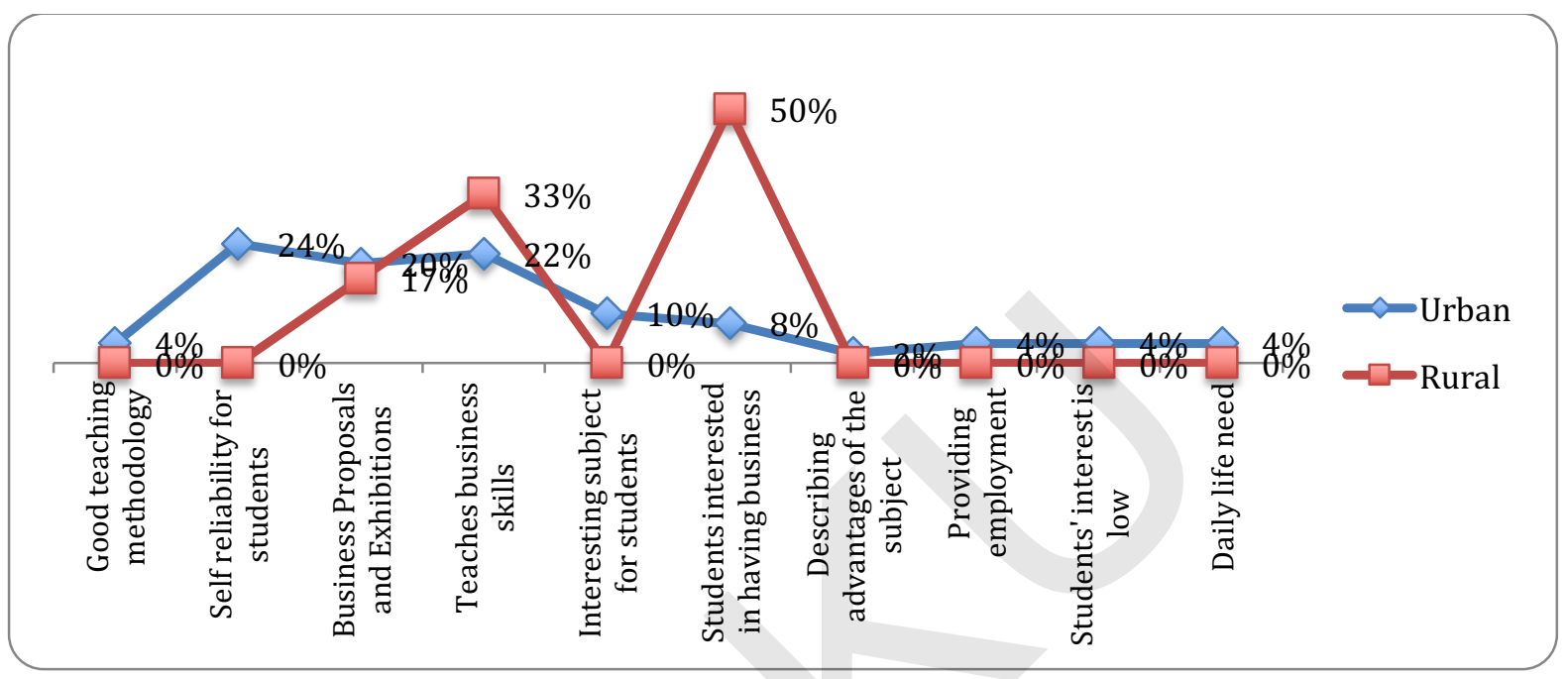

It was considered important to have collected information about the reasons provided by male and female teachers. Importantly, the three highest groups of both male and female teachers had similar thoughts about the reasons why their students were interested with the subject. $33 \%$ male and $31 \%$ female teachers thought that Tashabos teaches business skills to the students and it causes the greatest interests of the students with the subject. At the same time, $28 \%$ male and $29 \%$ female teachers discussed that students tend to have their own business and hence they give the subject full importance. Finally, for students of $13 \%$ male and $15 \%$ female teachers, business proposals and exhibitions were the major reason behind students' interest with the subject. Chart 99 explains the various reasons provided by male and female teachers on interest levels with Tashabos.

Chart 99: Reasons for Students' Interests with Tashabos (Teachers' Perspectives according to Gender)

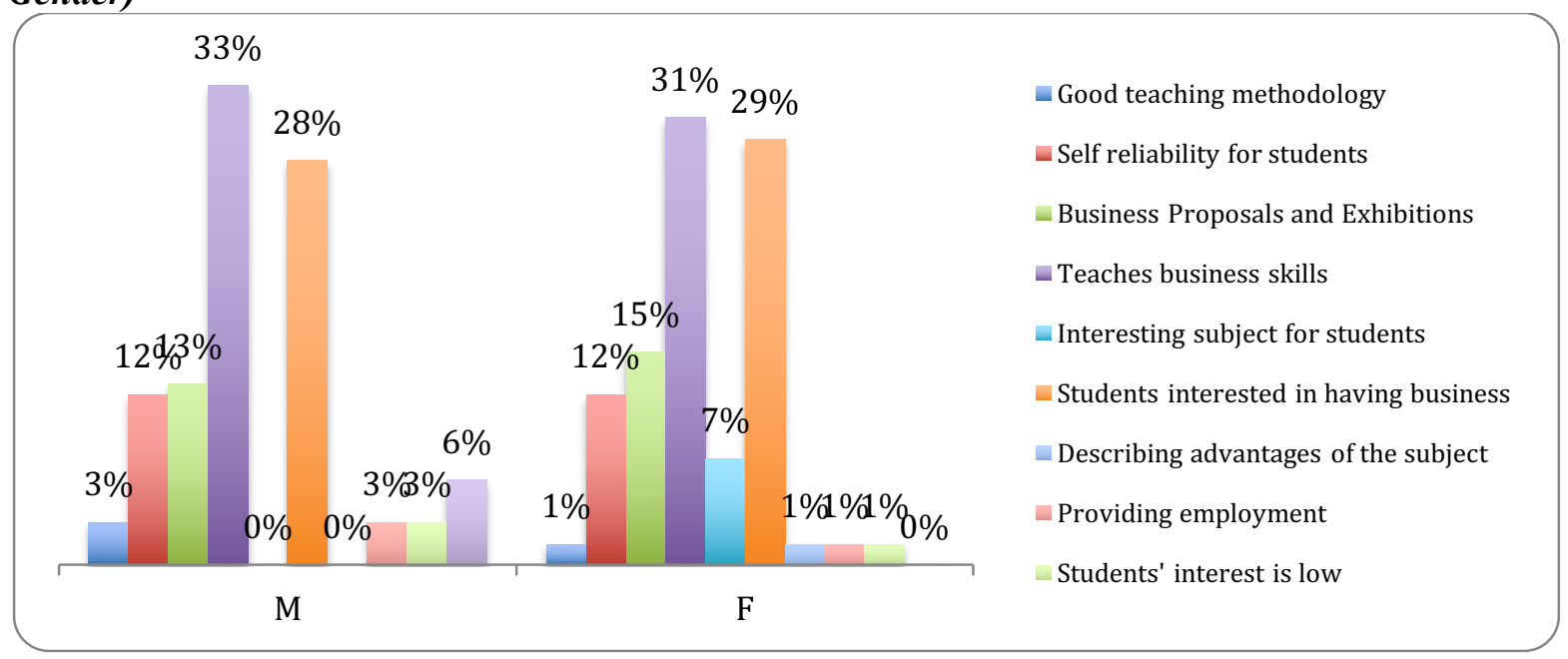


Since the students have had various reasons for their interests with the subject as per the statements made by the teachers, it was also important to know what topics were the most attractive to the students. It was found that $43 \%$ of the teachers mentioned that students have had keen interest with the topic of "Omid and Lema story", while for 13\% of the teachers "marketing" was more fascinating for their students than other topics. $9 \%$ of the teachers mentioned that their students had been interested in business management topics and another $9 \%$ of them declared that their student have taken a great part in business proposals and competitions. Chart 100 explains the important topics for students as per the teachers' thoughts.

\section{Chart 100: Interesting Topics from Tashabos to Students (Teachers' Perspectives)}

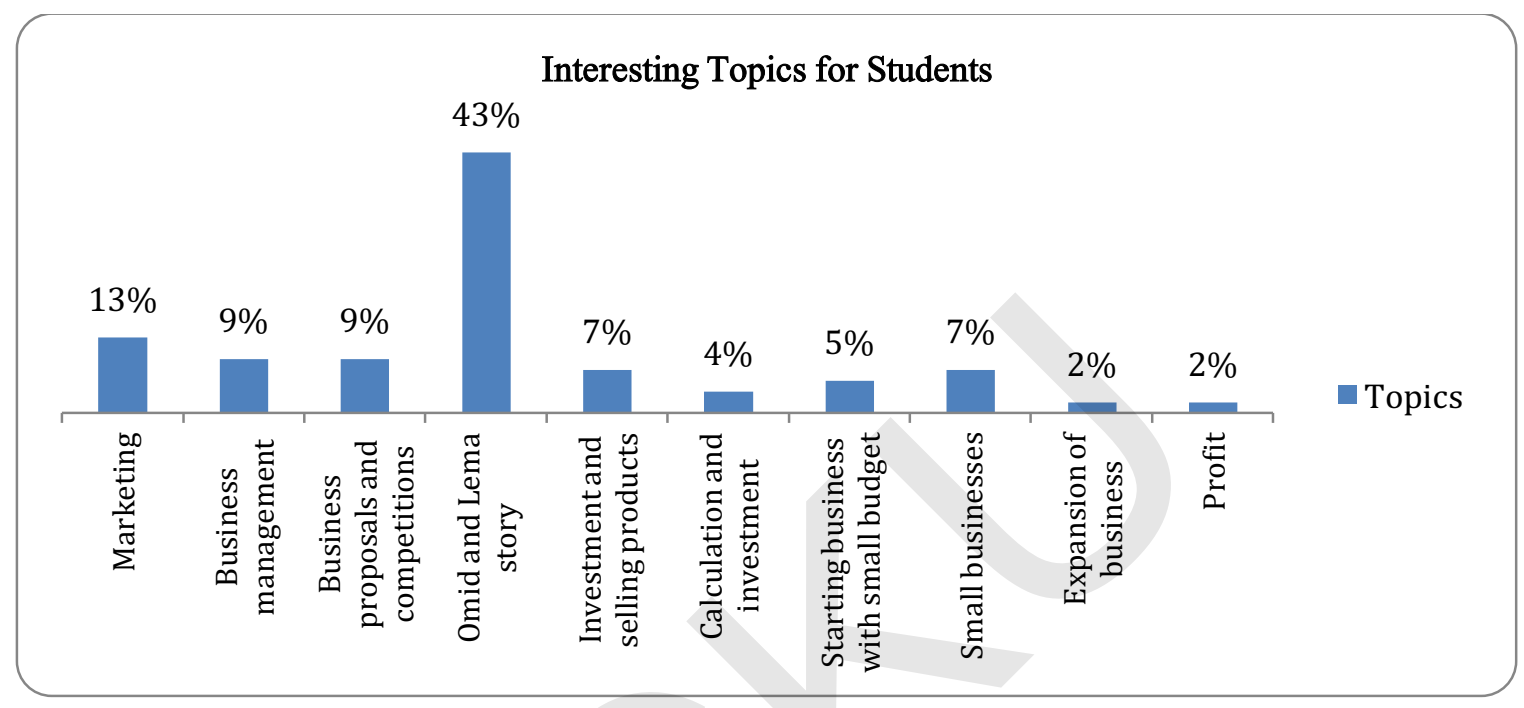

After talking about the interesting topics, the study explored the interesting topics for students as per teachers' views in urban and rural areas. It was found that for students of both urban (40\%) and rural $(67 \%)$ areas the most interesting topic was the story of Omid and Lema. In addition, when the data was analyzed for gender of the teachers, it was found that nearly half of the teachers among both male $(51 \%)$ and female $(48 \%)$ mentioned "Omid and Lema story" as the most interesting topics for their respective students. Charts 101 and 102 give complete picture of the interesting topics for the students as per the teachers' views.

Chart 101: Interesting Topics for Students in Tashabos (Teachers' Perspectives in Urban and Rural Areas)

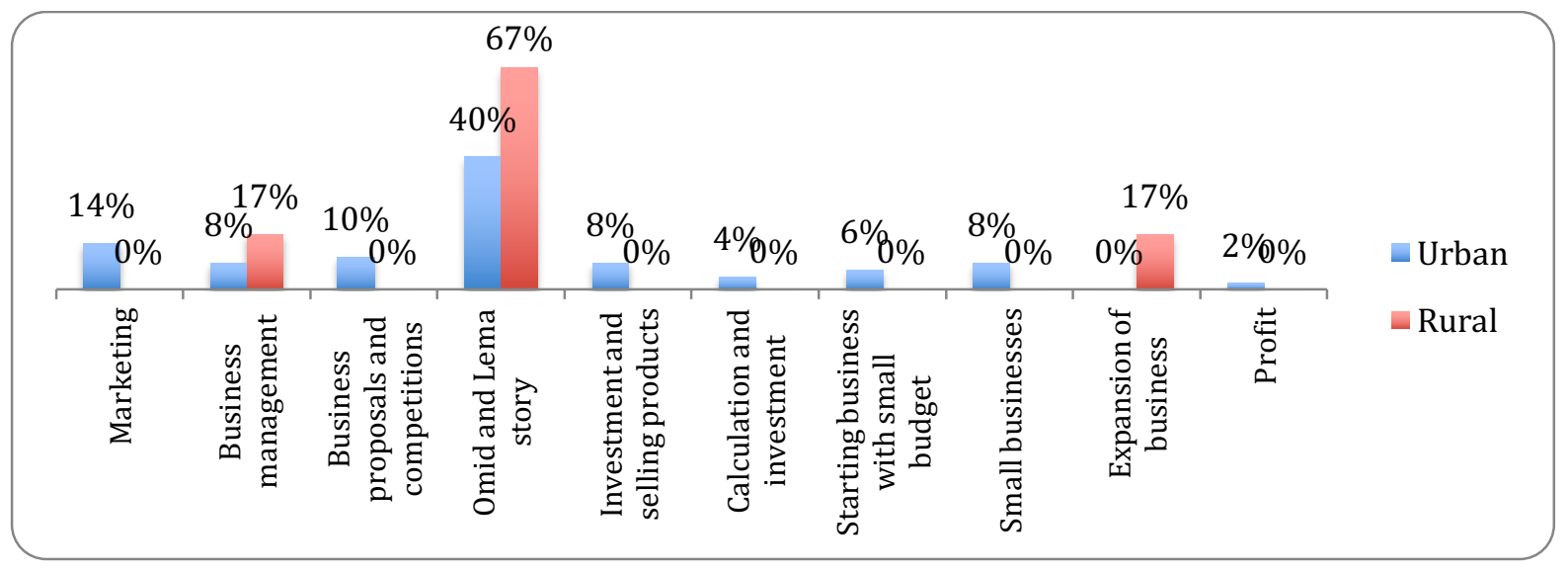


Chart 102: Interesting Topics for Students in Tashabos (Teachers' Perspectives according to Gender)

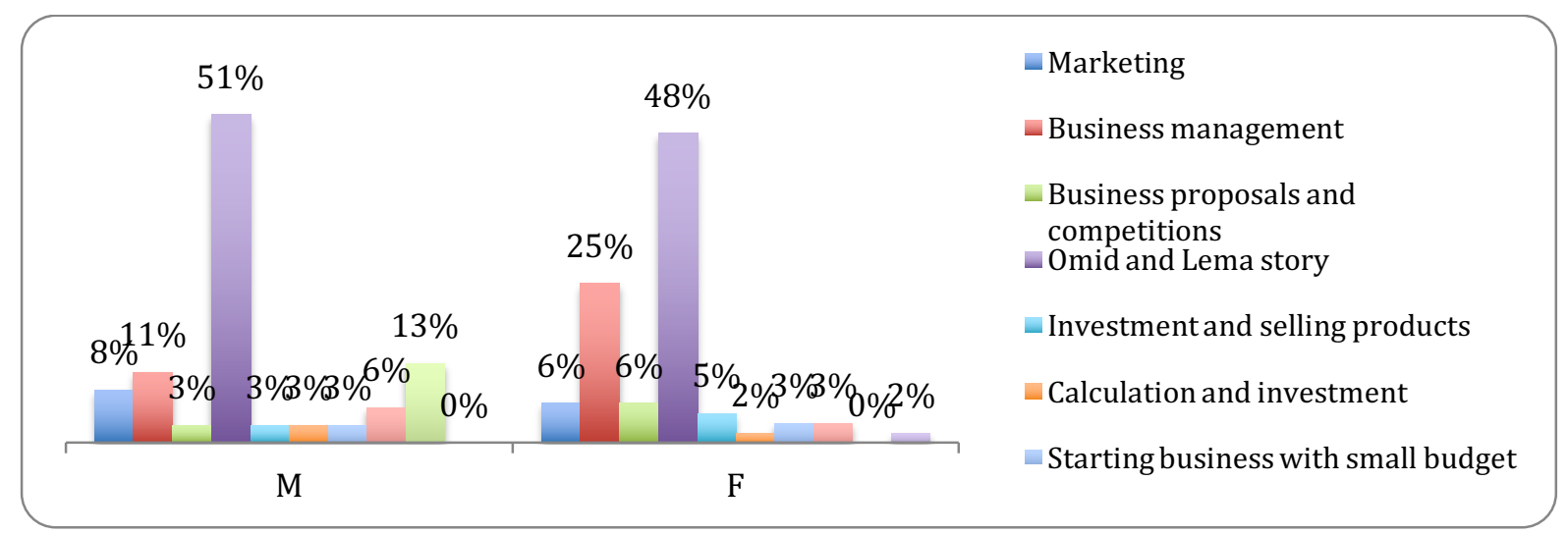

Not only the reasons for the students' interests were sought during the study but the teachers $(2 \%)$ who replied that students were not interested with Tashabos were also approached. These teachers mentioned that Tashabos is not an essential subject for the students. Therefore, the students are not that much interested with the subject.

Now that over half of the teachers admitted that they had observed the change in students' interest levels to the subject, it was considered to explore the causes for such variant interests of the students to the subject. 34\% of the teachers explained that better teaching methodologies have led to various levels of student's interest to the subject. However, $21 \%$ of the teachers have added that they have used practical teaching methods for the subject and this has driven to students' various levels of interest to the subject. At the same time, another majority of the teachers $(21 \%)$ talked about higher interest levels of their respective students to the subject. The data was then analyzed for the location of the students and it was found that the story was similar for urban teachers with $34 \%, 21 \%$ and $21 \%$ of them talked about "better teaching methodologies", "practical teaching of the subject", and "higher interests of their students" respectively. However, only one teacher from the rural communities had observed the difference in interest levels of the students and he asserted the cause as "most of the students have their own businesses and this has resulted in different levels of the interest". After analyzing the data for gender types of the participants, it was found that majority of the male (43\%) and female (27\%) teachers described "better teaching methodologies" as the sole reason behind students' various levels of interest to the subject. However, $29 \%$ of male teachers mentioned that their students have inherently higher interest to the subject while second majority of female teachers $(27 \%)$ discussed about the practical teaching of the subject behind the various levels of students' interests. Charts 103, 104 and 105 depict the complete picture behind the various levels of interests of the students with the subject as per the perceptions of Tashabos teachers. 
Chart 103: Reasons for Difference in Students' Interest Level to Tashabos Subject (Teachers' Perspectives)

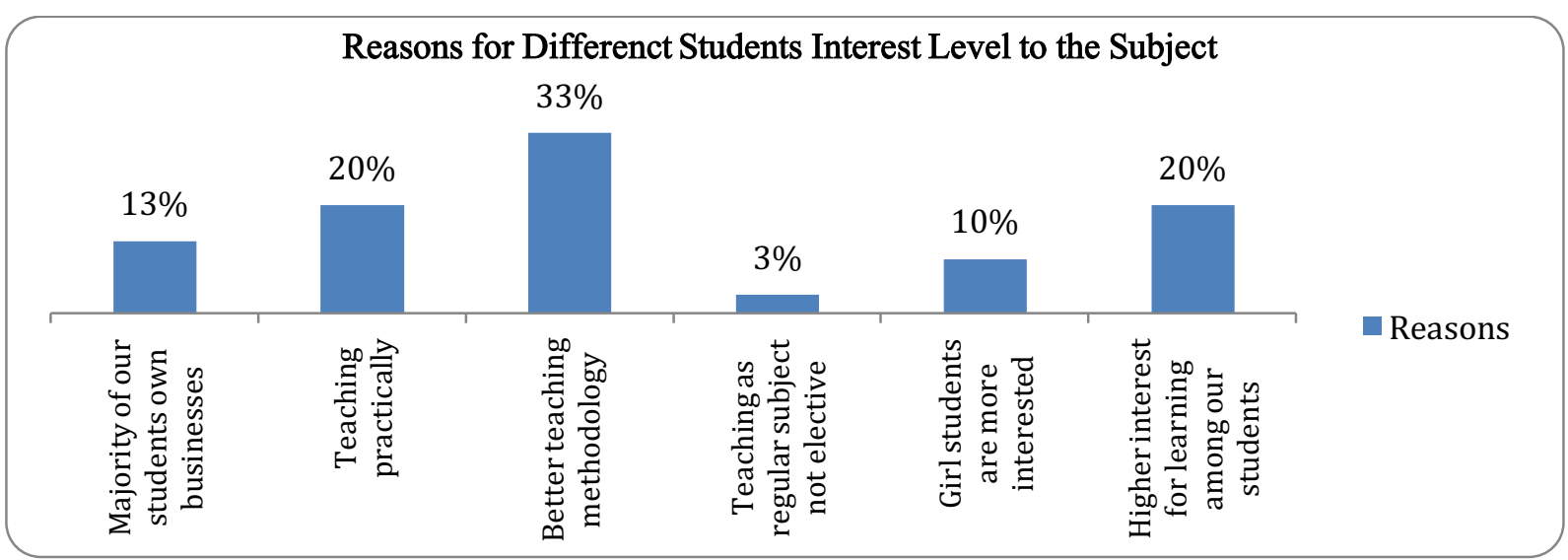

Chart 104: Reasons for Difference in Students' Interest Level to Tashabos Subject (Teachers' Perspectives in Urban and Rural Areas)

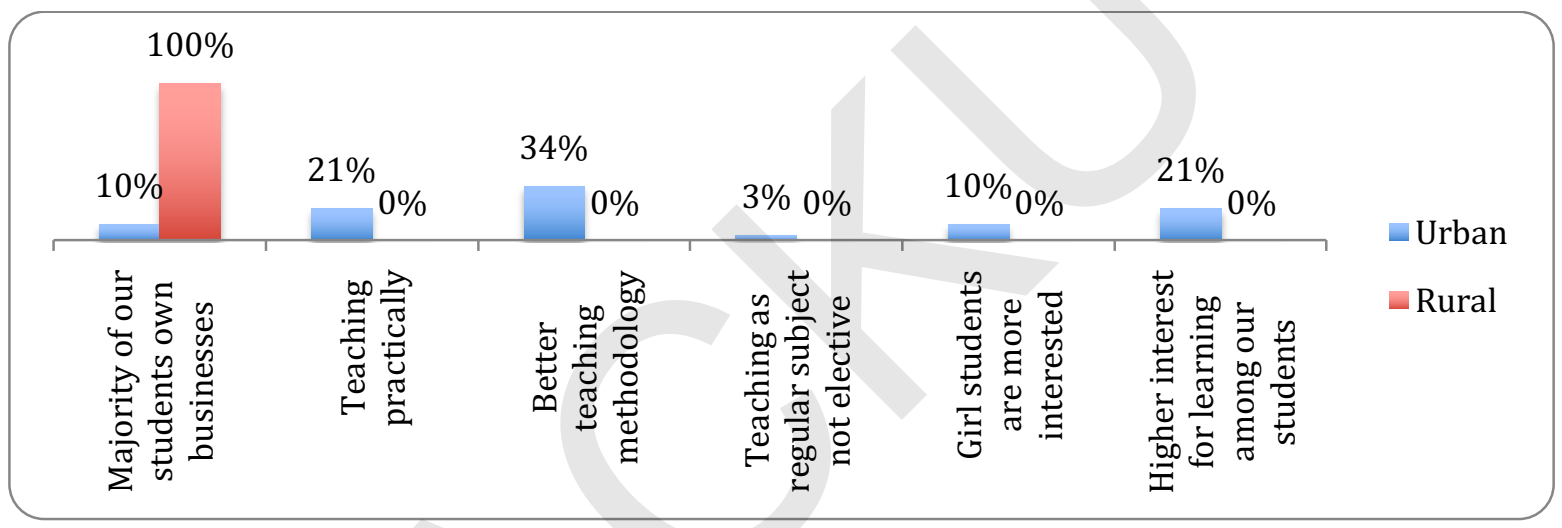

Chart 105: Reasons for Difference in Students' Interest Level to Tashabos Subject (Teachers' Perspectives according to Gender)

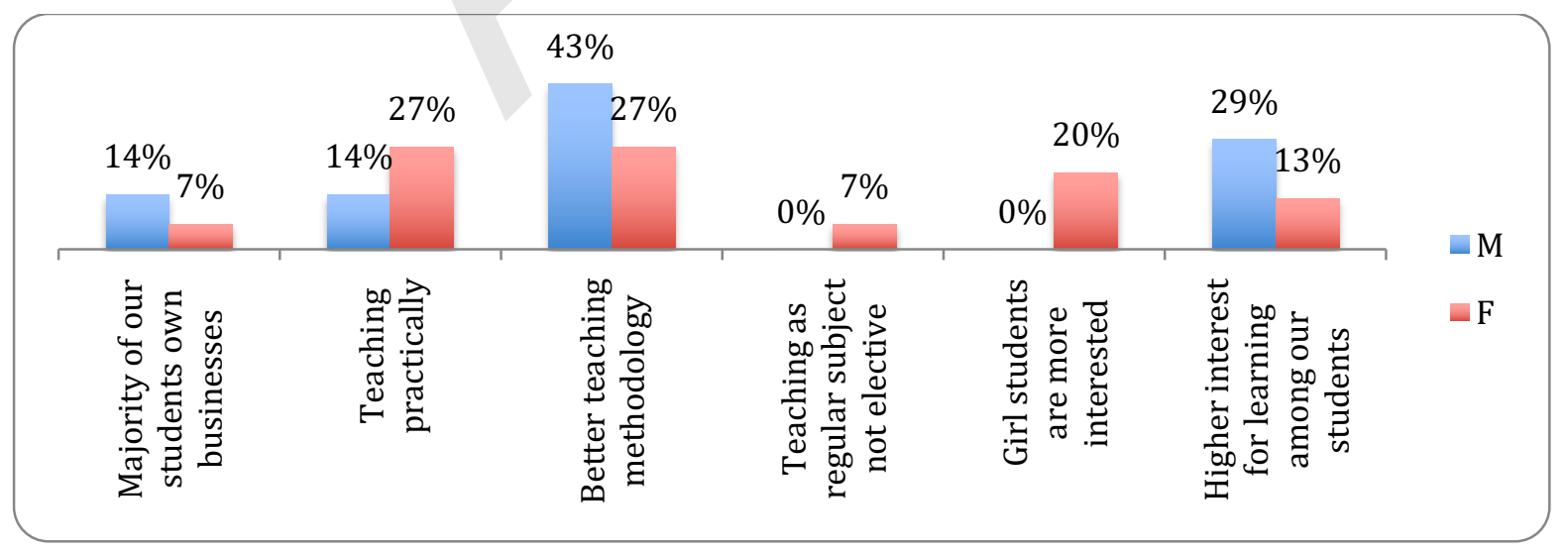

When talking about the interests of the students, there might have been some students of lower grades that don't study the subject, but yet they have interest with the subject. Thence, al the teachers were inquired if students of lower grades tend to talk about the subject with the teachers. Interestingly, $64 \%$ of the teachers were approached by lower grade students to learn about the subject. This is a very high figure and it denotes the success of the program with spreading key information about the importance 
of the subject. While comparing the data for urban and rural teachers, it was found that fewer urban teachers $(62 \%)$ than rural teachers $(83 \%)$ were asked about the subject. Talking about the gender types of the teachers, more female teachers $(86 \%)$ were inquired about the subject comparing their male counterparts (59\%). Charts 106, 107 and 108 tell us more about the teachers' responses about students of lower grades inquiring about the subject.

\section{Chart 106: Students of Lower Grades Talk about Tashabos (Teachers'Perspectives)}

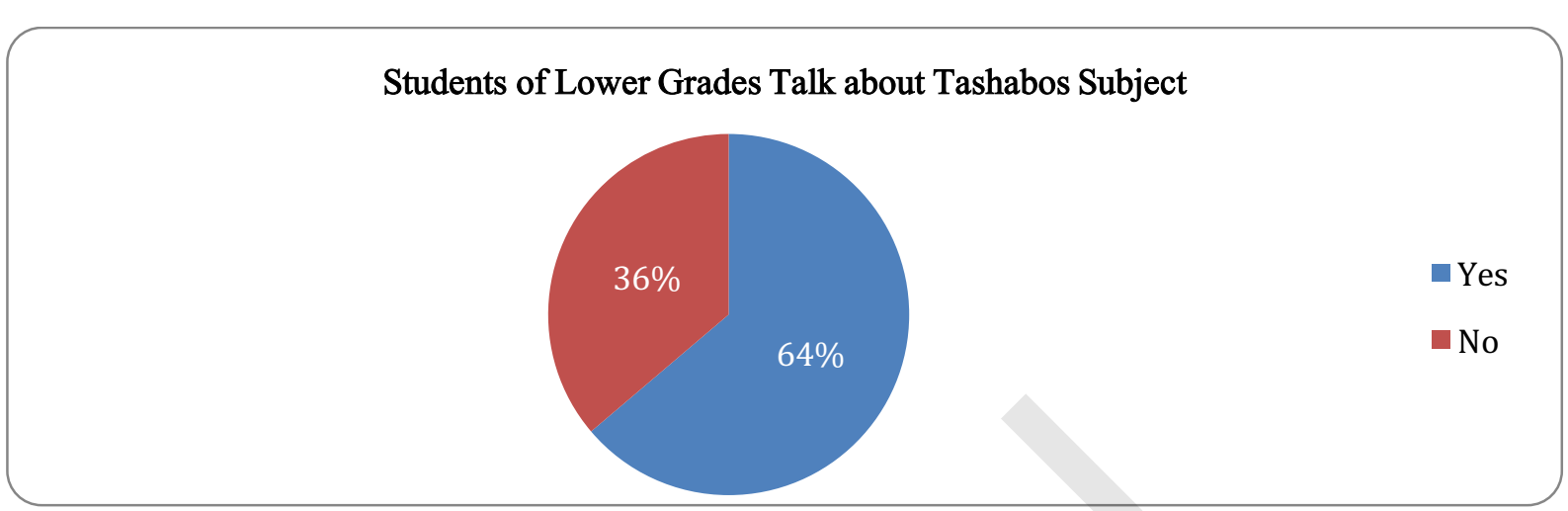

Chart 107: Students of Lower Grades Talk about Tashabos (Teachers' Perspectives in Urban and Rural Areas)

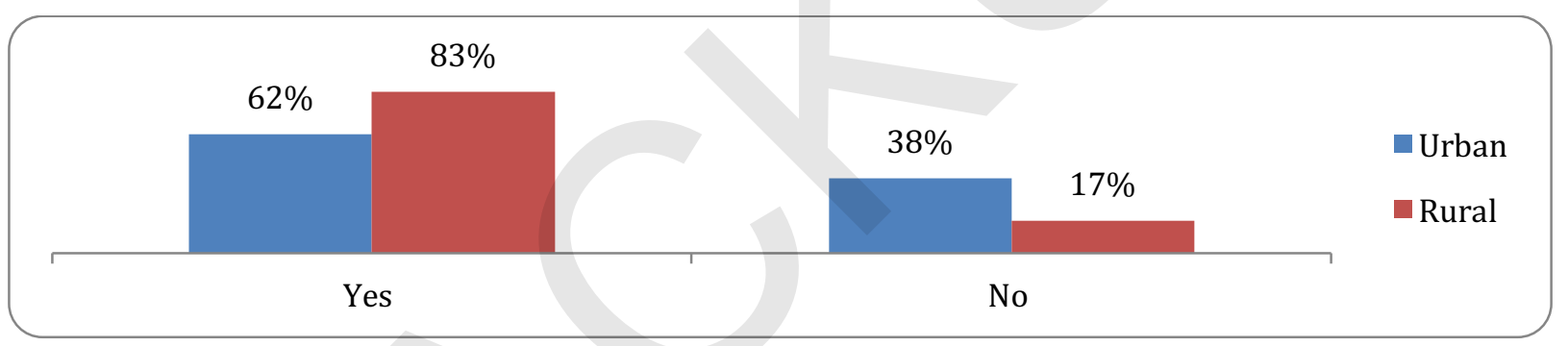

Chart 108: Students of Lower Grades Talk about Tashabos (Teachers' Perspectives according to Gender)

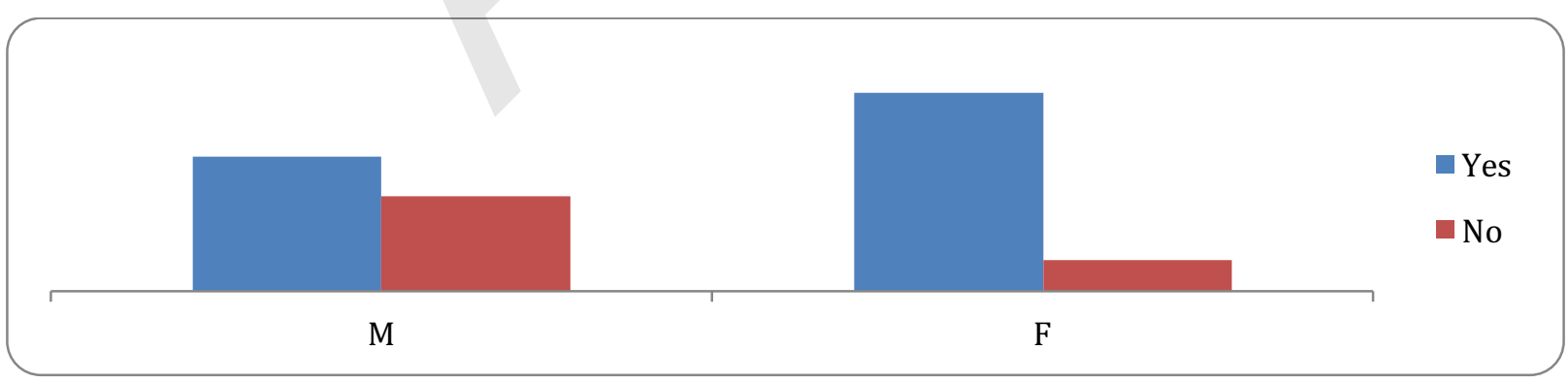

Since a higher percentage of teachers have been approached, it was considered to learn about the causes of lower grades students' interest to the subject. 56\% of the Tashabos teachers mentioned that Tashabos activities within schools have attracted the students of lower grade students to know and learn about the subject. At the same time, $19 \%$ of the teachers informed us that majority of the students are interested in having in business and this creates the sole topic of mutual discussion between teachers and students of lower grades. Chart 109 informs us about other possible causes for interest of lower grade students. 


\section{Chart 109: Discussion Points between Teachers and Lower Grade Students on Tashabos}

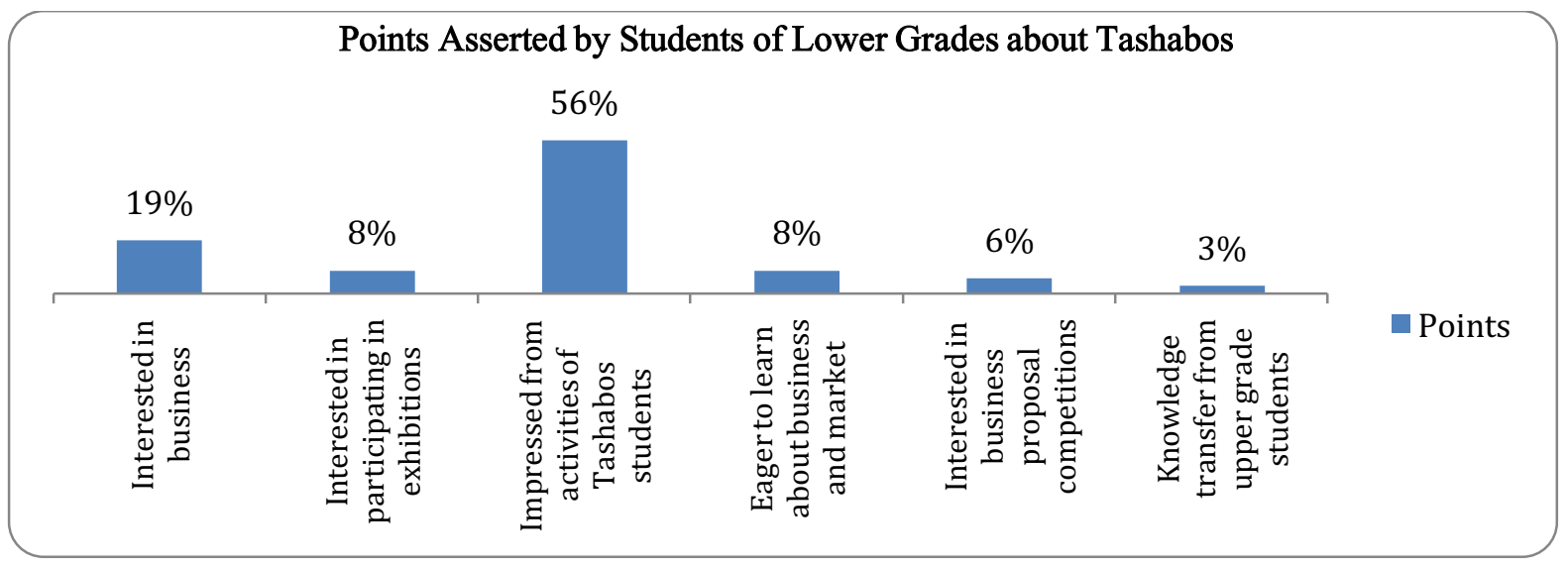

The teachers were then asked if their students know about the importance of the subject and as expected $97 \%$ of the replied positively to this question. These teachers mentioned that they have always been in discussion with the students about the importance of the subject. When we explored the data, it was found that $96 \%$ of the urban teachers and $100 \%$ of the rural teachers' students knew about the importance of the subject. However, when talking about the gender of the teachers, it was found that $3 \%$ of male teachers and $2 \%$ of female teachers' students were not aware about the importance of the subject. Charts 110, 111 and 112 gives the complete picture of the teachers' responses when asked, "Do students know about the importance of the subject?"

Chart 110: Students Know about the Importance of the Subject (Teachers' Perspectives)

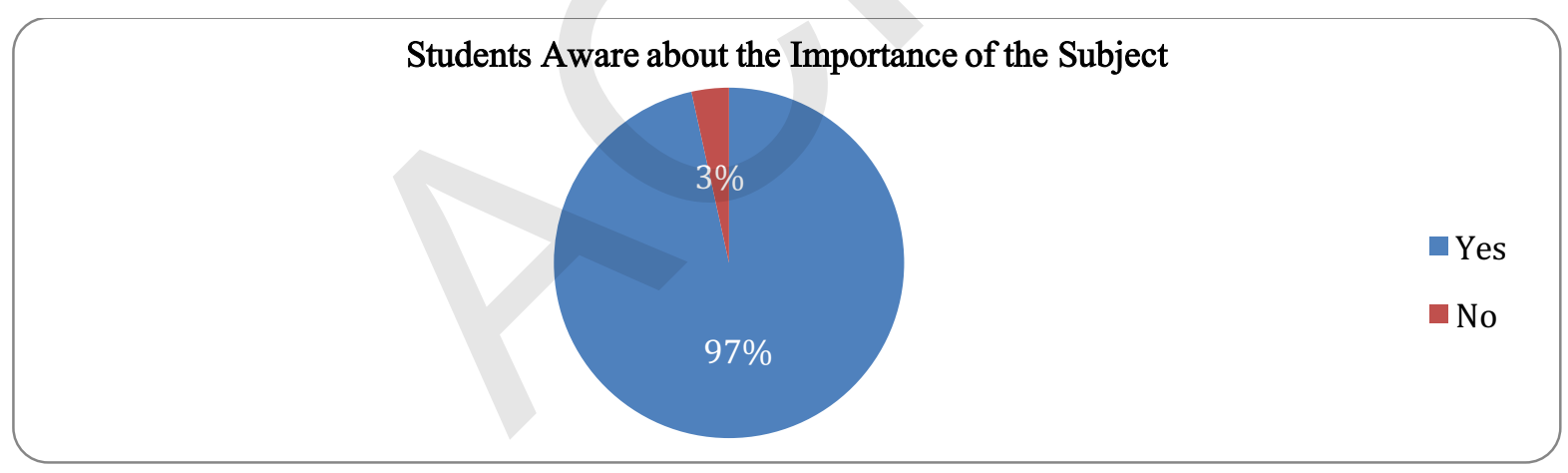

Chart 111: Students Know about the Importance of the Subject (Teachers' Perspectives in Urban and Rural Areas)

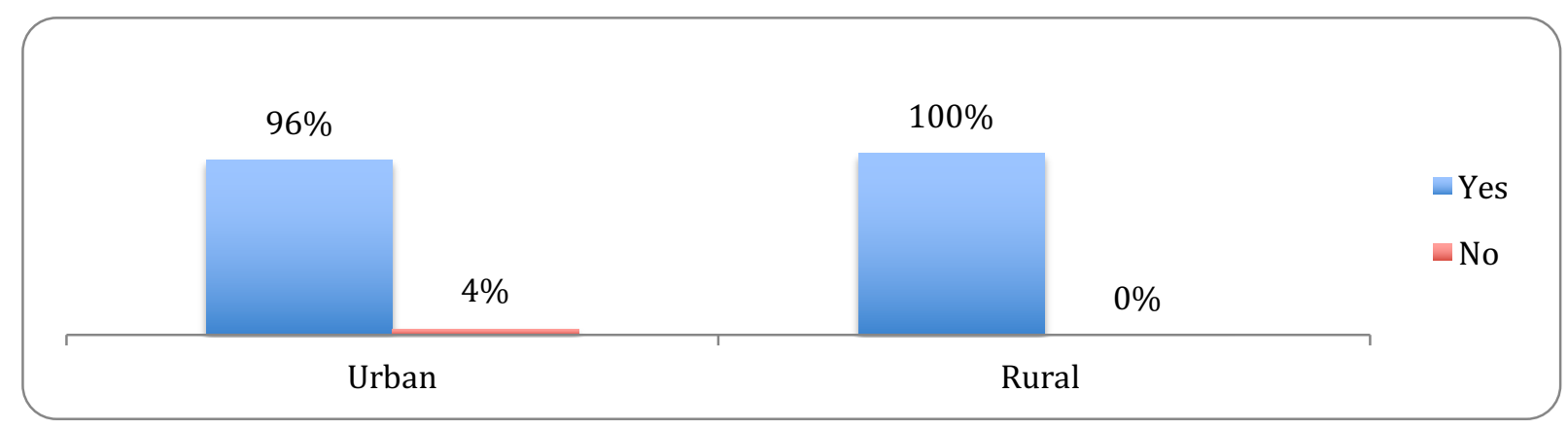


Chart 112: Students Know about the Importance of the Subject (Teachers' Perspectives according to Gender)

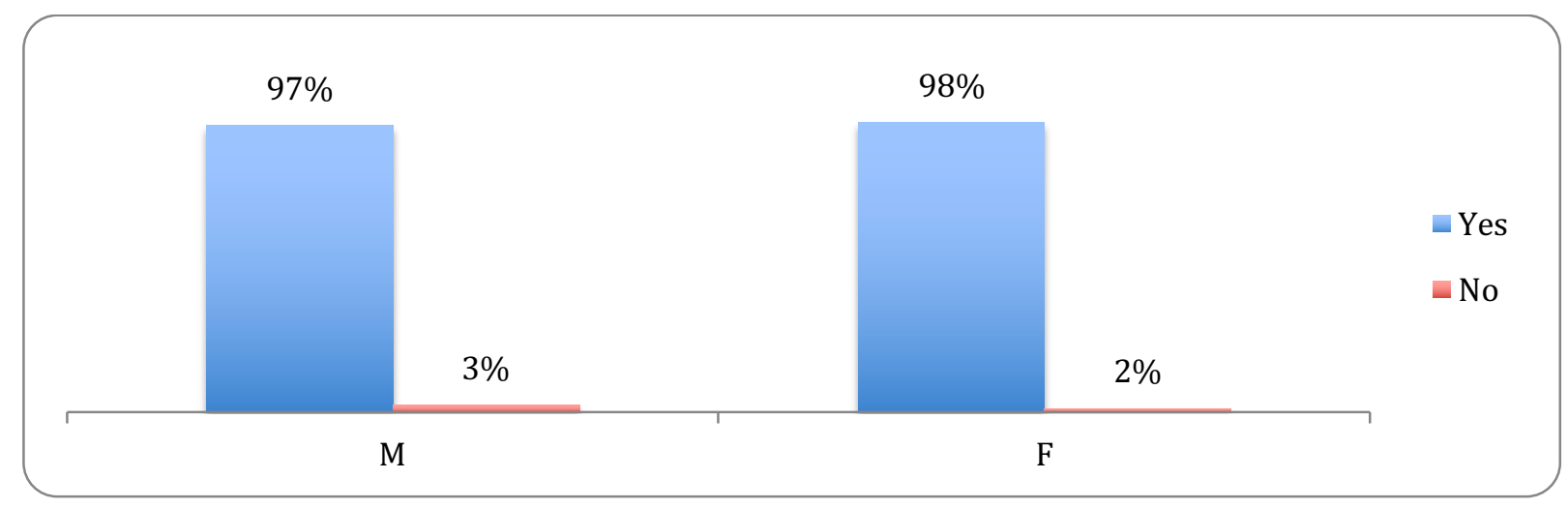

Now the teachers were inquired what topics do students share as the importance of the subject. $21 \%$ of the teachers replied that student love the subject because the student believed Tashabos is important for investments and increased self-reliability. At the same time, another $21 \%$ of the teachers pointed that for their students Tashabos is important because they have believed that Tashabos is important in initiating and expanding the businesses, while 14\% teachers' students thought importance of Tashabos subject in business proposals and competitions. Chart 113 provides the detail on importance of the Tahabos.

Chart 113: Points Asserted by Students about Importance of Tashabos (Teachers'Perspectives)

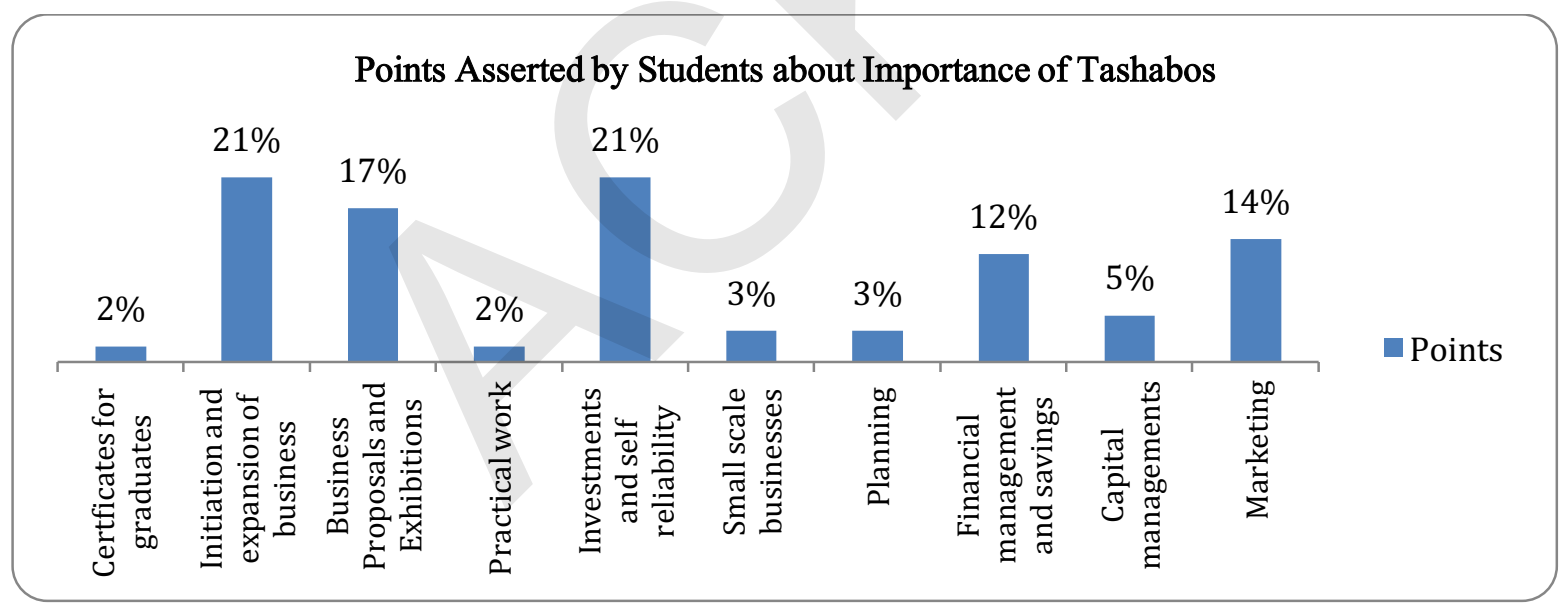

\section{Students' Products Demonstrations:}

When sufficient information about students' interests were collected, the study would like to know about the teachers' perspectives on the demonstration of the students' products. Therefore, all the teachers were asked if students' products have been demonstrated within their respective schools. Three fourth $(75 \%)$ of the teachers replied that they do conduct demonstrations of students' productions within the schools. However, when the teachers of urban and rural areas were separately inquired, it was found that more teachers in urban areas $(78 \%)$ than teachers in rural areas $(50 \%)$ were part of the students' demonstrations within their respective schools. Interestingly, in the gender types of the teachers, nearly all female teachers $(98 \%)$ were engaged in the students' products demonstrations within their schools, while the contribution from male teachers $(36 \%)$ have been very low for this activity.

Charts 114, 115 and 116 gives the complete information about the engagement of teachers in students' products demonstrations. 
Chart 114: Students' Products Demonstrated (Teachers' Perspectives)

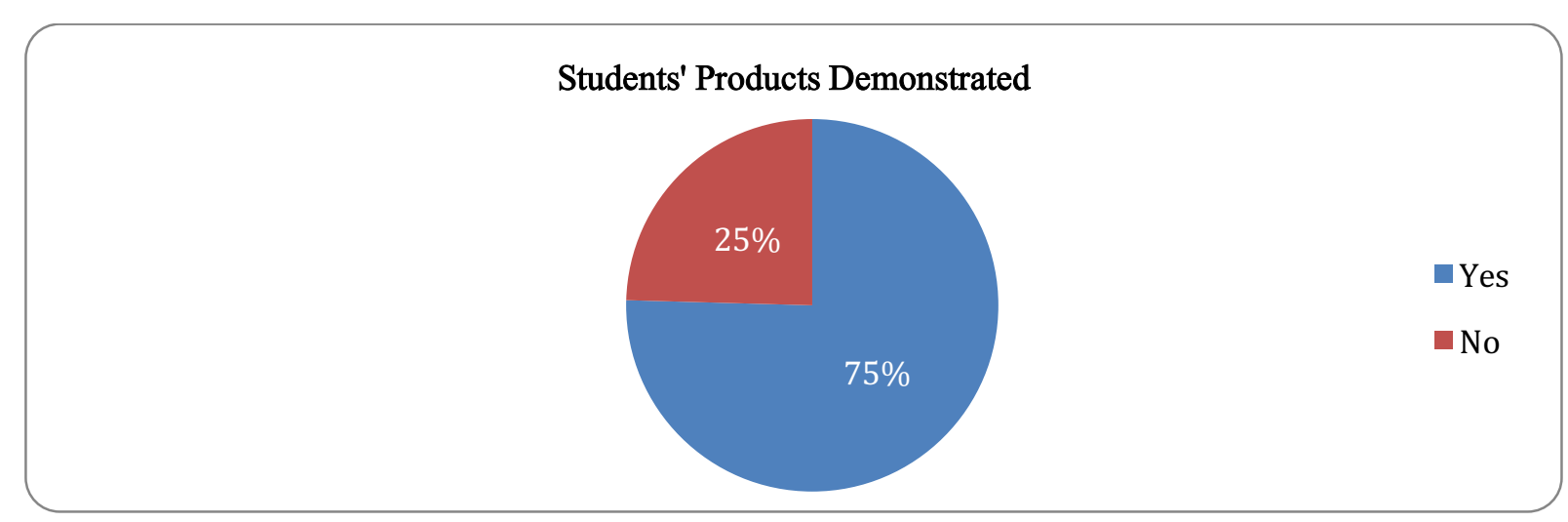

Chart 115: Students' Products Demonstrated (Teachers' Perspectives in Urban and Rural Areas)

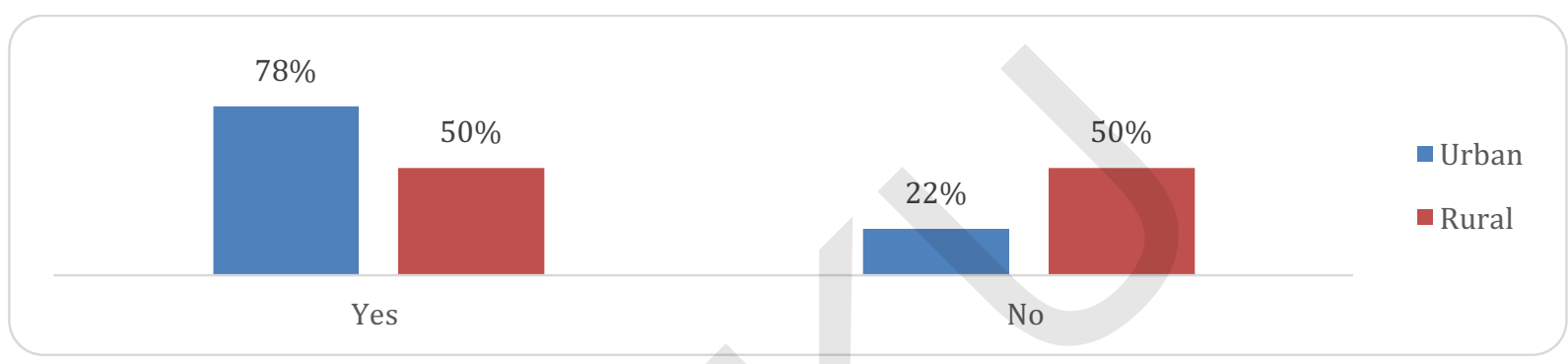

Chart 116: Students' Products Demonstrated (Teachers' Perspectives according to Gender)

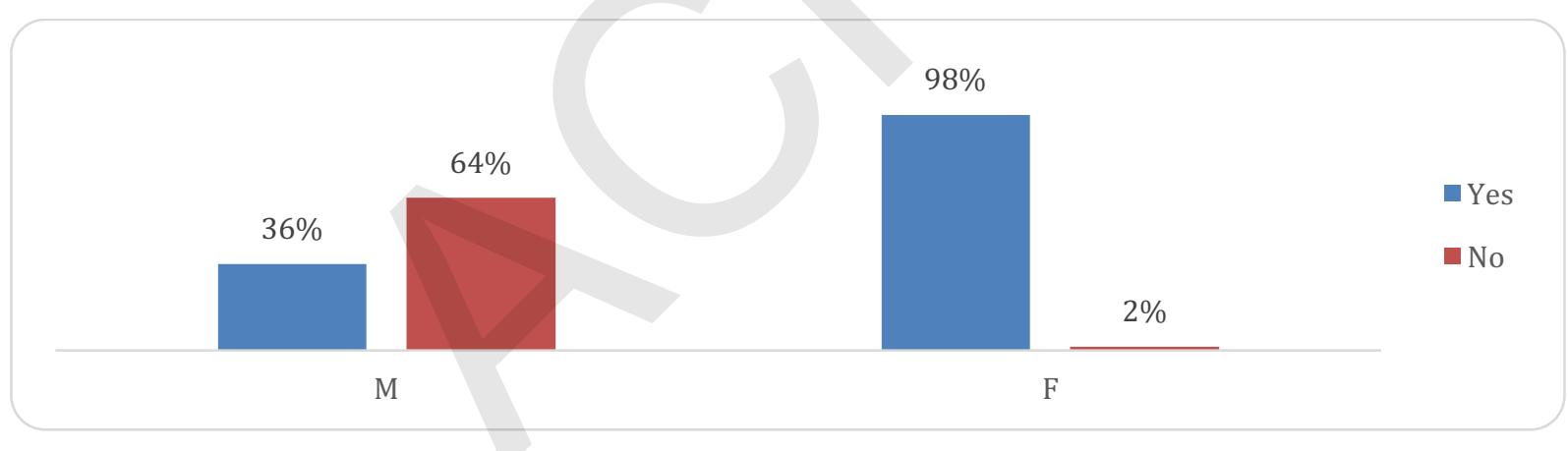

Now that demonstrations are conducted in a higher number of schools, it was deemed important to have collected information about the frequency of the demonstration plots. $55 \%$ of the teachers replied that demonstrations are conducted only once in a year within their schools, while $28 \%$ talked about twice a year conduction of the demonstrations. Yet, one tenth $(10 \%)$ of the teachers mentioned about thrice a year frequency of the demonstrations. While going to further details of the frequency of the demonstrations, it was found that once a year frequency was mostly observed among rural teachers' responses $(67 \%$ ) comparing to $51 \%$ of urban teachers. However, only $8 \%$ of the urban teachers mentioned about twice a year frequency of demonstrations, but $33 \%$ of the rural teachers stick with thrice a year occurrence of the demonstrations. Charts 117 and 118 give the complete picture of the frequency of the 
Chart 117: Frequency of Demonstrations (Teachers' Perspectives)

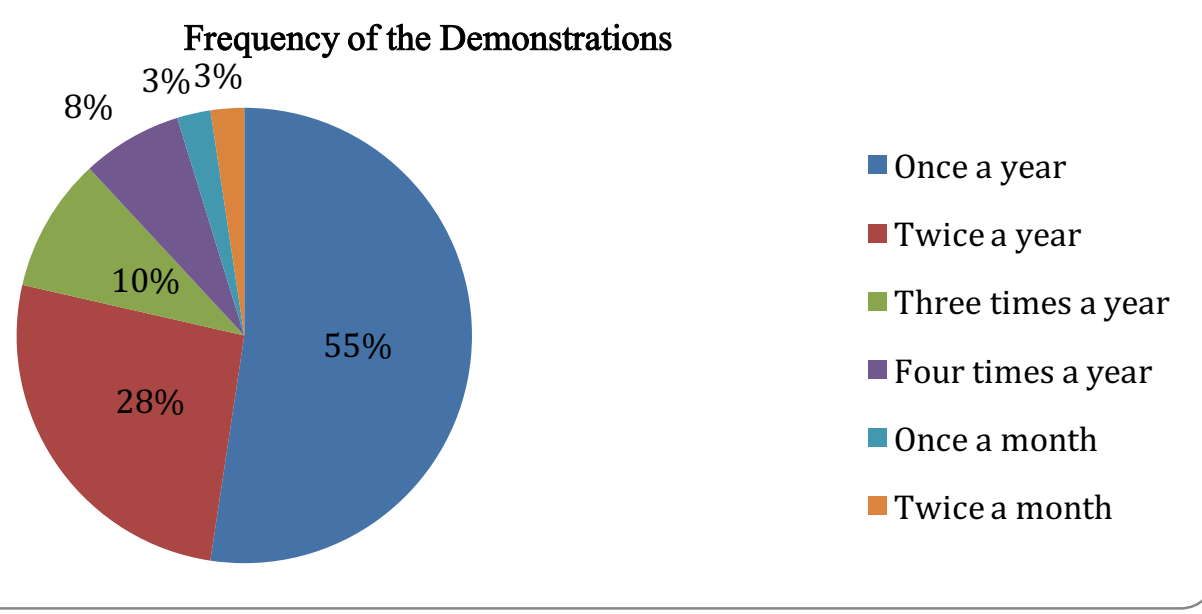

Chart 118: Frequency of Demonstrations (Teachers' Perspectives in Urban and Rural Areas)

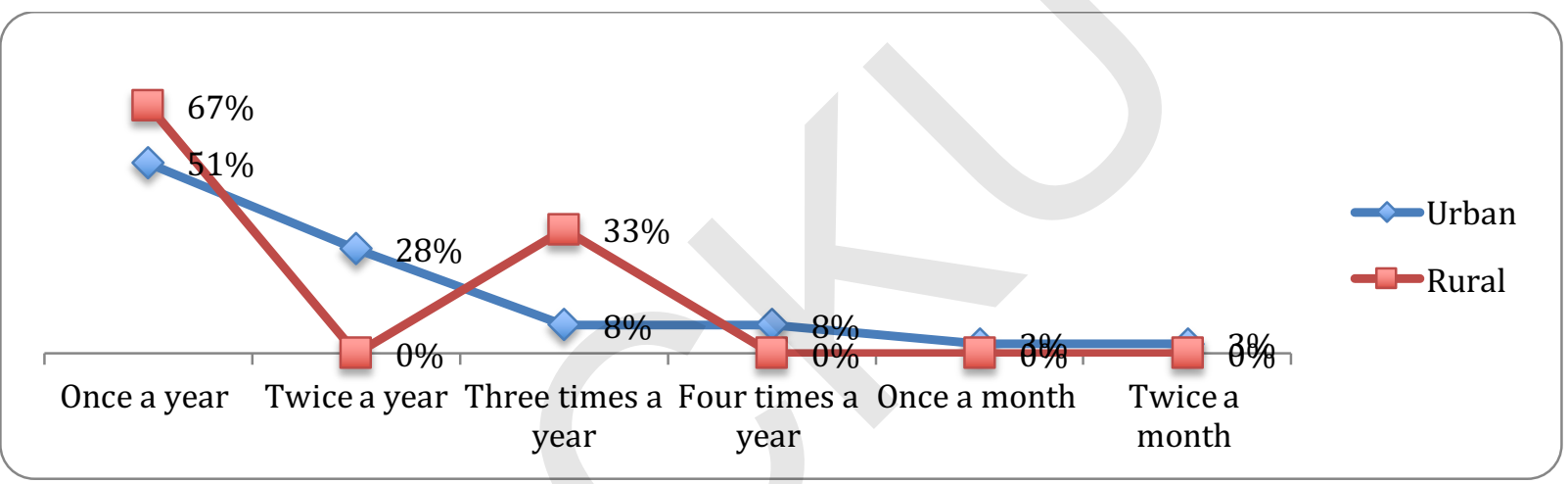

After collecting information about the role of the teachers in the demonstrations, the teachers were inquired about their roles in business proposals. It was found that $65 \%$ of the teachers mentioned that they assist the students during the entire process. However, 10\% of them stated that they have helped the students in informing them about the format of the BP and the another $10 \%$ added that they have assisted the students in writing the proposals. For both the teachers in urban $(61 \%)$ and rural $(100 \%)$ areas the major role has been assisting the students during the process. Similarly, majority of the male $(71 \%)$ and female $(85 \%)$ assisted their respective students in the entire process of the business proposals. Charts 119,120 and 121 tell us more about the roles of the teachers in business proposals.

Chart 119: Role of the Teachers in Business Proposals Development

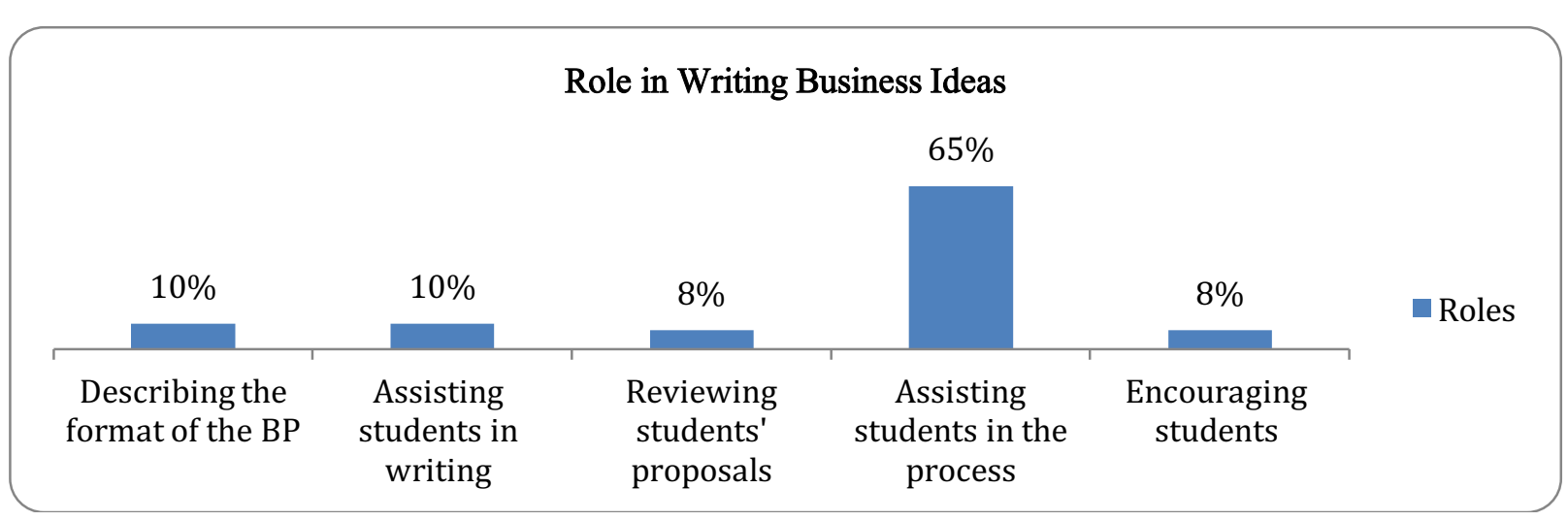




\section{Chart 120: Role of the Teachers in Business Proposals Development in Urban and Rural Areas}

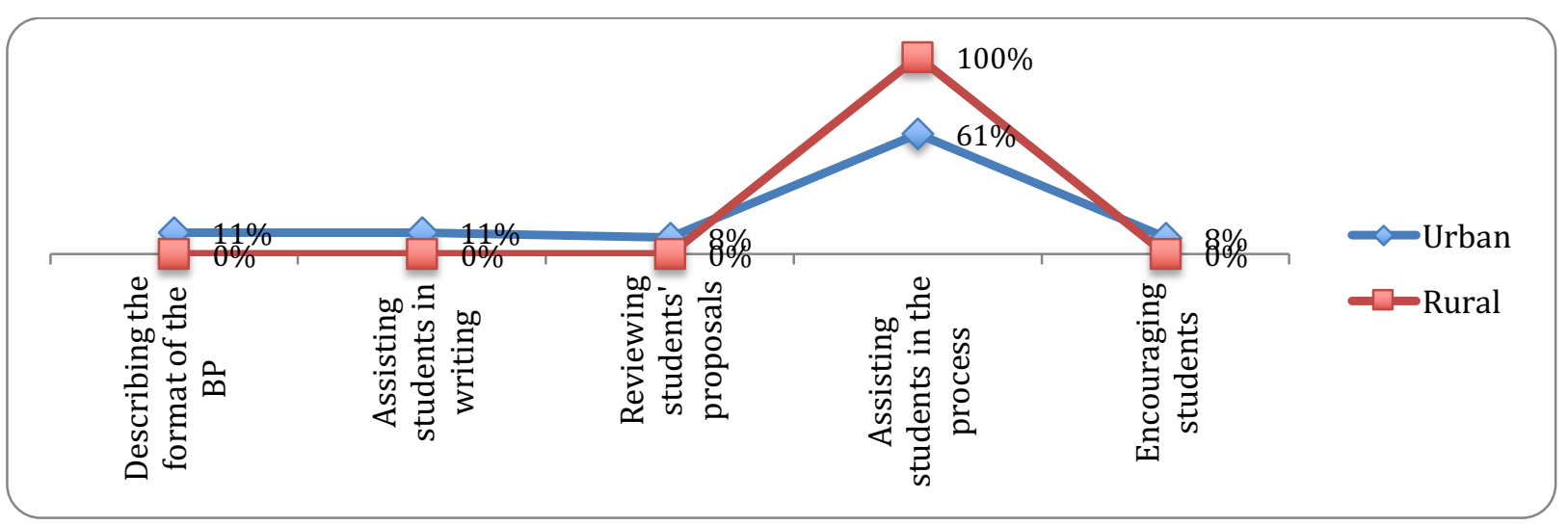

Chart 121: Role of the Teachers in Business Proposals Development according to Gender of the Teachers

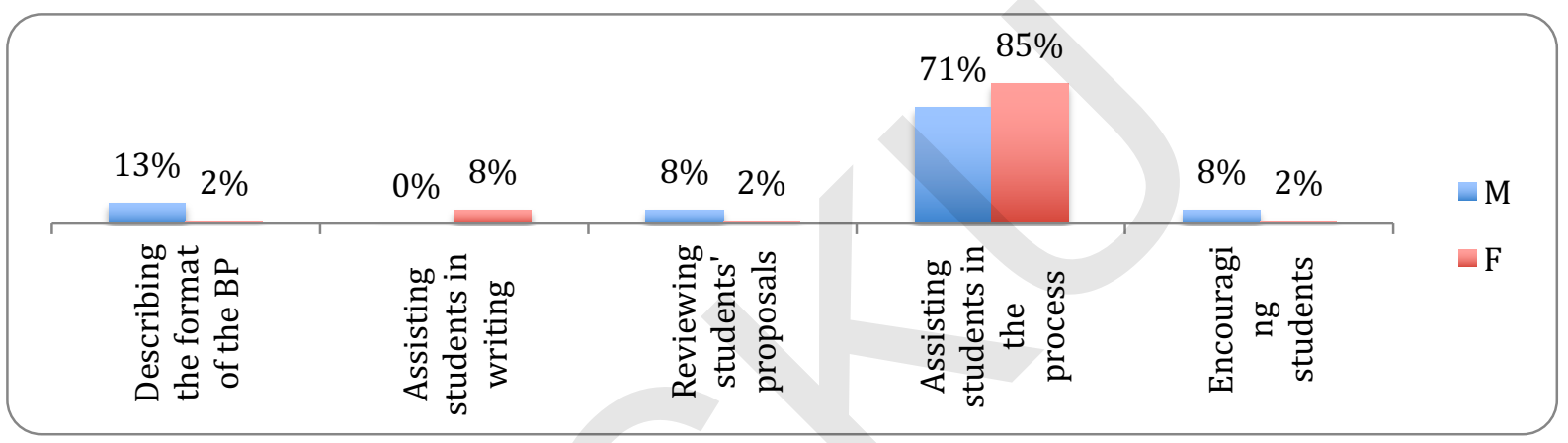

Since the teachers have been engaged during the proposal writing, the teachers were asked what innovative business ideas have been developed by the students. Therefore, one fourth $(25 \%)$ of the teachers replied that among the various business ideas, dress designing has greatly contributed to the students' self-reliability. At the same time, for $17 \%$ of the teachers, pickles were the source of selfreliability for their respective students and 14\% thought that embroidery dresses have contributed to students' self-reliability. Interestingly, the trend for the three best responses by the teachers was similar in both urban and rural areas as dress designing $25 \%$ in urban and $25 \%$ in rural areas), pickles $(16 \%$ in urban and $25 \%$ in rural areas), and embroidery dresses $(13 \%$ in urban and $25 \%$ in rural areas) have been linked to students' self-reliability by Tashabos teachers. Charts 122 and 123 adds more about the innovative business ideas leading to students' self reliability.

Chart 122: Innovative Business Ideas Leading to Students'Self-Reliability (Teachers' Perspectives)

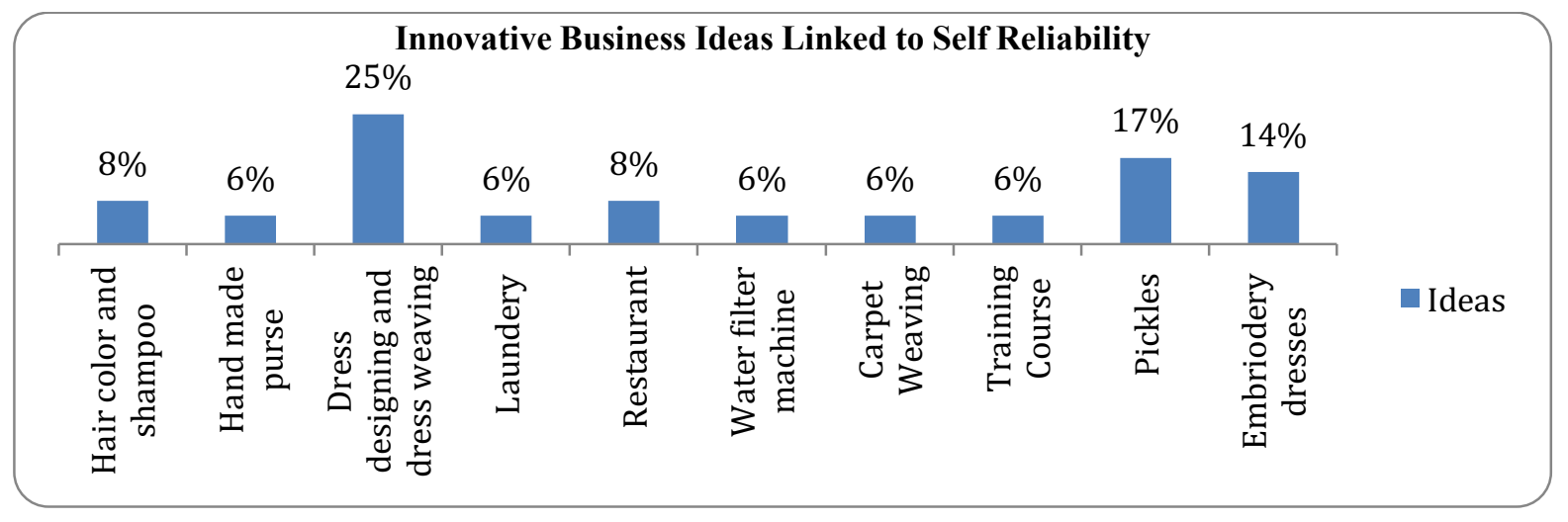


Chart 123: Innovative Business Ideas Leading to Students' Self-Reliability (Teachers' Perspectives in Urban and Rural Areas)

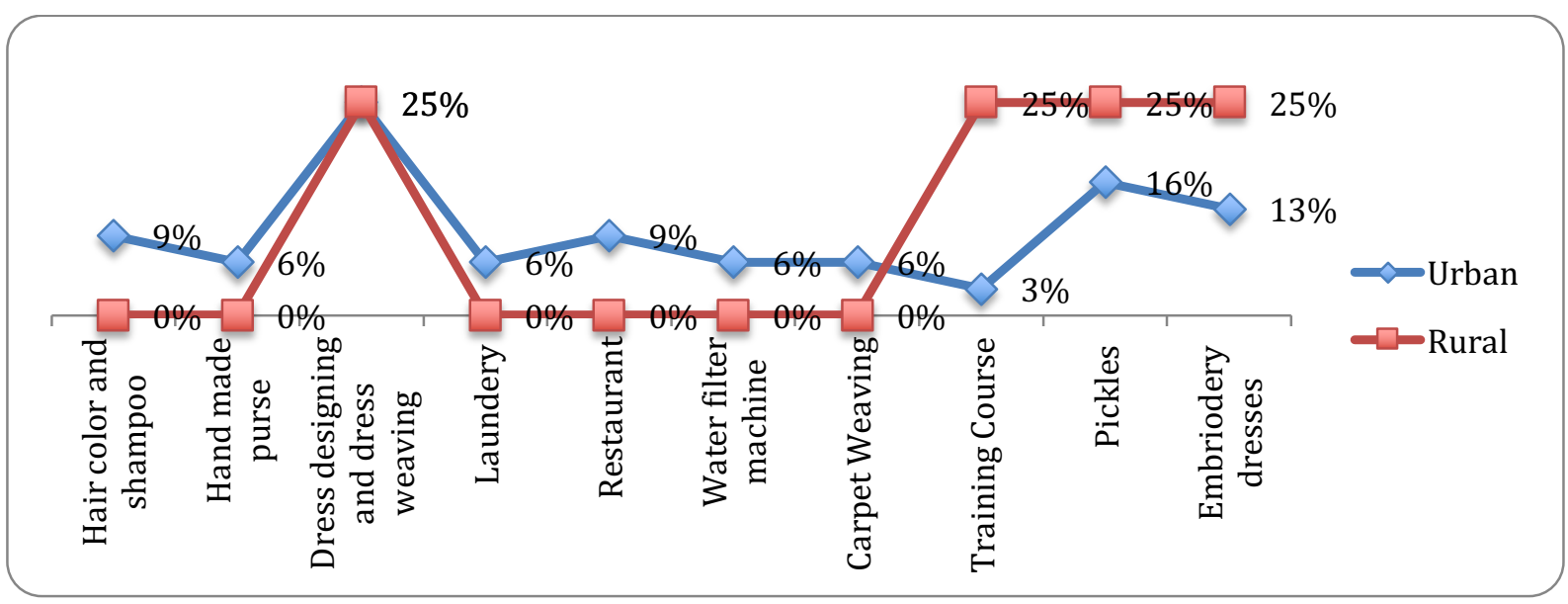

\section{Socioeconomic Aspects of Tashabos}

The teachers were also asked about the socioeconomic effects of the subject. Since the teachers were routinely teaching the subject and they were quite aware of the socioeconomic effects of the subject in the students' lives. Therefore, all the teachers positively replied that Tashabos is effective on students' socioeconomic lives. However, when the teachers were asked what effects has the subject on students' socioeconomic lives, $30 \%$ of the teachers mentioned that Tashabos assists in economic growth of the students. However, $26 \%$ of the teachers were talking about increase in self-reliability of the students and $10 \%$ mentioned that Tashabos reduces the unemployment rate among the students. However, when the data was analyzed for the location of the teachers, it was found that $32 \%$ of teachers in urban areas were in the favor of students' economic growth through the subject comparing to other $25 \%$ of teachers (in urban areas) thought that Tashabos helps in increased self-reliability of the students. The story was different for the teachers in rural areas because $38 \%$ of them mentioned that Tashabos increase self reliability of the students while $25 \%$ added that the subject combats poverty. The collected information was also analyzed for the gender types of the teachers and it was found that male Tashabos teachers were more in the favor of increase self-reliability by the subject (43\%) and $19 \%$ of them believed that Tashabos reduces the unemployment levels among the students. However, for $40 \%$ of the female teachers improving the economic conditions of the students was the sole socioeconomic effect of the subject and 17\% of the female teaches added that Tashabos reduces unemployment among students. However, the complete picture of the socioeconomic effects of the subject is portrayed in charts 124 , 125 and 126.

Chart 124: Socioeconomic Effects of Tashabos (Teachers' Perspectives)

\section{Types of Socioeconomic Effects of Tashabos Subject}

\begin{tabular}{|c|c|c|c|c|c|c|c|c|c|c|}
\hline & & $30 \%$ & & $26 \%$ & & & & & & \\
\hline $10 \%$ & $2 \%$ & & $8 \%$ & & $5 \%$ & $8 \%$ & $3 \%$ & $7 \%$ & $2 \%$ & \\
\hline 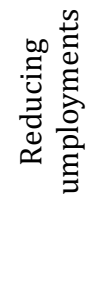 & 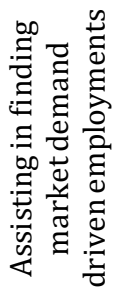 & 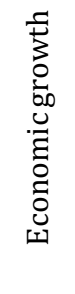 & 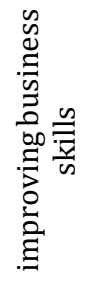 & 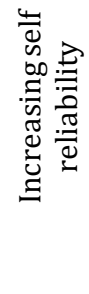 & 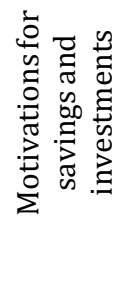 & 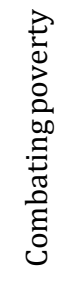 & 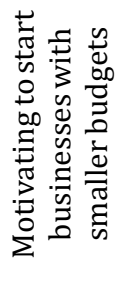 & 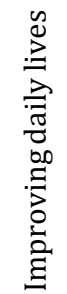 & $\begin{array}{l}\text { 品 } \\
\text { 䒕 } \\
\text { a }\end{array}$ & Effects \\
\hline
\end{tabular}


Chart 125: Socioeconomic Effects of Tashabos (Teachers' Perspectives in Urban and Rural Areas)

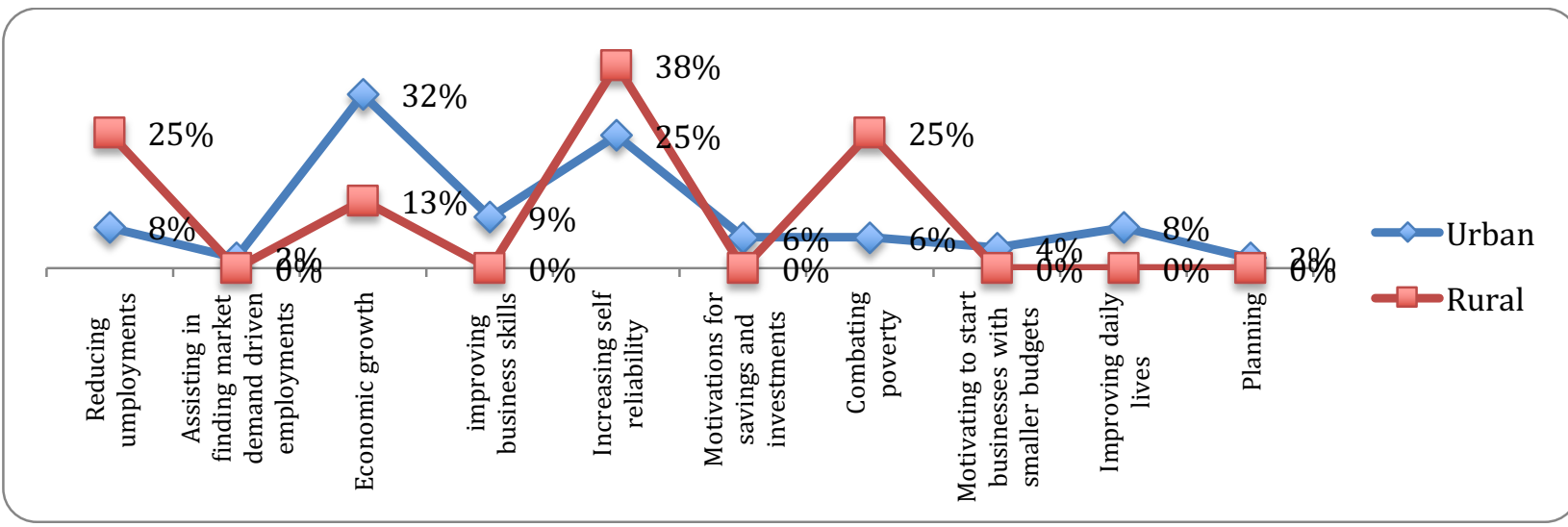

Chart 126: Socioeconomic Effects of Tashabos (Teachers' Perspectives according to Gender)

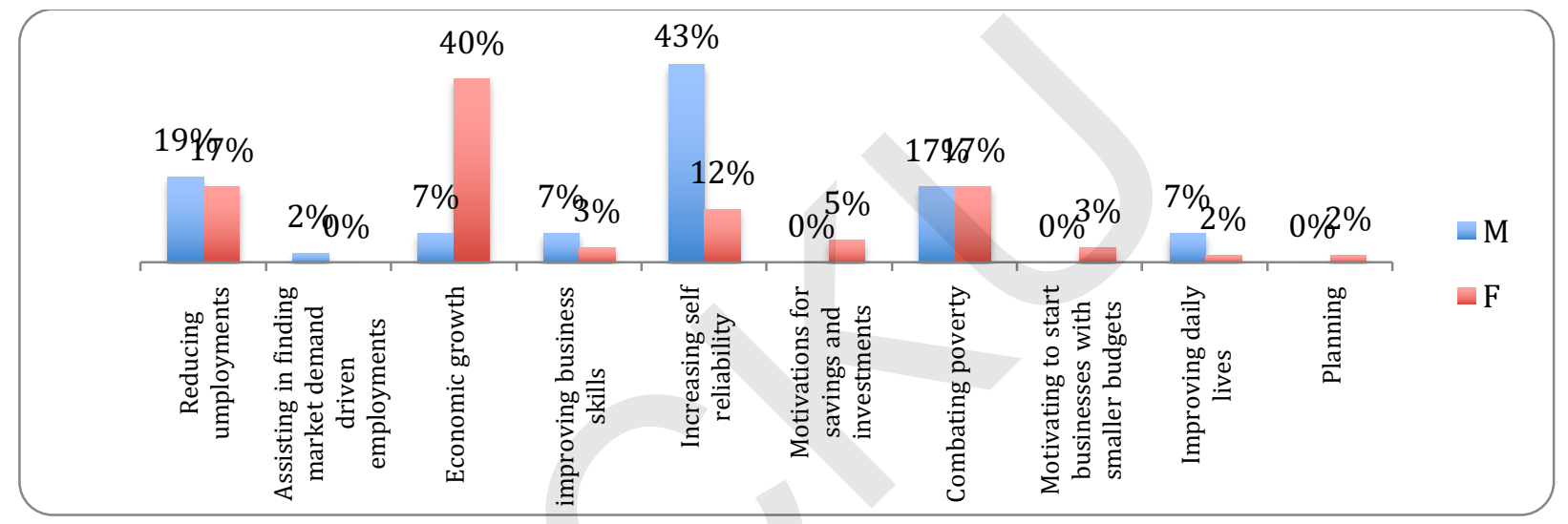

The teachers were, moreover, asked about the role of Tashabos subject in initiating/expanding a business. $71 \%$ of the teachers replied that Tashabos has been very effective during the stages of business initiation/expansion. At the same time, $17 \%$ of the teachers talked that Tashabos was an encouraging source for the student to initiate or expand a business. Similarly, $6 \%$ of the teachers added that Tashabos has taught the students on how to initiate a business with a smaller amount of budget. Chart 127 tells us more about the role of Tashabos in initiating or expanding a business.

Chart 127: Role of Tashabos in Initiating/Expanding a Business (Teachers' Perspective)

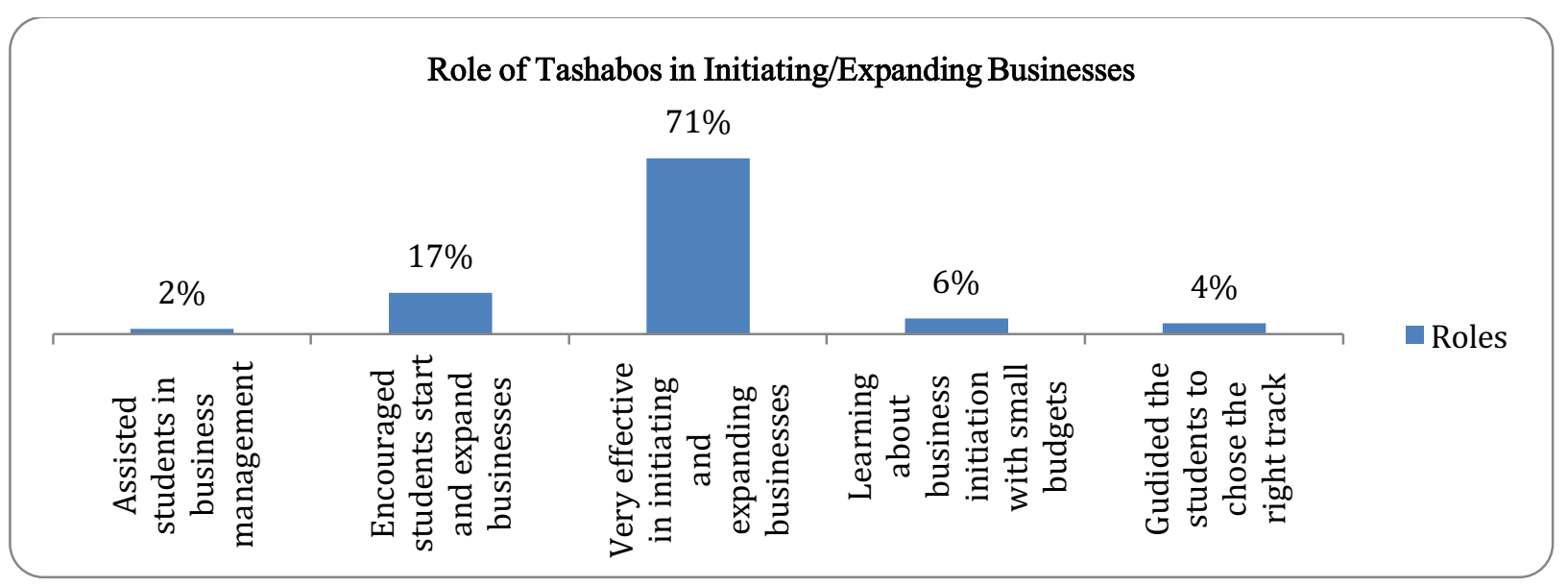




\section{Future of Tashabos}

In this section of the report, efforts were done to provide substantial evidence on the further expansion of the subject considering the importance of the subject both socially and economically in students' lives.

\section{Tashabos in National Education Curriculum}

As the subject has been being taught for nearly a decade and the ground level impact of the subject has been defined for the subject, it was very important to get the notions of Tashabos teachers regarding incorporation of the subject into the national curriculum. As expected $98 \%$ of the teachers showed their agreement with inclusion of the subject in the national curricula. It should be mentioned that $2 \%$ of the urban teachers were against the inclusion comparing to the entire number of teachers in rural areas and surprisingly, they were female teachers (2\%) opposed the inclusion comparing $100 \%$ of male teachers went in the favor of inclusion. Charts 128, 129 and 130 explain teachers' notions on inclusion of the subject into the national curriculum.

Chart 128: Tashabos Be Incorporated into the National Curriculum (Teachers' Perspectives)

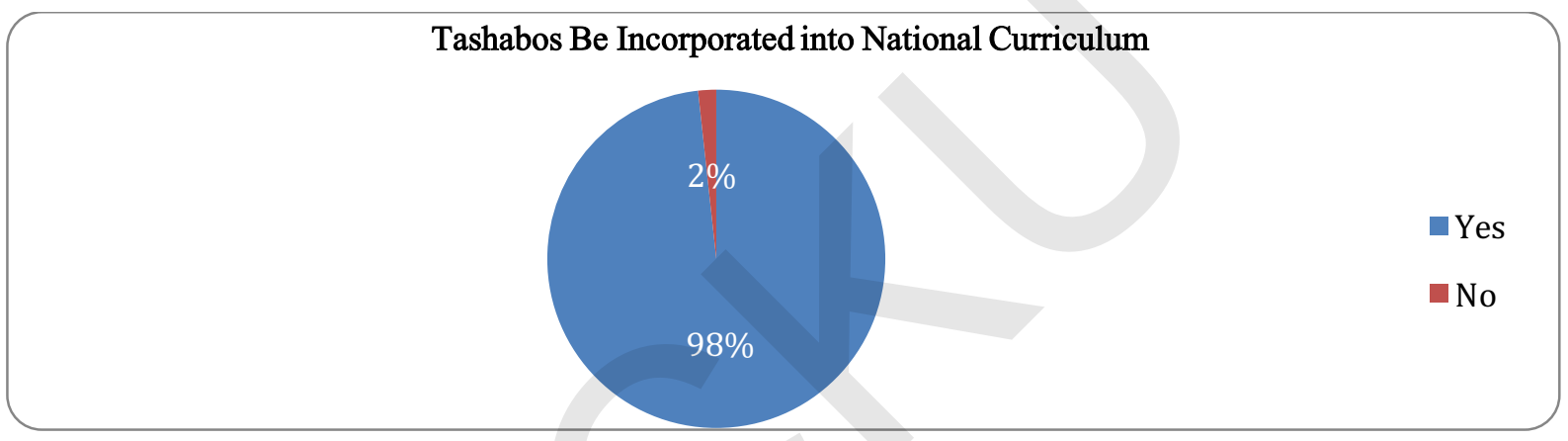

Chart 129: Tashabos Be Incorporated into the National Curriculum (Teachers' Perspectives in Urban and Rural Areas)

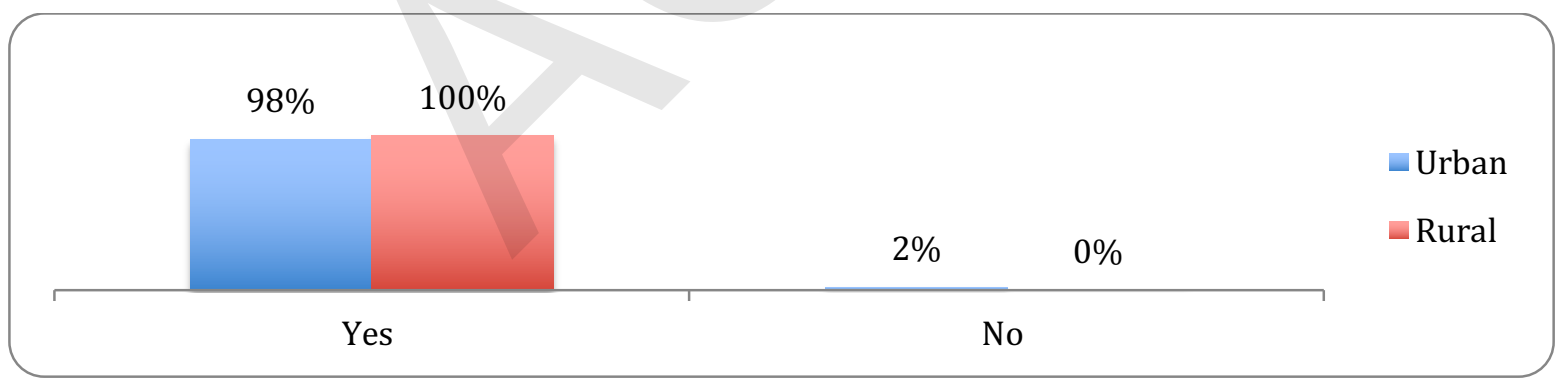

Chart 130: Tashabos Be Incorporated into the National Curriculum (Teachers' Perspectives according to Gender)

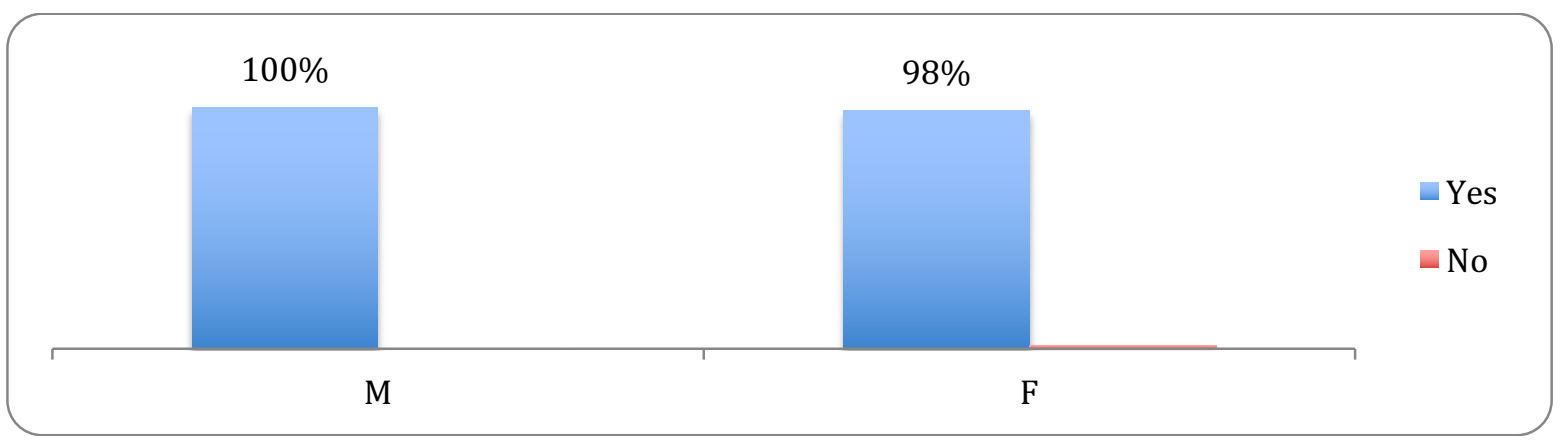


Since a very higher number of the teachers were in the favor of inclusion of the subject into the national curriculum, it was rationale to know about the reasons for inclusion. $38 \%$ of the teachers replied that Tashabos has been effective in increasing self-reliability of the students, while $30 \%$ of the teachers mentioned that Tashabos has practically benefited the students and another group of $11 \%$ of the teachers denoted that Tashabos has been more effective than other selective subjects. Chart 131 explains other reasons of including the subject no the national curriculum.

Chart 131: Reasons for inclusion of the Subject into the National Curriculum (Teachers' Perspectives)

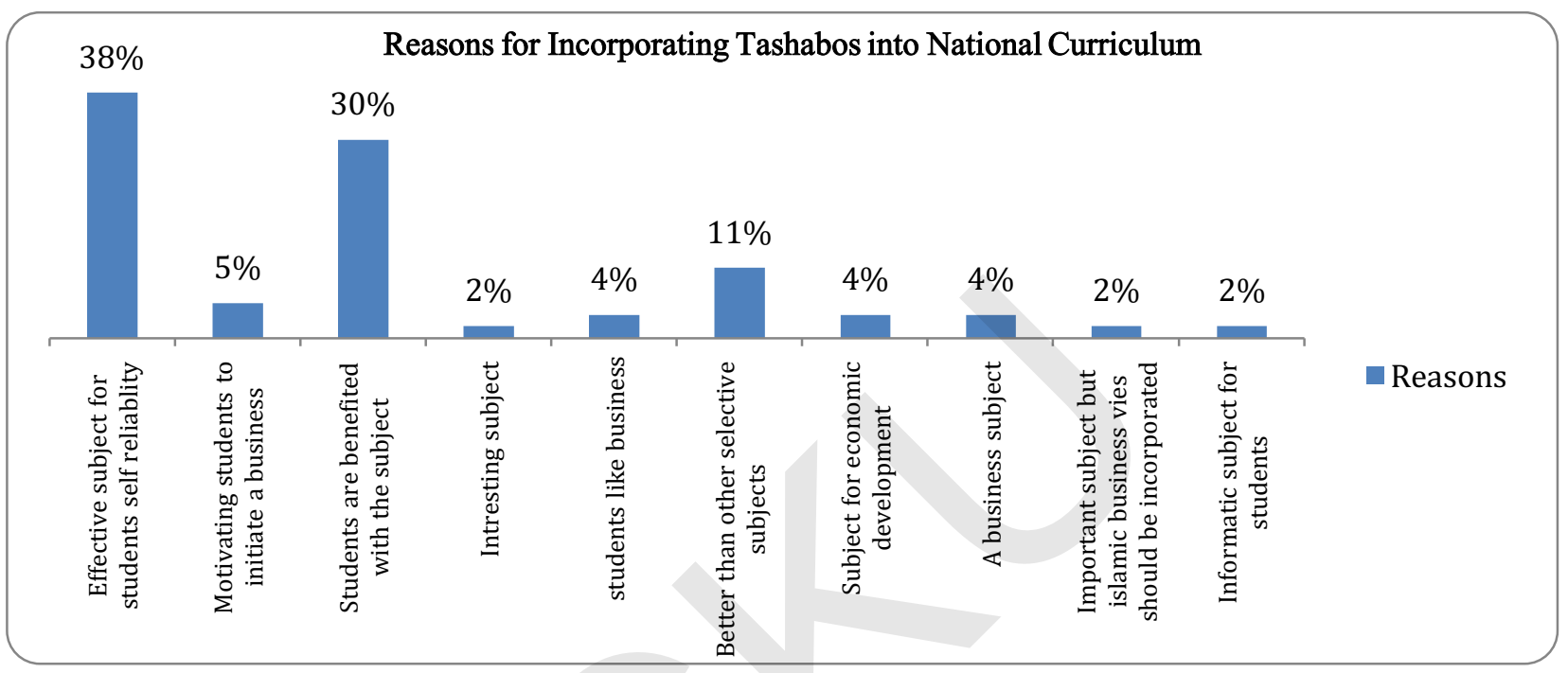

\section{Tashabos and Benefits:}

The teachers were also enquired if the teachers were benefited from teaching the subject down the years. $83 \%$ of the teachers mentioned that they were benefited. Among the teachers, urban teachers $(85 \%)$ were more benefited than rural teachers $(67 \%)$. However, more female teachers $(88 \%)$ than their male counterparts $(75 \%)$ have observed the benefits of teaching the subject. When the teachers were asked what benefits they have experienced, $58 \%$ of them replied that Tashabos had built their capacities in business. This reflects a very higher gain for the program because the program was able to spread important knowledge about business which linked with students. Charts 132, 133 and 134 talk more about teachers' benefits from Tashabos teaching.

\section{Chart 132: Benefited from Tashabos Teaching}

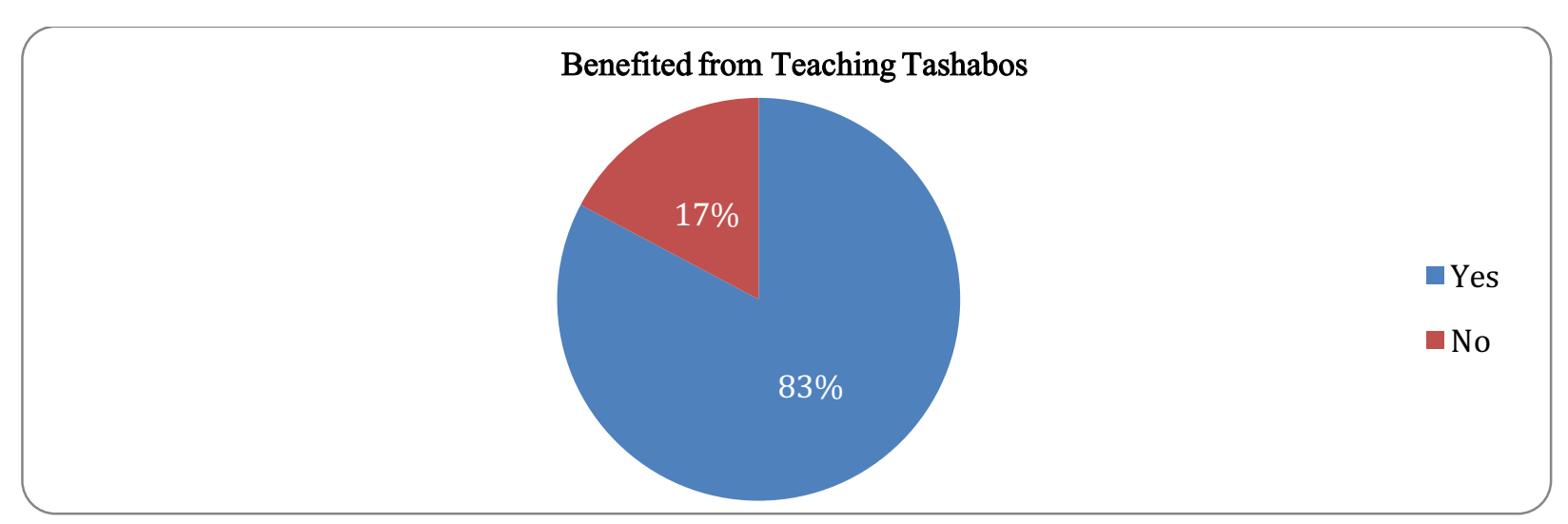


Chart 133: Benefited from Tashabos Teaching in Urban and Rural Areas

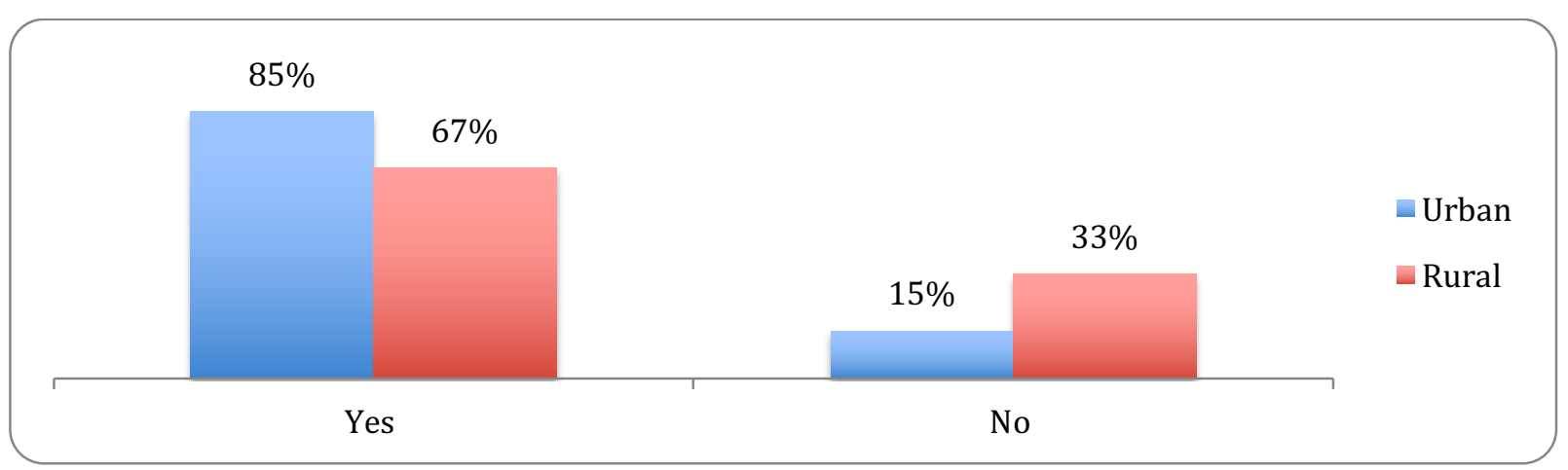

Chart 134: Benefited from Tashabos Teaching according to Gender

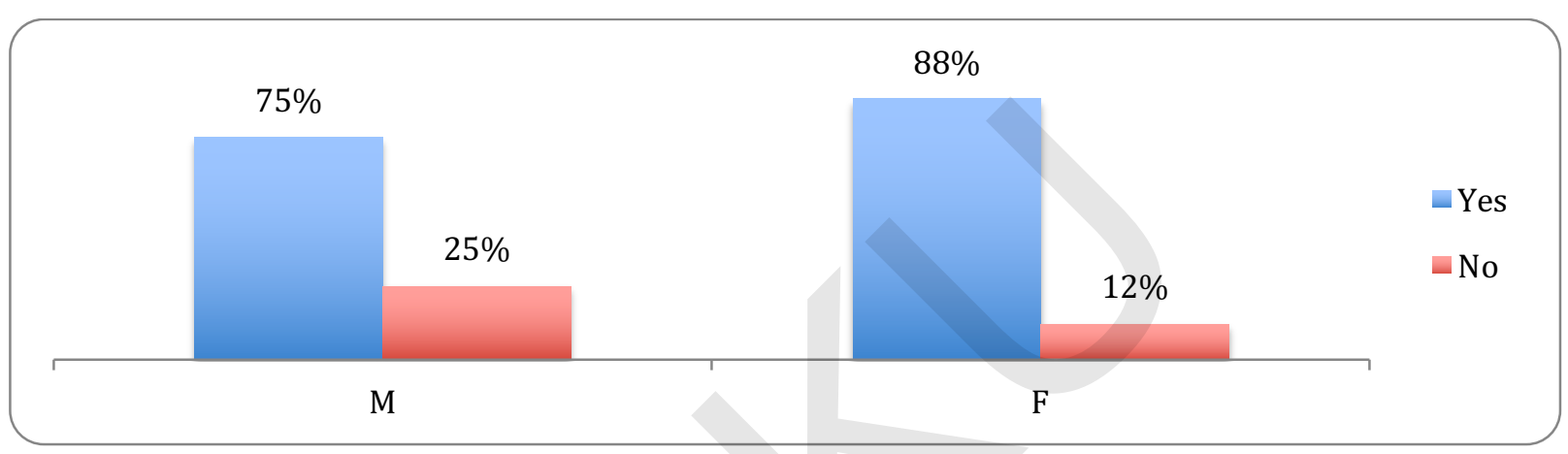

Teachers as Advocates of Tashabos

Finally, teachers were asked if they have ever shared any information about the subject. As expected $95 \%$ of Tashabos teachers have shared information about the subject with others. Higher number of rural teachers $(100 \%)$ comparing to urban teachers $(94 \%)$ have shared information about the subject. However, among the gender types, male teachers $(100 \%)$ have been prominent than their female counterparts $(95 \%)$ in spreading the information about the subject. Charts 135 and 136 give complete information about teachers who shared information about Tashabos and its importance with others.

\section{Chart 135: Shared information about Tashabos}

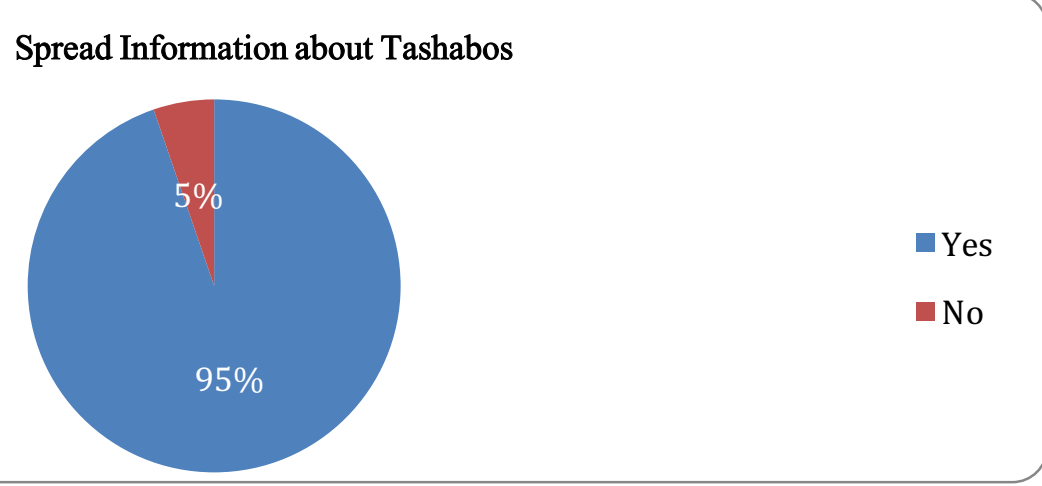


Chart 136: Shared information about Tashabos in Urban and Rural Areas

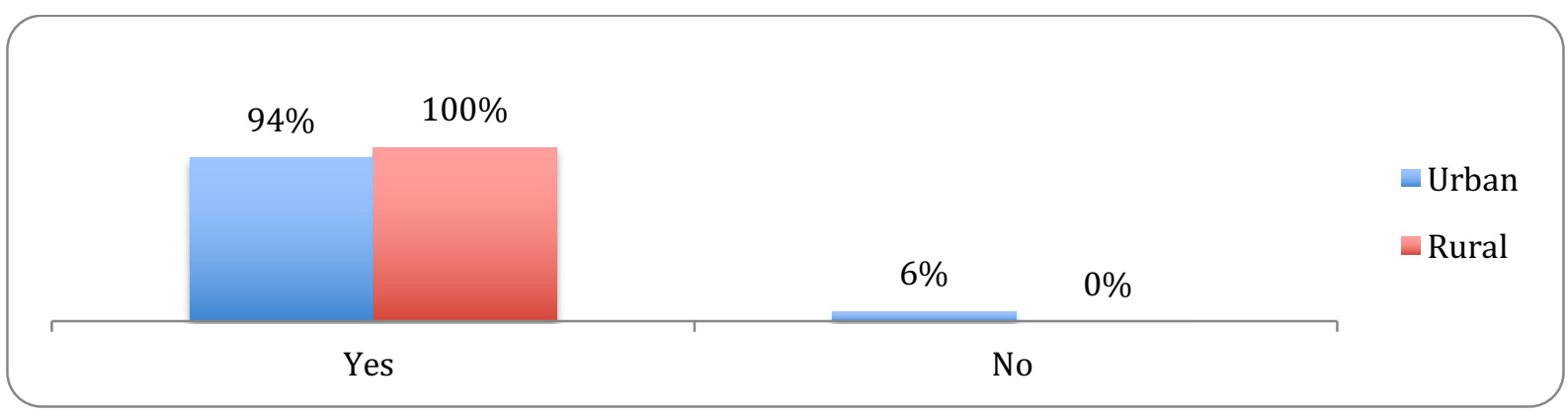

Finally, the teachers were asked what type of information they had shared about the subject and $50 \%$ of the teachers mentioned that they shared the contents and importance of the subject, while $27 \%$ of the teachers mentioned that they informed other how to initiate a business. Chart 137 explains the various types of information teachers have shared about Tashabos.

\section{Chart 137: Type of Information Shared about Tashabos}

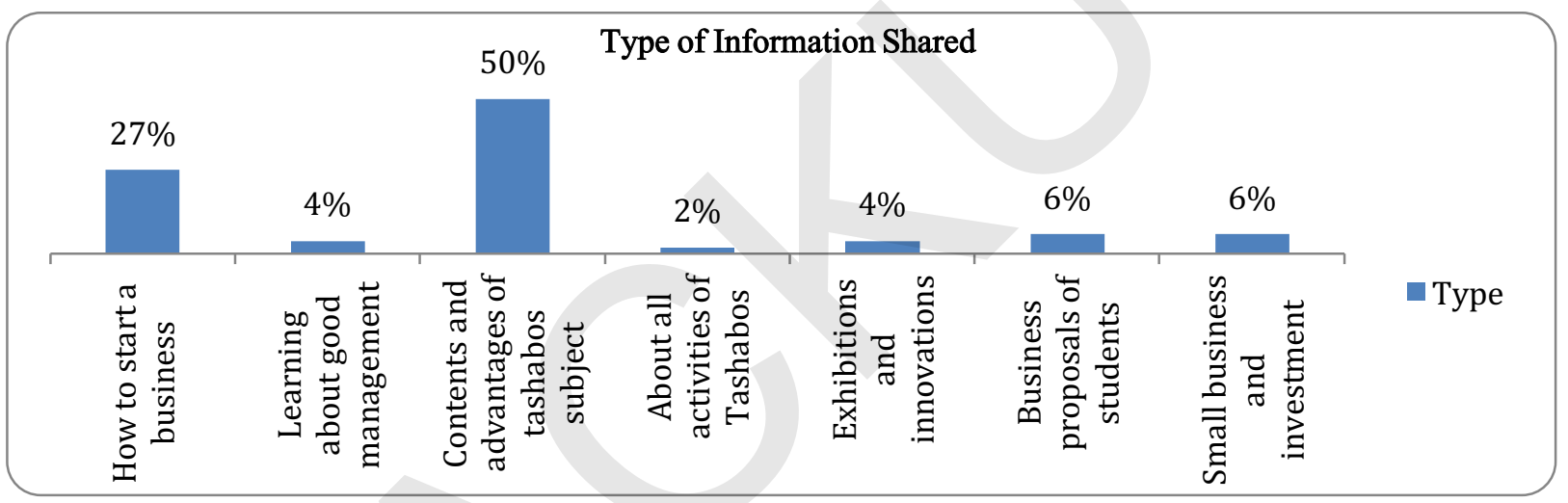

\section{Findings for School Administrations' Assessment:}

Since TEO has been supporting Tashabos subject teaching in 43 schools across the four provinces, it was considered vital to obtain the viewpoints of the 43 schools' administrations. Therefore, the administrations of the 43 schools were also among the target sample of the assessment. In addition, school administrations are the first recipients of any support from TEO and they are in an always contact with the Tashabos teachers. Consequently, their observations of the subject and the process would definitely enrich the program in a positive manner. During the assessment one of the administrations either principal or vice-principal of the school were interviewed. The objective behind targeting the administrations of the entire 43 schools was to collect a wide range of information about the subject from urban to rural areas.

After interviewing the school administration, the assessment would be able to know: a) the familiarity of the administrations with the subject; b) information about the support from TEO; c) keenness of Tashabos teachers with the subject; and d) perception of the administration on expansion of the program. To have collected information on the mentioned matters, a structured questionnaire was developed and administered. The collected data was analyzed from various angles. First of all the data was analyzed cumulatively regardless of sex and location. However, at the second step, the data was analyzed for gender types and then for location type of the respondents. At the later stage, the data was further analyzed for both male and female respondents in both urban and rural areas. Eventually, the data was analyzed provincially and according to districts. 


\section{General Characteristics of the Respondents:}

Sex:

Among the general characteristics of the respondents, gender types were firstly considered in the assessment. Of the total 43 schools, $37 \%$ (16) was boys while $63 \%(27)$ of them provided high school education for girls. In addition, it should be stressed of the total 43 schools, $36(84 \%)$ of the schools were in urban areas and the remaining $7(16 \%)$ schools were located in the rural areas. Therefore, it should be inferred that of the total administration assessment respondents $84 \%$ were from urban and $16 \%$ were from the rural areas. Considering the majority of the girls' high schools, it was expected having higher number of female school administrations, but the opposite was true for the gender types of the school administration respondents. 54\% of the total school administration respondents were males while the remaining $46 \%$ were of female gender. It should be mentioned that of the $54 \%$ male administration respondents, $41 \%$ were in urban while $13 \%$ were in rural areas. On the other hand, $43 \%$ of the total female respondents were from the urban areas whereas the remaining $3 \%$ were taking the charge of their schools in rural areas. In addition, gender distribution of the respondents didn't follow a similar trend in urban and rural areas as majority of the respondents $(52 \%)$ of the urban areas were females, but $83 \%$ of the administration respondents in rural areas were males. It should be discussed that female educated citizens in urban areas outnumbers female educated citizens in rural areas. After deeper analysis of the data, it was found that female administrators were higher in Kabul city $(65 \%)$ and Estalif district $(100 \%)$ comparing to male administrators in the respective areas. On the other hand, more male administrators were responsible for their respective schools in Nangarhar (75\%), Bamyan (80\%), Paghman district (100\%), Charasyab district (100\%), Shakardara district (100\%) and Guldara district (100\%) to female administrators. Charts 138 and 139 add more light on the gender disaggregation of the administration respondents.

\section{Chart 138: Gender Disaggregation of the Administration Respondents}

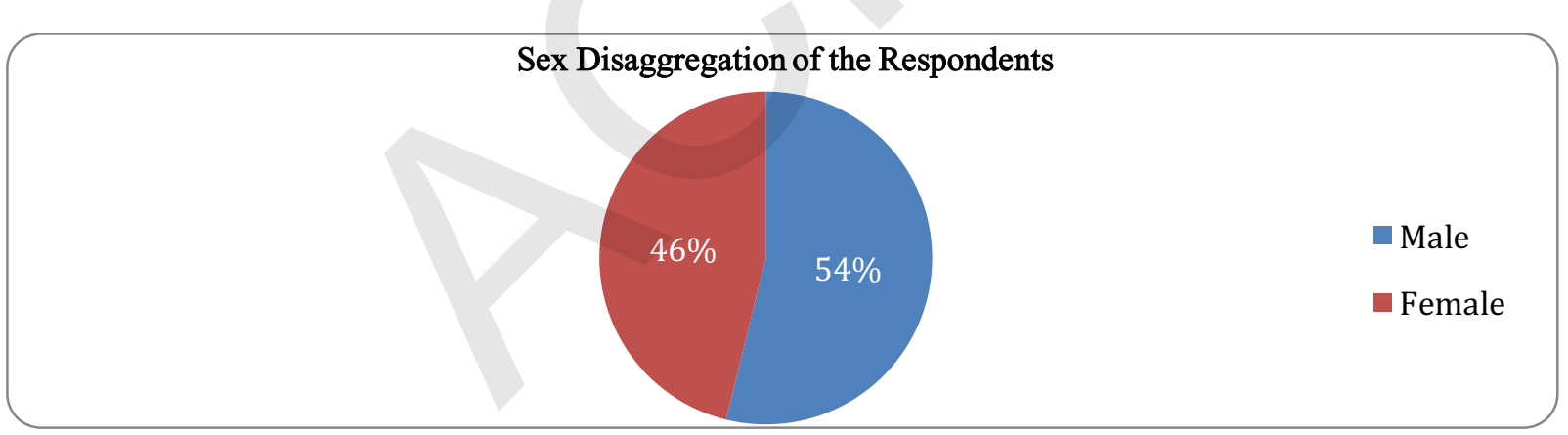

Chart 139: Gender Disaggregation of the Administration Respondents in Urban and Rural Areas

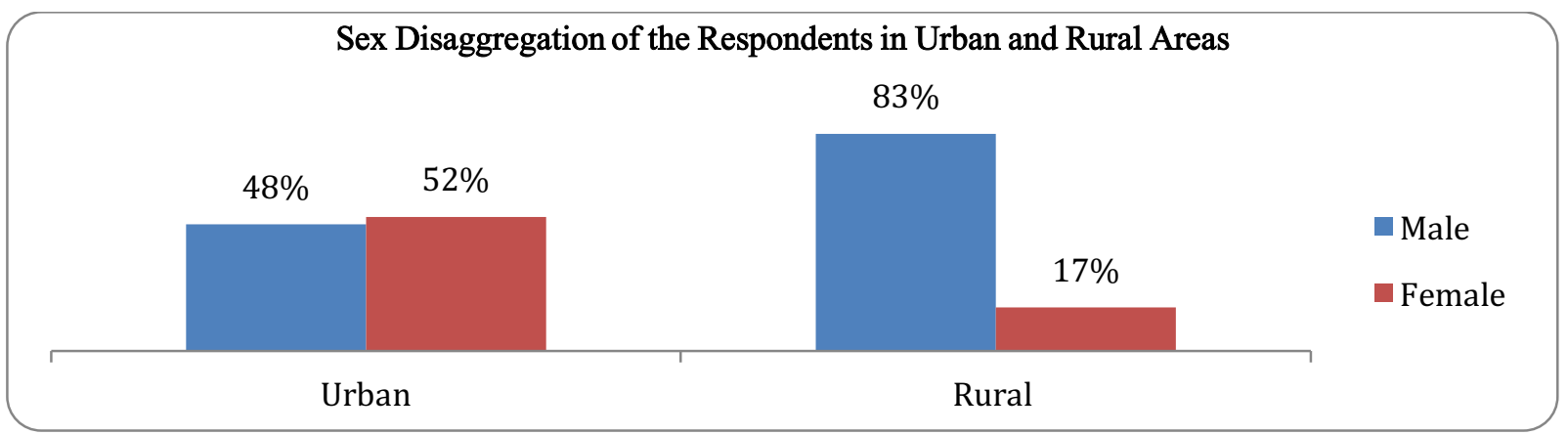

Of the total $77 \%$ of the principals, $64 \%$ of them were in urban areas while only $13 \%$ of them were in the rural areas. Similarly, larger portion of the vice-principals were in urban areas $(15 \%)$ and smaller portion 
in rural areas $(3 \%)$. Eventually, it should be stated that head masters $(5 \%)$ were only interviewed in the urban areas. Therefore, it can be said that $84 \%$ of the respondents were from urban and the remaining $16 \%$ were from the rural areas. However, when the respondents' occupations were analyzed in terms of their locations, it was discovered that $76 \%$ of the administrator respondents in urban areas were principals of their respective schools whereas the percentage of principals among rural respondents was higher at $83 \%$. Conversely, the number of vice-principals and head teachers interviewed was relatively higher in urban areas (18\% for vice-principals and $6 \%$ for head teachers) comparing to rural areas $(17 \%$ for vice-principals and $0 \%$ for head teachers). Charts 140 and 141 show the occupation distribution of the administrator respondents in urban and rural areas.

\section{Chart 140: Occupation Distribution of Administrator Respondents in Urban and Rural Areas}

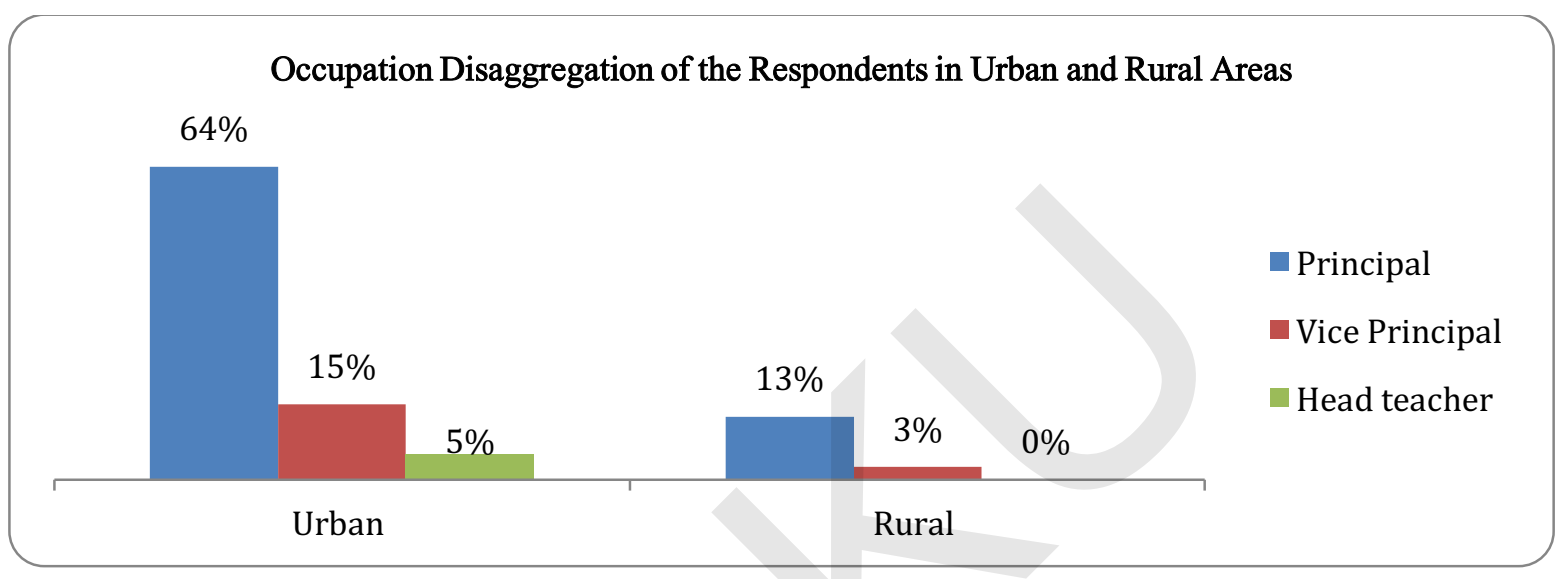

Chart 141: Occupation Distribution of Administrator Respondents in Urban and Rural Areas

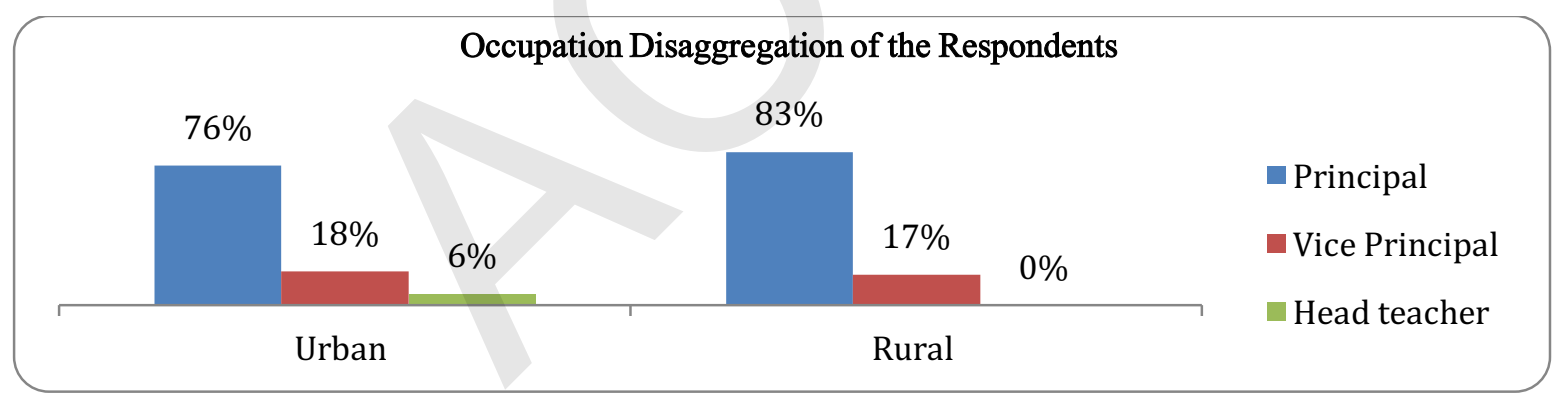

\section{Tashabos and Schools' Administrations}

\section{Familiarity with Tashabos}

TEO has been supporting teaching of Tashabos subject in 43 schools across 4 provinces since 2014 . TEO has provided support in various forms and these supports have been managed in coordination with the administrations of the respective 43 schools. Therefore, the assessment deemed important to get information about the subject from the school administrations. Firstly, acquaintance of the school administrations was inquired and administrations from the entire 43 schools were asked if they were familiar with the subject. Importantly, the administrations within all the 43 schools were familiar with the subject. It is considered very important as a success of the program in terms of spreading knowledge about the subject and provided support from TEO. Therefore, it can be stated that school administrations both male (100\%) and female (100\%) and from both urban areas (100\%) and rural areas (100\%) knew about the subject. Chart 142 summarizes familiarity level of the school administrations with Tashabos. 


\section{Chart 142: Familiarity Level of the School Administrations from Tashabos}

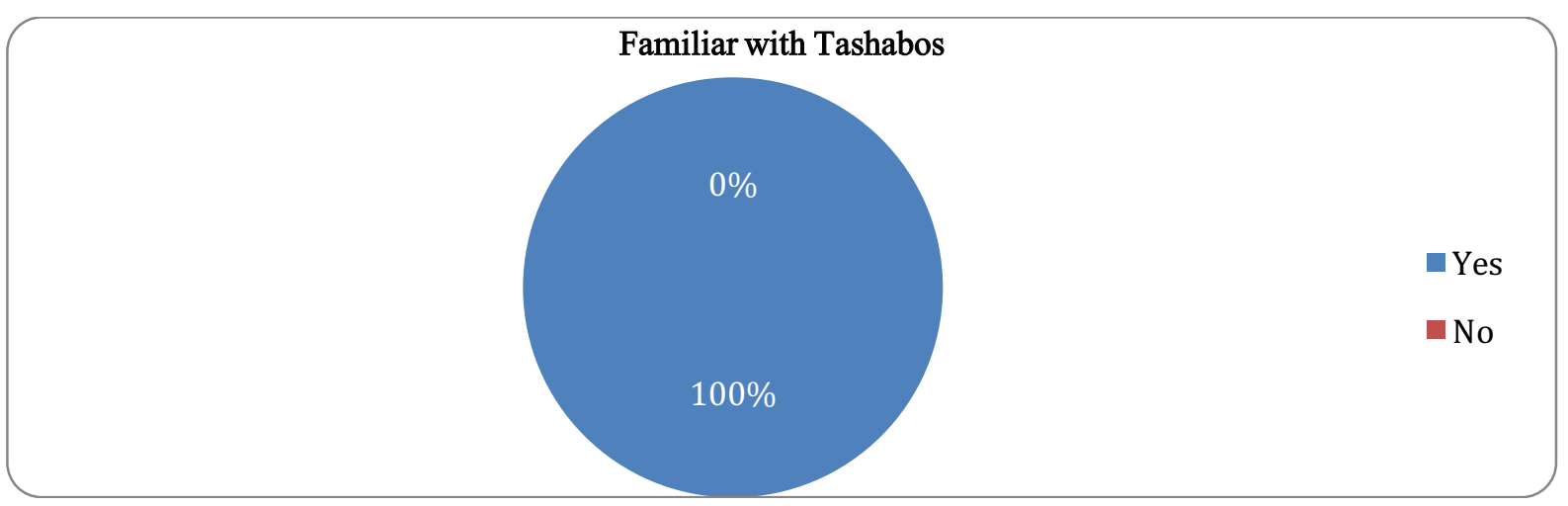

After knowing that the administrations in the entire 43 schools knew about the subject, they were all asked what information they could share about the subject. The majority of the school administrations (38\%) replied that Tashabos is a subject which teaches business and employment to the students. The second bulk of the school administrations (28\%) stressed that the subject encourages students to initiate a new business even with smaller amounts of budgets. However, nearly two tenth (18\%) mentioned that Tashabos helps students become self-reliable and business professionals. It should be mentioned that $84 \%$ of the school administrations provided very relevant information about the subject because all the viewpoints were somehow linked the importance of the subject with the business and employment for the students. On the other hand, the remaining $16 \%$ of the school administrations were talking about "Tashabos deals with business proposal competitions $(10 \%)$ ", "once a week teaching of the subject at schools $(3 \%)$ ", and "Tashabos talks about investments, small business and capital $(3 \%)$ ". These comments can be referred to more general rather than specific notions about the subject. However, when analyzing the data for school administrations of urban and rural areas, it was found that opposing views were presented by urban and rural areas' administrations. Within urban areas, majority of the school administrations $(42 \%)$ thought that Tashabos teaches business and employment to the students, while $27 \%$ of them believed that the subject encourages the students to initiate a new business with smaller amounts of budgets and only $15 \%$ of the school administrations were in the favor of "Tashabos helps students become self-reliable and business professional. On the other hand, the topmost views from the rural areas' school administrations were motivating students initiate a business with smaller amounts of budges (33\%); encouraging students to become self-reliable and business professional (33\%); teaching business and employment to the students (17\%); and dealing with business proposal competitions $(17 \%)$. It shows that same ideas about the subject were shared from the school administrations, but the percentage of the administrations varied for both urban and rural areas. Charts 143 and 144 shows the complete information about the information shared about the subject from the school administrations. 


\section{Chart 143: Shared Information about the Subject}

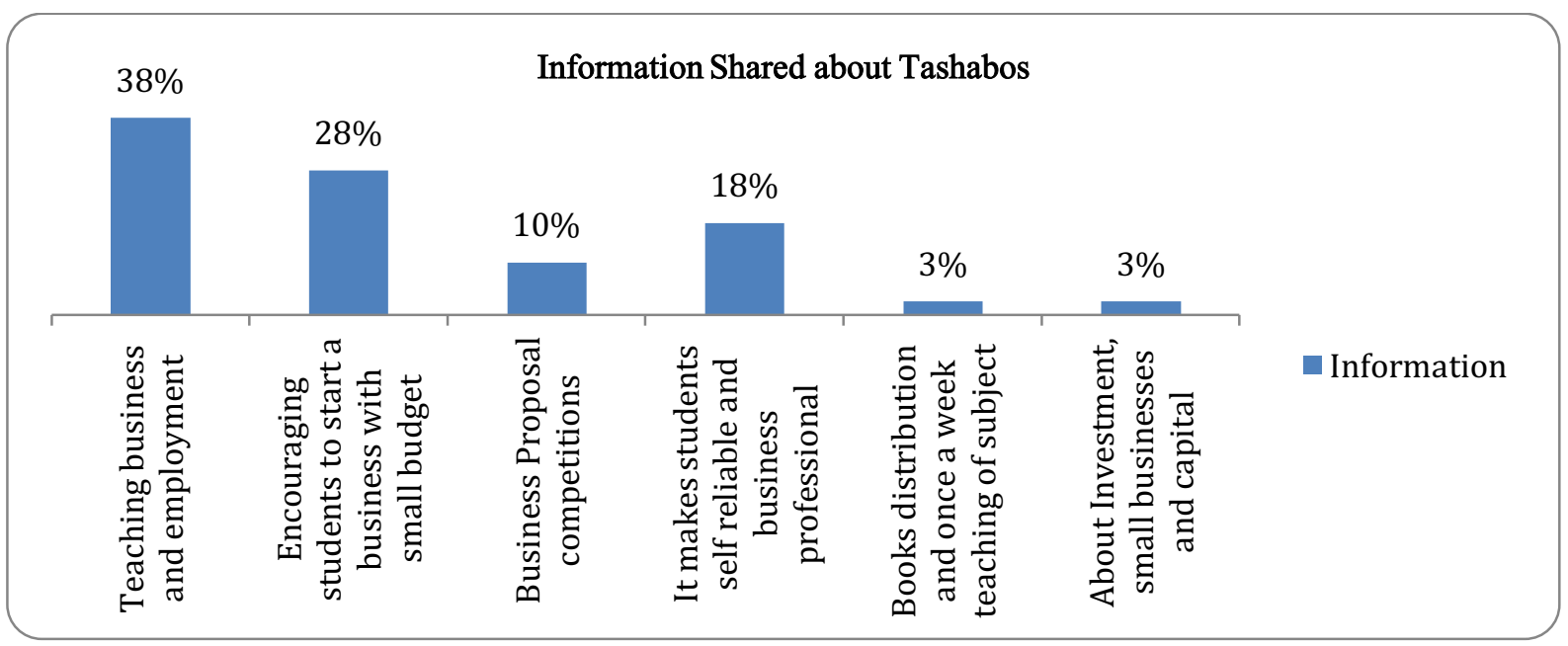

Chart 144: Shared Information about Tashabos from Administrations in Urban and Rural Areas

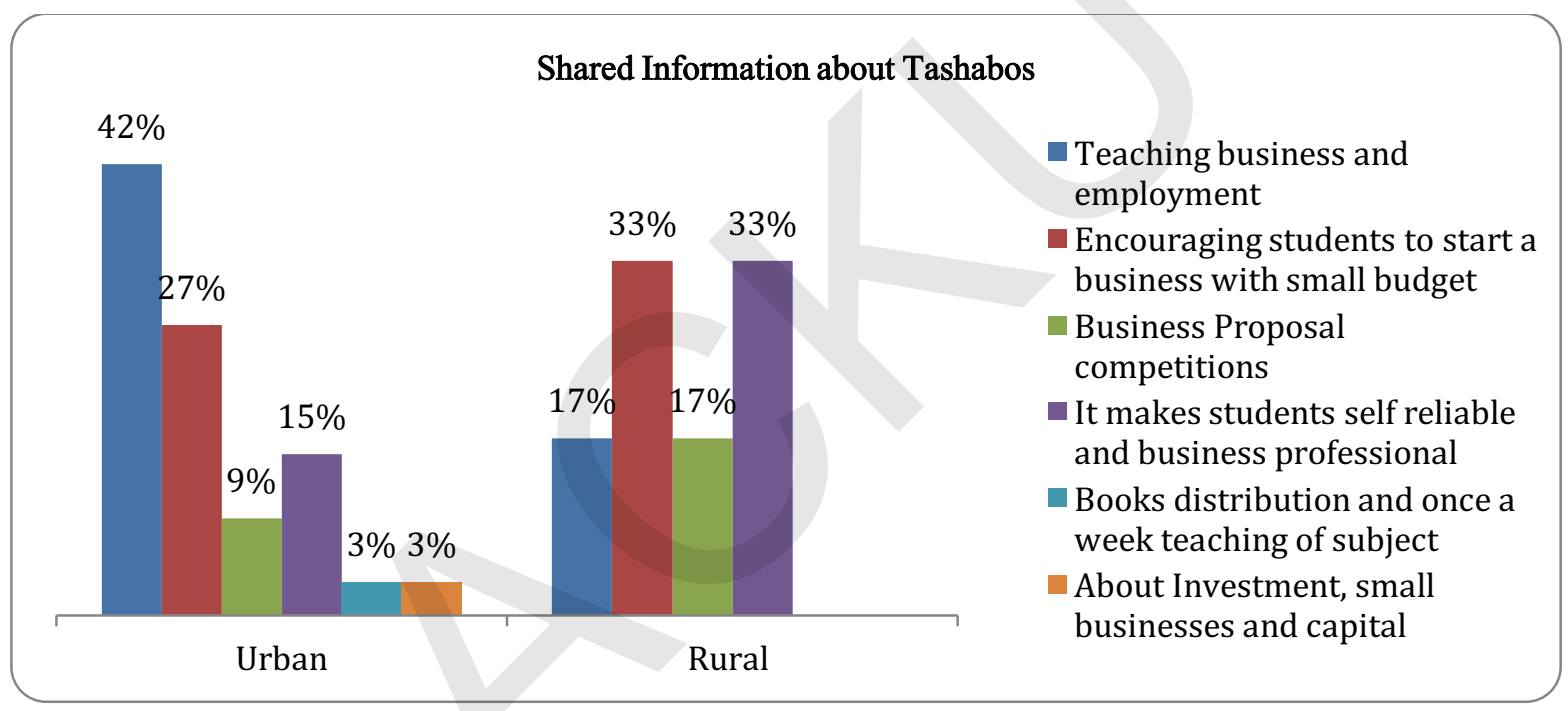

\section{Observations from Tashabos Teaching}

As mentioned all the school administrations knew about Tashabos and they shared their viewpoints on the subject as well. Now, since the school administrations are responsible to look over all the aspects including teaching within their respective schools, they were inquired if they have had participated in any of the Tashabos Teaching classes or if they have had observed Tashabos teaching in the classes. Fortunately, Tashabos was taught in front of over nine tenth (92\%) of the school administrations. It is considered very vital for the improvement of the program because if any deficits in the teaching methodologies exist, the administrations would tend to resolve it on their own utilizing their years of experiences in teaching. In case the problems in teaching the subject were observed to be very severe, TEO could be contacted for the improvements in the teaching so that the ultimate objective of Tashabos teaching is obtained. On the other hand, only $8 \%$ of the school administrations have not entered any Tashabos teaching class. However, the reasons behind why the classes were not observed were not sought by the surveyors, but it was witnessed that in some of the schools, the most experienced teachers are engaged in teaching the subject. Therefore, the need to observe the classes was brought down to nil for the school administrations. Of the total observed Tashabos teaching classes (92\%), 79\% were in urban areas, while the remaining $13 \%$ were in rural areas. At the same time, $5 \%$ school administrations in urban areas and 3\% in rural areas have considered observation of Tashabos teaching unimportant. Chart 145 explains the percentage of school administrations observed Tashabos teaching. 


\section{Chart 145: Percentage of School Administrations Observed Tashabos Teaching}

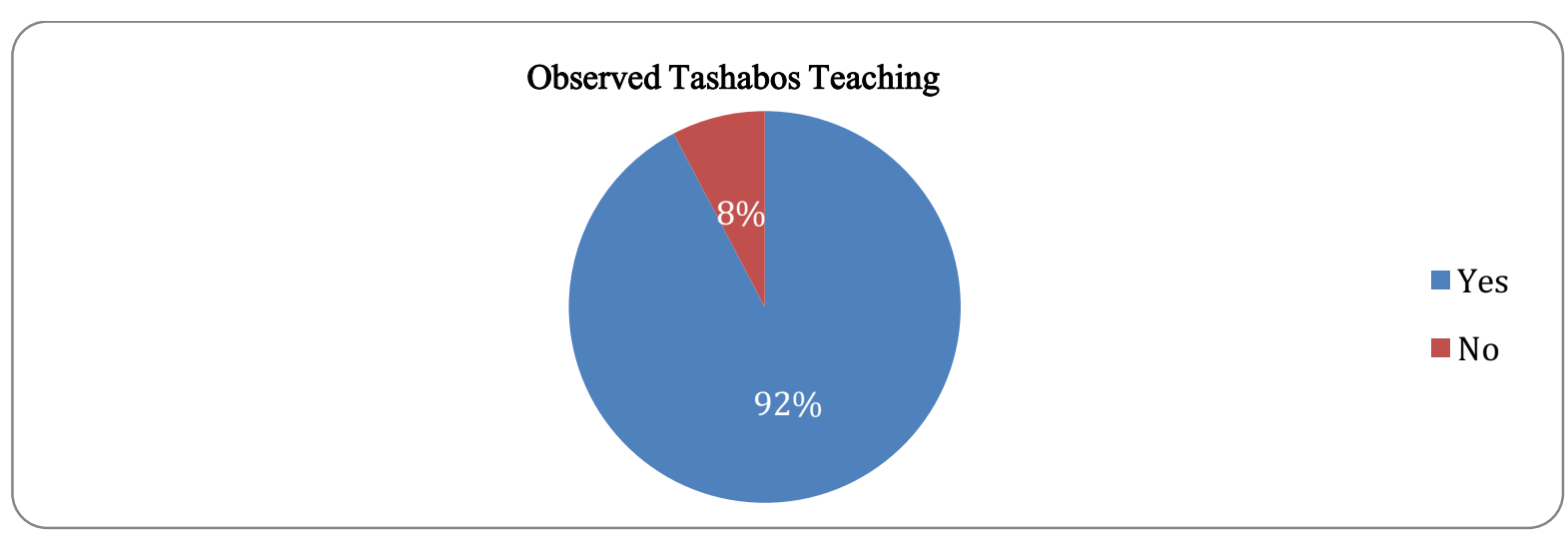

Coming into the location of the respondents, it was found $94 \%$ of the school administrations in urban areas have visited Tashabos teachings and have provided their feedbacks. On the other hand, the percentage of school administrations has dropped to $83 \%$ in rural areas who have observed Tashabos teaching in the classes. Therefore, it can be stated that lower number $(6 \%)$ of school administrations have not observed Tashabos teaching in urban areas comparing to $17 \%$ in rural areas. At the second step, the data was analyzed for gender types of the school administrations and it was found that more female (94\%) school administrators have observed Tashabos teaching comparing to male school administrators $(90 \%)$. However, when talking about both gender and location, it was found $100 \%$ male administrators in urban areas and $100 \%$ female administrators in rural areas have observed Tashabos teaching. Charts 146, 147 and 148 give the complete overview of the percentage of school administrations observed Tashabos teaching.

Chart 146: School Administrations Observed Tashabos Teaching in Urban and Rural Areas

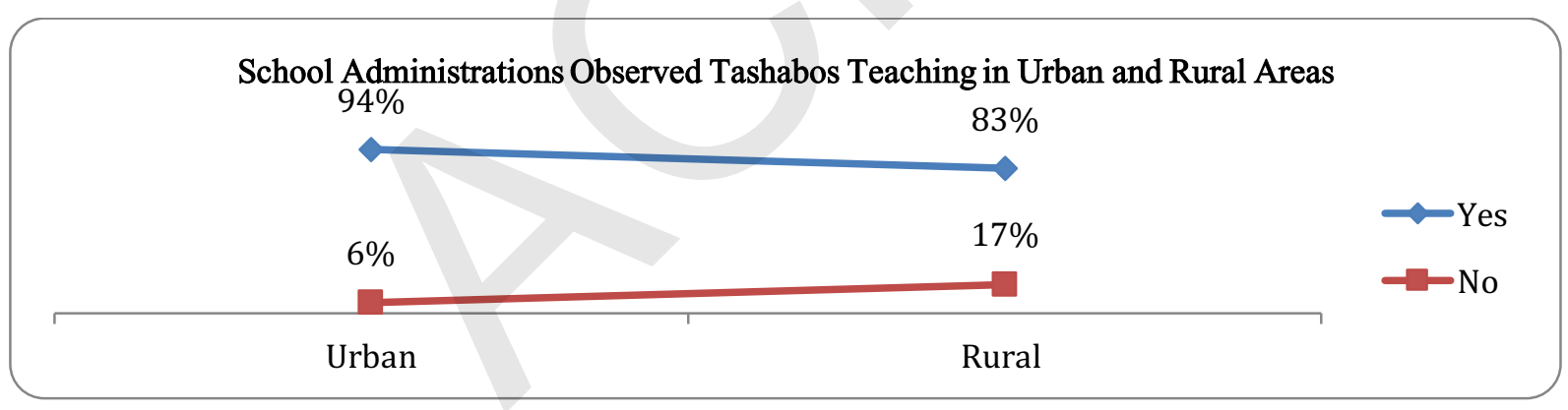

Chart 147: School Administration Observed Tashabos Teaching According to Gender

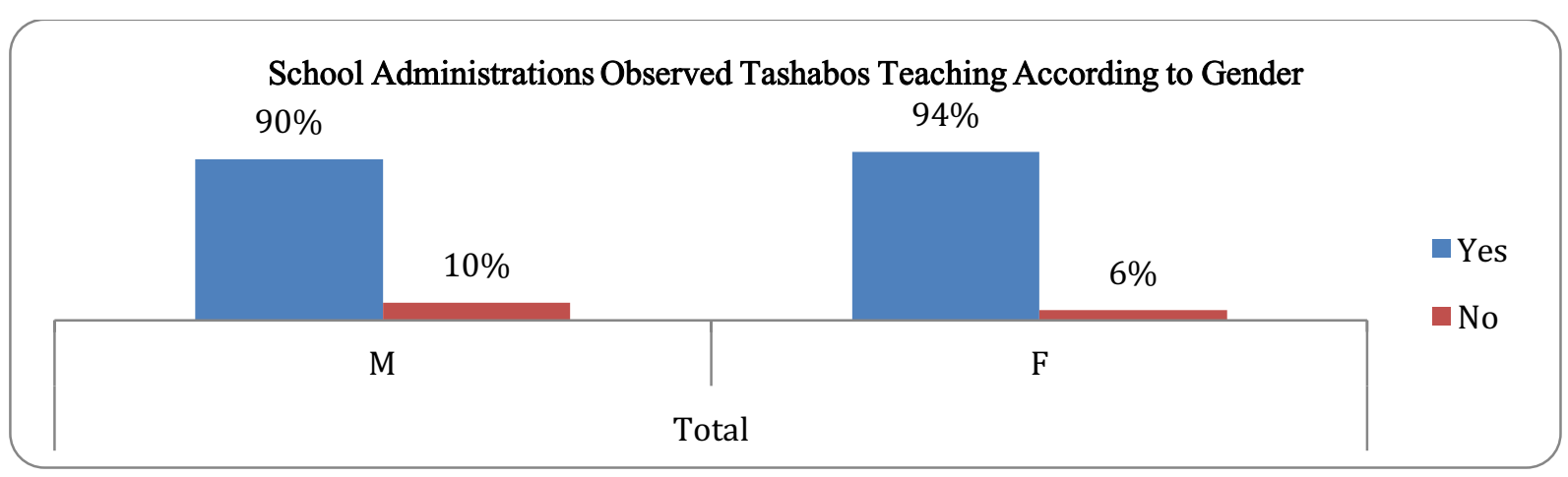


Chart 148: School Administrations Observed Tashabos Teaching According to Gender and Location

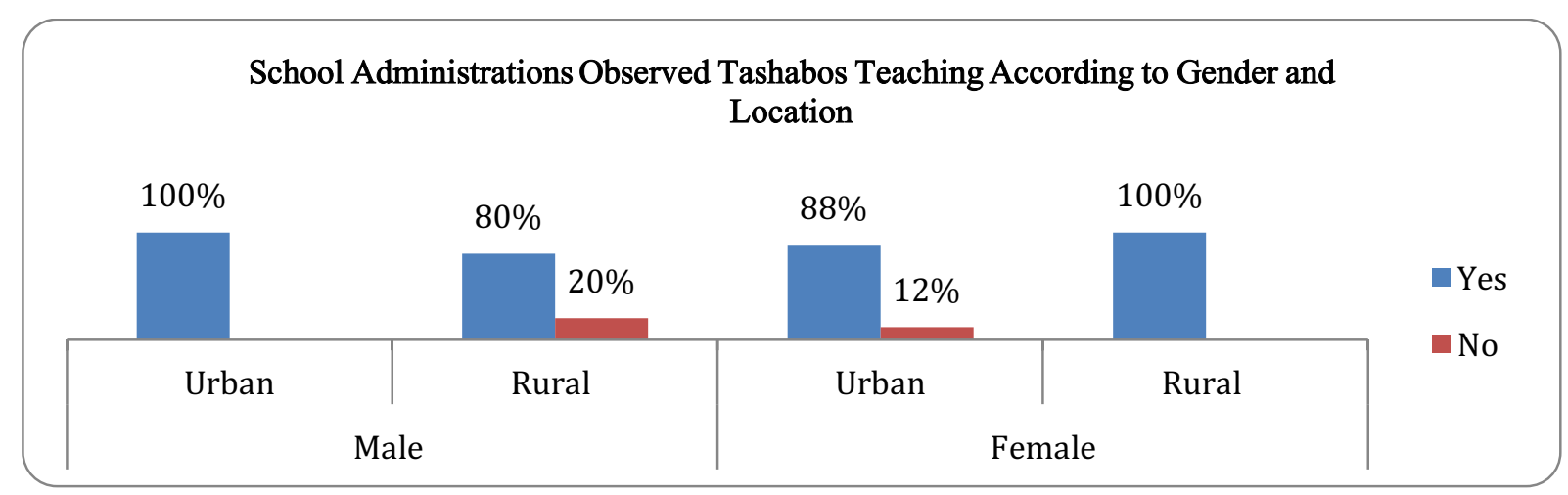

When over nine tenth $(92 \%)$ of the school administrations observed teaching of the subject within their respective schools, the administrations were asked about the quality of teaching. Administrations' viewpoints to this question have been considered vital for TEO in further improving the teaching qualities during coming years. The administrations were provided with the three options as far as teaching qualities of the subject is concerned: weak and ineffective; moderate and somehow effective and strong and effective. However, none of the administrations have backed the first option for the question because all of the administrations had something about the effectiveness of the subject in mind. Nearly, seven tenth $(69 \%$ ) of the school administrations (64\% in urban areas and $5 \%$ in rural areas) believed that Tashabos teachers had strong teaching skills of the subject and, moreover, they thought that teaching of the subject has been effective for the students. On the other hand, the remaining $31 \%(22 \%$ in urban areas and 9\% in rural areas) of the school administrations were talking about moderate teaching skills and somehow effectiveness of the subject. The data was further analyzed for the location of the respondents from administration assessment and it was found administrations of the urban schools mentioned the teaching qualities of the subject is strong and effective (74\%) comparing to $40 \%$ in rural areas. However, the reverse of the story was true for the second option to the question as exactly $60 \%$ of the school administrations in rural areas were in the favor of moderate teaching skill with somehow effectiveness of the subject, while the rate had decreased to $26 \%$ for school administrations of rural areas. Charts 149 and 150 depicts a complete overview of the viewpoints of the respondents for the quality of Tashabos teaching.

\section{Chart 149: Quality of Teaching Tashabos in Schools}

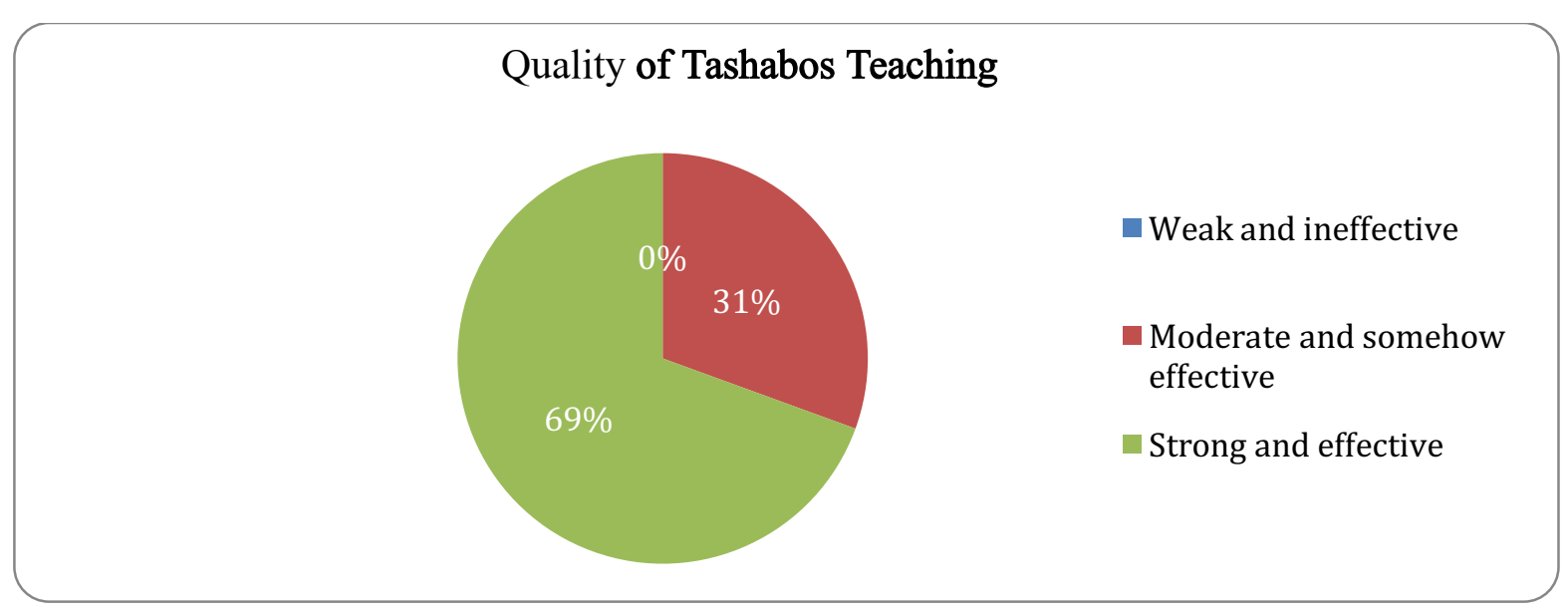




\section{Chart 150: Quality of Teaching Tashabos in Urban and Rural Areas}

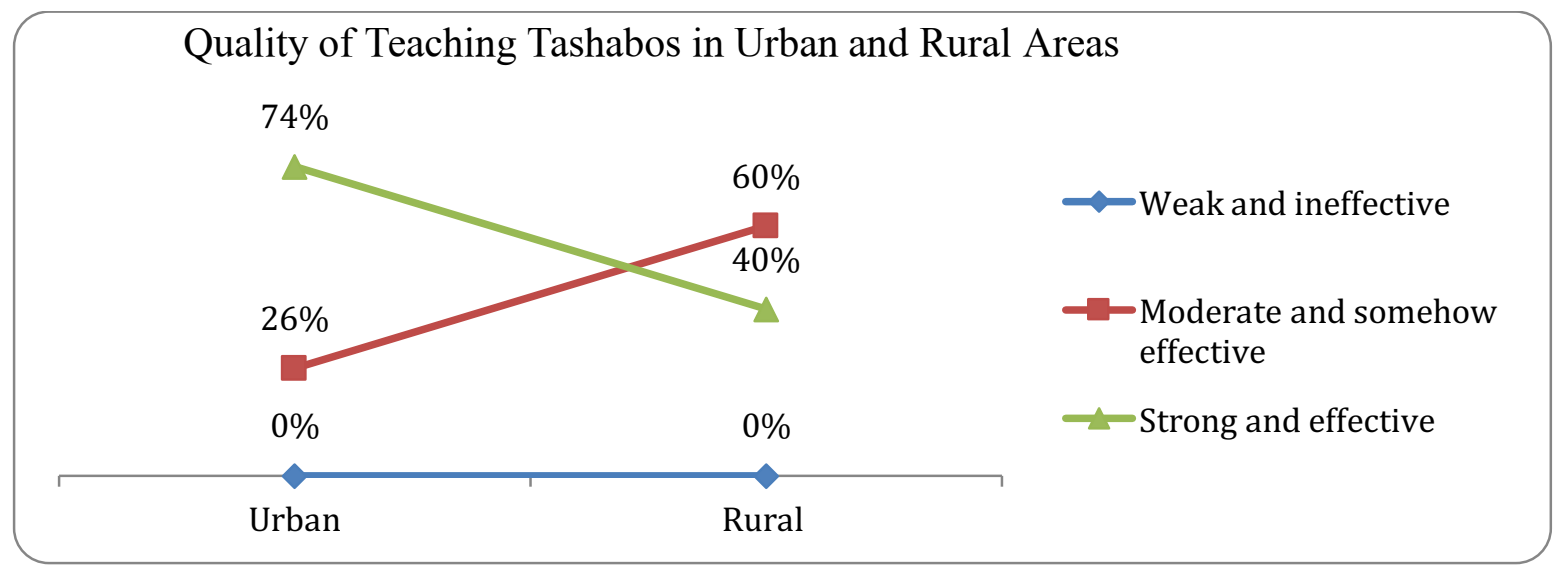

At the later stages, the data was analyzed for the gender types of the respondents and it was found that quality of teaching Tashabos was moderate and somehow effective for $53 \%$ male school administrators comparing to $47 \%$ going with strong and effective. However, the story was different for female administrators because nine tenth $(90 \%)$ of the female administrators thought that teaching Tashabos is strong and effective for their students, while a minor $(10 \%)$ of the respondents said teaching Tashabos is moderate and somehow effective. On the other hand, the study explored the quality of teaching Tashabos among respondents according to both their gender and location. It was found that male respondents in urban areas (69\%) responded that quality of teaching Tashabos is strong and effective, while higher number of male respondents in rural areas $(75 \%)$ answered the question with moderate and somehow effective. However, for majority of female respondents in both urban (80\%) and rural (100\%) areas the quality of teaching was admired as strong and effective for the students. Beyond gender analysis, the data was further analyzed for target areas and it was discovered that school administrators in rural areas were entirely satisfied with the quality of teaching the subject as they responded strong and effective for quality of teaching. However, the findings from urban areas showed that school administrators have various thoughts about the quality of teaching as $72 \%$ school administrators in Kabul city, $75 \%$ in Jalalabad, 60\% in Bamyan city and 100\% in Parwan city shared their information about the quality of teaching the subject as strong and effective. At the last end, the data was analyzed for gender disaggregation of the respondents in the target areas. Charts 151, 152, 153 and 154 depicts the detailed picture of the quality of teaching Tashabos subject:

\section{Chart 151: Quality of Teaching Tashabos according to Gender}

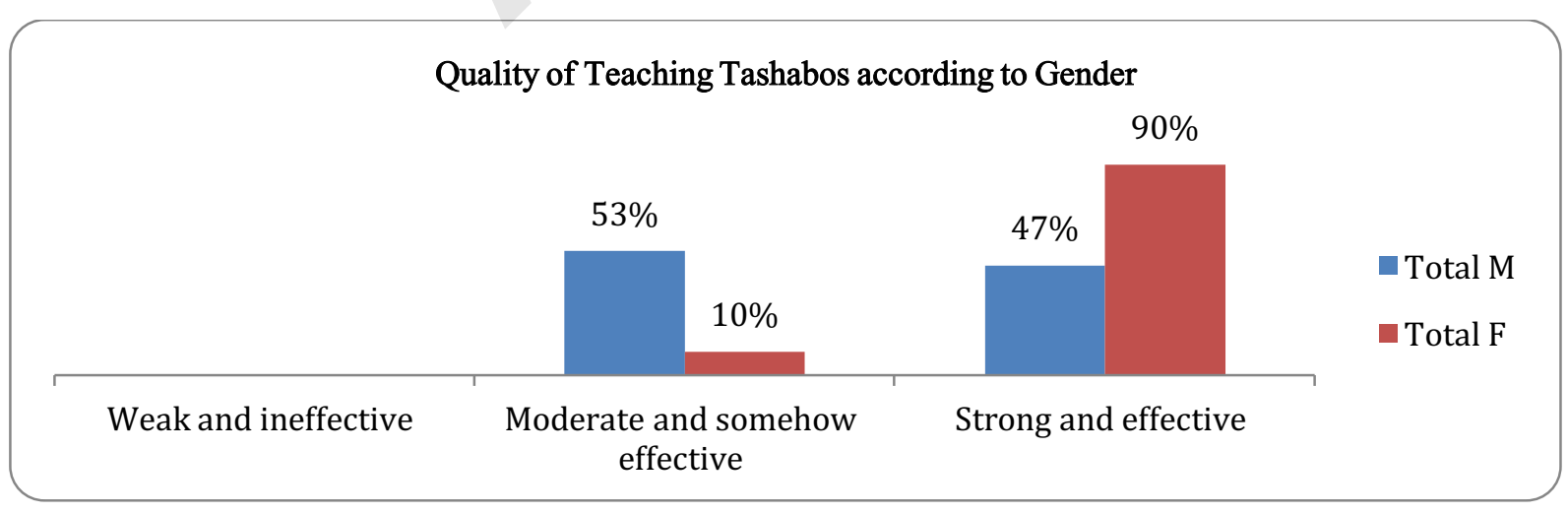




\section{Chart 152: Quality of Teaching Tashabos according to Gender and Location}

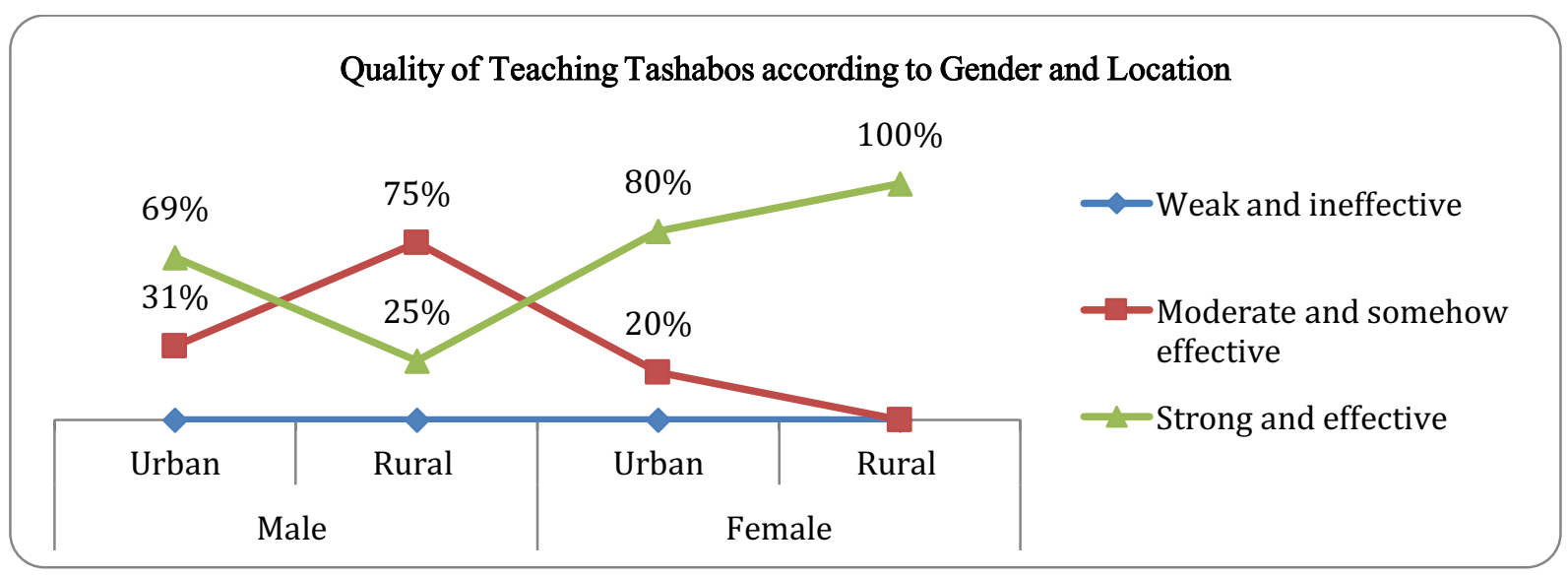

Chart 153: Quality of Teaching Tashabos in Target Areas

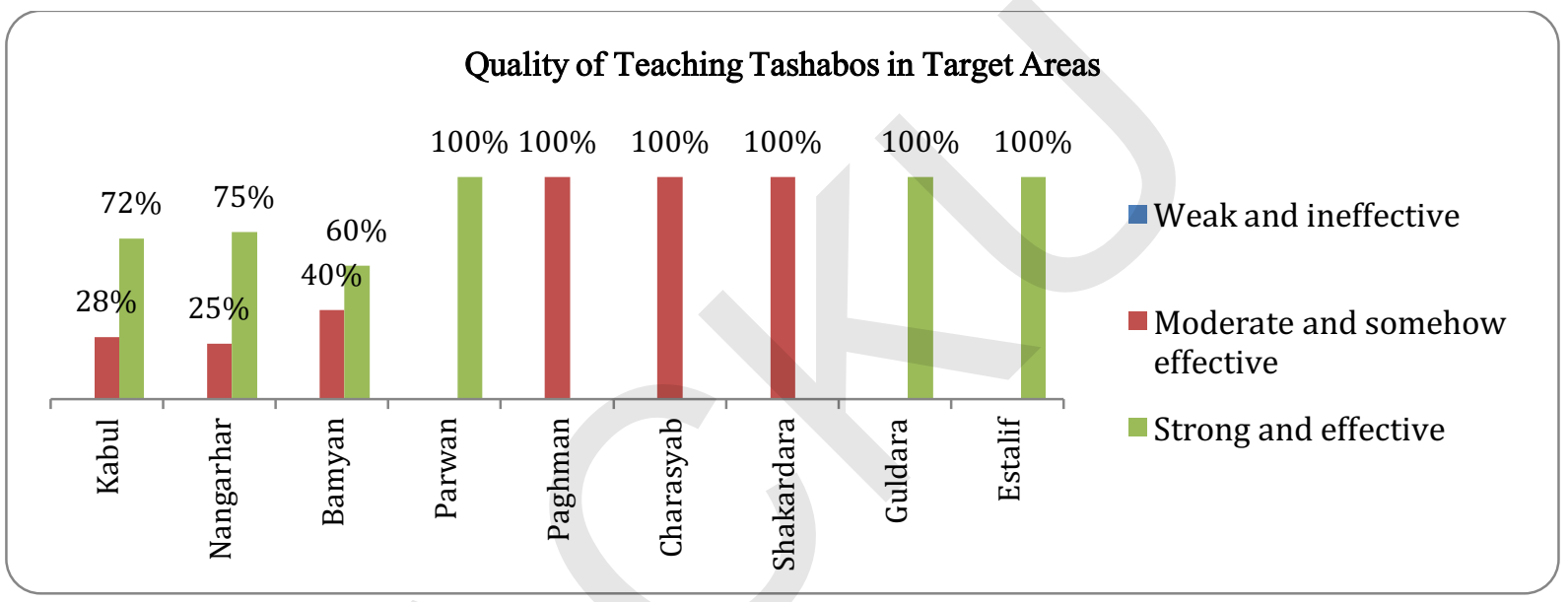

Chart 154: Quality of Teaching Tashabos in Target Areas according to Gender

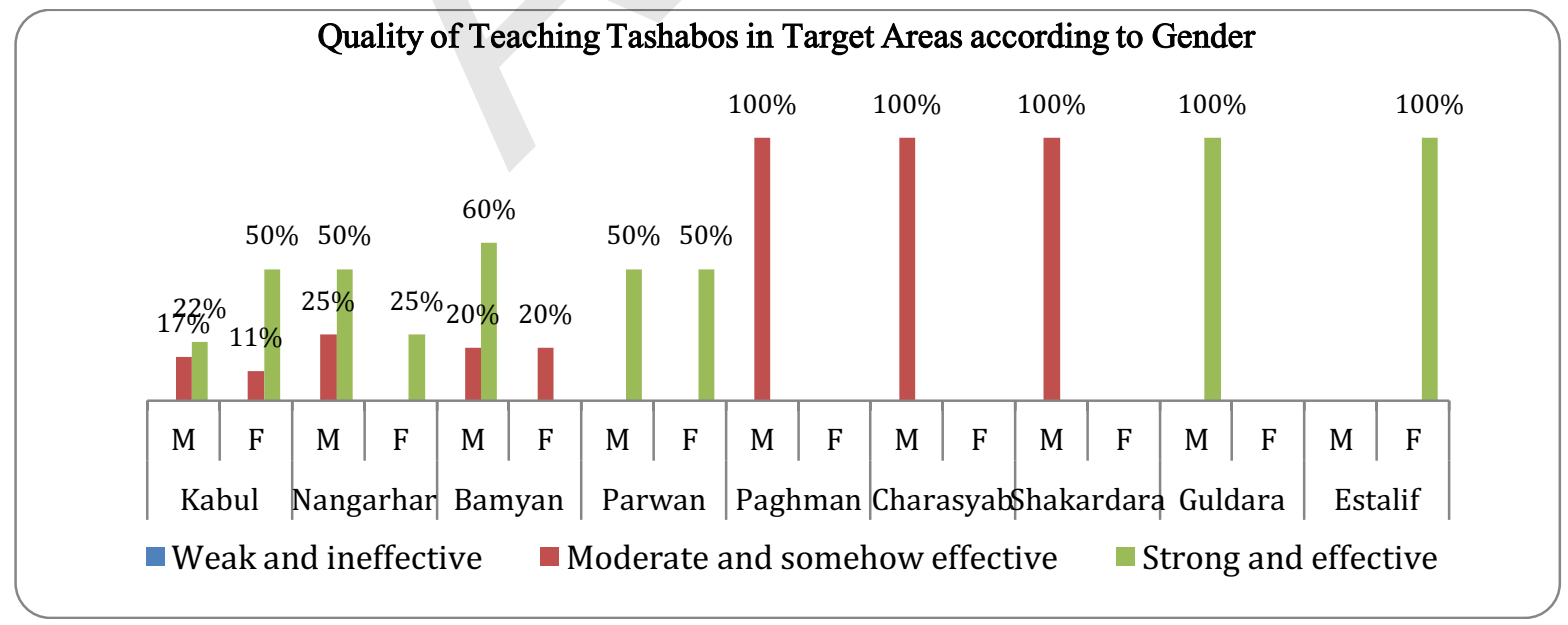

As per chart 148 , nearly seven tenth $(69 \%)$ of the school administrators believed that the subject is effective and the teaching quality is satisfactory, while the remaining $31 \%$ of the school administrators defined the subject somehow effective. Therefore, the school administrators were asked about rationales for such beliefs and thoughts about the subject. Therefore, the school administrators provided a mix of opinions about the importance and teaching methodologies of the subject. $31 \%$ of the school 
administrators mentioned that the teachers have used a very well approach of teaching and students have higher interest with the subject. On the other hand, another $31 \%$ of the administrators believed that the teachers convince the students become self-reliant. Thence, it can be inferred that higher number of school administrators talk about the effectiveness of the subject and acceptable teaching approaches by the teachers. Importantly, $17 \%$ of the school administrators mentioned that teachers talk about students' productions during the classes, which motivates others for initiations and innovation. On the other hand, $23 \%(14 \%$ mentioned about lack of professional teachers; $6 \%$ talked about lack of technical and financial support to students; and 3\% believed that students participate less in the classes) of the school administrators presented their opinions about somehow effectiveness of the subject and its teaching methodologies. $14 \%$ of the school administrators talked about the lack of professional teachers to teach the subject. It was obvious that the viewpoints of school administrators from urban and rural areas varied. It was found that the responses from urban school administrators $(85 \%)$ supported effectiveness of the teaching, while majority of the school administrators in rural areas $(60 \%)$ talked about somehow effectiveness of the teaching. Explicitly speaking 32\% of the urban school administrators believed that teachers' methodologies are good and students have higher interest. At the same time another $32 \%$ of the school administrators mentioned that Tashabos teachers always tend to impress students about the effectiveness of the subject in self-reliance of the students in economic terms. However, the figures on the abovementioned responses from rural school administrators constituted $20 \%$ and $20 \%$ respectively, but the remaining $60 \%$ mentioned that professional teachers lacking in the rural areas. Charts 155 and 156 explains the thoughts for effectiveness of the Tashabos teaching.

\section{Chart 155: School Administrators' Thoughts about Effectiveness of Teaching Tashabos}

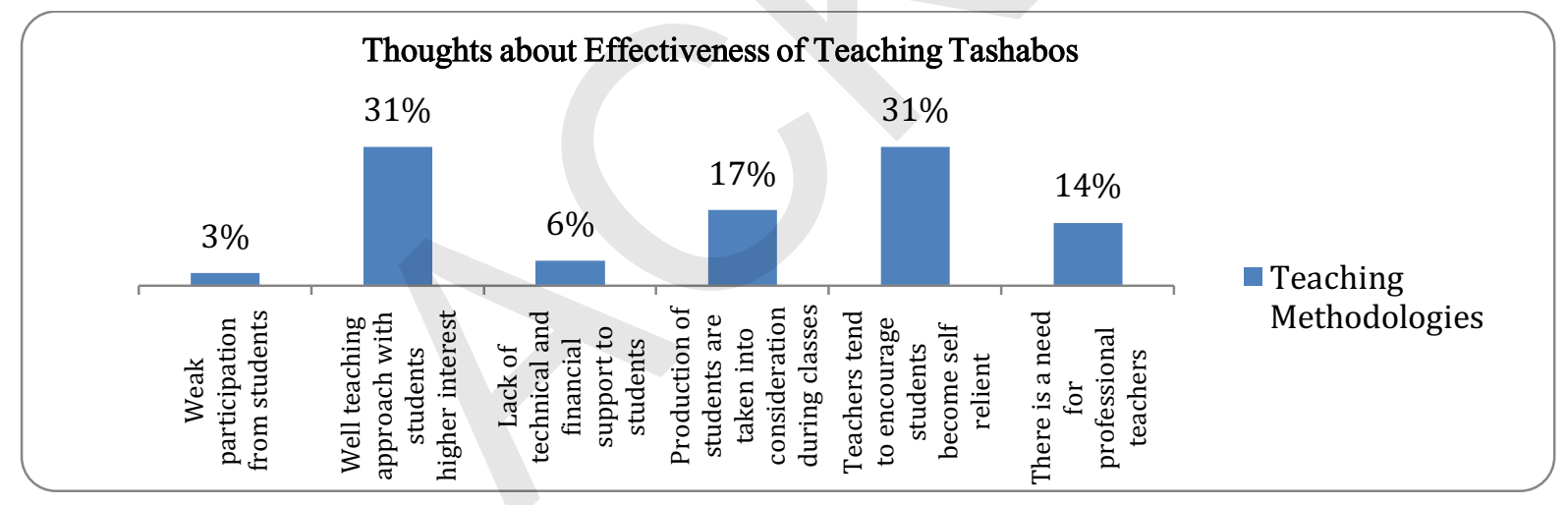

\section{Chart 156: School Administrators Thoughts about Effectiveness of Teaching Tashabos in Urban} and Rural Areas

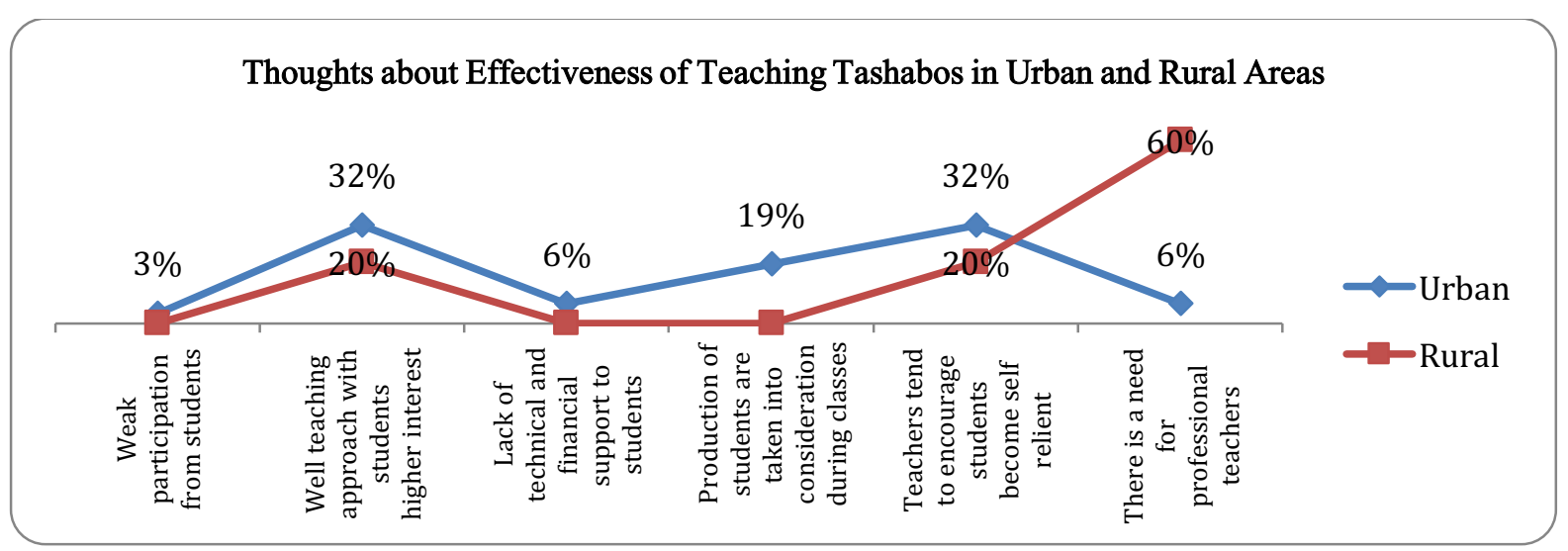




\section{School Administrators and TEO}

It was already discussed that all the school administrators were familiar with the subject. Since Tashabos teaching is supported by TEO, it was necessary to know if the school administrators knew about the organization as well. Therefore, all the school administrators were asked if they knew that TEO supports teaching of the subject in 43 schools. Fortunately, all the school administrators from both urban and rural areas knew that TEO has supported teaching of the subject in their respective schools. Chart 157 depicts the cognizance of the administrators about TEO's supports.

\section{Chart 157: School Administrators familiarity with TEO}

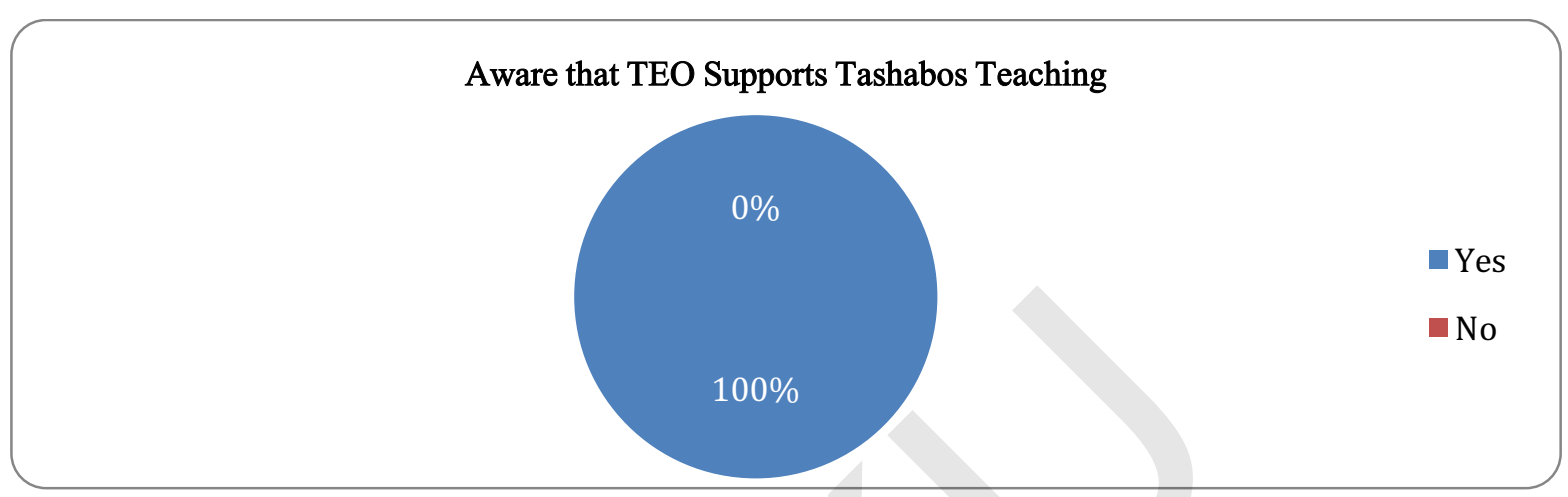

At least one teacher has taught Tashabos in 43 target schools to students of high schools. In addition, teachers needed to be trained or oriented on the subject for better teaching. Therefore, the study focused to collect information if the teachers have been trained, so all the school administrators were queried if they had any information about the training of the teachers. Fortunately, all the school administrators were aware if Tashabos teachers have been trained. 92\% of the school administrators mentioned that Tashabos teachers within their respective schools have been trained while the remaining $8 \%$ said that Tashabos teachers are yet to be trained on the subject by relevant stakeholders. The findings from administrators are aligned with the findings from Tashabos teachers because only $8 \%$ of the Tashabos teachers are still to be trained on the subject. Chart 158 shows viewpoints of the schools' administrators on training of the teachers.

\section{Chart 158: Percentage of Teachers Trained on Tashabos (School Administrators Perspective)}

\section{Teachers Trained on Tashabos (School Administrators Perspective)}

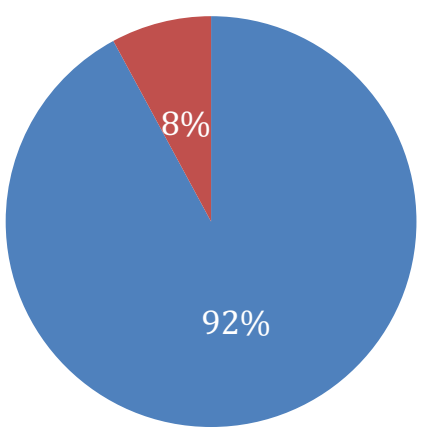

The importance of the subject has already been discussed in the previous sections. In addition, Tashabos teachers have been awarded with some remunerations. Therefore, considering the importance and remuneration there should be some other teachers within the schools willing to teach the subject. Therefore, all the school administrators were questioned about eagerness of other teachers in teaching 
the subject. As expected others teachers in over three fourth $(76 \%)$ of schools showed their keenness to join the Tashabos teachers' community under the umbrella of TEO. On the other hand, school administrators of $24 \%$ schools hadn't point out a single teacher other than Tashabos ones to teach the subject. It is considered a huge achievement for the program because TEO has been able to spread knowledge about the importance of the subject to a wider community of intellectuals. In addition, it is recommended for the program to identify these teachers and if resources allow, train them on the subject to avoid any shortage of Tashabos teachers in the future. Chart 159 shows the percentage of schools where other teachers are also fervent to teach Tashabos.

Chart 159: Other Teachers Keen to Teach Tashabos (School Administrators Perspective)

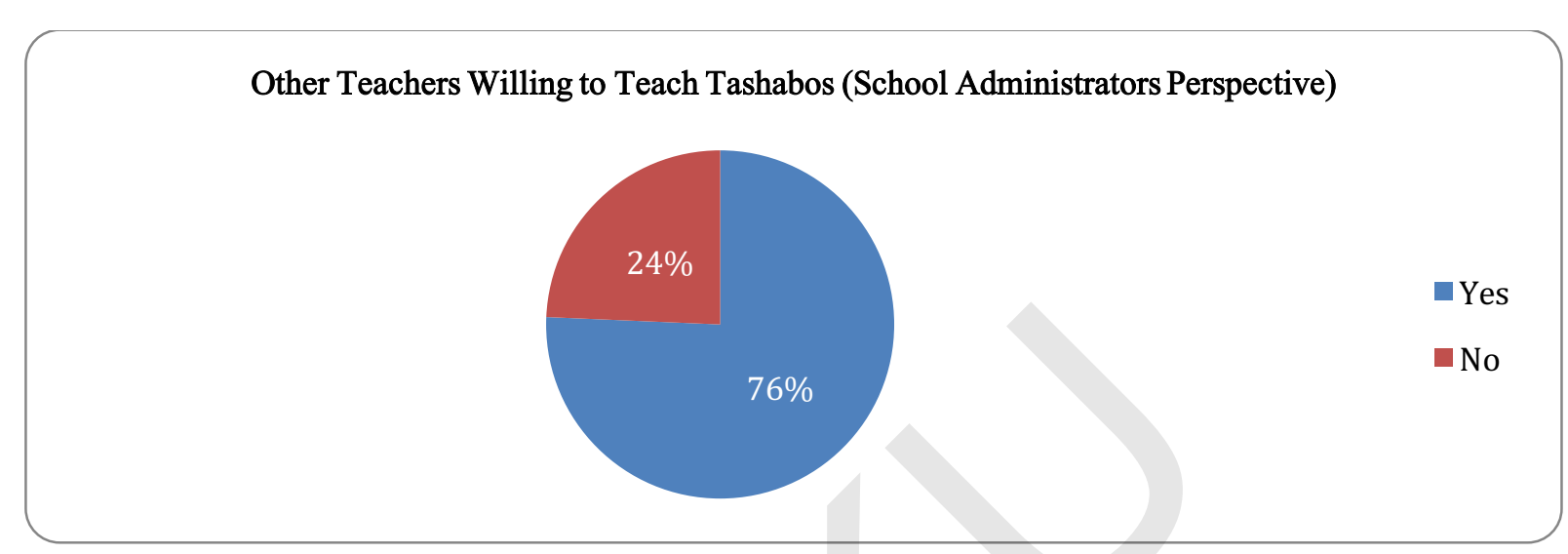

During the interview with the school administrators, it was found that the administrators have been responsible for many years. Therefore, the administrators were asked if they have observed any changes in the teaching of the subject. TEO was quite blessed that nearly nine tenth (89\%) of the school administrators have observed the change in the teaching of the subject, but $11 \%$ of them mentioned that teachers have been following the unique teaching skills. After analyzing the data in urban and rural areas, it was found that school administrators in urban areas (91\%) outnumbered administrators in rural areas $(83 \%)$ in witnessing the change in teaching skills for Tashabos. In addition, the data was further analyzed for the gender types of the school administrators and it was found that more female school administrators $(94 \%)$ have perceived the change in teaching than male school administrators $(87 \%)$. However, when the data was further analyzed for both gender and location of the administrators, it was found that male administrators in urban areas $(93 \%)$ were more proactive in detecting the change in teaching than male administrators in rural areas $(80 \%)$. However, the reverse of the story was true for the female school administrators as the change in teaching was more sensible for rural administrators $(100 \%)$ than urban female administrators $(88 \%)$. Now, the data was analyzed for the target locations and it was found that except for administrators of Kabul city (85\%) and Charasyab district (50\%), the entire administrators in all the other target areas have noticed a change in the teaching skills for Tashabos. Charts 160,161,162, 163 and 164 and Table 1 reflect the complete information about the number of school administrators observed a change in the teaching skills of the teachers.

Chart 160: School Administrators Observed a Change in the Teaching of Tashabos

Teaching Skills Changed over the Course of Few Years

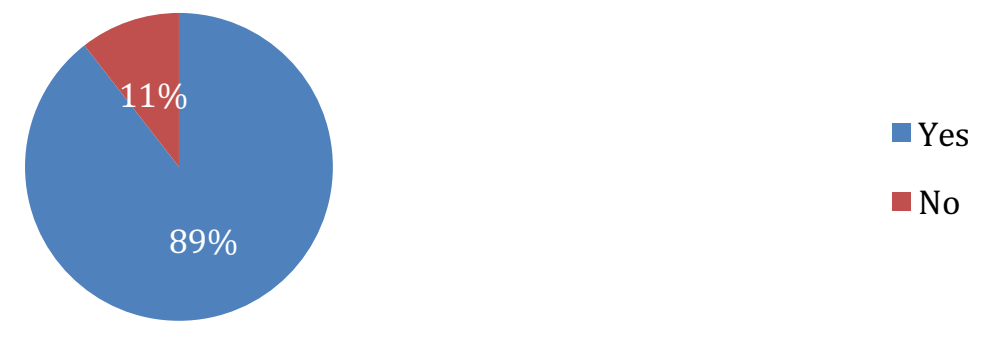


Chart 161: School Administrators Observed a Change in the Teaching of Tashabos in Urban and Rural Areas

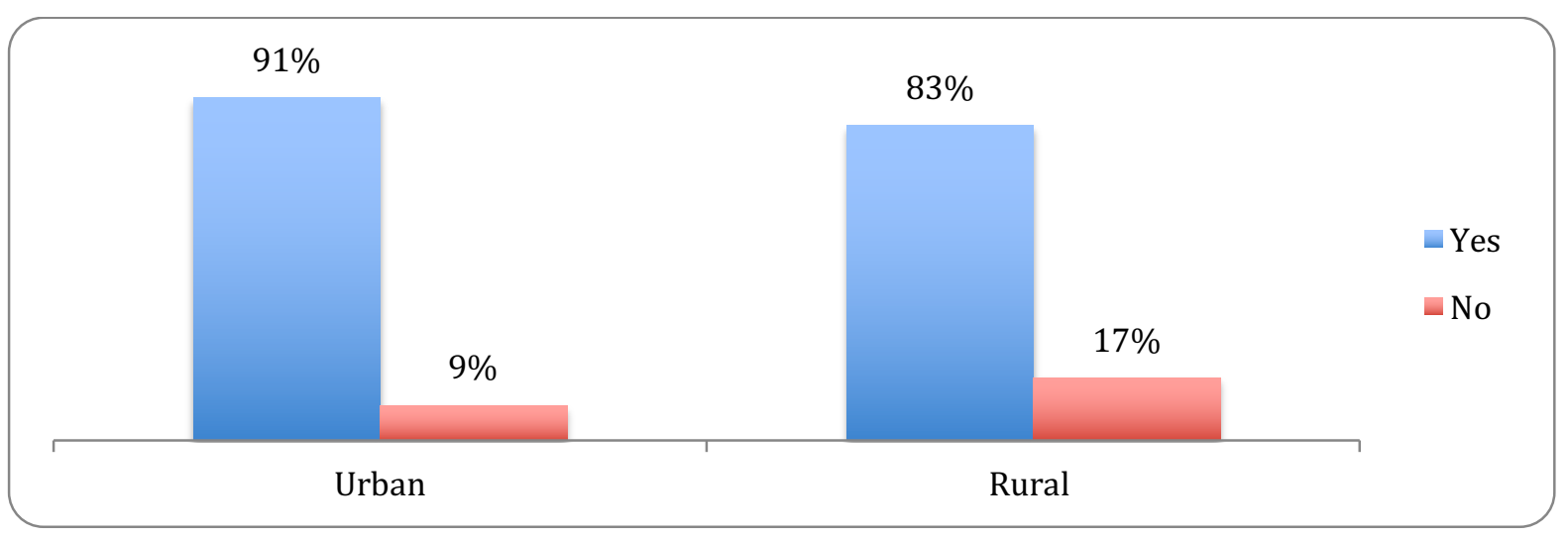

Chart 162: Schools Administrators Observed a Change in the Teaching of Tashabos according to Gender

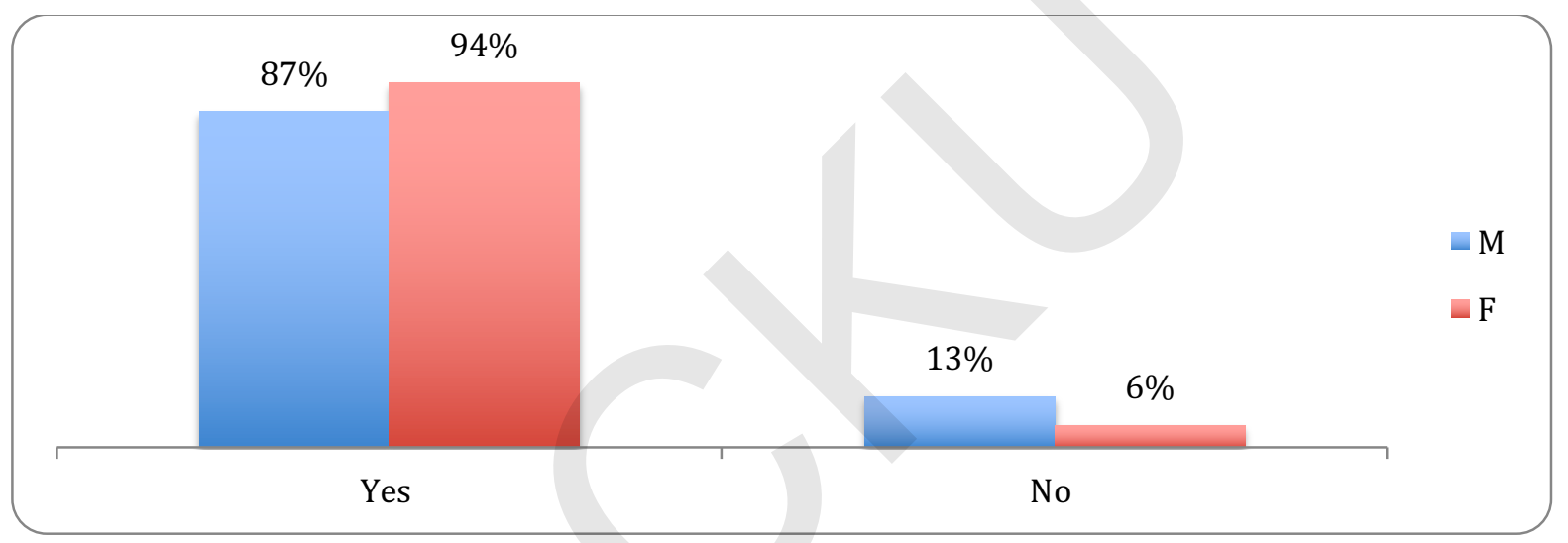

Chart 163: Schools Administrators Observed a Change in the Teaching of Tashabos according to Gender and Location

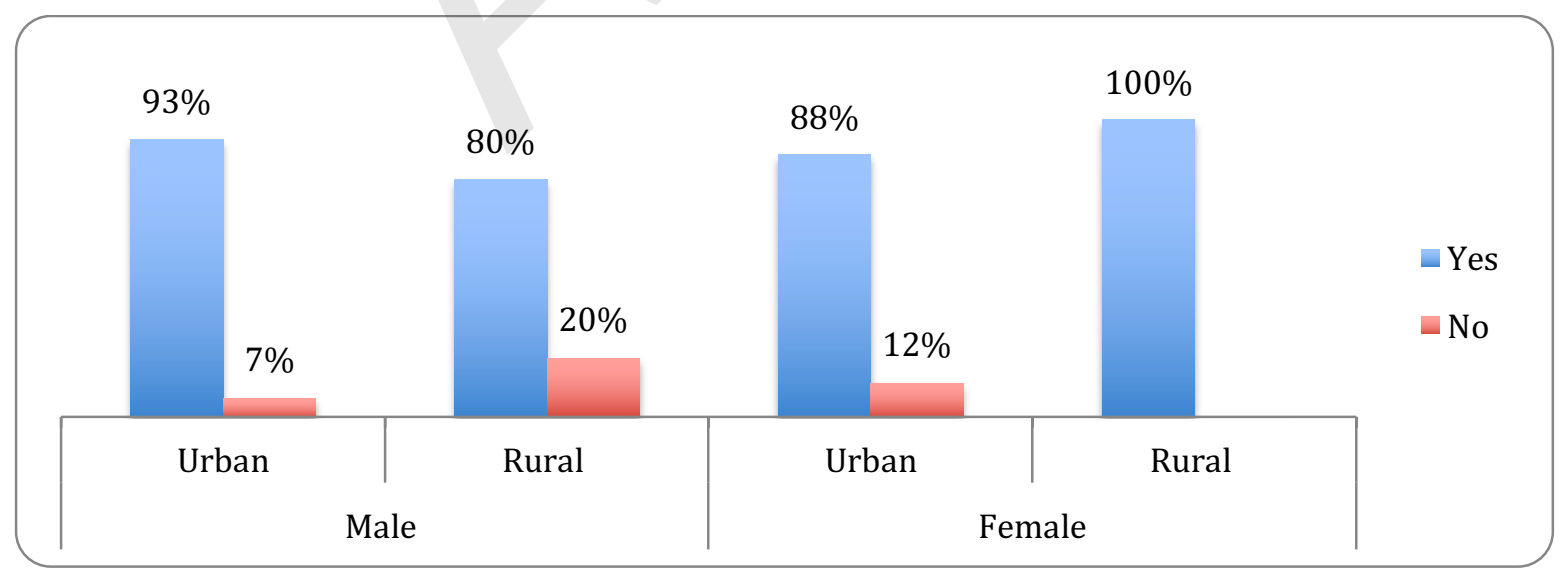


Chart 164: Schools Administrators Observed a Change in the Teaching of Tashabos in Target Areas

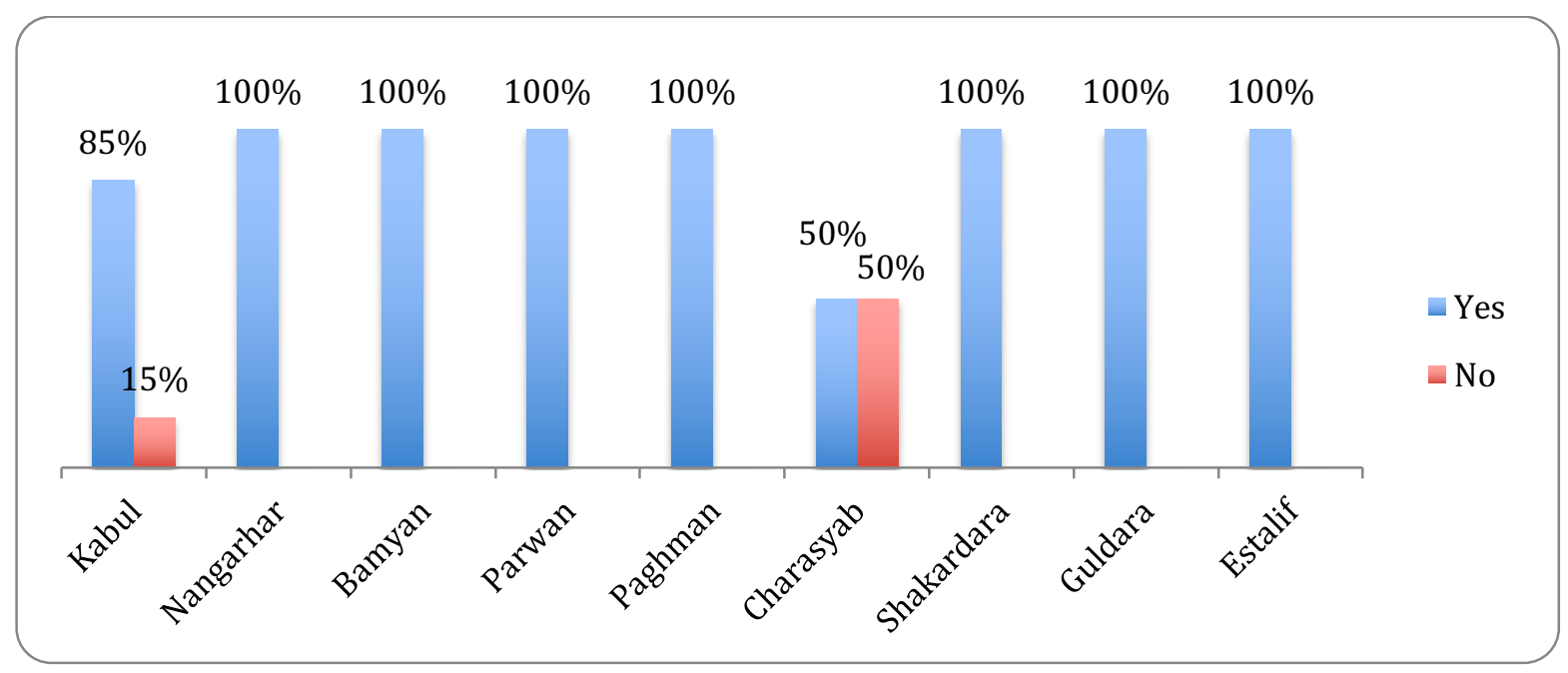

Table 1: Schools Administrators Observed a Change in the Teaching of Tashabos in Target Areas according to Gender

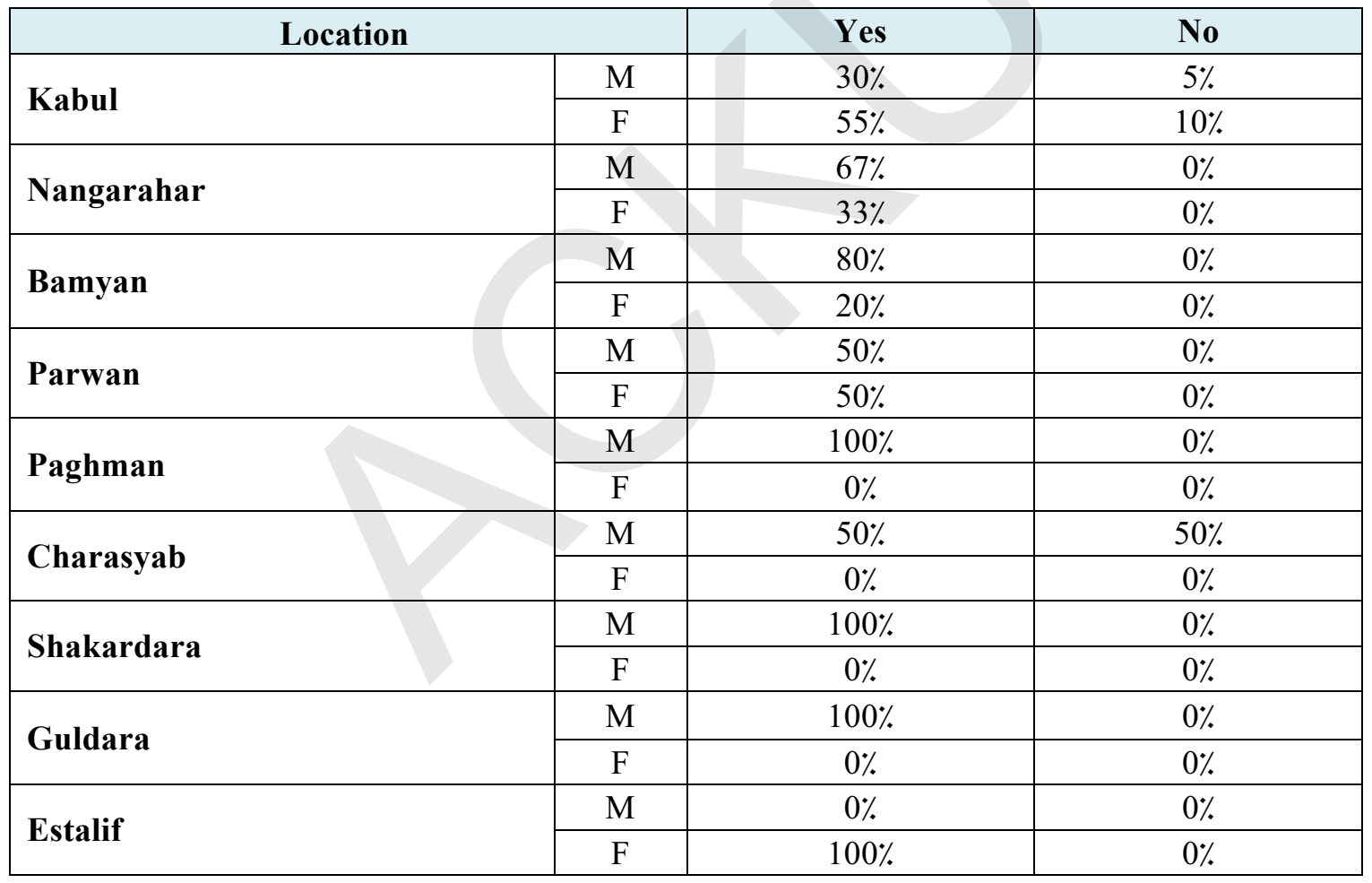

The collected data on the changes in teaching skills was further analyzed to the administrators' locations to get an overview of the types of the changes in urban and rural areas. It was found that school administrators in urban areas $(31 \%)$ have had a similar thought about the change in teaching skills as the entire school administrators did in the above. However, the majority of the school administrators in rural areas $(40 \%)$ mentioned that more of their students were able to start new businesses. This change is a very important for the program because the change is completely aligned with the objectives of the program in creating a platform for students to be entrepreneurs. However, the similar change was observed by only $10 \%$ of the school administrators in urban areas. At the same time, another majority $(40 \%)$ of the school administrators in rural areas talked about the discipline of the exhibition programs comparing to previous years. This change in the rural areas of the country can be regarded a very essential achievement for the program because organizing such programs in the rural parts of the 
country is never easy considering the limitations and challenges against it. Chart 165 demonstrates the complete picture of the changes in teaching skills the school administrators have observed in urban and rural areas.

\section{Chart 165: Changes in Teaching Skills in Urban and Rural Areas (School Administrators} Perspective)

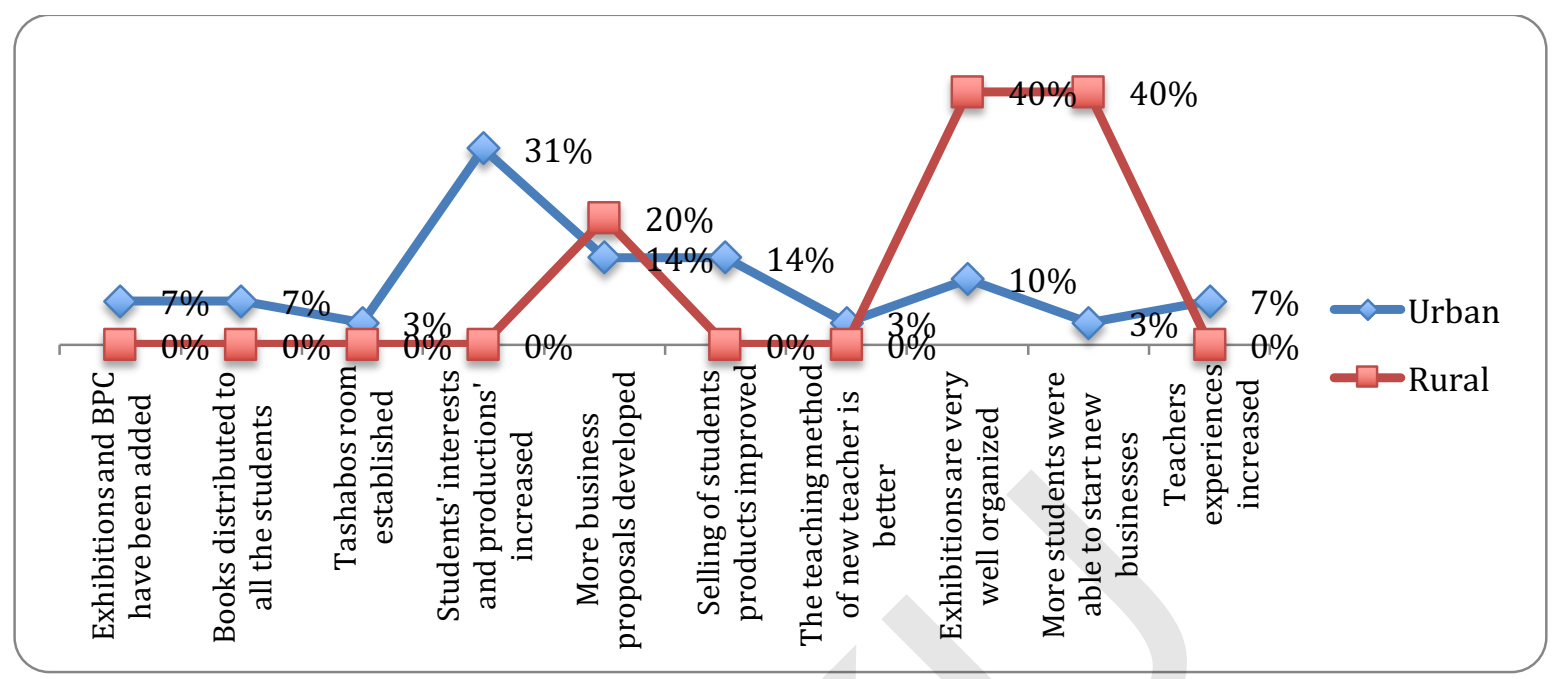

Afterwards, the data was further analyzed for the gender types of the school administrators and it was found that highest percentage of the male school administrators (25\%) have mentioned that they have witnessed higher number of students started new businesses. However, majority of the female school administrators $(61 \%)$ mentioned about the order of the exhibition under TEO comparing to previous years. Chart 166 explains more about the various changes the school administrators observed according to gender.

\section{Chart 166: Changes in Teaching Skills of Tashabos according to Gender}

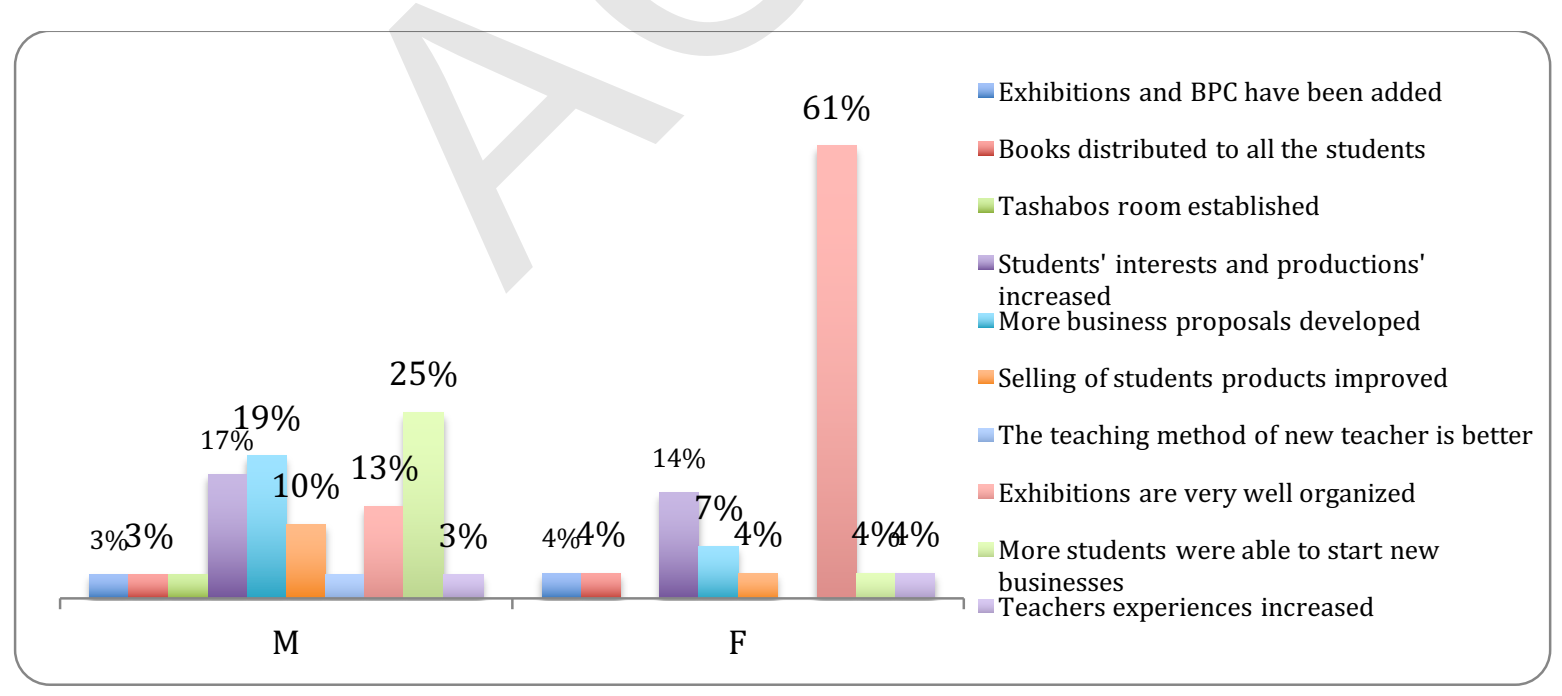

\section{Future of Tashabos Subject and School Administrations}

School administrators have expressed their comments about the importance of the subject in the previous sections. Considering the importance of the subject in changing the future of the students, the school administrators were asked if the subject should be part of the national curriculum of the MoE. Fortunately, over nine tenth $(92 \%)$ of the school administrators agreed to incorporate the subject into the 
national curriculum and accordingly only $8 \%$ showed their opposition to the query. Chart 167 explains the percentage of the school administrators suggested incorporation of the subject into the national curriculum.

Chart 167: Tashabos Be Incorporated into the National Curriculum (School Administrators' Perspectives)

\section{Incorporate Tashabos into the National Curriculum}

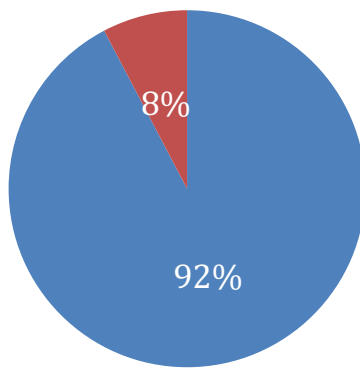

Yes

No

All the school administrators provided viable comments about the importance of the subject and more than nine tenth $(92 \%)$ of them claimed that Tashabos should be part of the national curriculum. Therefore, there might a chance that other school administrations have talked about the subject with administrators of schools where Tashabos has been taught. Therefore, school administrators were all enquired to know if other school administrators have had communications about the subject. Fortunately, school administrations of other schools have had communications with $32 \%$ of the school administrators. Though the figure is a very small one, but still the advocacy of TEO for the subject has attracted the attention of a large number of schools. For the better success of the program in expanding the program, TEO needs to communicate the success of the program with other schools in the relevant areas to lobby for the inclusion of the subject into the national curriculum. After analyzing the data based on the location of the school administrators, communications with the school administrators on the subject were observed with higher number of rural school administrators $(50 \%)$ comparing to urban school administrators $(28 \%)$. It is noticed that higher number of rural schools has shown their interest to the subject for inclusion of the subject within their routine curriculum. This explains the importance of the subject for the rural communities and this should be taken into deep consideration by TEO if lobbying for the subject is planned in the future. Charts 168 and 169 depicts the percentage of the school administrators who were contacted by other school administrations for Tashabos information.

Chart 168: Other Administrations Eager to Incorporate the Subject into the Routine Curriculum (School Administrators Perspectives)

Other Administrations Eager to Incorporate the Subject into the Routine Curriculum

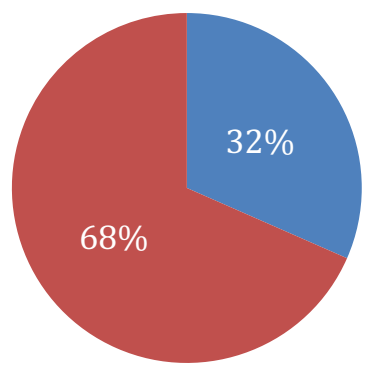


Tashabos Impact Assessment May 18 2017.docx Future of Tashabos Subject and School Administrations

Chart 169: Other Administrations Eager to Incorporate the Subject into the Routine Curriculum in Urban and Rural Areas (School Administrators Perspectives)

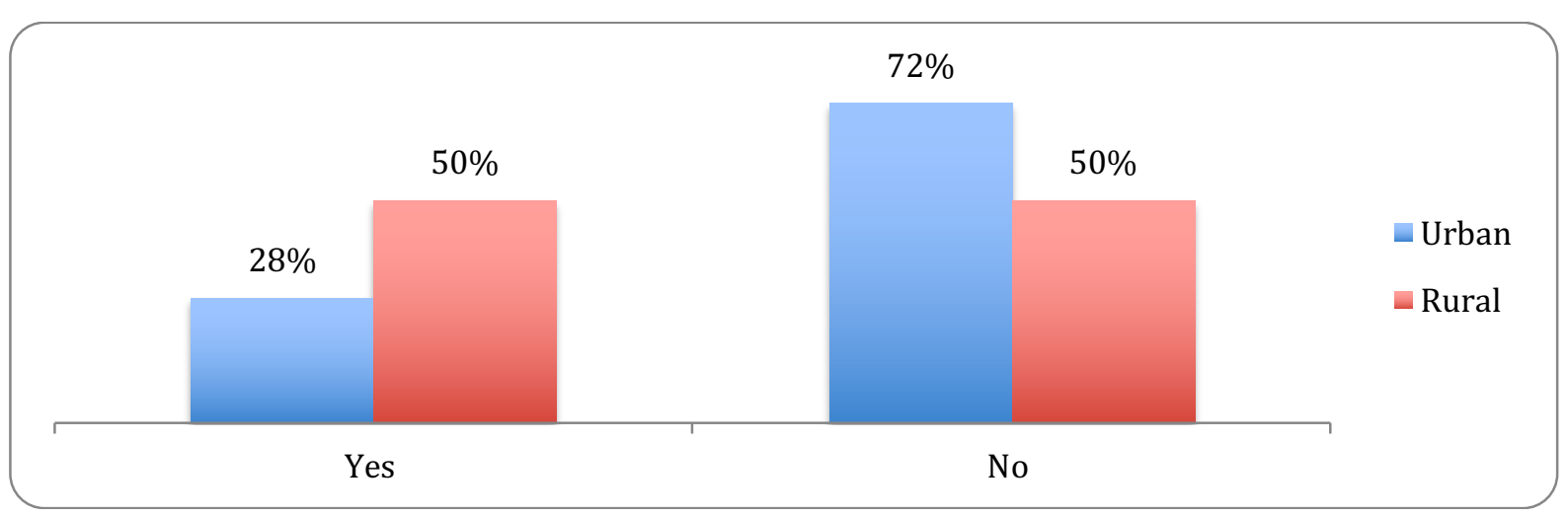




\section{Findings for Parents' Assessment:}

Among the target groups for the assessments were the parents of the students studied Tashabos subject. In addition, the assessment focused to identify parents of those students who were able to either initiate/expand a business or secure an employment. It was quite fortunate that at least 5 students within each school were able to fit with the proposed criteria. Considering the sampling size calculation with $5 \%$ confidence interval, $95 \%$ confidence level and 400 target number of students, 80 parents were targeted for the assessment and interview purposes.

In order to have had clear information about the parents' perspectives regarding the subject and its impact, the assessment team distributed the target number of parents into TEO target locations. This gave a diverse data on parents' views about the subject from urban to rural areas. During interviewing the students, their parents were also approached at the same time. Considering the gender sensitivity, male parents were interviewed by male surveyors, while female parents were interviewed by female surveyors. The parents were asked about their views on Tashabos subject, Tashabos subject and their children and effects of the subject on their children.

\section{General Characteristics of the Parent Respondents:}

\section{Locations:}

The respondents were selected from TEO's target locations. As the majority of the students studying Tashabos are within Kabul city, it was expected to have higher number of parents' interviews within Kabul City. As evident from chart 169, exactly half of the parent respondents were from Kabul city. At the other end only $3 \%$ of the parents were interviewed in Estalif district, which is in line with the lowest number of students studying Tashabos within TEO's target locations. The disaggregation of parent respondents was essential in terms of collecting knowledge about scale of effectiveness of Tashabos program within TEO's target locations. Chart 170 gives a complete overview of the parent respondents.

\section{Chart 170: Address Disaggregation of Parent Respondents}

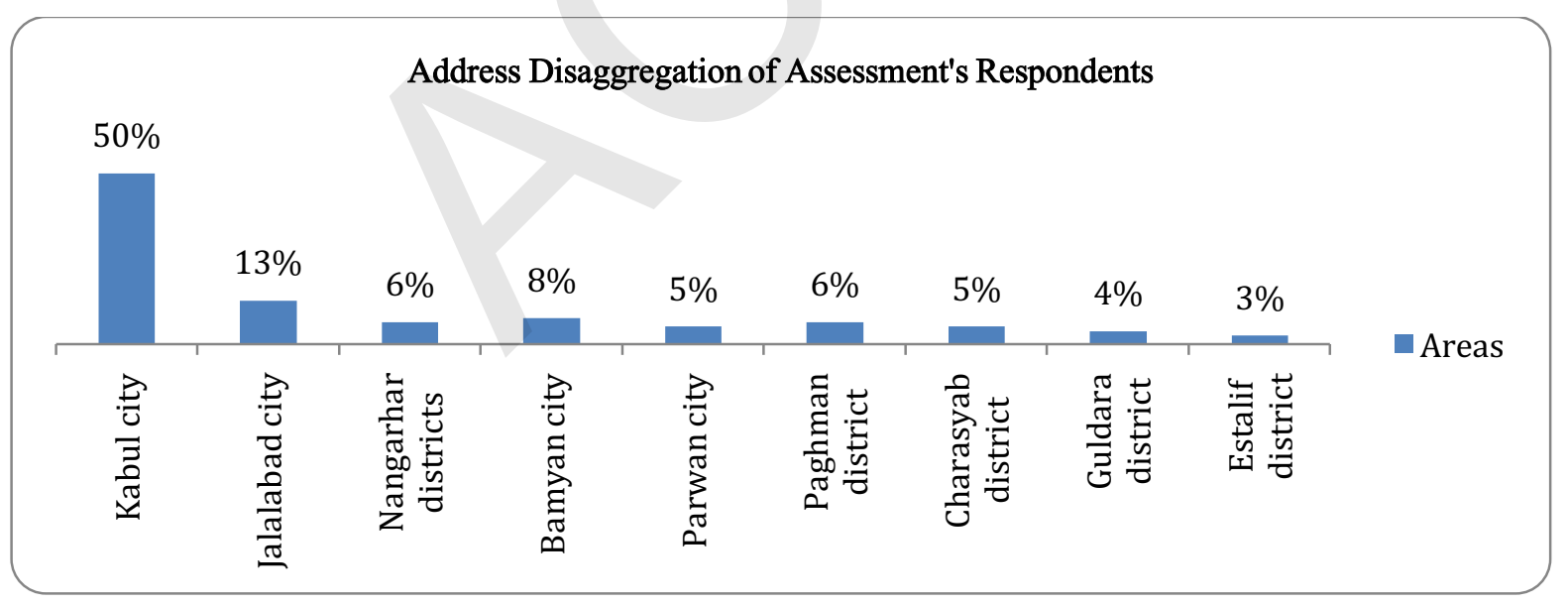

\section{Student Children:}

Number of children studying at school for each of the parent respondent was also inquired. This allowed the assessment to gauge the cognizance level of the parent regarding their children and their studies at school. Fortunately, all the respondents both from urban and rural areas had their at least one of their children at schools. The number of enrolled children varied from one to six for the respondents. The average number of children enrolled at schools for parents was almost 3 children. It should be mentioned that the average number of children was different for urban and rural areas as averagely 3 children were enrolled at schools in urban areas, but the average number was one child for rural areas. 
Two children studying at school was the most prevalent for parent respondents at $29 \%$ while three children, one child, four children, five children and six children were $2^{\text {nd }}$ to $6^{\text {th }}$ most prevalent for parent respondents with $24 \%, 19 \%, 15 \%, 6 \%$ and $5 \%$ respectively. Interestingly, a similar trend was observed for both urban $(27 \%)$ and rural (37\%) areas as two children outweighed other options for parent respondents, while three children (24\% for urban and $26 \%$ for rural areas), one child $(19 \%$ for urban and $21 \%$ for rural areas) and four children (15\% for urban and $16 \%$ for rural areas) stood at $2^{\text {nd }}$ to $4^{\text {th }}$ positions. As expected the higher number of children at school was observed in urban areas as five and six children enrolled at schools constituted answers for $8 \%$ and $7 \%$ of the parent respondents in urban areas respectively. However, no parent respondents in rural areas had either five or six children at schools. Chart 171 gives the complete overview of number of children studying at school.

Chart 171: Number of Children Enrolled at Schools for Parent Respondents

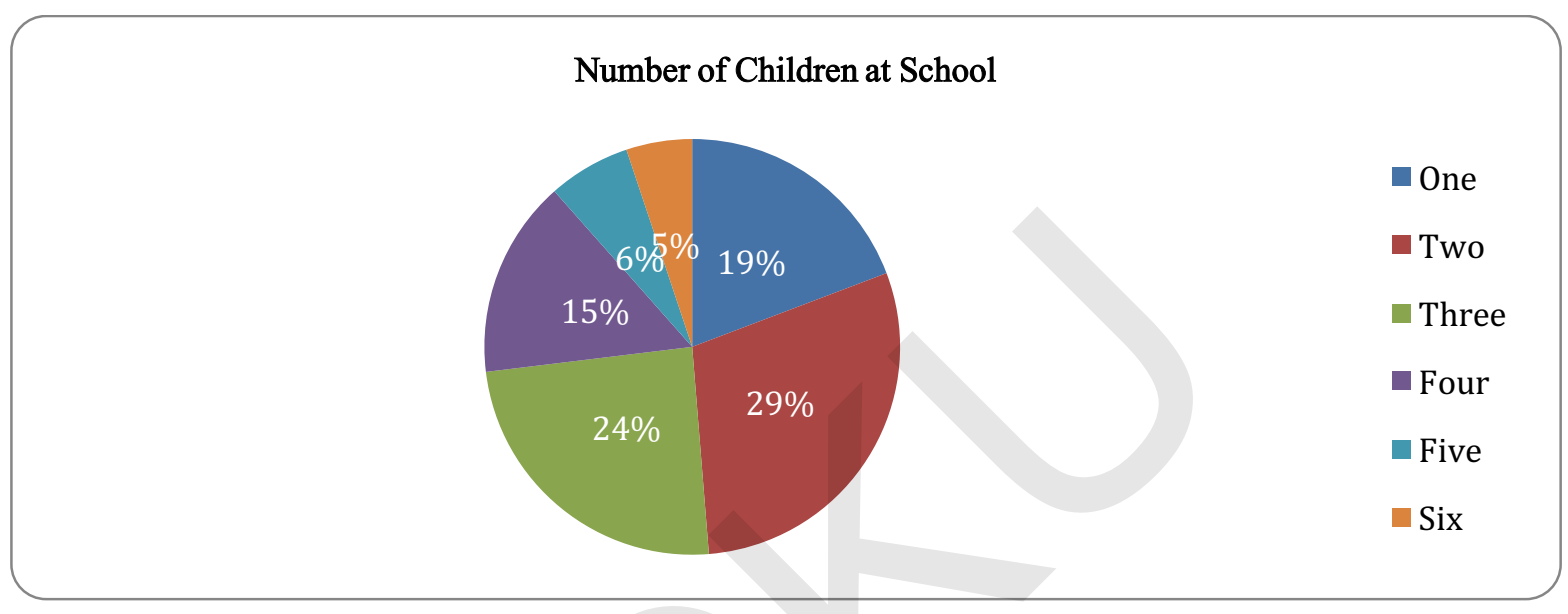

\section{Parents Perspectives about Tashabos}

After acquiring general information about the parent respondent, specific information on parents' knowledge and perspective on Tashabos was collected. Structured questionnaire for the purpose was used and the information generally dealt with information about the subject; children's interest with the subject; communication about the subject between children and parent; utilization of the concepts of the subject in parents' business and finally the interview finishes with asking some questions about socioeconomic effects of the subject on children's lives. Each of these topics will be taken into consideration separately.

\section{Familiarity with Tashabos:}

Before directly inquiring about parents' familiarity with the subject, all the parents' were asked if they knew about the grades their children are at schools. Collecting this information was considered very essential because asking parents about Tashabos needed children of grades 10 to 12 at school. We assume if parents knew about their children's grades, they can exchange information about Tashabos between each other. Since most of the respondents were educated, it was deemed as a simple question for them because they stressed knowing about their children is the most important aspect of raising children. Not a point of concern for the surveyors was even illiterate and parents with lower education levels had information about their children's grades. As per chart 171, 97\% of the parent respondents did know about their children's grades in school. Of the remaining $3 \%$, shockingly a parent who was Grade 14 graduate didn't know about his children's grades at schools. Not surprisingly, the $3 \%$ parents were male parents and this can be illustrated in our society where mothers tend to be more aware of their children than fathers. 
Chart 172: Parent Respondents Aware about their Children's Grades

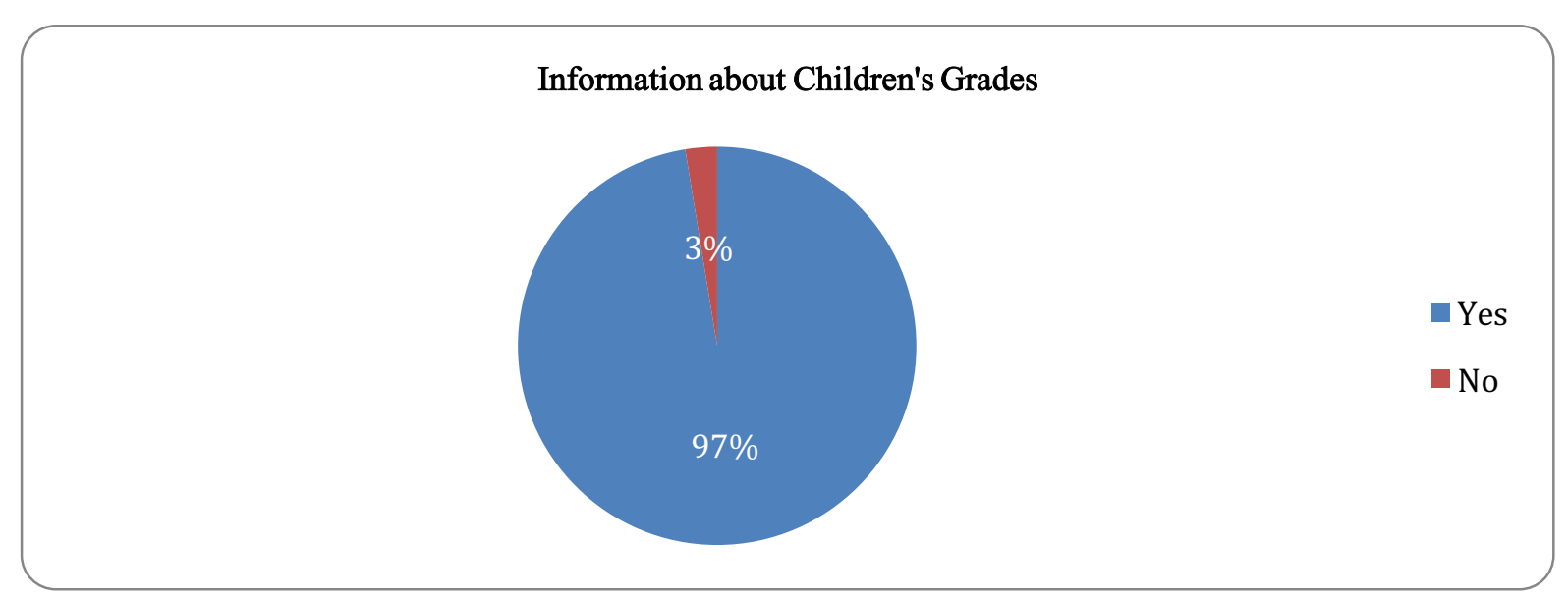

All the respondents were questioned if they had information about Tashabos. Over one fourth (82\%) of the parent respondents did have information about Tashabos subject. Of the total $82 \%$, parent respondents in urban areas with $86 \%$ had more information about the subject comparing to parent respondents in rural areas with $68 \%$ Conversely, the number of parent respondents $18 \%$ of the total respondents) didn't have information about Tashabos subject was more in rural areas (32\%) to urban areas (14\%). Coming into gender disaggregation for the question, it was found that among $82 \%$ parents respondents yes to the question, female parents with $84 \%$ outnumbered male parents with $78 \%$ In addition, among the parents responded no to question (18\%), male parents with $22 \%$ were more than female parents with $16 \%$. Having looked more at the analysis of $82 \%$ respondents with positive response to the question, it was found that in urban areas more female parents $(88 \%)$ responded positively to male parents $(81 \%$. However, in rural areas male parents dominated with $73 \%$ comparing to $63 \%$ female parents with yes answers. Opposite of the story was true for parents $(18 \%)$ responded no to the above question. In urban areas male parents (19\%) and in rural areas female parents (38\%) dominated over. Charts 173 , 174 and 175 give a complete picture about parent respondents knowing about Tashabos.

\section{Chart 173: Parent Respondents Have Information about Tashabos}

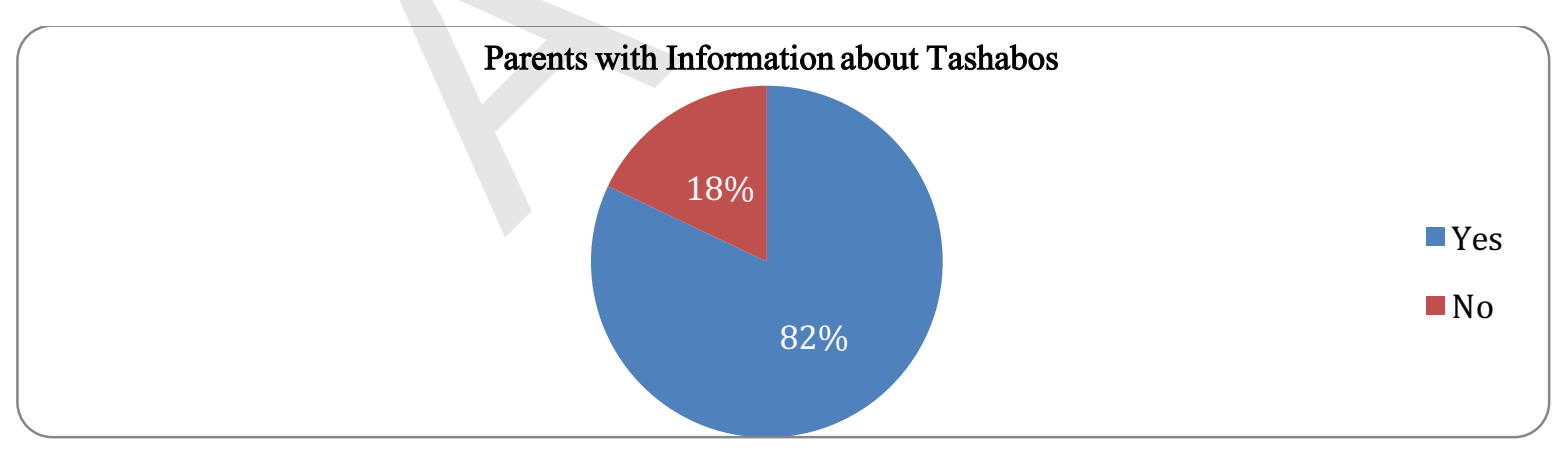

Chart 174: Parent Respondents Have Information about Tashabos

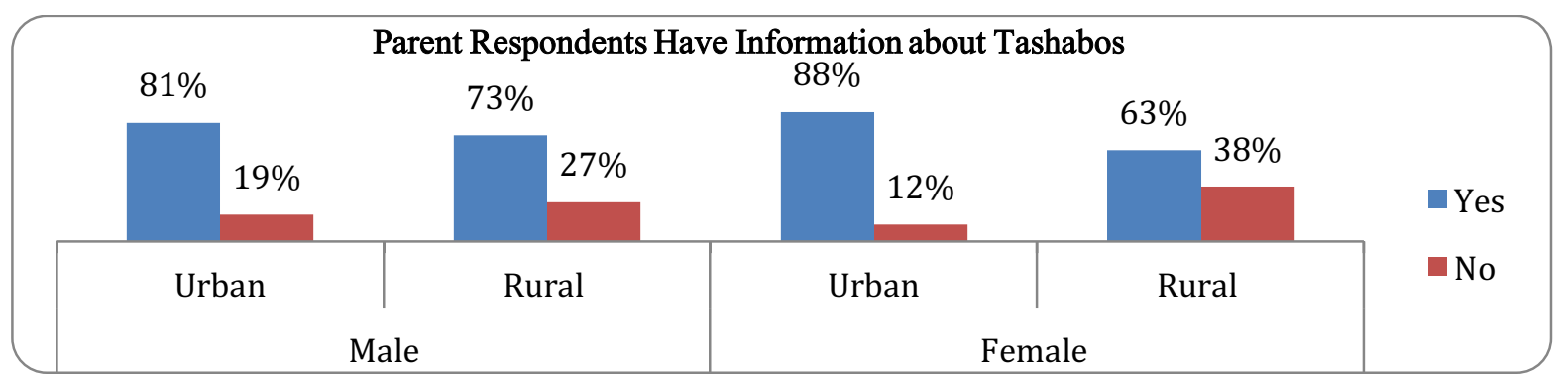


Chart 175: \% Parent Respondents in Urban and Rural Areas and \% Male and Female Parent Respondents

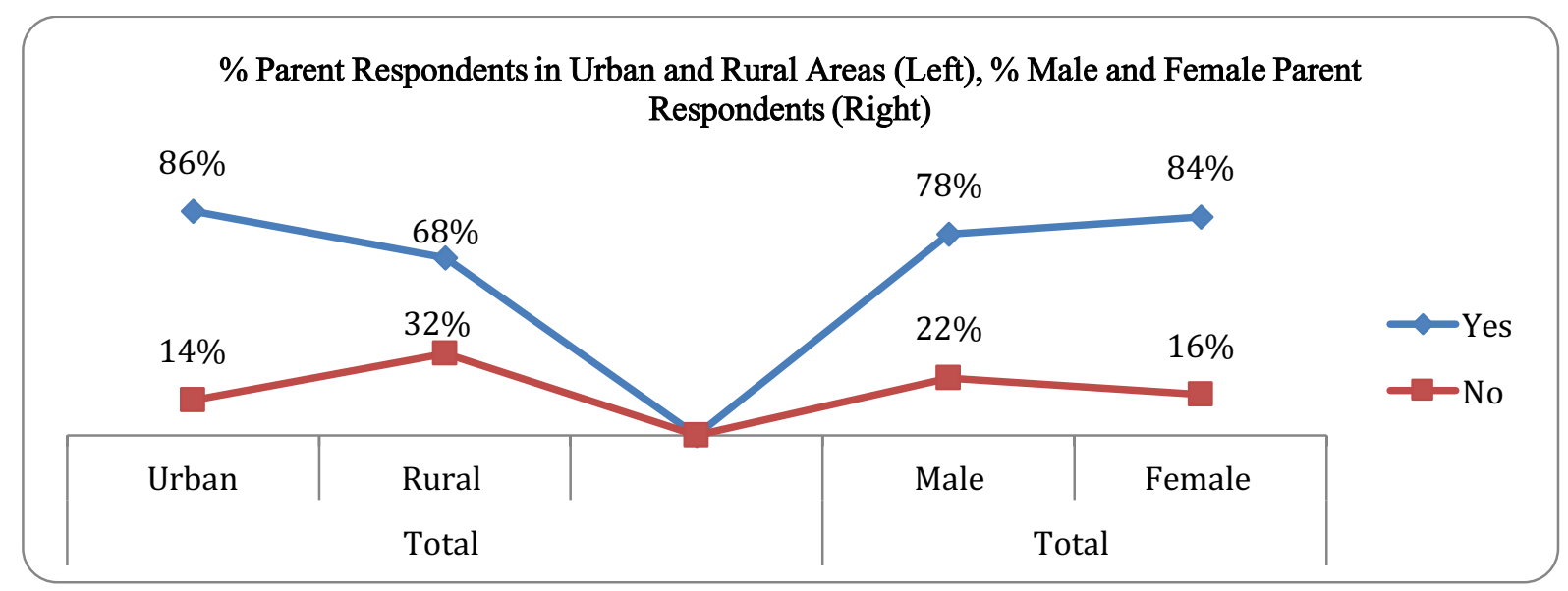

The assessors then shifted the direction of the question towards collecting specific information the respondents share about Tashabos. Of the total $82 \%$ parents had information about Tashabos, more than one third $(36 \%)$ of them stated that Tashabos is a subject dealing with business and employment. However, $17 \%$ of the respondents mentioned that Tashabos was part of the MoE curriculum. Although the information they shared was contrary to the fact, the information was shared by parent respondents who were at least high school graduates. This was a bit daunting for the assessor why educated parents shared such information. Therefore, the assessor further explored and found that these parents want the subject be incorporated into the national curriculum. It can be attributed to a kind of advocacy for the subject that educated parents did mention that the subject is part of the MoE curriculum. However, 13\% of the parent respondents replied that the subject is important for improving economic condition, while other $13 \%$ of the respondents stated that Tashabos deals with only business. It should be mentioned that nearly four fifth $(79 \%)$ of the respondents' answers were of economic importance. This explains the effectiveness of the subject in providing opportunities of economic growth for students and effectiveness of the program about awareness of their parents' about the point on improved economy. Tashabos a subject deals with business and employment was the response for both male $(30 \%)$ and female (38\%) parent respondents outstripped other responses. However, the second best response for male parent respondents $(26 \%)$ was "part of MoE curriculum", while $15 \%$ of the female parent respondents viewed "Tashabos a subject deals with business" as the second best option after "Tashabos a subject deals with business and employment". The third best option for 17\% male parents was Tashabos improving economic condition, but $13 \%$ female respondents agreed on Tashabos part of the MoE curriculum option as third best. Interestingly, 38\% parents in urban areas and 35\% parents in rural areas mentioned that Tashabos is a subject dealing with business. At the same time, Tashabos a subject part of the MoE curriculum grabbed the attention of $18 \%$ parents in urban areas and $15 \%$ parents in rural areas. However, the response option for third highest parent respondents varied in urban and rural areas as "improving economic condition" was the response for parents in urban areas with $14 \%$ and $15 \%$ of rural parent respondents provided "dealing with business" as information about Tashabos. Chart 176 and Table 2 takes parents' information on Tashabos into deeper consideration. 
Chart 176: Parent Respondents' Information about Tashabos Subject

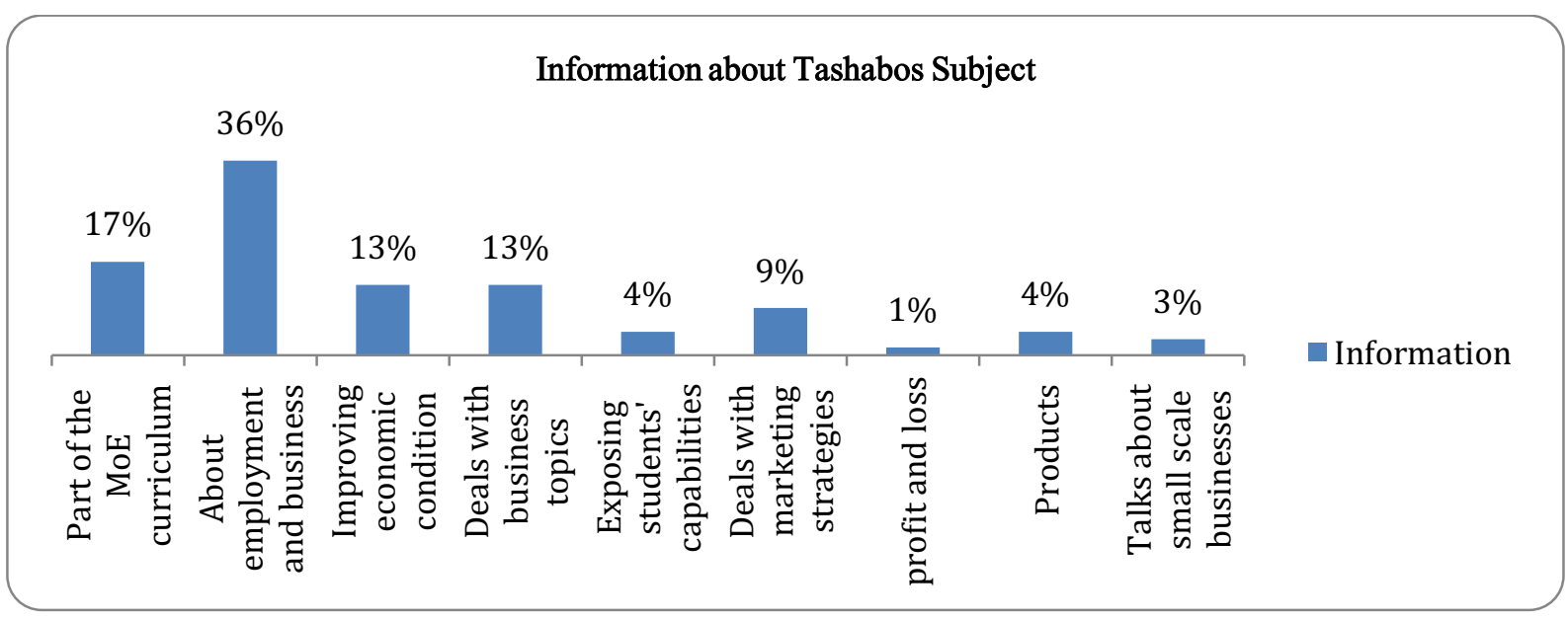

Table 2: Shared Information on Tashabos by Parent Respondents according to Gender and Location

\begin{tabular}{|l|c|c|c|c|}
\hline \multirow{2}{*}{\multicolumn{1}{|c|}{ Type of Information }} & \multicolumn{2}{c|}{ Male } & \multicolumn{2}{c|}{ Female } \\
\cline { 2 - 5 } & Urban & Rural & Urban & Rural \\
\hline Part of the MoE curriculum & $27 \%$ & $25 \%$ & $14 \%$ & $0 \%$ \\
\hline About employment and business & $40 \%$ & $13 \%$ & $33 \%$ & $80 \%$ \\
\hline Improving economic condition & $20 \%$ & $13 \%$ & $12 \%$ & $0 \%$ \\
\hline Deals with business topics & $7 \%$ & $13 \%$ & $14 \%$ & $20 \%$ \\
\hline Exposing students' capabilities & $7 \%$ & $0 \%$ & $5 \%$ & $0 \%$ \\
\hline Deals with marketing strategies & $0 \%$ & $13 \%$ & $12 \%$ & $0 \%$ \\
\hline profit and loss & $0 \%$ & $13 \%$ & $0 \%$ & $0 \%$ \\
\hline Products & $0 \%$ & $13 \%$ & $5 \%$ & $0 \%$ \\
\hline Talks about small scale businesses & $0 \%$ & $0 \%$ & $5 \%$ & $0 \%$ \\
\hline
\end{tabular}

Now that $82 \%$ of the parent respondents shared their knowledge about Tashabos, it was necessary to have looked at source of information the parents had gotten on Tashabos. Nearly half of the respondents $(46 \%)$ acquired the information about Tashabos from their children. This was reckoned as a substantial step for expansion of the subject because it can be inferred that a communication on the subject has been sensible between children and parents. Another majority of parents $(37 \%)$ shared their viewpoints on Tashabos subject after they had studied the subject. This was also considered an important breakthrough for the program because a bulk of parents was interested to learn about the subject. Besides the two aforesaid sources, the remaining 13\% of the parents learned about Tashabos through other resources which include: Tashabos teacher; reading related articles; media; teaching Tashabos; attending seminars on Tashabos. It should be taken into consideration that the final $4 \%$ of the parents collected the information about the subject after participating in the exhibitions and BP competitions. Therefore, TEO can benefit exhibitions as a platform for advocating the subject among general populations. Chart 177 gives a complete overview of the sources of acquiring information on Tashabos. 
Chart 177: Sources of Acquiring Information on Tashabos

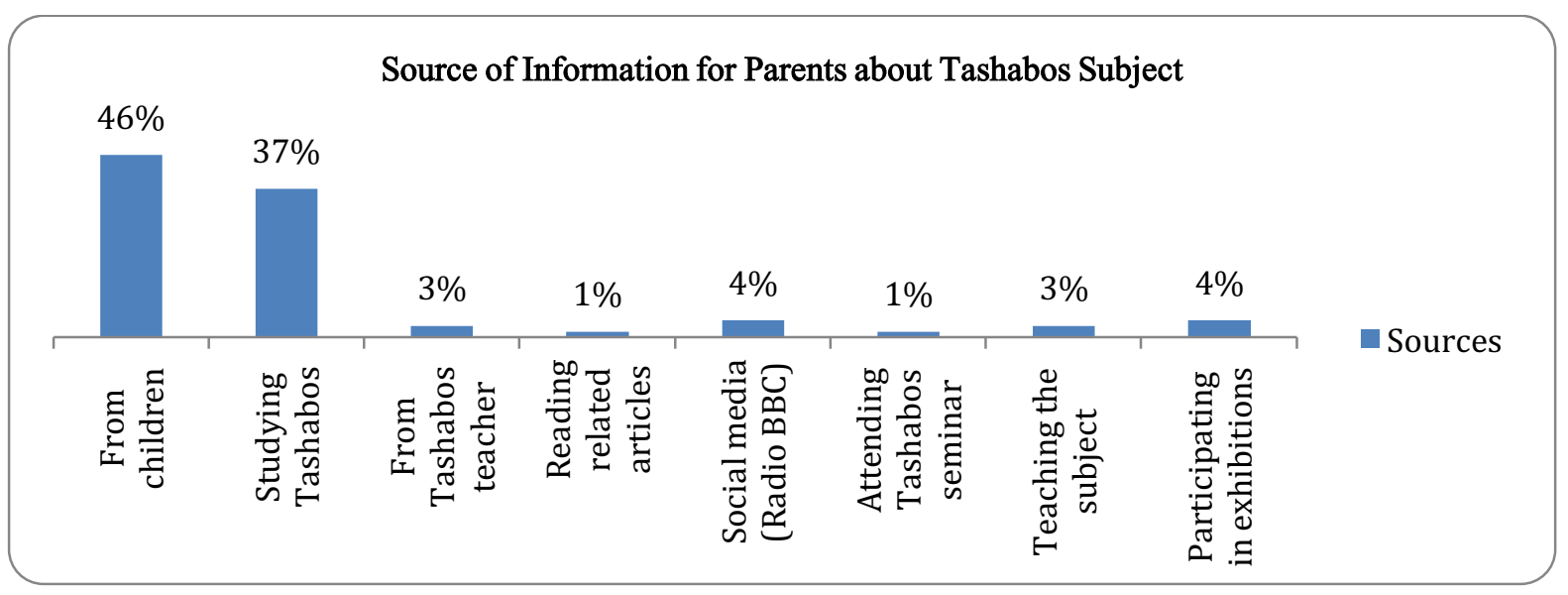

Source of information was a point of interest for the assessment, so the data was further analyzed to find out the varieties in information resources for male and female parents and in urban and rural areas. It was found that $54 \%$ of male parent respondents learned about Tashabos after studying the subject while $33 \%$ of the male parent respondents got information about the subject from their children. However, the opposite was true for female parent respondents as $52 \%$ of female parents learned about the subject from their children whereas $28 \%$ of them studied Tashabos to have learned about it. It should be mentioned that media was also useful in disseminating information about Tashabos as $4 \%$ of both male and female parent respondents were able to increase their knowledge about the subject. On the other hand, $7 \%$ of the female parents participated in the exhibition and BP competitions and understood something about the subject. Interestingly, in both urban and rural areas parents have learned about the subject from their children (43\% for urban areas and 56\% for rural areas) and studying the subject $39 \%$ for urban areas and $31 \%$ for rural areas). It should be discussed that relevant articles (6\% for rural areas) and media $(6 \%$ for rural areas) were useful sources for sharing knowledge of Tashabos in rural areas comparing to urban areas with $0 \%$ for relevant articles and $4 \%$ for media. Conversely, activities associated with Tashabos program itself were fruitful in increasing the knowledge of parents in urban areas comparing to rural areas as talking with Tashabos teacher ( $4 \%$ for urban areas), attending Tashabos seminars $(2 \%$ for urban areas), teaching Tashabos $(4 \%$ for urban

areas) and participating in exhibition (7\% in urban areas). However, none of the parent respondents in rural areas learned about the subject through activities related to Tashabos program itself. Table 3 explicitly explains how parents learned about the subject according to both gender types and locations.

Table 3: Sources of Acquiring Information on Tashabos According to Gender and Location

\begin{tabular}{|l|c|c|c|c|}
\hline \multirow{2}{*}{\multicolumn{1}{|c|}{ Sources }} & \multicolumn{2}{c|}{ Male } & \multicolumn{2}{c|}{ Female } \\
\cline { 2 - 5 } & Urban & Rural & Urban & Rural \\
\hline From children & $17 \%$ & $50 \%$ & $50 \%$ & $75 \%$ \\
\hline Studying Tashabos & $75 \%$ & $33 \%$ & $29 \%$ & $25 \%$ \\
\hline Others & $0 \%$ & $0 \%$ & $0 \%$ & $0 \%$ \\
\hline From Tashabos teacher & $0 \%$ & $0 \%$ & $5 \%$ & $0 \%$ \\
\hline Reading related articles & $0 \%$ & $8 \%$ & $0 \%$ & $0 \%$ \\
\hline Social media (Radio BBC) & $0 \%$ & $8 \%$ & $5 \%$ & $0 \%$ \\
\hline Attending Tashabos seminar & $8 \%$ & $0 \%$ & $0 \%$ & $0 \%$ \\
\hline Teaching the subject & $0 \%$ & $0 \%$ & $5 \%$ & $0 \%$ \\
\hline Participating in exhibitions & $0 \%$ & $0 \%$ & $7 \%$ & $0 \%$ \\
\hline
\end{tabular}




\section{Children's Interest to the Subject}

The program was able to gauge students' interest to the subject within school by analyzing pre- and post-test scores, assessing the attendance sheet of the students and participation of the students in BP competitions. At the same time, students' interest outside of school was important to have been measured. Therefore, specific questions were developed for the purpose. Since students are most often within their homes, parents were approached to learn about the students' interest to the subject. When the parents were asked if their children had been studying Tashabos at home, 92\% replied yes while the remaining $8 \%$ of the parents replied against. Among the $35 \%$ male parent respondents to this question, $89 \%$ replied that their children do study Tashabos at home, but $11 \%$ of the male parent respondents' children hadn't studied Tashabos at their homes. Similarly, of the total $65 \%$ female parent respondents, 94\% expressed that their children study Tashabos at home, while children of the remaining $6 \%$ female parents hadn't been interested to study the subject at their homes. In addition, it has been already mentioned that $76 \%$ of parents whose children were studying in urban schools and $26 \%$ parents whose children were studying at rural schools were interviewed. Rural schools' students were more interested to the subject than urban schools' students as children of $95 \%$ rural parents were studying the subject at their homes comparing to children of $92 \%$ urban parents. Charts 178 and 179 explains \% of parents' children studying the subject at their homes.

\section{Chart 178: Parent Respondents' Children Study Tashabos at Home}

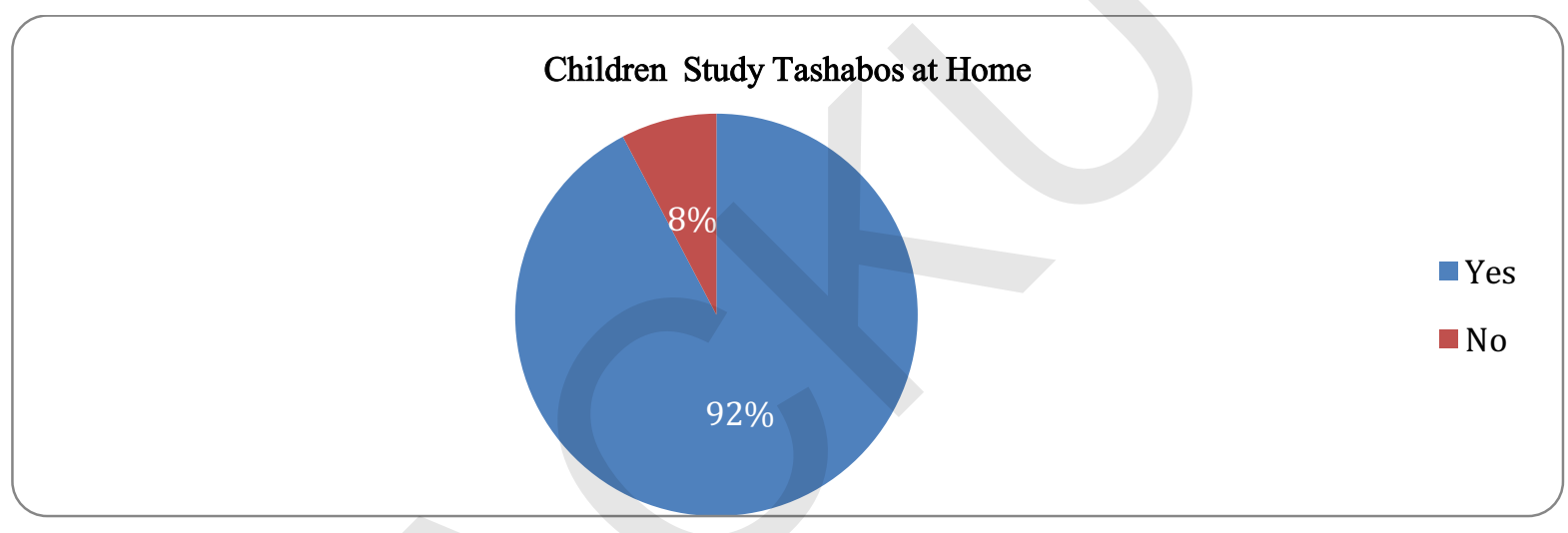

Chart 179: Parent Respondents' Children Study Tashabos at Home according to Gender and Location

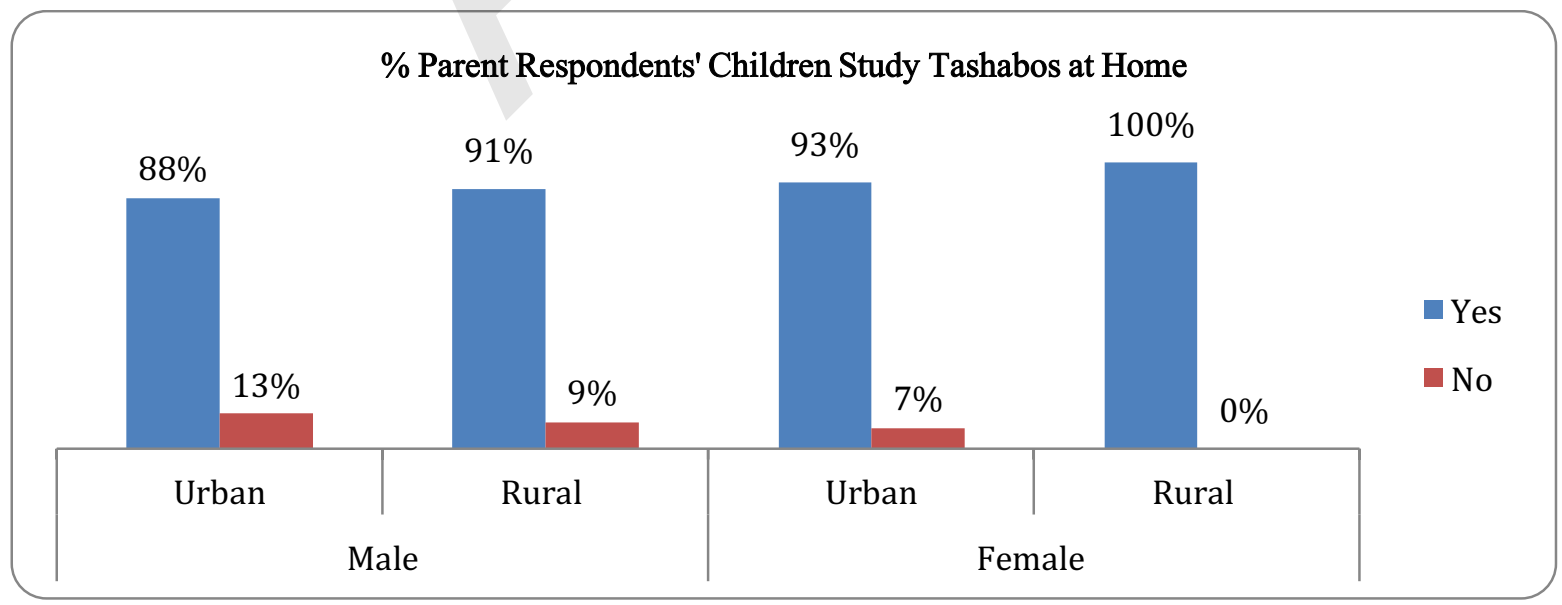

Since a very large number of children were studying Tashabos at home besides studying at school, it was necessary to know why the students are interested to study the subject a lot. Nearly one third $(31 \%)$ of the parent respondents believed that because Tashabos was one of the school subjects, their children had to study the subject at home along with school. Interestingly, educated parents of at least high schools have said that Tashabos is one of the school's subjects. In addition, nearly one fourth $(23 \%)$ of 
the parents thought Tashabos increases self-reliability of the children, so the children tend to study the subject at home as well. 19\% of the parent respondents mentioned "learning about business" as a sole cause for children's interest to the subject, while $11 \%$ of parents said their children have found the subject interesting for themselves, hence they tend to give extra time to study the subject. At the same time, there were various reasons noted by the remaining $16 \%$ of parent respondents for children's interest to the subject and these include: how to write business proposals (4\%), to have income (6\%), to commence a new business $(5 \%)$ and to learn about profit and loss $(1 \%)$. Chart 180 shows various reasons mentioned by parents for their children's interest to the subject.

\section{Chart 180: Reasons for Children's Interest to the Subject}

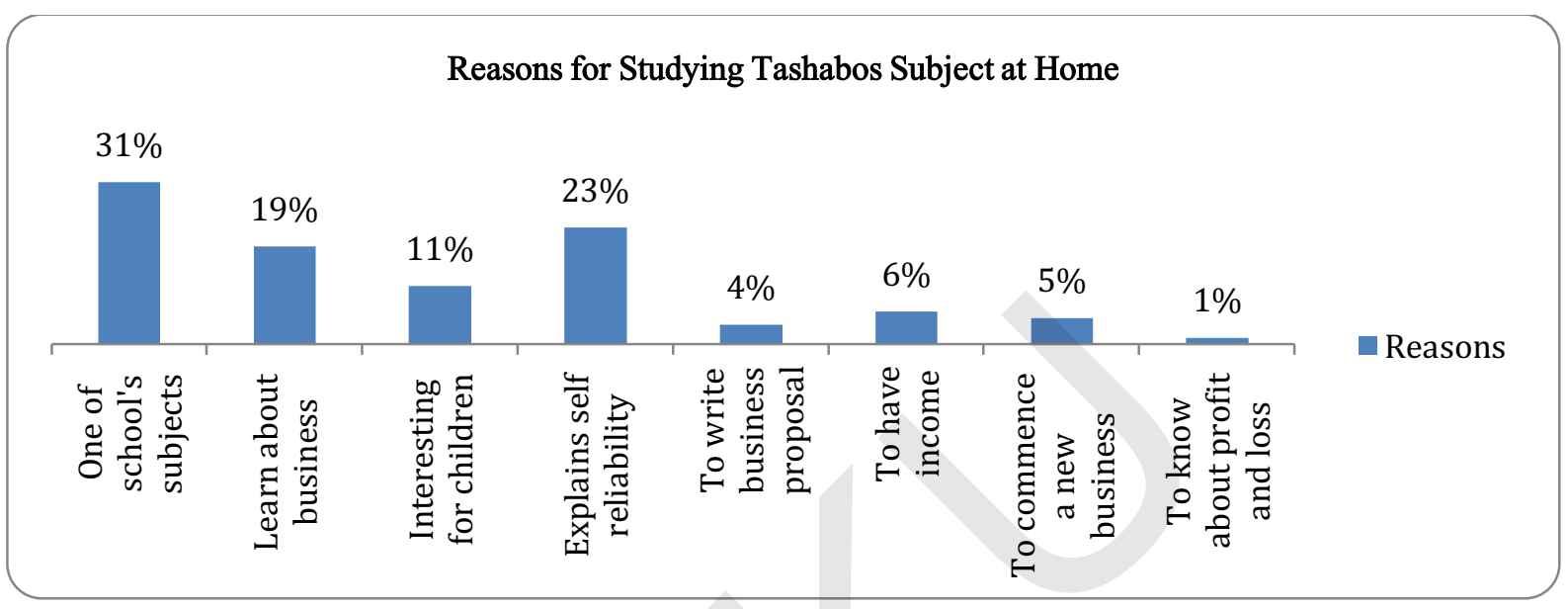

After further analysis of the data according to gender and location, it was found that the first three most important ideas for both male and female parent respondents varied as $35 \%$ male parent respondents believed that Tashabos is one of the school's subjects and their children should study the subject at home. On the other hand, $22 \%$ of the parents mentioned that their children want to know about business and $13 \%$ of them argued that their children tend to study the subject because Tashabos improves selfreliability of the students. Thoughts of $30 \%$ of female parent respondents were alike the $35 \%$ male parent respondents as they also believed Tashabos was among their children's school subjects and that is why their children study the subject both at home and school. However, unlike the male parent respondents, $26 \%$ of female parent respondents gave importance to "Tashabos increases self-reliability of their children" and for the reason their children have been keen to study the subject at home as well. Finally, $18 \%$ of the female parent respondents talked about their children's ambitions to learn about business and for the reason their children were eager to learn about the subject. "Tashabos subject is one of school's subject", "Tashabos explains self-reliability" and "Tashabos used to learn about business" were the sole reasons for $34 \%, 27 \%$ and $17 \%$ parent respondents in urban areas behind their children's interest to the subject. On the other hand, 25\%, 19\% and 13\% parents in rural areas believed that "Tashabos teaches business", "Tashabos was a school subject" and "children found the subject interesting". Therefore, the reasons behind studying Tashabos at home was somehow universal to both male and female parent respondents and for parent respondents in both urban and rural areas. Chart 181 depicts the complete picture of reasons for children's interest to the subject based on their parents' perspectives in both urban and rural areas. 
Chart 181: Reasons for Children's Interest to Subject (Parents' Perspectives)

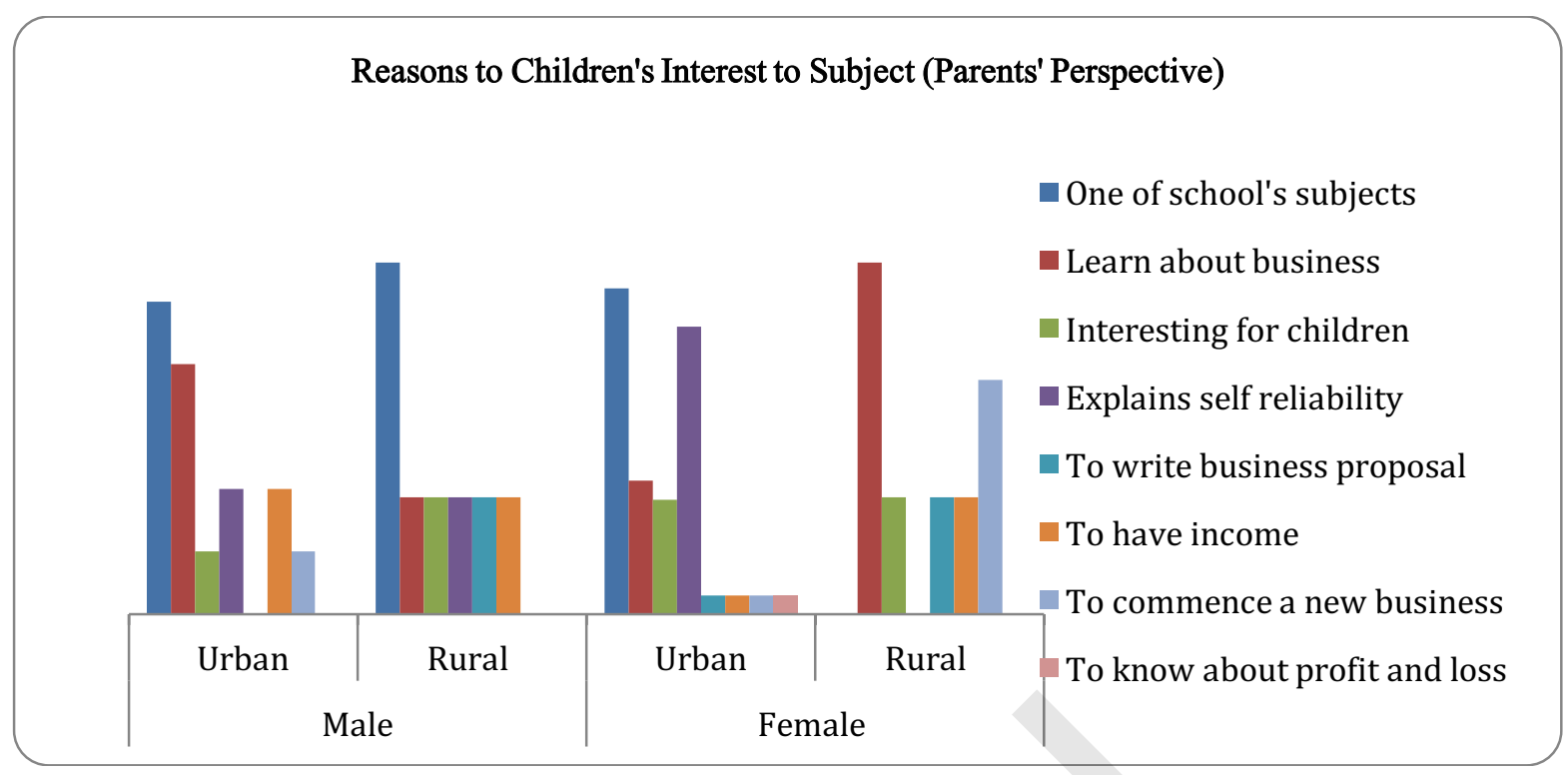

\section{Socioeconomic Effects of Tashabos (Parents' Perspectives)}

As it is discussed among the objectives of teaching Tashabos is to understand students on principles of business and ultimately empower them to become self-reliant. In addition, it is evident if students initiate a business and become self-reliable, surely the life of the student is affected socioeconomically as inherent changes are observed within his/her personality. Therefore, all the parent respondents were asked if Tashabos subject is socioeconomically effective on students' lives. As expected $96 \%$ of the parent respondents answered positively that the subject has socioeconomic effects on their children's lives. $4 \%$ parents who negatively replied to the question were parents who didn't have information about Tashabos subject. Chart 182 shows the percentage of parents agreed with the socioeconomic effects of the subject.

\section{Chart 182: Tashabos Effective on Children's Socioeconomic Lives (Parents' Perspectives)}

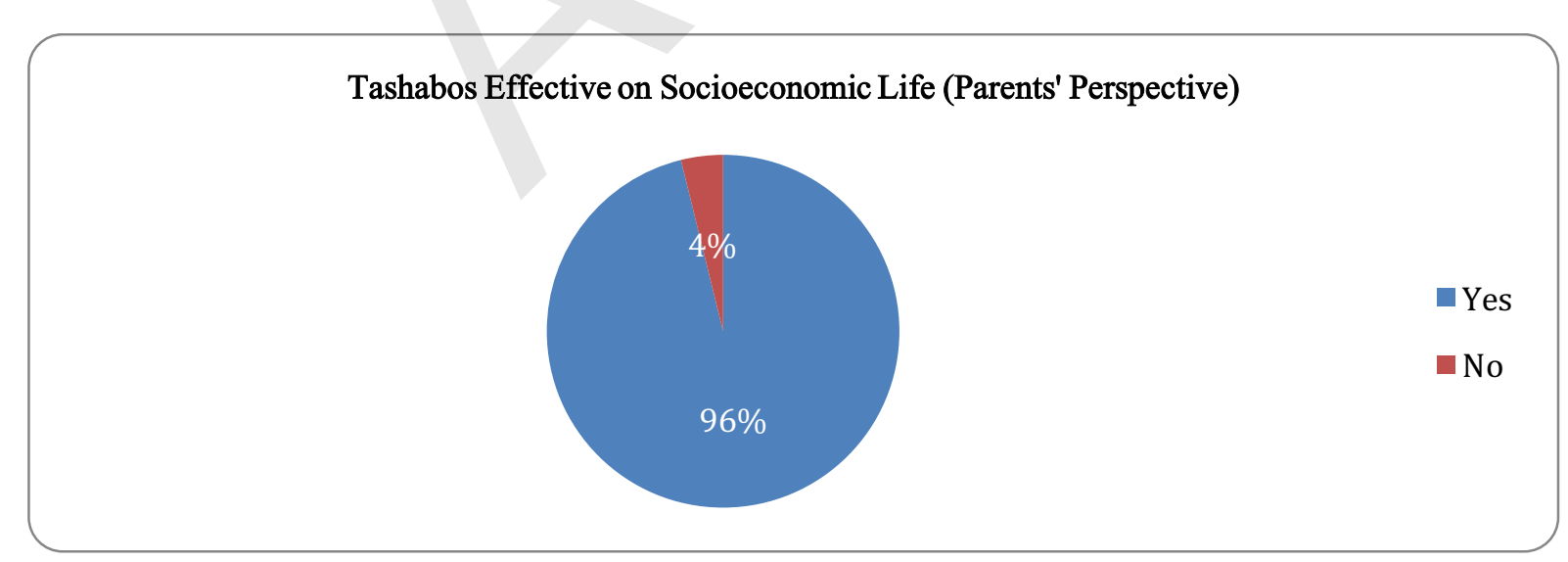

It should be taken into consideration that $96 \%$ of both male and female parent respondents replied that Tashabos does affect their children's socioeconomic lives. However, talking about the location of the respondents, it was found that all the parent respondents in rural areas agreed with socioeconomic effects of Tashabos on their children's lives while in urban areas only $95 \%$ of parents agreed with the above statement. On the other hand, in urban areas more female parent respondents (95\%) approved socioeconomic effects of Tashabos comparing to male parent respondents $(94 \%)$. However, as mentioned in rural areas, all the parent respondents both male $(100 \%)$ and female $(100 \%)$ cited about the 
socioeconomic effects of Tashabos. Chart 183 shows parents' agreement to socioeconomic effects of Tashabos in urban and rural areas.

\section{Chart 183: Parents' Agreement to Socioeconomic Effects of Tashabos in Urban and Rural Areas}

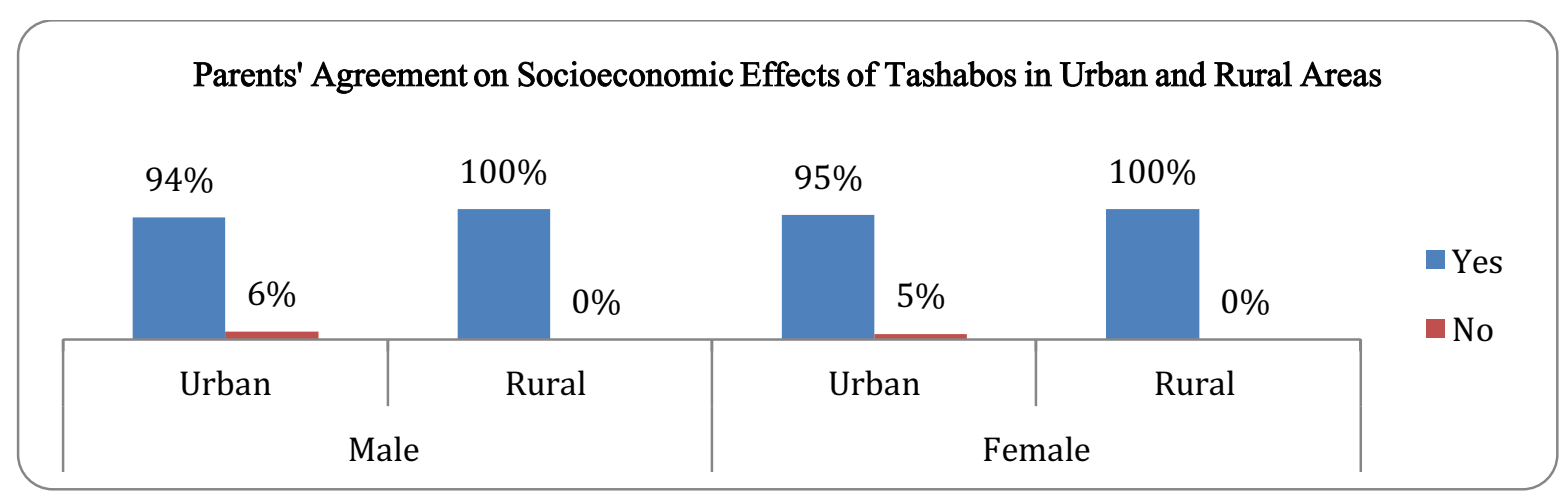

Tashabos and Business/Employment

The program knew that Tashabos is beneficial to initiate/expand a business and at the same time look for/secure employments. Therefore, the program wanted to explore if Tashabos concepts have been/will be utilized by the parents or their children in either business or employment. Therefore, all the parent respondents were asked if they have ever run a business. After replying to the question, 55\% parents have had run a business while the remaining $45 \%$ have never been engaged with business. As expected nearly two folds of male parent respondents $(81 \%)$ have run business comparing to female parent respondents $(41 \%)$. Surprisingly, business was more common as an employment for parents in rural areas $(79 \%)$ comparing to parents in urban areas $(47 \%)$. Therefore, it can be expressed that in rural areas more parents both male $(91 \%)$ and female $(63 \%)$ have run businesses comparing to both male $(75 \%)$ and female (37\%) parents in urban areas. Charts 184, 185 and 186 depicts parents' involvement in business.

\section{Chart 184: Parents Ever Run a Business}

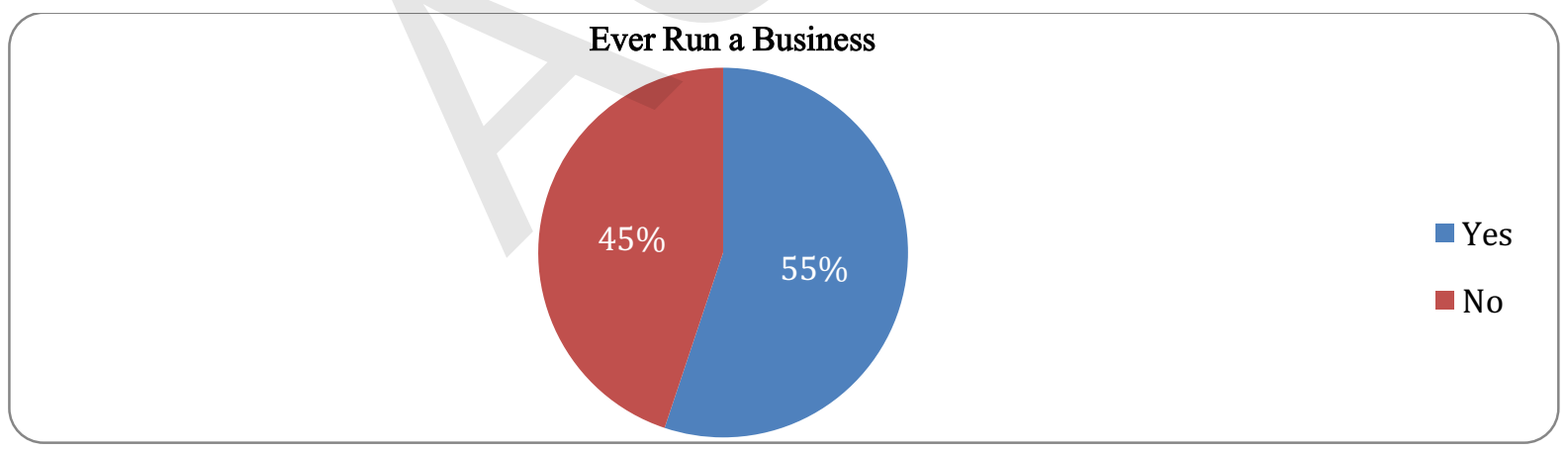

Chart 185: \% Male and Female Parents Involved in Business (Left) and \% Parents Involved in Business in Urban and Rural Areas (Right)

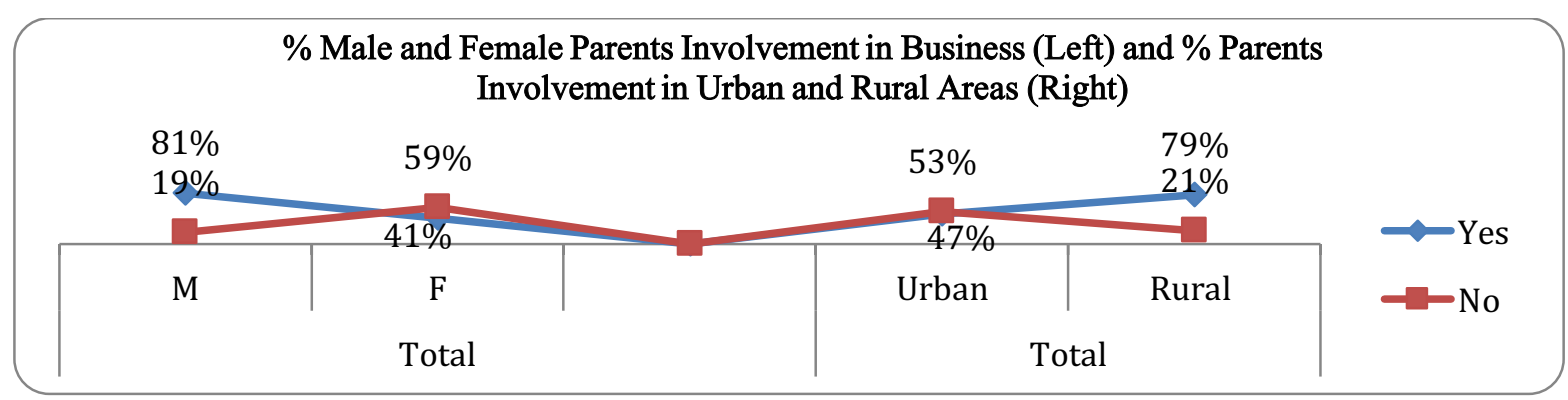




\section{Chart 186: Parents' Involvement in Business}

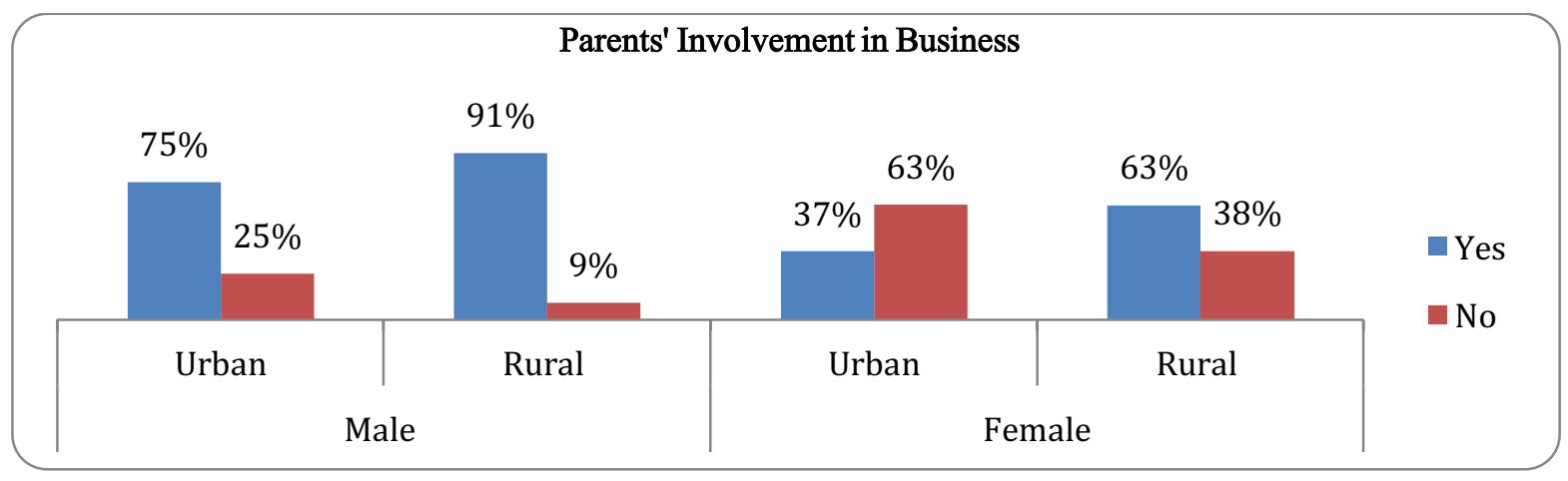

The program also wanted to know if concepts of Tashabos are utilized within their business. Therefore, the parents who had run business were asked about it and 64\% of the parents responded positively whereas the remaining $36 \%$ went against it. Female parent respondents $(75 \%)$ have used the knowledge of Tashabos within their business more than male parent respondents $(33 \%)$ and the knowledge was used by parents in urban areas (68\%) comparing to parents in rural areas $(33 \%)$. In addition, considering the gender and location, it was found that female parents in both urban $(73 \%)$ and rural areas $(100 \%)$ have been benefited by the concepts of Tashabos in their business comparing to male parents in both urban $(50 \%)$ and rural $(0 \%)$ areas. Charts 187 and 188 explains the usage of Tashabos concepts in their business.

\section{Chart 187: Used the Concepts of Tashabos in Business}

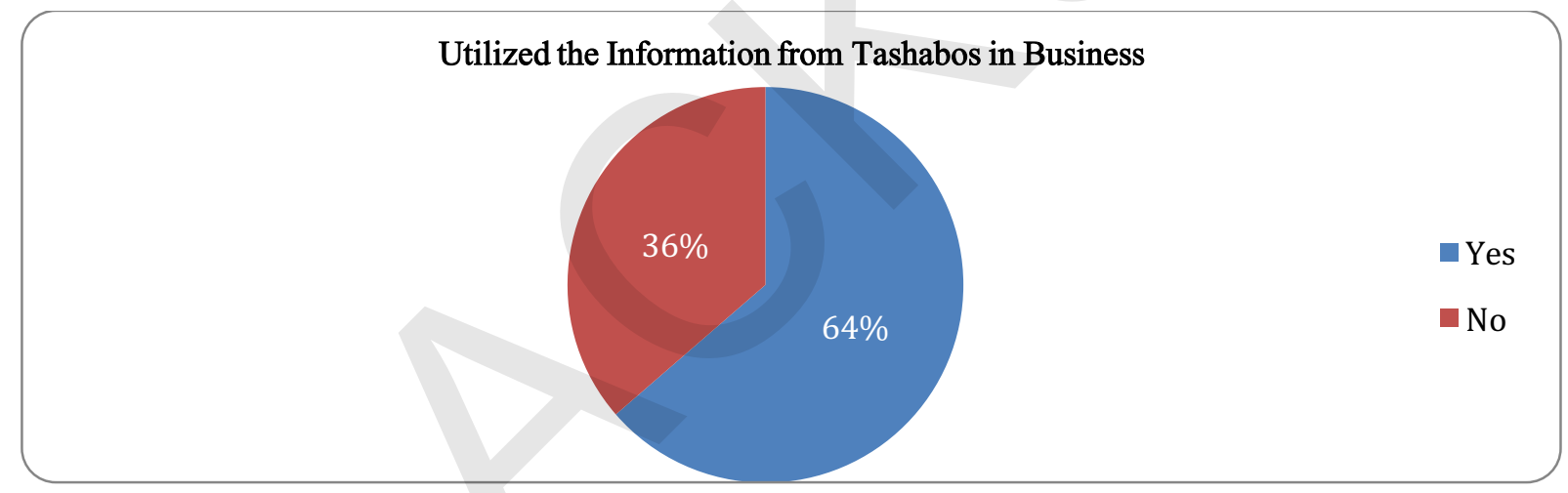

Chart 188: Utilization of Tashabos Concepts in Business

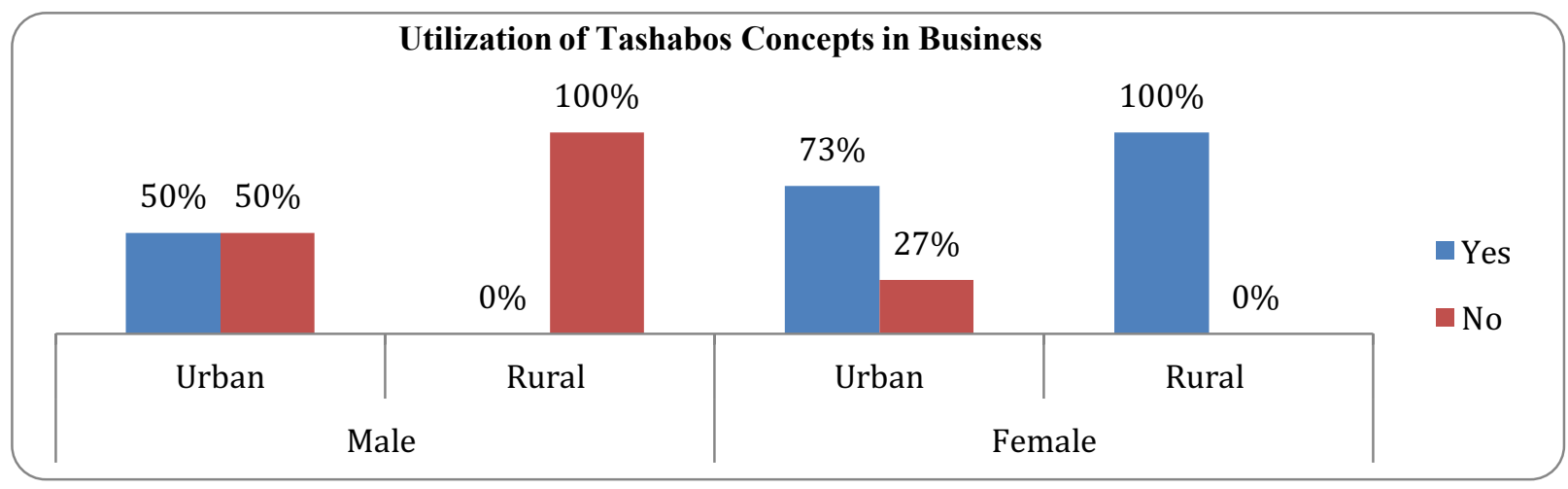

Now, the parent respondents who did use the knowledge of Tashabos in their businesses were asked to explain the role of the knowledge in running their businesses. The majority of the parent respondents (70\%) replied that using the knowledge have made their businesses more successful, while the $20 \%$ of the parents were saying that the knowledge had a motivating role for their businesses because of the 
effectiveness of concepts in guiding the business towards success. At the same time, the final $10 \%$ of the parent respondents insisted with knowledge they were able to attract investments. To summarize, as per the conception of the parents if the knowledge of Tashabos is rightly utilized in the business, the business would move toward the successful ends with gains, profits and expansion of the business. 57\% of Male parent respondents had successful businesses after using the information of Tashabos, while $29 \%$ of male parent respondents were talking about attraction of investments and for $14 \%$ of the male parent respondents the knowledge was motivating for their businesses. Conversely, nearly three fourth $(77 \%)$ of the female parent respondents mentioned that with using the knowledge of Tashabos they have become successful businesspersons, but the remaining $23 \%$ of the female parent respondents were motivated after incorporating the knowledge of Tashabos within their businesses. On the other hand, the highest three responses from parent respondents in both urban and rural areas matched as $69 \%$ urban parent respondents and 75\% rural parent respondents explained the success of their business with the concepts of Tashabos, while Tashabos subject motivated 19\% urban parent respondents and $25 \%$ rural parent respondents within their businesses. However, only $13 \%$ parents were able to attract investments in the urban areas comparing to $0 \%$ in rural areas. Charts 189 and 190 explains the roles of Tashabos concepts in businesses.

\section{Chart 189: Role of Tashabos in Running Business}

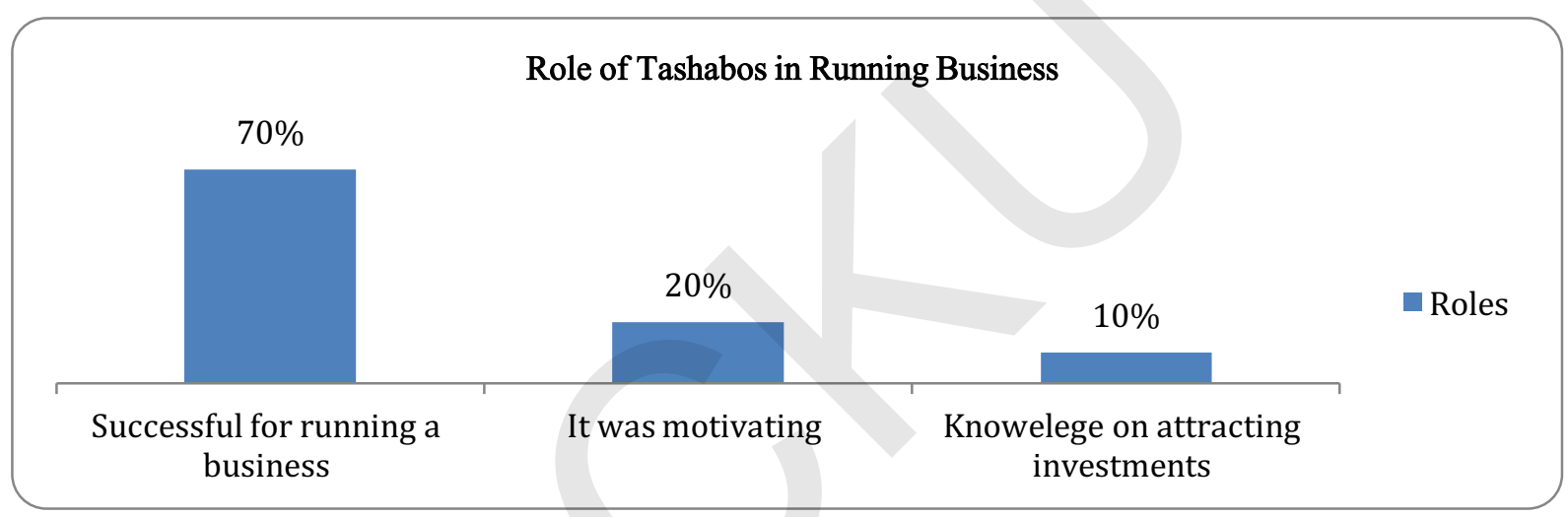

Chart 190: Importance of Utilizing Tashabos Knowledge in Business

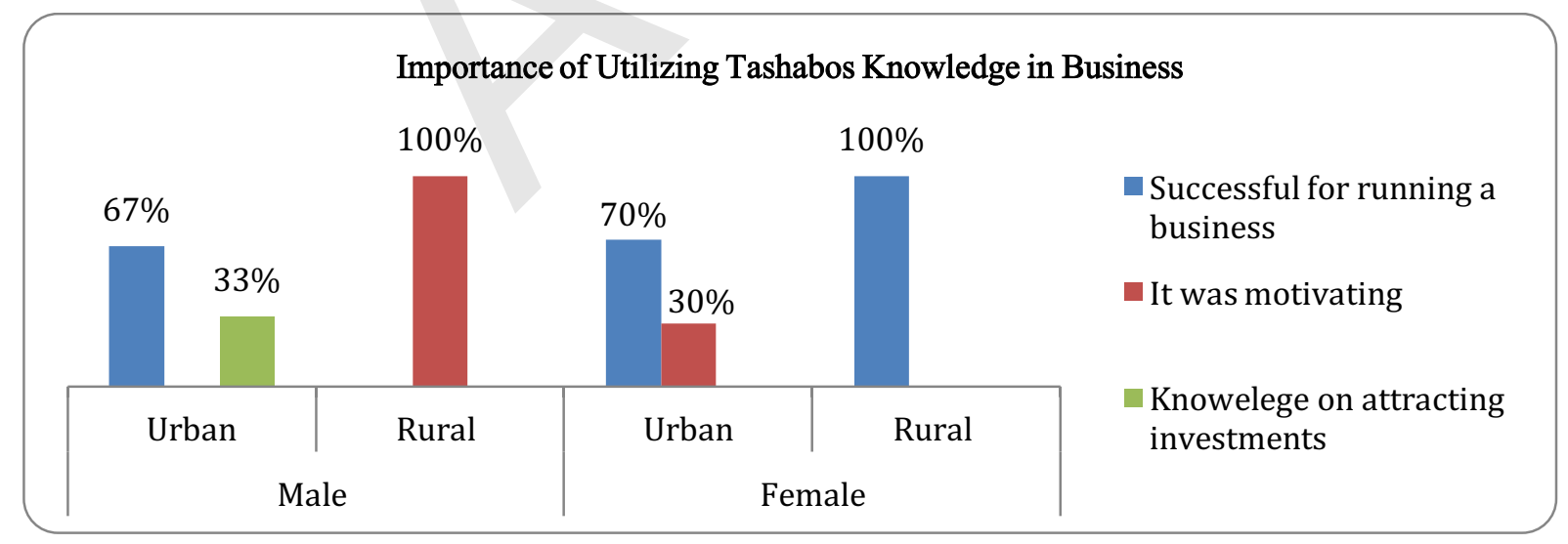

After knowing about the facts of importance of Tashabos subject from parent respondents, the program wanted to know assess the consensus level of the parents if their children are able to initiate/expand a business with the help of knowledge they acquire from the subject. Therefore, all the parent respondents were questioned if the knowledge from the subject would help their children to either initiate or expand a business. Considering the importance of Tashabos over nine tenth $(93 \%)$ of the parent respondents heavily answered that their children could easily initiate/expand a business, while $7 \%$ of the parents who didn't have information about the subject rejected the belief of initiating/expanding a business with the help of Tashabos. It was further revealed that male parent respondents with $96 \%$ had more faith on the 
subject for initiating/expanding a business comparing to female parent respondents with $92 \%$ Conversely, all the parent respondents $(100 \%)$ in rural areas believed that their children could easily initiate/expand a business with the help of Tashabos comparing to parent respondents in urban areas $(91 \%)$. In addition, it was found that parent respondents both male (100\%) and female $(100 \%)$ in rural areas thought that their children would initiate/expand a business with the help of the subject comparing to parent respondents both male (93\%) and female (91\%) in urban areas. Charts 191 and 192 explain more about the parents' perceptions regarding initiating/expanding a business with the help of the subject.

\section{Chart 191: Children Able to Initiate/Expand a Business (Parents'Perspectives)}

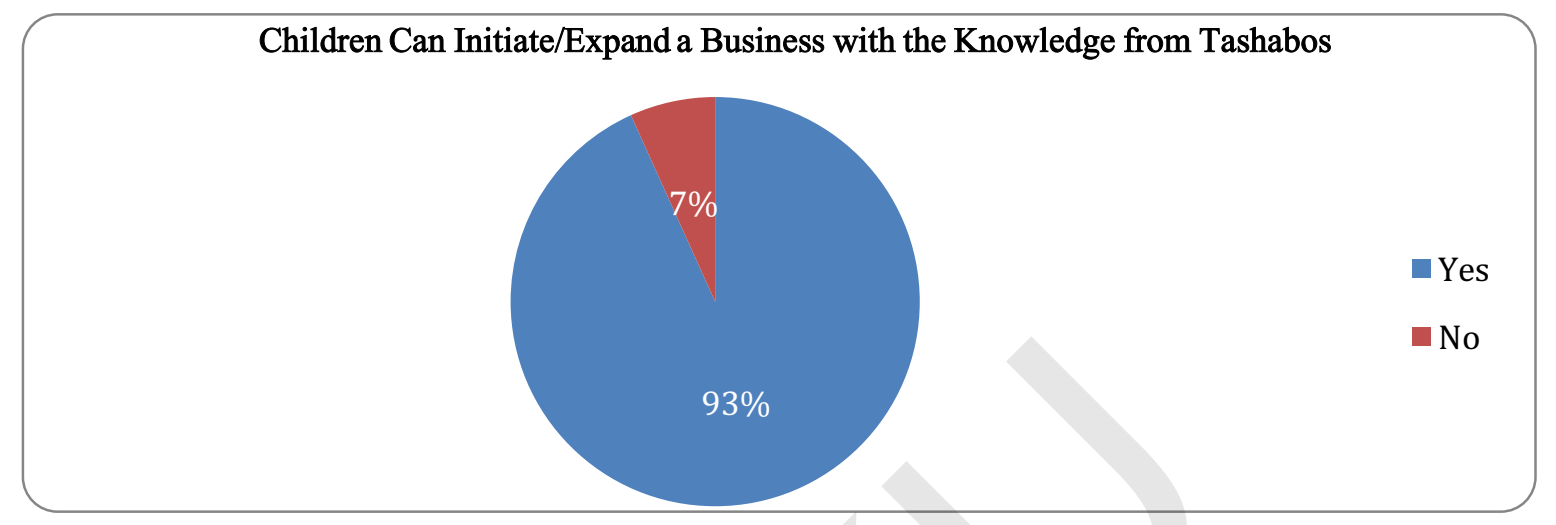

Chart 192: Parents'Perceptions on Children Able to Initiate/Expand a Business

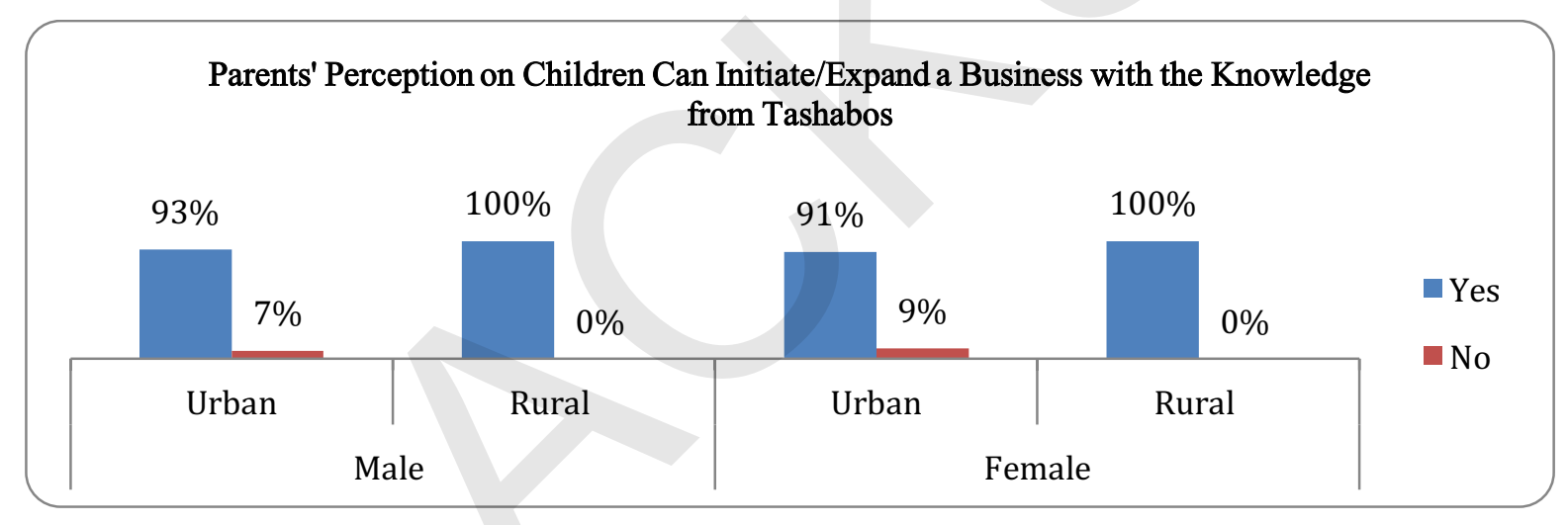

When a business is either initiated or expanded, the level of success and effectiveness needs to be examined as well. Therefore, the parent respondents who believed that with the knowledge from Tashabos their children can initiate/expand a business were asked about the success of businesses initiated/expanded with the help of knowledge from Tashabos. As expected more than half of the parent respondents (52\%) believed that the businesses will be very successful if run on the basis of Tashabos principles. On the other hand, 39\% of the parent respondents said the businesses will be successful, but moderately and the remaining $8 \%$ of the parent respondents were thinking if a business is initiated or expanded with the help of Tashabos concepts, it might be somehow successful considering the lower experience of their children in business. Fortunately, none of the parent respondents mentioned about failures of the business if established and run using Tashabos ideas and principles. Chart 193 shows the percentage of parents explained the success level of businesses initiated/expanded with the concepts from Tashabos. 
Chart 193: Success Level of the Businesses Initiated/Expanded with the Help of Knowledge from Tashabos (Parents' Perspectives)

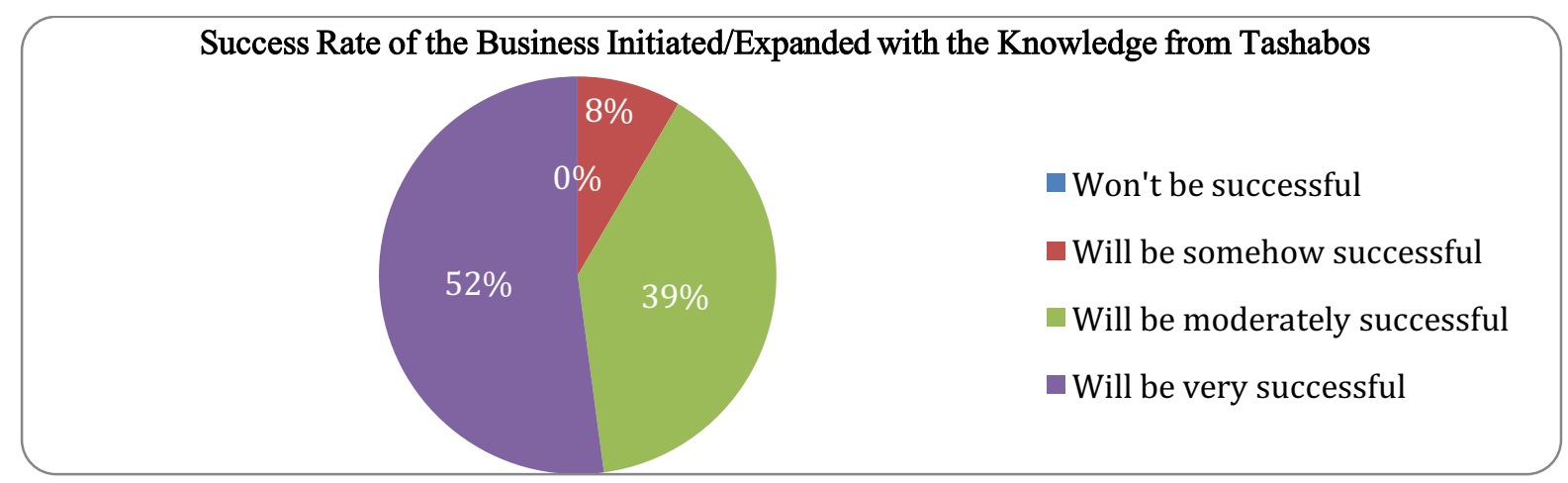

It was, then, found that female parents with 55\% were more confident than male parents with $46 \%$ that the businesses would be very successful. However, business being moderately successful was the belief for male parents $(50 \%)$ to female parents $(34 \%)$. In addition, $11 \%$ of the female parents argued that the businesses would be successful while lower percentage of male parents $(4 \%)$ agreed the idea with female parents. 54\% parents from urban areas mentioned that the businesses will be very successful. This should be stressed that the figure has surpassed percentage of parents in rural areas as only $47 \%$ of the parents also thought businesses' high success. Conversely, parents in rural areas were thinking that businesses would be moderately $(42 \%)$ and somehow $(11 \%)$ successful. It should be mentioned pros of these ideas in urban settings were fewer with $38 \%$ thinking of moderate success and $8 \%$ of somehow success. After further disaggregation of the data, it was explored that urban male parents $(46 \%)$ to rural male parents $(45 \%)$ were anticipating higher success of the businesses, but larger number of rural male parents $(55 \%)$ to urban male parents $(46 \%)$ believed that the businesses would be moderately successful and the reverse was true for somehow success of the business as only $8 \%$ of urban male parents were thinking such. Urban female parents believed that with the support of Tashabos ideas the businesses would be either very successful (56\% comparing to rural female parents with $50 \%)$ or moderately successful $(36 \%$ comparing to rural female parents with $25 \%$ ). However, rural female parents $(25 \%)$ were more in numbers to have thought businesses somehow successful comparing to urban female respondents $(8 \%)$. Table 4 , 5 and 6 explain the levels of business success if initiated or expanded with the concepts of Tashabos.

Table 4: Success Level of Business if Initiated or Expanded with the Concepts of Tashabos (Parents' Perspectives)

\begin{tabular}{|l|c|c|}
\hline Success Levels & M & F \\
\hline Won't be successful & $0 \%$ & $0 \%$ \\
\hline Will be somehow successful & $4 \%$ & $11 \%$ \\
\hline Will be moderately successful & $50 \%$ & $34 \%$ \\
\hline Will be very successful & $46 \%$ & $55 \%$ \\
\hline
\end{tabular}


Table 5: Success Level of Business if Initiated or Expanded with the Concepts of Tashabos (Parents' Perspectives)

\begin{tabular}{|l|c|c|}
\hline Success Levels & Urban & Rural \\
\hline Won't be successful & $0 \%$ & $0 \%$ \\
\hline Will be somehow successful & $8 \%$ & $11 \%$ \\
\hline Will be moderately successful & $38 \%$ & $42 \%$ \\
\hline Will be very successful & $54 \%$ & $47 \%$ \\
\hline
\end{tabular}

Table 6: Success Level of Business if Initiated or Expanded with the Concepts of Tashabos (Parents' Perspectives)

\begin{tabular}{|l|c|c|c|c|}
\hline \multirow{2}{*}{\multicolumn{1}{|c|}{ Success Levels }} & \multicolumn{2}{c|}{ Male } & \multicolumn{2}{c|}{ Female } \\
\cline { 2 - 5 } & Urban & Rural & Urban & Rural \\
\hline Won't be successful & $0 \%$ & $0 \%$ & $0 \%$ & $0 \%$ \\
\hline Will be somehow successful & $8 \%$ & $0 \%$ & $8 \%$ & $25 \%$ \\
\hline Will be moderately successful & $46 \%$ & $55 \%$ & $36 \%$ & $25 \%$ \\
\hline Will be very successful & $46 \%$ & $45 \%$ & $56 \%$ & $50 \%$ \\
\hline
\end{tabular}

Afterwards the parents were questioned how the concepts of Tashabos have dealt with the success of the businesses. However, the parents' responses are for all the four success levels mentioned above. Nearly six tenth $(58 \%)$ of the parent respondents viewed that Tashabos concepts guide the businesses to the right directions, so the chances for the higher success of the businesses increase. However, thoughts of the second highest number of parent respondents were supporting either somehow success or moderate success because $13 \%$ of the parent respondents stressed that lower experience of their children in business. It is inferred that the subject is not the cause for lower success of the businesses, but lower experiences of their children in managing business. At the same time, $12 \%$ of the parent respondents were talking about interests of their children for small scale businesses. It, therefore, explains that the small scale businesses would be very successful if initiate/expanded with the help of Tashabos. When the data was further analyzed, it was found that more female parents $(62 \%)$ believed that Tashabos is effective in guiding the business toward the right directions comparing to male parents $(57 \%)$. However, $13 \%$ of male parents believed that inclusion of the Tashabos concepts into the business resulted in higher income level while the idea was supported by lower number of female respondents $(4 \%)$. In addition, the other $13 \%$ of parent respondents were taking increased knowledge of their children on principles of business by the subject into consideration for success of the business, but only $4 \%$ of female parents backed the thoughts of male parents. On the other hand for female parent respondents it was discovered that "lower experiences of their children" was the thought for second highest female parent respondents with $16 \%$ whereas only $7 \%$ of the male parents were agreed in this regards. Besides, $13 \%$ of the female parents believed that with the help of Tashabos their children would be able to initiate/expand a successful small scale business, but the notion had small supporters from the opposite gender (7\%). When analyzing the location of the respondents, it was revealed that both urban $(57 \%)$ and rural $(62 \%)$ parents believed that Tashabos would rightly guide the business. However, $17 \%$ of urban parents were talking about the lower experiences of their children rather than effectiveness of the subject towards successful business and $13 \%$ of the parents in urban areas were thinking about the importance of Tashabos in success of small scale businesses. Conversely, $15 \%$ of the rural parents amended the success of the business to increased knowledge of their children on business principles. This was never possible without the help Tashabos. Similarly, only $8 \%$ of the rural parents were linking the importance of the 
subject with small scale businesses. Chart 194 and Table 7 give the complete information about reasons for success of the businesses initiated or expanded with the help of Tashabos subject.

\section{Chart 194: Reasons for Success in the business Initiated/Expanded with Tashabos Concepts}

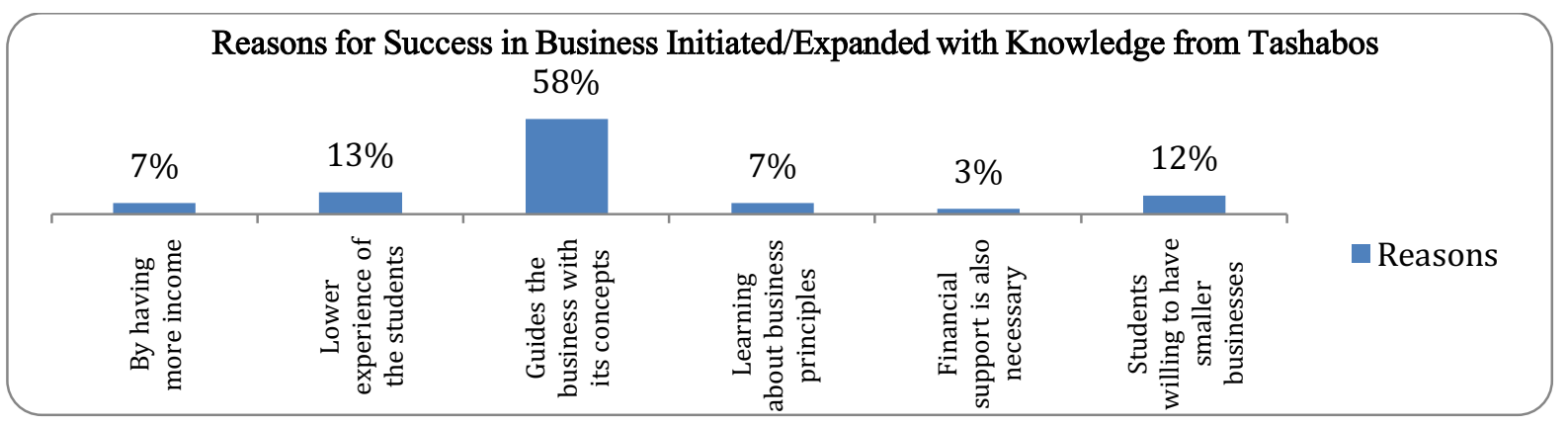

Table 7: Reasons for Success in Businesses Initiated/Expanded with Knowledge from Tashabos (Parents' Perspectives)

\begin{tabular}{|l|c|c|c|c|c|c|c|c|}
\hline \multirow{2}{*}{ Reasons } & \multicolumn{2}{|c|}{ Gender } & \multicolumn{2}{c|}{ Location } & \multicolumn{2}{c|}{ Male } & \multicolumn{2}{c|}{ Female } \\
\cline { 2 - 10 } & $\mathrm{M}$ & $\mathrm{F}$ & Urban & Rural & Urban & Rural & Urban & Rural \\
\hline By having more income & $13 \%$ & $4 \%$ & $6 \%$ & $8 \%$ & $14 \%$ & $13 \%$ & $5 \%$ & $0 \%$ \\
\hline $\begin{array}{l}\text { Lower experience of the } \\
\text { students }\end{array}$ & $7 \%$ & $16 \%$ & $17 \%$ & $0 \%$ & $14 \%$ & $0 \%$ & $18 \%$ & $0 \%$ \\
\hline $\begin{array}{l}\text { Guides the business with its } \\
\text { concepts }\end{array}$ & $53 \%$ & $60 \%$ & $57 \%$ & $62 \%$ & $57 \%$ & $50 \%$ & $58 \%$ & $80 \%$ \\
\hline $\begin{array}{l}\text { Learning about business } \\
\text { principles }\end{array}$ & $13 \%$ & $4 \%$ & $4 \%$ & $15 \%$ & $0 \%$ & $25 \%$ & $5 \%$ & $0 \%$ \\
\hline $\begin{array}{l}\text { Financial support is also } \\
\text { necessary }\end{array}$ & $7 \%$ & $2 \%$ & $2 \%$ & $8 \%$ & $0 \%$ & $13 \%$ & $3 \%$ & $0 \%$ \\
\hline $\begin{array}{l}\text { Students willing to have } \\
\text { smaller businesses }\end{array}$ & $7 \%$ & $13 \%$ & $13 \%$ & $8 \%$ & $14 \%$ & $0 \%$ & $13 \%$ & $20 \%$ \\
\hline
\end{tabular}

Apart from business, the program also wanted to assess if Tashabos is also effective in securing employments for the students. Therefore, all the parent respondents were questioned if Tashabos subject is beneficial for their children to get employments. Of the total parent respondents, $91 \%$ agreed with the effectiveness of Tashabos in employments for their children, but only $9 \%$ of the parent respondents opposed. When analyzed further, it was found that female parent respondents $(94 \%)$ were more faithful on the effectiveness of Tashabos in securing employments for their children comparing to male parent respondents $(85 \%)$. On the other hand, parent in urban areas (92\%) outnumbered parents in rural areas $(89 \%)$ in accepting the fact that Tashabos is a useful subject when it comes to securing employments for their children. When both gender and location of the respondents were analyzed, it was found that male parents in rural areas $(91 \%)$ were talking about the effectiveness of the subject in securing employments comparing to male parents in urban areas $(81 \%)$. Reverse of the story was true for female parent respondents as more of female parent respondents in urban areas (95\%) believed their children would be able to get employments with the help of Tashabos comparing to female parent respondents in rural areas $(88 \%)$. Charts 195 and 196 depict the complete overview of the parents' agreement in effectiveness of the subject in securing employments for their children. 
Chart 195: Securing Employments for the Parent Respondents' Children with the Help of Knowledge from Tashabos.

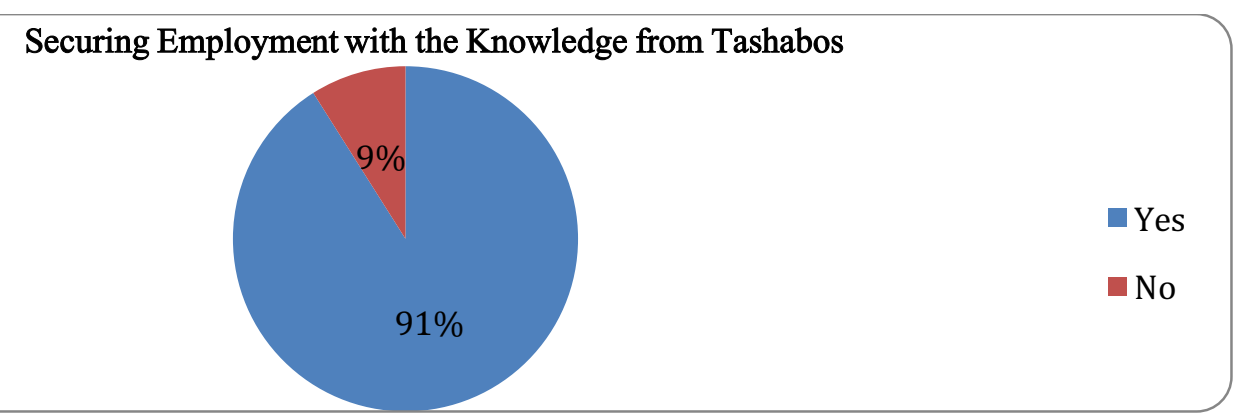

Chart 196: Securing Employments with the Knowledge from Tashabos (Parents' Perspectives)

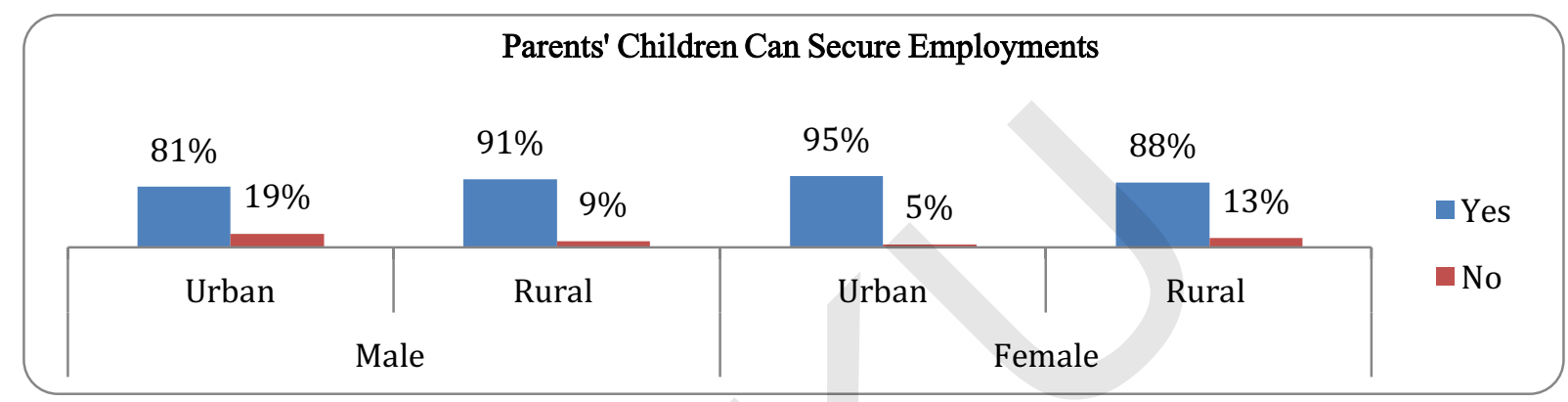

Afterwards the parents were asked about the causes of securing employments by their children with the help of knowledge they get from Tashabos. Over half of the parent respondents (53\%) replied that Tashabos opens the minds of their children about the concepts and principles of employments. Therefore, their children would be able to secure employments with increased knowledge about employments. The second highest group of parent respondents (18\%) thought that Tashabos gives birth to business ideas to their children and their children could pick a suitable business and employments among the buffet for themselves after analyzing their capabilities. In addition, $12 \%$ of the parents added that Tashabos motivates their children for employments and after such motivations their children would definitely be able to secure employments. At the same time, $10 \%$ of the parent respondents were talking about initiating business with small investments. They explained that Tashabos has motivated their children to initiate a business even with small investments and further expand and develop the business. The remaining $8 \%$ of the parent respondents also gave a mix of views in regards to importance of Tashabos in securing employments. Chart 197 explains the various reasons for importance of Tashabos in securing employments.

\section{Chart 197: Reasons for Importance of Tashabos in Securing Employments}

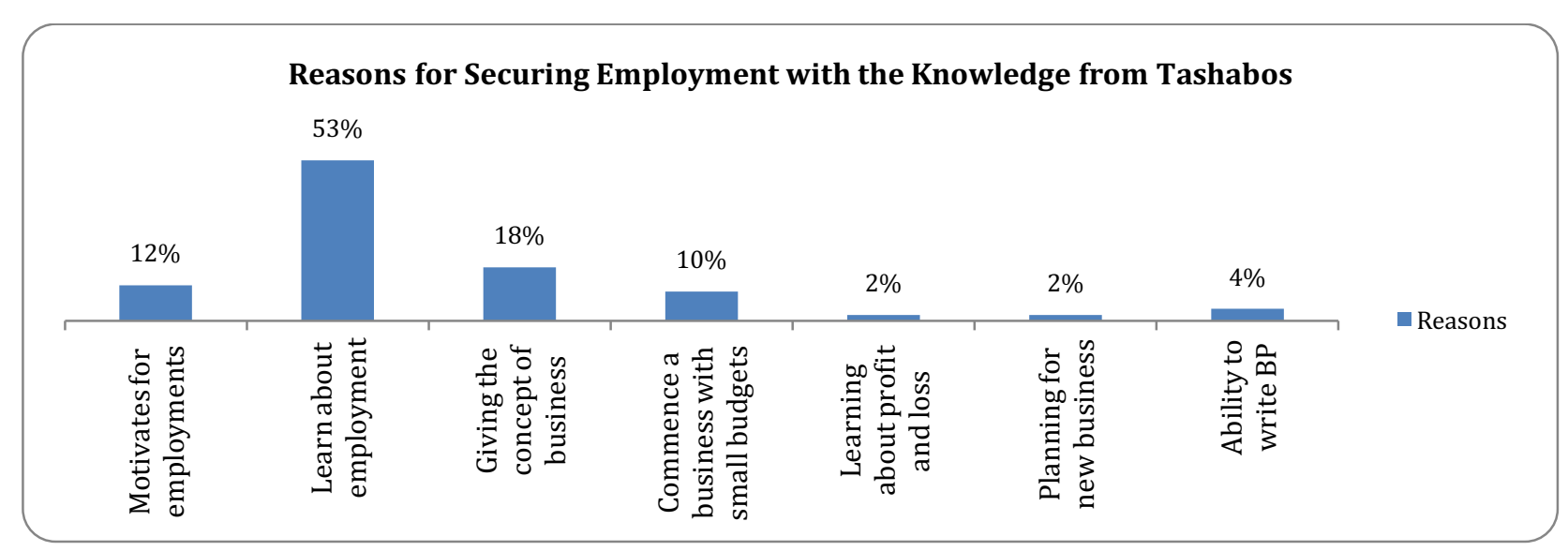




\section{Chapter 3: Conclusions and Recommendations}

\section{Conclusions:}

1: TEO has been able to create a great platform for the students with ultimate vision of students' economic empowerment because there were a higher number of the students who had utilized their gained knowledge in improving their business or securing employments for themselves.

2: The program was successful in terms of tackling the obstacles against girls' engagement in family values and decisions because TEO has enabled the students to become economically empowered.

3: TEO has provided equal learning opportunities for the students of both urban and rural areas irrespective of their genders. The importance of the subject was highly sensible in the rural areas comparing to urban areas and making the subject a substantial asset to the students in rural areas to become self reliant.

4: Tashabos has helped a higher number of students in their businesses. Thus transforming their businesses into profitable ones. This in turn affects the family and beyond the society because working opportunities have been provided to many youths hindering them from social unfavorable engagements.

5: Topics for the subject have been selected with great curiosity because most of the students talked about the importance of the subject in their promotions as far as their businesses and employments were concerned. In addition, these topics have been linked to students' daily lives and improving the social aspects of the students.

6: The students were practically encouraged for businesses through business proposals and demonstrations. Most of the students had dared to take their products out of their houses and exposed them to the buyers. There were a lot of students highlighting the importance of the process for maturation of their business abilities.

7: All the target groups of the study advocated for the incorporation of the subject into the national curriculum.

8: TEO has approached to continue teaching the subject through most experienced teachers having years of teaching experiences in Tashabos.

9: Teachers have been inquired by students of lower grades about the subject. This is very important for the continuation of the program because the lower grade students would study the subject with higher levels of interests.

10: Nearly all the students have been aware of the importance of the subject. This issue is of vital importance to the program because the students would definitely utilize the knowledge they gained in their future ultimately achieving the goal of TEO.

11: Tashabos teachers have been advocates of the program because they have shared a lot of information about the subject with others. Moreover, they have expressed their agreement on inclusion of the subject into the national curriculum. 
12: It should be mentioned that all the school administrations were aware about the subject and its importance. This is attributed to successful management skills of the program because program implementations would be run smoothly.

13: Nearly all the school administrations have observed teaching of the Tashabos classes. This has increased the importance of the program because the program has been routinely supervised by the school administrations even in the absence of TEO staffs.

14: Majority of the school administration mentioned that teaching methodologies of the subject is very effective for the students if they were planning for their future in the form of business.

15: Majority of the school administrations have shared information about the subject with others.

16: Nearly all the parents were aware of the subject. This is very important for the program because the program has attained the support of the parents in promoting studying of the subject within their families. In addition, sufficient time and opportunities will be provided to the students in studying the subject at their homes.

17: Majority of the parents have named Tashabos among the third subjects their children have been studying. This is very important and substantial for the program because the program has been able to spread a lot of information about the subject.

18: A higher number of the parents have utilized the concepts of Tashabos within their businesses. This shows the practical importance of the subject because a wider range of the population have been benefited from the subject in an indirect manner.

19: Majority of the parents believed that if businesses are initiated with principles of Tashabos, the business would be very successful.

20: Tashabos has been very beneficial for business needed a lower amount of investments, which might assist a high volume of the students to initiate a business.

\section{Recommendations:}

1: In order to have a better picture of the progress made by the program, it is important to include the students who have graduated from schools and currently running a business or having an employment in the study. This would allow TEO to get a rather complete information about the tangible impacts of the program at the community levels.

2: Within the sample size for the study, it should be recognized in the future that if only students of 12 grades be selected because they could provide rather a complete information about the program and its effectiveness, would be better. The students of $10^{\text {th }}$ grades will provide some basic information from their own experiences and knowledge to more academic information they have learned from the subject.

3: In order to have a factual evidence about the effectiveness of the program, students and teachers of other schools where Tashabos is not taught to be included in the study. This would offer the ground to compare the effects of the Tashabos in performance of Tashabos entrepreneurs and non-Tashabos entrepreneurs. 
4: The study should be planned in appropriate timing to reduce the rush on all: students, teachers, school administrators, surveyors and the organization itself. Therefore, the next studies should be planned at the initiation of the second term for all the four provinces. This would allow a sufficient time for accurate planning of the study.

5: If affordable, assessing impact and effectiveness of a program better to be given to a third party.

6: For the next studies, all those students who have businesses prior to studying Tashabos should be treated as different target groups than those initiated business during studying Tashabos. For this study, differentiation of such students was not visible.

7: In order to have a complete knowledge from the program, it is better to deploy various data collection methodologies. For example, businesses of the students should be observed; teaching of Tashabos and the process should be observed; a consultative workshop should be organized between school administrators of schools; consultative workshop should be conducted for the teachers; consultative workshop should be planned for relevant stakeholder working in either education or vocational trainings; key informants should be interviewed from the governmental and non-governmental sectors. 